\title{
Knee osteoarthritis and aquatic cycling
}

Citation for published version (APA):

Rewald, S. (2018). Knee osteoarthritis and aquatic cycling: Development and evaluation of an exercise programme. [Doctoral Thesis, Maastricht University]. Datawyse / Universitaire Pers Maastricht. https://doi.org/10.26481/dis.20180711sr

Document status and date:

Published: 01/01/2018

DOI:

10.26481/dis.20180711sr

Document Version:

Publisher's PDF, also known as Version of record

\section{Please check the document version of this publication:}

- A submitted manuscript is the version of the article upon submission and before peer-review. There can be important differences between the submitted version and the official published version of record.

People interested in the research are advised to contact the author for the final version of the publication, or visit the DOI to the publisher's website.

- The final author version and the galley proof are versions of the publication after peer review.

- The final published version features the final layout of the paper including the volume, issue and page numbers.

Link to publication

\footnotetext{
General rights rights.

- You may freely distribute the URL identifying the publication in the public portal. please follow below link for the End User Agreement:

www.umlib.nl/taverne-license

Take down policy

If you believe that this document breaches copyright please contact us at:

repository@maastrichtuniversity.nl

providing details and we will investigate your claim.
}

Copyright and moral rights for the publications made accessible in the public portal are retained by the authors and/or other copyright owners and it is a condition of accessing publications that users recognise and abide by the legal requirements associated with these

- Users may download and print one copy of any publication from the public portal for the purpose of private study or research.

- You may not further distribute the material or use it for any profit-making activity or commercial gain

If the publication is distributed under the terms of Article $25 \mathrm{fa}$ of the Dutch Copyright Act, indicated by the "Taverne" license above, 


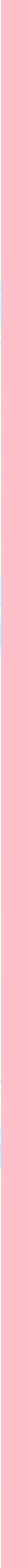

Stefanie Rewald 
The research presented in this dissertation was conducted at the Care and Public Health Research Institute (CAPHRI), Department of Epidemiology, Maastricht University. CAPHRI participates in the Netherlands School of Primary Care Research (CaRe).

The research described in this dissertation was funded by the Netherlands Organisation for Scientific Research (NWO), grant number 022.003.036.

All rights are reserved. No part of this book may be reproduced or transmitted in any form or by any means, without the written permission from the author or, where appropriate, the publisher of the article.

(C) Stefanie Rewald, Maastricht 2017

The photograph on the chapter pages shows the art installation "De ontsnapping" from the Belgian artist Erik Nagels. The art installation was displayed at the beach in Oostende in the summer of 2013. It shows a large group of life-size sculptures of professional cyclists that were created in the honour of the $100^{\text {th }}$ anniversary of the Tour of Flanders in 2013. For his artwork, the artist was inspired by the small, brightly coloured plastic toy cyclists that were added as a gimmick to washing powder in the Sixties and Seventies.

Layout: $\quad$ Tiny Wouters

Cover: Annika Rewald

Production: Datawyse: | Universitaire Pers Maastricht

ISBN: 978-94-6295-963-7

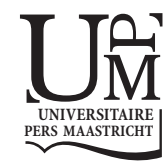




\title{
Knee Osteoarthritis and Aquatic Cycling
}

\section{Development and evaluation of an}

\section{exercise programme}

\author{
Dissertation \\ to obtain the degree of Doctor at Maastricht University, \\ on the authority of the Rector Magnificus, \\ Prof. dr. Rianne M. Letschert in accordance with the decision \\ of the Board of Deans, to be defended in public \\ on Wednesday 11 July 2018, at 14:00 hours
}

by

Stefanie Rewald 
Supervisors

Prof. dr. R.A. de Bie

Prof. dr. A.F. Lenssen

\section{Co-Supervisors}

Dr. E.P.E Mesters

Dr. P.J. Emans

\section{Assessment Committee}

Prof. dr. R.J.E.M. Smeets (chair)

Prof. dr. A.E.R.C.H. Boonen

Prof. dr. J. Dekker (VU University Medical Center (VUmc) Amsterdam)

Dr. A.J.A. Köke

Dr. P.J. van der Wees (Radboud University Medical Centre (Radboudumc)

Nijmwegen) 


\section{TABLE OF CONTENTS}

$\begin{array}{lll}\text { Chapter } 1 \text { General introduction } & 7\end{array}$

Chapter 2 Aquatic circuit training including aquatic cycling in patients 21 with knee osteoarthritis: a feasibility study

Chapter 3 Effect of aquatic cycling on pain and physical functioning 35 compared with usual care in patients with knee osteoarthritis: study protocol of a randomised controlled trial

Chapter 4 Aquatic cycling - what do we know?

A scoping review on head-out aquatic cycling

Chapter 5 Efficacy of aquatic cycling on knee pain and physical functioning in patients with knee osteoarthritis:

a randomised controlled trial

Chapter 6 General discussion

Summary

Samenvatting

Zusammenfassung

Valorisation addendum

Acknowledgements

About the author

List of publications 



\section{CHAPTER 1}

General introduction 

This dissertation describes the development and evaluation of an aquatic cycling programme for patients with knee osteoarthritis. The introduction summarises key facts about knee osteoarthritis, explains the development of aquatic cycling, and presents hypotheses of why cycling on a stationary bike while immersed in water might be a valuable form of aquatic exercise for patients with knee osteoarthritis.

\section{KNEE OSTEOARTHRITIS}

Osteoarthritis (OA) is a chronic disease that can occur in any joint of the human body. $\mathrm{OA}$ involves damaging and thinning of the cartilage, structural changes in the surrounding bone and osteophyte formation, ligamentous laxity, loss of strength in the periarticular muscles and synovial inflammation. ${ }^{1,2}$

The knees and hands are commonly affected by OA. However, OA is also known to affect hips, facet joints and feet. ${ }^{3-5}$ Because of the universal involvement of knee and hip joints during tasks such as walking and stair climbing, it is not surprising that knee and hip OA was ranked at number eleven out of 291 diseases contributing to global disability in 2010. ${ }^{6}$ Both increasing age and the obesity epidemic are primary factors contributing to the increasing prevalence of OA. By 2020, on a global scale OA is expected to rank in the top five of most disabling diseases. ${ }^{7,8}$

The lifetime risk for developing knee OA is approximately $45 \%$ and several factors seem to cause knee OA. ${ }^{9}$ However, the development of knee OA appears to be largely influenced by the interplay between mechanical and systemic risk factors. Examples of systematic risk factors are increasing age, obesity, female sex, physical (in)activity, ethnicity and genetics. ${ }^{1,3,8,10}$ Furthermore, individuals with a history of knee injury and/or malalignment of the knee or lower leg muscle weakness, which are all examples of mechanical factors, might have an increased risk for developing $O A, 1,3,8$

The diagnosis and severity of knee $\mathrm{OA}$ is based on a clinical evaluation of the knee joint. ${ }^{11} \mathrm{~A}$ typical clinical evaluation consists of an anamnesis (i.e., exploring risk factors and symptoms knee $\mathrm{OA}$ ) and a physical examination assessing the existence of crepitus, impaired range of motion and bony enlargement. ${ }^{11}$ Radiographic images can be used to detect changes in the knee joint. Typical signs of knee OA include narrowing of the joint space, changes in subchondral bone and formation of osteophytes at joint margins. ${ }^{11}$ The Kellgren Lawrence score ${ }^{12}$ is a widely used tool to classify radiographic changes in knee OA using five grades ranging from zero (no presence of $O A$ ) to four (severe OA).

In general, knee OA develops slowly from early to late stages causing knee pain and disability. ${ }^{1}$ Throughout the time course of the disease, symptoms develop from loaddependent knee pain (e.g. after exercise) to chronic knee pain during the day or even at night. ${ }^{13}$ Problems performing activities of daily living might result in restrictions in 
physical and social participation. These impairments can eventually affect mood and quality of sleep and life, which makes knee OA a whole person disease. ${ }^{1}$

\section{(AQUATIC) EXERCISE FOR PATIENTS WITH KNEE OSTEOARTHRITIS}

Many of the pathogenic factors and symptoms associated with knee OA may be lessened and/or improved with lifestyle changes. For example, regular participation in exercise is a mainstay involved in conservative treatment. ${ }^{14}$ There now is substantial evidence suggesting routine exercise can alleviate symptoms of knee $\mathrm{OA}$, and has a beneficial influence on cardiovascular risk factors and comorbidities. ${ }^{15-17}$ However, exercise training is under-utilized in individuals with knee OA. ${ }^{18}$ One of the barriers to exercise is that performing exercise with the osteoarthritic knee appears counterintuitive to patients because this may provoke painful symptoms. ${ }^{19}$

For individuals, as OA patients, who have limited pain-tolerance for weight-bearing activities, water-based exercise is frequently recommended. The buoyancy of water lessens the effects of body weight and results in joint decompression. Evidence suggests that aquatic exercise positively affects knee pain, physical function and quality of life in patients with $O A .{ }^{20}$ In most instances, aquatic exercise for OA patients is performed in shallow water and does not include full-body under water immersion. These head-out aquatic exercise sessions include aerobic exercise, strengthening exercise or a combination of both. Equipment can be used to increase exercise intensity and variation. ${ }^{21-23}$ In addition to small size aquatic equipment such as bench stepping-platforms, other land-based exercise equipment such as treadmills and stationary bikes are available in water-proof versions. More recently, aquatic cycling has emerged as a trendy fitness activity. ${ }^{24,25}$

\section{AQUATIC CYCLING}

Aquatic cycling is a head-out aquatic exercise activity performed on a stationary bike in a swimming pool. Participants are immersed at a water level between navel and chest height to ensure that the legs are immersed during the whole cycling movement without floating off the saddle. In addition to leg exercises, which include both seated and out-of-saddle positions, arm and upper body exercises against water resistance are incorporated in a typical aquatic cycling session. These descriptions hold true for an upright cycling position, which is most common. However, there are also aquatic bikes that are constructed for semi-recumbent cycling and sometimes legwork is combined 
with arm ergometer exercises. This dissertation will focus on aquatic cycling in the upright position for patients with knee OA.

\section{Historical perspective}

Scientific research on aquatic cycling started in the late sixties, peaked in the mideighties and from 2007 onwards a renewed interest has emerged (Figure 1.1).

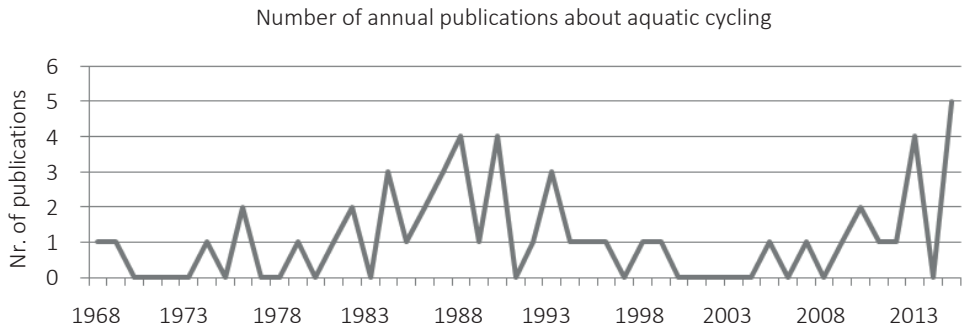

Figure $1.1 \quad$ Number of annual publications between 1968 and 2016

In the late sixties, astronauts were preparing for the first space flights and researchers used water as a medium to mimic weightlessness and to study effects that space might have on physiological functions of the human body. ${ }^{26-32}$ Another research interest during this period was the exposure of humans to different water temperatures. ${ }^{33-42}$ For example, cold-water exposure was used to simulate a boating accident and to investigate the influence of physical movement on body temperature. In the aforementioned studies aquatic cycling was used to isolate the effects of immersion and to study thermoregulatory responses, rather than to study the effects of aquatic cycling as a form of aquatic exercise.

As interest in health and fitness increased in the 1970s and 1980s, aquatic aerobics increased in popularity. In the mid-1980s several organisations such as the Aquatic Exercise Association (AEA) and the Aquatic Therapy and Rehabilitation Institute (ATRI) came into existence to provide professional guidance for the development of aquatic exercise and aquatic therapy. The benefits of low-impact aerobic exercise programmes in water became more apparent and were promoted by athletes who used aquatic exercise as a form of supplementary training or during recovery from injuries. ${ }^{43}$ At the same time, aquatic bikes were also being recognized as a tool useful for aquatic fitness. For example, cardiovascular and thermoregulatory responses to aquatic cycling in pregnant women and patients with cardiovascular diseases became research topics. ${ }^{29,}$ $44-47$ 
In 2007 and onward, aquatic cycling has grown in popularity as a health fitness activity. In addition to public interest, there has become a regained research interest in aquatic cycling with the focus shifting beyond its value as just an exercise activity, but to its application as a therapeutic tool. ${ }^{50}$

Accompanying the increased interest in aquatic therapy, the design of aquatic bikes has improved. Up until the 1990s, most aquatic bikes were constructed from landbased cycle ergometers. ${ }^{51}$ Today, manufacturers design bikes specifically for the purpose of aquatic cycling. The majority of bikes are created for upright cycling and the bikes have fins (variable in length) or cups (variable in number) on the flywheel that increase pedal resistance and has to be set on land prior to the session. Aquatic bikes like the one shown in Photograph $1.1 \mathrm{~A}$ are relatively low in cost (approximately $1.700 €)$, easy to store and need low to no maintenance. These bikes enable swimming pools to provide aquatic cycling as a group-based fitness activity. In the context of aquatic therapy and used in scientific research, aquatic bikes are equipped with magnetically or electromagnetically resistance mechanisms (Photograph 1.1B-D), enabling adjustment of the resistance during pedalling instead.

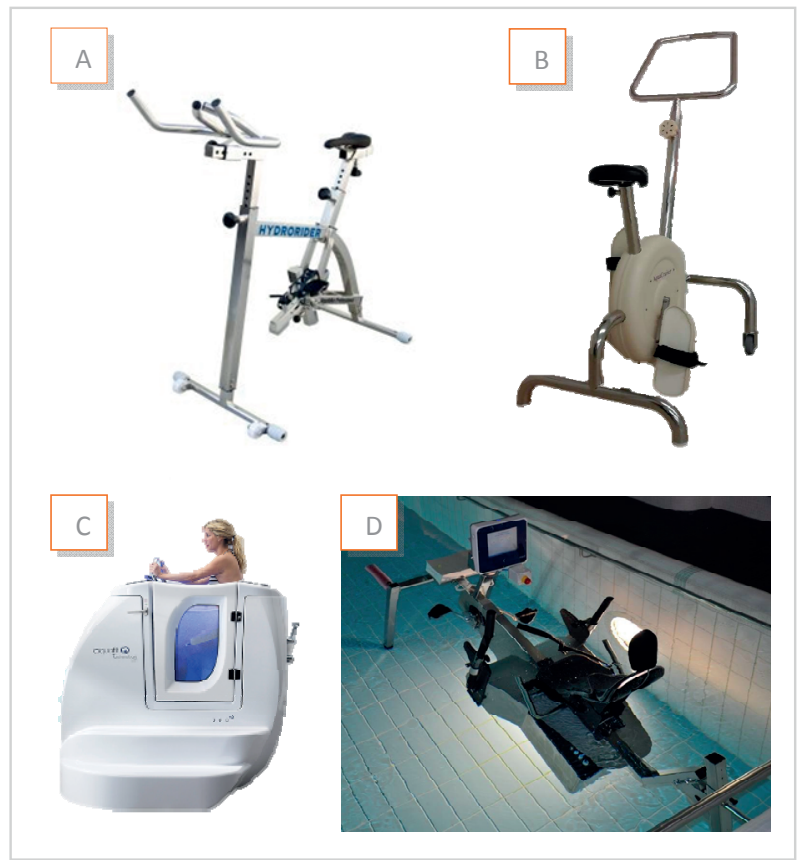

Photograph 1.1 Aquatic bikes with different resistance mechanisms:
A Profix Aqua Bike ${ }^{\mathrm{TM}}$ from Hydrorider $^{\circledR}$,
B AquaCruiser II $^{\mathrm{TM}}$ from AquaKinetiqs,
C Aquafit360 ${ }^{\text {'M }}$ from Aquafit Technologie ${ }^{\mathrm{TM}}$,
D Reha-Aquabike from Swissrehamed $\mathrm{GmbH}$ 


\section{Aquatic cycling for patients with knee OA}

Aquatic immersion and, hence, aquatic cycling initiates physiological changes that are beneficial in the management of knee OA. These physiological adjustments translate to the following perceptions described by patients with knee OA exercising in warm water: feeling of weightlessness, relaxation and the ability to move with more freedom and ease coupled with less pain compared with land-based exercise. ${ }^{52-54}$ As such, immersion into water is suggested to essentially affect all homeostatic systems (Figure 1.2).

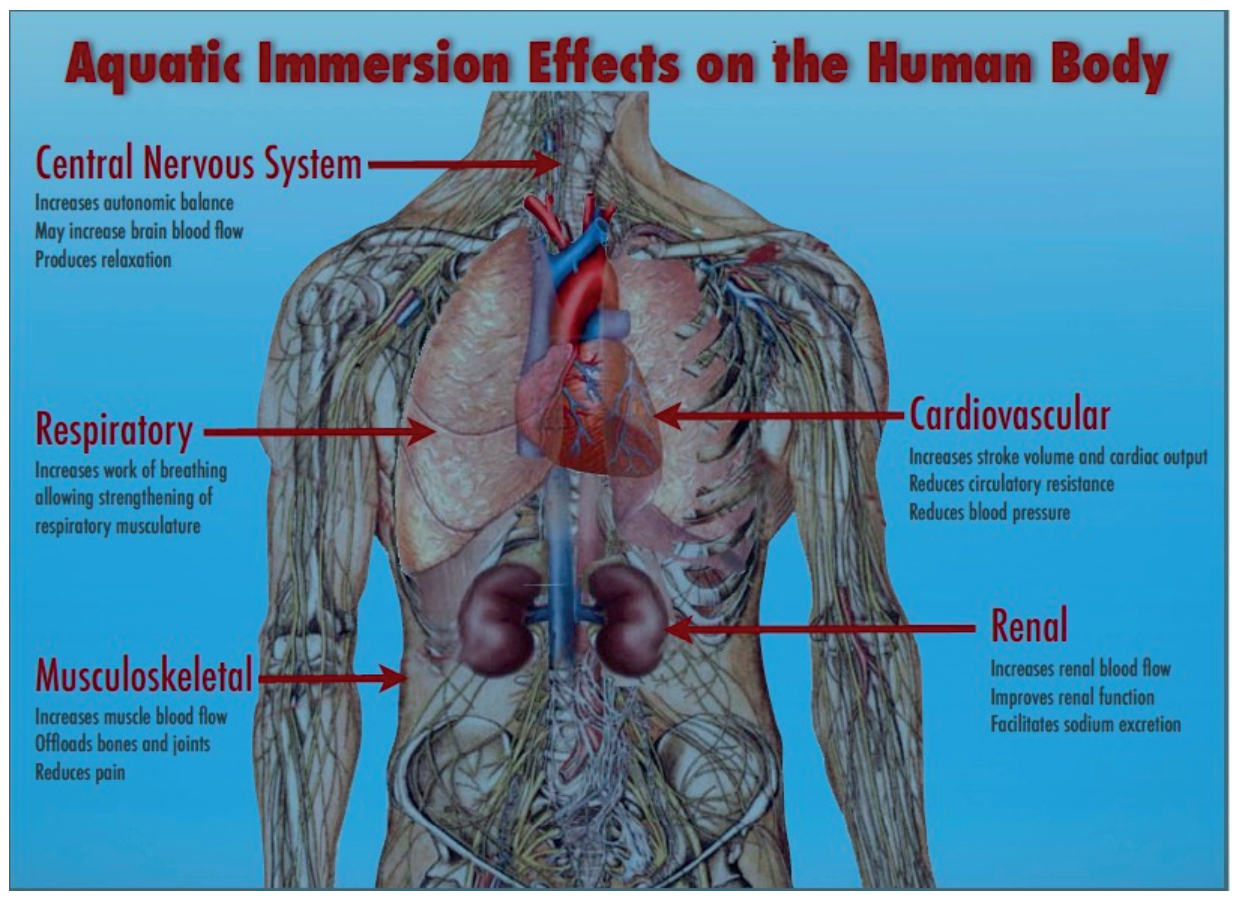

Figure 1.2 Effects of water immersion on the human body (used with permission of Bruce E. Becker, MD)

The biophysiological aspects of water immersion combined with potential effects of aquatic cycling that are directly (i.e. the musculoskeletal system) or indirectly related (i.e. cardiovascular system, central nervous system) to knee OA will be discussed in more detail. 


\section{Musculoskeletal system}

The pain-diminishing effect of water immersion is caused by a variety of factors. For example, during resting immersion approximately $50 \%$ of blood pumped out of the heart is redistributed to skin and muscles ${ }^{55}$ supporting an increase in oxygen delivery. This is suggested to help in the dissipation of algogenic chemicals and metabolic waste products causing pain. ${ }^{56}$ Furthermore, mild water pressure and the diuretic effect of water immersion can help to reduce oedema, with pain also possibly decreasing via reduction in joint swelling. ${ }^{57}$ In addition, the pedal movement associated with aquatic cycling also activates the calf-muscle pump while supporting lymphatic circulation. ${ }^{58,59}$ Moreover, the increase in blood flow and joint decompression may facilitate muscle relaxation, whereby contributing to pain-relief. ${ }^{56}$ With aquatic cycling participants are being immersed up to the xiphoid process and due to the buoyancy of the water the body weight is off-loaded by approximately $50 \%$. As a result, joint compression of the lower back and the hips, knee and ankle joints is decreased. Another advantage of cycling immersed in water is the reduction of strain on the immersed and moving body parts due to the viscous properties of water. Because the density of water is approximately 800 times higher than air, it provides an equal amount of resistance in all planes of motion. This resistance dampens the speed of movement and prevents jerky movements and dead spots during the pedalling motion.

In addition to the benefits of the aquatic environment, cycling is also a frequently recommended exercise activity for patients with knee OA. Cycling is a simple activity and easy to learn with most adults in Europe learning to ride a bicycle in early childhood. Recent research showed that Dutch patients with knee OA cycle more often than people without knee $O A .{ }^{60}$ Seated bicycling is a low-impact exercise and the knee is kept stable while the knee is exercised through a large range of motion. ${ }^{61}$ Furthermore, the largest muscle groups of the lower extremities are used during cycling. Land-based stationary cycling interventions for OA patients have shown to improve typical symptoms of knee OA. ${ }^{62,63}$ These group-based interventions led to significant reductions in knee pain, improved physical functioning and gait. ${ }^{62,63}$

\section{Cardiovascular system}

Aquatic immersion influences the distribution of the blood volume due to the external pressure that water exerts on the body. This means that during immersion up to the xiphoid process the central blood volume, which is the blood volume in the thorax, is increased by approximately $600 \mathrm{ml} .{ }^{64}$ Approximately, two-thirds of the blood is shifted to the lung circulation and the heart takes up one-third of the redistributed blood. ${ }^{65}$ Consequently, a greater volume of blood is entering the heart during the diastole and causes an increased stretch of the myocardium. As a response to the increased volume and stretch, the blood volume ejected during the following systole, which is called the stroke volume, is also increased. Interestingly, the stroke volume during resting 
immersion in water is comparable to the stroke volume during aerobic exercise on land in sedentary individuals. ${ }^{52,66}$ Thus, just sitting on the aquatic bike in the water might already be a light aerobic training assuming that most patients with knee OA do not meet the recommendations for physical activity. ${ }^{67,68}$ Another reason why aquatic exercise is ideal for deconditioned people is that immersion decreases the peripheral resistance and so the effort to circulate the blood is decreased and the heart works more efficient.

\section{Central nervous system}

Water immersion and exercise affect the central nervous system and thereby modulate pain sensation and mood. First, warm water temperatures and the hydrostatic pressure on the skin are thought to stimulate the thermal and mechanoreceptors and this non-painful input might diminish or decrease pain sensation. ${ }^{56,69}$ Second, evidence suggests that exercise has beneficial effects on mental health and improves symptoms of depression, anxiety and stress. ${ }^{70}$ Several physiological, immunological and psychological mechanisms seem to be responsible for these positive effects of exercise on mood states. ${ }^{70}$ Although most research investigated land-based aerobic training, ${ }^{70}$ there is also some evidence showing that both passive immersion and aquatic exercise might have a beneficial influence on mood and relaxation. ${ }^{53,54,71}$

\section{AIM AND OUTLINE OF THIS DISSERTATION}

Therapy involving cycling exercises in a heated pool may prove to be useful as a therapeutic tool for individuals with knee osteoarthritis. However, this therapeutic approach for patients with mild- to- moderate knee osteoarthritis has not been investigated. Therefore, the main project in this dissertation aimed to both develop and evaluate an aquatic cycling programme that is tailored to the needs of patients with knee osteoarthritis. A full aquatic cycling training programme was developed using a two-step model. First, the feasibility of aquatic cycling was evaluated (Chapter 2), Second, a 12-week aquatic cycling programme was developed (Chapter 3). We discovered during the conception and design phase of the exercise programme a dearth of systematic reviews of research focused on aquatic cycling. Therefore, as part of this thesis, a broad scoping review was conducted to identify the available research on aquatic cycling (Chapter 4). In a randomised controlled trial design the 12-week aquatic cycling programme was compared with usual care for patients with mild to moderate knee osteoarthritis (Chapter 5). We evaluated the therapeutic effects of our novel aquatic cycling programme on measurements of pain and physical function. Finally, this dissertation concludes with a general discussion of the main findings and implications for future research (Chapter 6). 


\section{REFERENCES}

1. Roos EM, Arden NK. Strategies for the prevention of knee osteoarthritis. Nature Reviews: Rheumatology. 2016;12:92-101.

2. Glyn-Jones S, Palmer AJ, Agricola R, Price AJ, Vincent TL, Weinans $H$, et al. Osteoarthritis. Lancet. 2015;386:376-87.

3. Johnson VL, Hunter DJ. The epidemiology of osteoarthritis. Best Practice \& Research: Clinical Rheumatology. 2014;28:5-15.

4. Litwic A, Edwards MH, Dennison EM, Cooper C. Epidemiology and burden of osteoarthritis. British Medical Bulletin. 2013;105:185-99.

5. Gommer A, Poos M, Hulshof T. Prevalentie en aantal nieuwe gevallen van artrose [Internet]. Bilthoven: RIVM; 2016 [cited 2017 Dec 28]. Available from: https://www.volksgezondheidenzorg.info/onderwerp/ artrose/cijfers-context/huidige-situatie - node-prevalentie-en-aantal-nieuwe-gevallen-van-artrose.

6. Cross M, Smith E, Hoy D, Nolte S, Ackerman I, Fransen M, et al. The global burden of hip and knee osteoarthritis: estimates from the global burden of disease 2010 study. Annals of the Rheumatic Diseases. 2014;73:1323-30.

7. Woolf AD, Pfleger B. Burden of major musculoskeletal conditions. Bulletin of the World Health Organization. 2003;81:646-56.

8. Murphy LB, Moss S, Do BT, Helmick CG, Schwartz TA, Barbour KE, et al. Annual Incidence of Knee Symptoms and Four Knee Osteoarthritis Outcomes in the Johnston County Osteoarthritis Project. Arthritis Care \& Research. 2016;68:55-65.

9. Murphy L, Schwartz TA, Helmick CG, Renner JB, Tudor G, Koch G, et al. Lifetime risk of symptomatic knee osteoarthritis. Arthritis and Rheumatism. 2008;59:1207-13.

10. Allen KD. Racial and ethnic disparities in osteoarthritis phenotypes. Current Opinion in Rheumatology. 2010;22:528-32.

11. Zhang W, Doherty M, Peat G, Bierma-Zeinstra MA, Arden NK, Bresnihan B, et al. EULAR evidence-based recommendations for the diagnosis of knee osteoarthritis. Annals of the Rheumatic Diseases. 2010;69:483-9.

12. Kellgren JH, Lawrence JS. Radiological assessment of osteo-arthrosis. Annals of the Rheumatic Diseases. 1957; 16:494-502.

13. Neogi T. The epidemiology and impact of pain in osteoarthritis. Osteoarthritis and Cartilage. 2013;21:1145-53.

14. Nelson AE, Allen KD, Golightly YM, Goode AP, Jordan JM. A systematic review of recommendations and guidelines for the management of osteoarthritis: The chronic osteoarthritis management initiative of the U.S. bone and joint initiative. Seminars in Arthritis and Rheumatism. 2014;43:701-12.

15. Nuesch E, Dieppe P, Reichenbach S, Williams S, Iff S, Juni P. All cause and disease specific mortality in patients with knee or hip osteoarthritis: population based cohort study. British Medical Journal (Clinical Research Ed). 2011;342:d1165.

16. Hawker GA, Croxford R, Bierman AS, Harvey PJ, Ravi B, Stanaitis I, et al. All-cause mortality and serious cardiovascular events in people with hip and knee osteoarthritis: a population based cohort study. PloS One. 2014;9:e91286.

17. Fransen M, McConnell S, Harmer AR, Van der Esch M, Simic M, Bennell KL. Exercise for osteoarthritis of the knee: a Cochrane systematic review. British Journal of Sports Medicine. 2015;49:1554-7.

18. Hinman RS, Nicolson PJ, Dobson FL, Bennell KL. Use of nondrug, nonoperative interventions by community-dwelling people with hip and knee osteoarthritis. Arthritis Care \& Research. 2015;67:305-9.

19. Dobson F, Bennell KL, French SD, Nicolson PJ, Klaasman RN, Holden MA, et al. Barriers and facilitators to exercise participation in people with hip and/or knee osteoarthritis: synthesis of the literature using behavior change theory. American Journal of Physical Medicine and Rehabilitation. 2016;95:372-89.

20. Bartels EM, Juhl CB, Christensen R, Hagen KB, Danneskiold-Samsoe B, Dagfinrud H, et al. Aquatic exercise for the treatment of knee and hip osteoarthritis. Cochrane Database Syst Rev. 2016;3:CD005523. 
21. Lu M, Su Y, Zhang Y, Zhang Z, Wang W, He Z, et al. Effectiveness of aquatic exercise for treatment of knee osteoarthritis: Systematic review and meta-analysis. Zeitschrift für Rheumatologie. 2015;10.1007/s00393-014-1559-9.

22. Waller B, Ogonowska-Slodownik A, Vitor M, Lambeck J, Daly D, Kujala UM, et al. Effect of therapeutic aquatic exercise on symptoms and function associated with lower limb osteoarthritis: systematic review with meta-analysis. Physical Therapy. 2014;94:1383-95.

23. Barbosa TM, Marinho DA, Reis VM, Silva AJ, Bragada J. Physiological assessment of head-out aquatic exercises in healthy subjects: a qualitative review. Journal of Sports Science \& Medicine. 2009;8:179-89.

24. Giacomini F, Ditroilo M, Lucertini F, De Vito G, Gatta G, Benelli P. The cardiovascular response to underwater pedaling at different intensities: a comparison of 4 different water stationary bikes. Journal of Sports Medicine and Physical Fitness. 2009;49:432-9.

25. Yazigi F, Pinto S, Colado J, Escalante Y, Armada-da-Silva PA, Brasil R, et al. The cadence and water temperature effect on physiological responses during water cycling. European Journal of Sport Science. 2013;13:659-65.

26. Christie JL, SheldahI LM, Tristani FE, Wann LS, Sagar KB, Levandoski SG, et al. Cardiovascular regulation during head-out water immersion exercise. Journal of Applied Physiology. 1990;69:657-64.

27. Connelly TP, Sheldahl LM, Tristani FE, Levandoski SG, Kalkhoff RK, Hoffman MD, et al. Effect of increased central blood volume with water immersion on plasma catecholamines during exercise. J Appl Physiol (1985). 1990;69:651-6.

28. Sheldahl LM, Tristani FE, Connelly TP, Levandoski SG, Skelton MM, Cowley AW, Jr. Fluid-regulating hormones during exercise when central blood volume is increased by water immersion. American Journal of Physiology. 1992;262:R779-85.

29. Hanna RD, Sheldahl LM, Tristani FE. Effect of enhanced preload with head-out water immersion on exercise response in men with healed myocardial infarction. The American Journal of Cardiology. 1993;71:1041-4.

30. Sheldahl LM, Tristani FE, Clifford PS, Hughes CV, Sobocinski KA, Morris RD. Effect of head-out water immersion on cardiorespiratory response to dynamic exercise. Journal of the American College of Cardiology. 1987;10:1254-8.

31. Sheldahl LM, Tristani FE, Clifford PS, Kalbfleisch JH, Smits G, Hughes CV. Effect of head-out water immersion on response to exercise training. Journal of Applied Physiology. 1986;60:1878-81.

32. Sheldahl LM, Wann LS, Clifford PS, Tristani FE, Wolf LG, Kalbfleisch JH. Effect of central hypervolemia on cardiac performance during exercise. Journal of Applied Physiology. 1984;57:1662-7.

33. Toner MM, Sawka MN, Foley ME, Pandolf KB. Effects of body mass and morphology on thermal responses in water. J Appl Physiol (1985). 1986;60:521-5.

34. Toner MM, Sawka MN, Holden WL, Pandolf KB. Comparison of thermal responses between rest and leg exercise in water. J Appl Physiol (1985). 1985;59:248-53.

35. Toner MM, Sawka MN, Pandolf KB. Thermal responses during arm and leg and combined arm-leg exercise in water. Journal of Applied Physiology. 1984;56:1355-60.

36. Young AJ, Sawka MN, Levine L, Burgoon PW, Latzka WA, Gonzalez RR, et al. Metabolic and thermal adaptations from endurance training in hot or cold water. J Appl Physiol (1985). 1995;78:793-801.

37. Young AJ, Sawka MN, Quigley MD, Cadarette BS, Neufer PD, Dennis RC, et al. Role of thermal factors on aerobic capacity improvements with endurance training. J Appl Physiol (1985). 1993;75:49-54.

38. Avellini BA, Shapiro Y, Fortney SM, Wenger CB, Pandolf KB. Effects on heat tolerance of physical training in water and on land. Journal of Applied Physiology. 1982;53:1291-8.

39. McArdle WD, Magel JR, Lesmes GR, Pechar GS. Metabolic and cardiovascular adjustment to work in air and water at 18, 25, and 33 degrees C. Journal of Applied Physiology. 1976;40:85-90.

40. McArdle WD, Magel JR, Spina RJ, Gergley TJ, Toner MM. Thermal adjustment to cold-water exposure in exercising men and women. Journal of Applied Physiology. 1984;56:1572-7.

41. McArdle WD, Toner MM, Magel JR, Spina RJ, Pandolf KB. Thermal responses of men and women during cold-water immersion: influence of exercise intensity. European Journal of Applied Physiology and Occupational Physiology. 1992;65:265-70.

42. Shapiro Y, Avellini BA, Toner MM, Pandolf KB. Modification of the Monark bicycle ergometer for underwater exercise. Journal of Applied Physiology. 1981;50:679-83. 
43. Becker BE, Cole AJ. Comprehensive Aquatic Therapy. 3rd ed. Pullmann, WA: Washington State University Publishing; 2010.

44. Katz VL, McMurray R, Berry MJ, Cefalo RC. Fetal and uterine responses to immersion and exercise. Obstetrics and Gynecology. 1988;72:225-30.

45. Katz VL, McMurray R, Berry MJ, Cefalo RC, Bowman C. Renal responses to immersion and exercise in pregnancy. American Journal of Perinatology. 1990;7:118-21.

46. Katz VL, McMurray R, Goodwin WE, Cefalo RC. Nonweightbearing exercise during pregnancy on land and during immersion: a comparative study. American Journal of Perinatology. 1990;7:281-4.

47. McMurray RG, Fieselman CC, Avery KE, Sheps DS. Exercise hemodynamics in water and on land in patients with coronary artery disease. Journal of Cardiopulmonary Rehabilitation. 1988;8:69-75.

48. Bansi J, Bloch W, Gamper U, Kesselring J. Training in MS: influence of two different endurance training protocols (aquatic versus overland) on cytokine and neurotrophin concentrations during three week randomized controlled trial. Multiple Sclerosis. 2012;19:613-21.

49. Bansi J, Bloch W, Gamper U, Riedel S, Kesselring J. Endurance training in MS: short-term immune responses and their relation to cardiorespiratory fitness, health-related quality of life, and fatigue. Journal of Neurology. 2013;260:2993-3001.

50. Garzon M, Gayda M, Garzon L, Juneau M, Nigam A, Leone M, et al. Biomechanical analysis to determine the external power output on an immersible ergocycle. European Journal of Sport Science. 2015; $15: 271-8$.

51. Dressendorfer RH, Morlock JF, Baker DG, Hong SK. Effects of head-out water immersion on cardiorespiratory responses to maximal cycling exercise. Undersea Biomedical Research. 1976;3: 177-87.

52. Becker BE. Aquatic therapy: scientific foundations and clinical rehabilitation applications. $P M \& R$ : the journal of injury, function, and rehabilitation. 2009;1:859-72.

53. Robiner WN. Psychological and physical reactions to whirlpool baths. Journal of Behavioral Medicine. 1990;13:157-73.

54. Perini R, Milesi S, Biancardi L, Pendergast DR, Veicsteinas A. Heart rate variability in exercising humans: effect of water immersion. European Journal of Applied Physiology and Occupational Physiology. 1998;77:326-32.

55. Epstein M. Renal effects of head-out water immersion in humans: a 15-year update. Physiological Reviews. 1992; 72:563-621.

56. Hall J, Swinkels A, Briddon J, McCabe CS. Does aquatic exercise relieve pain in adults with neurologic or musculoskeletal disease? A systematic review and meta-analysis of randomized controlled trials. Archives of Physical Medicine and Rehabilitation. 2008;89:873-83.

57. Gianesini S, Tessari M, Bacciglieri P, Malagoni AM, Menegatti E, Occhionorelli S, et al. A specifically designed aquatic exercise protocol to reduce chronic lower limb edema. Phlebology. 2016;10.1177/0268355516673539.

58. Stick C, Grau H, Witzleb E. On the edema-preventing effect of the calf muscle pump. European Journal of Applied Physiology and Occupational Physiology. 1989;59:39-47.

59. Stick C, Heinemann W, Witzleb E. Slow volume changes in calf and thigh during cycle ergometer exercise. European Journal of Applied Physiology and Occupational Physiology. 1990;61:428-32.

60. Herbolsheimer F, Schaap LA, Edwards MH, Maggi S, Otero A, Timmermans EJ, et al. Physical Activity Patterns Among Older Adults With and Without Knee Osteoarthritis in Six European Countries. Arthritis Care \& Research. 2016;68:228-36.

61. Liebs TR, Herzberg W, Ruther W, Haasters J, Russlies M, Hassenpflug J. Ergometer cycling after hip or knee replacement surgery: a randomized controlled trial. The Journal of Bone and Joint Surgery American volume. 2010;92:814-22.

62. Mangione K, McCully K, Gloviak A, Lefebvre I, Hofmann M, Craik R. The effects of high-intensity and low-intensity cycle ergometry in older adults with knee osteoarthritis. Journals of Gerontology Series A: Biological Sciences and Medical Sciences. 1999;54:M:184-90.

63. Salacinski A, Krohn K, Lewis S, Holland M, Ireland K, Marchetti G. The effects of group cycling on gait and pain-related disability in individuals with mild-to-moderate knee osteoarthritis: a randomized controlled trial. Journal of Orthopaedic and Sports Physical Therapy. 2012;42:985-95. 
64. Arborelius M, Jr., Ballidin UI, Lilja B, Lundgren CE. Hemodynamic changes in man during immersion with the head above water. Aerospace Medicine. 1972;43:592-8.

65. Risch WD, Koubenec HJ, Beckmann U, Lange S, Gauer OH. The effect of graded immersion on heart volume, central venous pressure, pulmonary blood distribution, and heart rate in man. Pflügers Archiv European Journal of Physiology. 1978;374:115-8.

66. Vella CA, Robergs RA. A review of the stroke volume response to upright exercise in healthy subjects. British Journal of Sports Medicine. 2005;39:190-5.

67. de Groot IB, Bussmann JB, Stam HJ, Verhaar JA. Actual everyday physical activity in patients with endstage hip or knee osteoarthritis compared with healthy controls. Osteoarthritis and Cartilage. 2008;16:436-42.

68. Farr JN, Going SB, Lohman TG, Rankin L, Kasle S, Cornett M, et al. Physical activity levels in patients with early knee osteoarthritis measured by accelerometry. Arthritis and Rheumatism. 2008;59:1229-36.

69. Bender T, Karagulle Z, Balint GP, Gutenbrunner C, Balint PV, Sukenik S. Hydrotherapy, balneotherapy, and spa treatment in pain management. Rheumatology International. 2005;25:220-4.

70. Mikkelsen K, Stojanovska L, Polenakovic M, Bosevski M, Apostolopoulos V. Exercise and mental health. Maturitas. 2017;106:48-56.

71. Watanabe E, Takeshima N, Okada A, Inomata K. Comparison of water- and land-based exercise in the reduction of state anxiety among older adults. Perceptual and Motor Skills. 2000;91:97-104.

72. Boidin M, Lapierre G, Paquette Tanir L, Nigam A, Juneau M, Guilbeault V, et al. Effect of aquatic interval training with Mediterranean diet counseling in obese patients: results of a preliminary study. Annals of Physical and Rehabilitation Medicine. 2015;58:269-75. 



\section{CHAPTER 2}

Aquatic circuit training including aqua-cycling in patients with knee osteoarthritis: a feasibility study

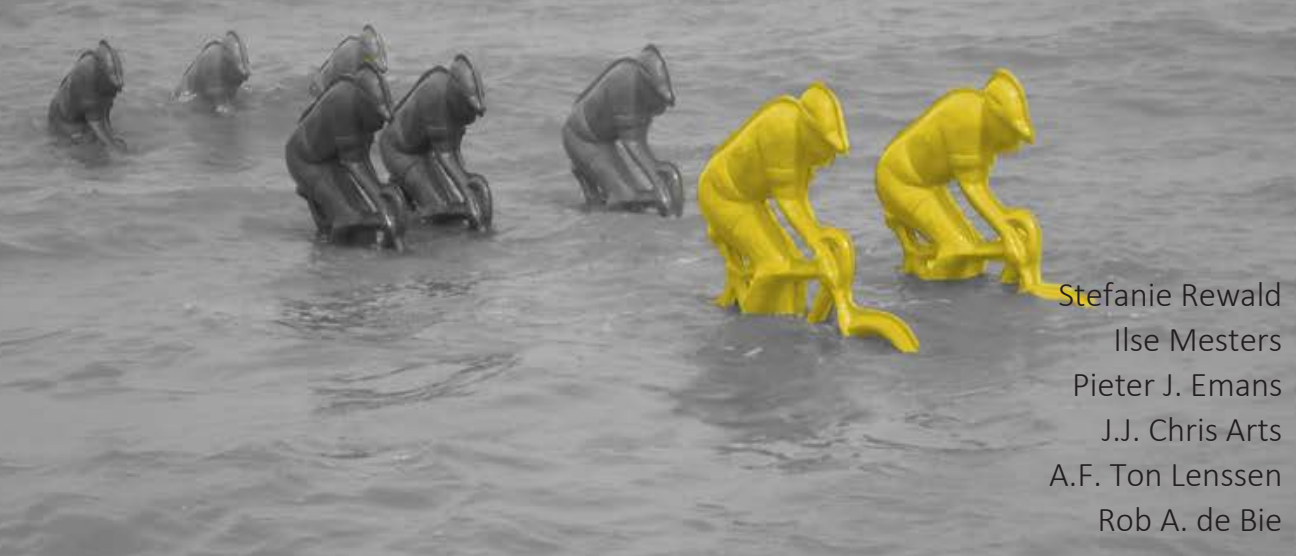

Journal of Rehabilitation Medicine. 2015;47(4):376-381 


\section{ABSTRACT}

\section{Background}

Aquatic cycling is easy to learn, acceptable, and safe for patients with knee osteoarthritis. It can therefore be an ideal component of aquatic circuit training.

\section{Objective}

To investigate the feasibility of a small group-based aquatic exercise programme including aquatic cycling.

\section{Design}

A feasibility study using quantitative (pre-post) and qualitative (cross-sectional) assessments.

\section{Participants}

A volunteer cohort of 10 women and men, age range $46-77$ years, with knee osteoarthritis.

\section{Methods}

Focus group interviews explored participants' experience with the training. Pre- and postexercise knee pain, attendance, progression in training, and adverse events were registered.

\section{Results}

Seventy per cent of patients attended all sessions. Focus groups revealed high levels of satisfaction with the selection of exercises, and participants valued the immediate pain relief experienced. Participants progressed well. However, aquatic cycling in an out-of-the-saddle position was too demanding for most participants.

\section{Conclusion}

An aquatic circuit training that includes aquatic cycling is feasible for patients with knee osteoarthritis. Participants reported pain reduction and were positive about the diverse exercise programme. Aquatic cycling in a seated position is a safe and controlled type of movement. 


\section{INTRODUCTION}

Water-based exercise is frequently recommended for patients with knee osteoarthritis $(\mathrm{OA})$, especially when land-based training is restricted by the experience of pain. ${ }^{1}$ The hydrostatic pressure, temperature and buoyancy of water result in relief of body weight, muscle relaxation, decreased joint compression, and pain reduction. ${ }^{2}$ Aquatic cycling is an upcoming fitness-trend in Europe and combines stationary cycling with the advantages of exercising in an aquatic environment. Previous research on rehabilitation after anterior cruciate ligament reconstruction and total knee surgery showed that aquatic cycling in addition to usual care resulted in greater improvement in range of motion (ROM) and more rapid reduction in knee joint swelling compared with standard care. ${ }^{3,4}$ A small pre-post test study with 19 patients with rheumatic diseases showed a positive influence on well-being, strength and mobility after ten weeks aquatic cycling. ${ }^{5}$ Based on the results of previous studies it is hypothesized that participants with knee OA would also accept this type of exercise. However, aquatic bikes are expensive. Most therapy pools do not have enough space to store several aquatic bikes. We developed an aquatic circuit training for small groups of three participants consisting of aquatic exercises and aquatic cycling. The present study aims to evaluate the feasibility of an eight-week aquatic circuit training in terms of adherence, possibility to progress in exercise level, occurrence of adverse events, operational aspects and patient acceptance.

\section{METHODS}

\section{Design}

A convergent mixed-methods design was used to describe different aspects of feasibility. The study was a proof of concept of a full-scale trial, which was approved by the local ethics committee (NL42617.068.12, NTR 3766).

\section{Participants}

Recruitment was carried out from February to April 2011 at Maastricht University Medical Centre. Participants were identified by their orthopaedic surgeon and signed a written informed consent. Eligible participants were diagnosed with knee OA and had an indication for conservative therapy including pharmacological and exercise treatment. Exclusion criteria were: a planned total knee arthroplasty, acute infection/inflammation, neuromuscular disease, and severe cardio-respiratory problems. 


\section{Measures and data collection procedure}

Focus group interviews were chosen to explore participants' experiences with aquatic circuit training. The question guide (Table 2.1) was based on typical questions for formative programme evaluation and included questions about positive and negative aspects of the training and aspects that should be changed, dropped or fine-tuned.

Table 2.1 Focus group questions

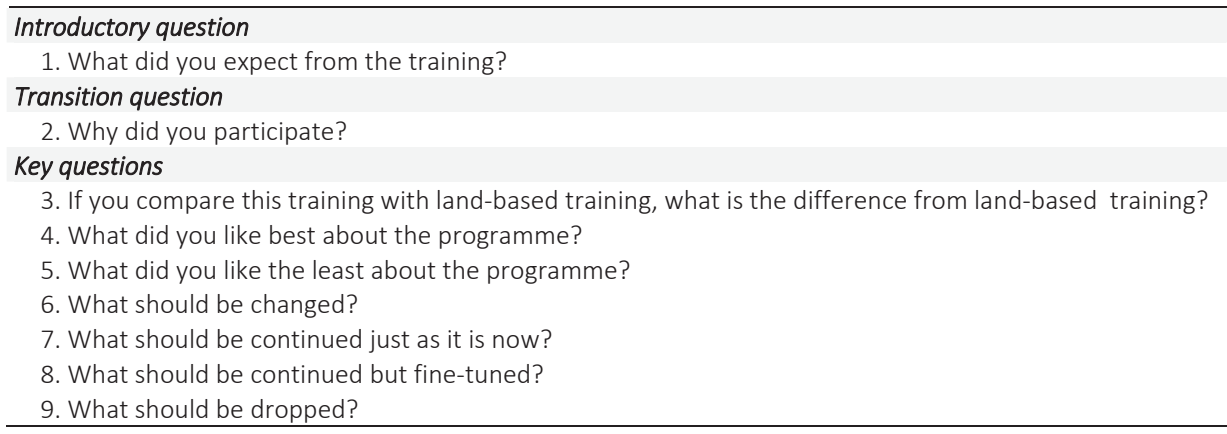

The focus groups were recorded and documented in a transcript. Only the physiotherapist and the interviewer had access to the records and full transcripts. The statements of participants were separated from personal data by the following code: gender (male/female), age, and focus group number. The focus groups took place in a meeting room of Maastricht University. Both focus groups lasted for 1.5 hours with a break after 45 minutes.

Quantitative data was collected on self-reported pre- and post-exercise knee pain on a numeric pain rating scale (NRS). ${ }^{6,7}$ Furthermore, attendance, progression in training and adverse events was registered. In addition to patient-relevant information the physiotherapist registered experiences with execution of the training and supervision of the groups and logistical aspects with the installation of the circuit training.

\section{Intervention}

Participants trained in small groups of maximal three participants, once a week for 45 minutes over an eight-week period. The aquatic circuit training was offered free to the patients; they only had to meet the cost of transport. The training was carried out in a heated therapy pool $\left(32^{\circ} \mathrm{C}\right)$ of the physiotherapy department of Maastricht University Medical Centre+, supervised by a physiotherapist who was also in the pool herself. The circuit training comprises aquatic cycling on the AquaCruiser $\mathrm{II}^{\mathrm{TM}}$, functional exercises, such as stepping and chair stands, ROM and strength exercises. Gait exercises were performed as a warm-up and cool-down. A detailed description of the 
content and goals of the exercises according to the framework from van der Leeden et al. is given in Table 2.2.

Table 2.2 Description of the aquatic circuit programme

Exercises: Water-based circuit training in groups of 3 patients, once a week, 45 min per session, supervised by 1 physiotherapist who is also in the pool.

Primary intervention goal:

- feasibility of aquatic cycling:

- ease of learning of correct aquatic cycling techniques

- exploring pedalling frequency and resistance during aquatic cycling

Secondary intervention goals (ICF):

- b770: gait pattern function (exercise 1)

- b710: mobility of joint functions (exercise 1, 2, 5, 7)

- b715: stability of joint functions (exercise 5, 3, 4, 9)

- b740: muscle endurance functions (exercise 2, 3, 5)

- b760: control of voluntary movement functions (exercise 1-9)

- b620: proprioceptive function (exercise 3, 4, 5, 6)

Level 1

1. Gait training (2-4 laps each direction):

1.1. Forward=normal gait and step length and correct foot movement (heel to forefoot)

1.2. Backward=reverse foot movement (forefoot to heel)

1.3. Sideways=step to the left and bring right foot to the left v.v.

2. Aquatic cycling: cycling forward; move extended arms alternating forward/backward (10 min)

3. Stepping on an underwater step: step down and up

4. Squats

5. Flexion and extension of the unloaded knee (1-leg stance, bar work: 1-hand hold)

6. Hip abduction (bar work: 1-hand hold)

7. Cycle legs: Sitting on pool noodle or hanging on it (noodle in the back)

8. Stretching $m$. quadriceps, $m$. iliopsoas, adductors, hamstrings, calf (10 s, 3-4 reps)

9. Pool noodle balance: step over the immersed pool noodle, move the pool noodle around the body, sitting on the pool noodle

\section{Level 2}

1. Gait training (2-4 laps each direction):

1.1. Forward=normal gait and step length correct foot movement (heel to forefoot), 1 lap heels up, 1 lap heels to buttock

1.2. Backward=reverse foot movement (forefoot to heel)

1.3. Sideways=step to the left and bring right foot to the left v.v.

2. Aquatic cycling: cycling forward/ backward, change pedalling direction after 2 min (total duration 10 min)

3. Stepping on an underwater step: step up then over, turn and repeat

4. Squats: go up and down in 3 steps (hold each position for $5 \mathrm{~s}$ )

5. Flexion and extension of the unloaded knee (1-leg stance, freestanding)

6. Hip abduction/adduction (bar work: 1-hand hold)

7. Cycle legs: sitting on pool noodle or hanging on it (noodle in the back)

8. Stretching m. quadriceps, m. iliopsoas, adductors, hamstrings, calf (10 s, 3-4 reps)

9. Pool noodle balance: step over the immersed pool noodle, move the pool noodle around the body, sitting on the pool noodle 
Table 2.2 (continued)

\section{Level 3}

1. Gait training (2-4 laps each direction):

1.1. Forward=normal gait and step length correct foot movement (heel to forefoot), 1 lap heels up, 1 lap heels to buttock

1.2. Backward=reverse foot movement (forefoot to heel)

1.3. Sideways $=$ step to the left and bring right foot to the left v.v.

2. Aquatic cycling: cycling in sitting* and half-sitting** position, change position after $4 \mathrm{~min}^{*}, 1 \mathrm{~min} * *$,

$2 \min ^{*}, 1 \min ^{* *}, 2 \min ^{*}$

3. Stepping: go up and down in sideways

4. Squats, while pushing and pulling a pool noodle with arms on shoulder height

5. Push pool noodle down (under the foot of the free leg) while extending knee and hip, let the pool noodle come up gently until hip and knee reach $90^{\circ}$ flexion (bar work: 1-hand hold)

6. Lunge sideways

7. Cycle legs: sitting on pool noodle or hanging on it (noodle in the back)

8. Stretching $m$. quadriceps, $m$. iliopsoas, adductors, hamstrings, calf (10 s, 3-4 reps)

9. Pool noodle balance: step over the immersed pool noodle, move the pool noodle around the body, sitting on the pool noodle

\section{General information}

- Main focus on:

- correct aquatic cycling technique

- knee position (neutral knee alignment, active control of knee position) during the exercises

- Duration: warming-up: 5-10 min, exercise 1 exercise 2-6: 10 min with individually chosen pedalling frequency and resistance exercise 3-6: 1 min ( $15-20$ repetitions) each with 1-min rest cooling-down: 5-10 min, exercise 1 (in uneven weeks), 7, 8, 9 (even weeks)

- Resting time between exercises: 1 min (including change of workstation)

- Intensity: exercise 1, 7-9: 7-10 on Borg scale exercise 2-6: 11-13 on Borg scale

- Progression to level 2 and 3 if:

- knee pain during and after the exercises $<5$ on a NRS for pain

- patients performed the exercises with light to moderate exertion (Borg scale, no observation for any visible signs of overexertion)

- patients performed the exercise with good quality of performance (based on the visual inspection of the physical therapist)

- Training devices:

- Underwater step

- Aquatic bike "AquaCruiser II ${ }^{\mathrm{TM}}$ " (placed at the bottom of a pool; participants needed to be immersed to xiphoid process level)

NRS: numeric rating scale; v.v.: vice versa

\section{Data analysis}

Focus group analysis was guided by the steps of framework analysis for descriptive accounts. ${ }^{9}$ The raw data was summarised per question from the interview guide and linked with illustrative quotes from the raw data. To enhance clarity, recurring themes additional to the questions were developed in regular discussion between the physiotherapist and the interviewer.

The Wilcoxon signed-rank test examined differences in pre- and post-exercise scores of knee pain. Results are presented as means and z-scores (z). Standard deviation (SD) 
and $95 \%$ confidence interval $(\mathrm{Cl})$ were calculated. A significance level of a 2 -sided $p<0.05$ was set.

\section{RESULTS}

Between February and April 2011 the orthopaedic surgeon identified 24 eligible patients, of whom 11 were willing to participate. One participant fell on her knee at home before signing the informed consent, which exacerbated her complaints and made it impossible for her to participate. The main reasons for not participating were: not interested, no specific reason given $(n=8)$; change of mind with respect to OA treatment, decided to stop conservative treatment and to undergo total knee surgery $(n=2)$; satisfied with physiotherapy twice a week $(n=2)$; and too occupied $(n=1)$.

The final cohort comprised 10 participants (7 women) aged between 46 and 77 years (mean 59.6 (SD 9.61)). The majority of the cohort was employed $(n=6), 3$ participants were retired, and 1 participant was seeking work. Radiological assessment of the tibiofemoral joint showed Kellgren/Lawrence scores of $2(n=2), 3(n=4)$ and $4(n=4)$. In addition, 2 patients had grade 2 patellar OA. Elapsed time since diagnosis of knee OA ranged from 1 to 180 months (mean 62 months; SD 69.06). Treatment history varied from injections $(n=5)$, physiotherapy $(n=5)$, medical fitness training $(n=4)$ and pain medication $(n=3)$. Four people exercised regularly and continued their exercise routines (cycling on a home-trainer, exercises for the lower back and medical fitness) during the study period. Others had experiences with medical fitness $(n=2)$ and aquatic fitness $(n=1)$, but were not participating in these activities at the time of the study.

\section{Feasibility of the training protocol}

The adherence rate for all sessions was 70\%. Two people missed one and four sessions, respectively, because of holidays. For work-related reasons one participant could only attend five sessions.

All the exercises in the conditioning section consisted of three levels. Except for two exercises, all patients could progress to level three. Pushing the pool noodle underwater up and down was difficult for two participants because the buoyancy of the pool noodle raised their supporting leg from the floor. Based on the physiotherapists' judgement of a low exercise capacity $(n=4)$ and too few sessions or too long breaks between the sessions to progress $(n=3)$ all women remained at level two with the aquatic cycling exercise. Participants perceived resistance levels two and three as comfortable for pedalling, and scored aquatic cycling at an individual chosen pedalling frequency as light (men) to moderate (women) on the Borg scale 
independent from the resistance. Cycling in an out -of-the-saddle position (level 3) was evaluated as hard on the Borg scale.

One adverse event occurred during the cooling down section of one session. One participant's foot slipped during gait training, scoring five on the pain scale. Knee pain decreased quickly after the end of the session.

A swimming pool with an adjustable floor is preferable, because of the weight of the aquatic bike. Two people are needed to immerse the bike if the floor of the pool is not height-adjustable or has an entrance for disabled people. Transportation of the aquatic bike inside and outside the pool is easy as it has two wheels at the front. The saddle height is easily adjustable by professionals or patients even when the bike is immersed. A difference in body height of more than $20 \mathrm{~cm}$ can result in suboptimal levels of immersion among participants. In order to ensure that participant's legs are underwater during cycling participants must be immersed to a minimum height of the navel and a maximum height of the xiphoid process. During shallow-water exercises immersion to chest height is preferred so that participants can perform all exercises, such as squatting without immersing their head.

Participants could step on and off the aqua-bike without assistance and were able to start exercising with minimal instruction. In addition, the combination of arm movements and cycling was easy to learn and participants needed no assistance during hand-free cycling. Because the cycling part lasted longer than the other exercises only two participants changed workstations at the same time, which allowed time for tailored feedback.

\section{Qualitative evaluation}

Two focus group interviews were conducted, with four and three participants, respectively. Two people could not attend the interviews because they were on holiday; another participant had other appointments $(n=1)$ on the day the focus groups were held. Illustrative quotes from both interviews are shown in Table 2.3. Initially participants were asked about their expectations. Participants answered that they were motivated to try-out the training because exercise was known as a means to control symptoms of $\mathrm{OA}$. They knew that cycling and aquatic exercises are frequently recommended to people with knee OA because of their low impact on the knee joints. Participants described the training as a total body workout with the focus on joint mobility and a light to moderate exercise intensity. In comparison with land-based training the pain relief effect was highlighted. Other reported effects were release of a certain tension around the knee and higher self-efficacy about physical functioning. Participants believed that the warmth and buoyancy of the water had a great impact on the reduction of pain, initiation and maintenance of movements. They felt that they could perform the cycling movements in the water more easily, although they experienced pedalling on the AquaCruiser $\mathrm{II}^{\mathrm{TM}}$ as more tiring. The participants were 
very positive about the selection of, and variety of, exercises. With regard to the aquatic cycling section participants stated that they would have liked to cycle for longer than $10 \mathrm{~min}$ on the AquaCruiser $\mathrm{II}^{\mathrm{TM}}$. Nevertheless, cycling alone with no other exercises would be too monotonous. Participants evaluated the training as suitable for their needs and exercise capabilities. Even someone with fear of water could participate without problems. Participants only had few suggestions for further optimization of the training. Participants who were not employed suggested scheduling the training in the morning. Furthermore, all participants would opt for a higher exercise frequency and a display on the aquatic bike with information about performance to make the training more efficient.

Table $2.3 \quad$ Illustrative quotes from the focus group interviews

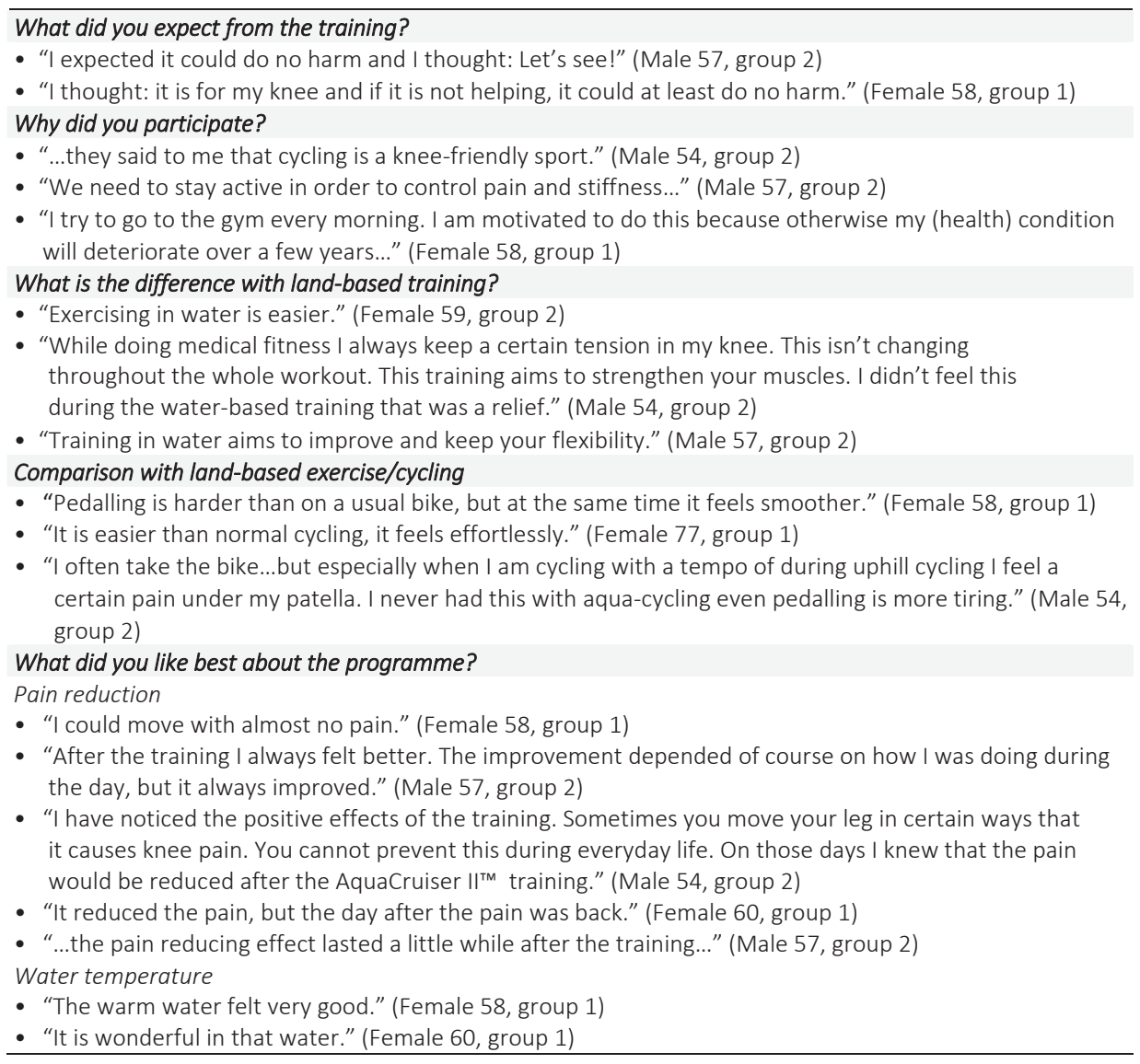


Table 2.3 (continued)

Selection of exercises

- "I came with pleasure to every session. It was fun to do the exercises" (Male 54, group 2)

- "The exercises in combination with the warmth of the water gave a good feeling." (Female 58, group 1)

- "I really liked the combination of exercises." (Female 59, group 2)

- "I would like to do aquatic cycling at the beginning and in the end, but always in combination with the other exercises."

- "It is a total body workout." (Female 77, group 1)

What did you like the least about the programme?

- "Everything was fine, it was really great!" (Female 58, group 1)

What should be changed?

- "Nothing! I am afraid of water and for me it really was an overcoming. In the beginning I needed much assistance, but this got better with every session." (Female 77, group 1)

Motivation to continue the training

- "I would like to know where I can continue this type of training." (Female 77, group1)

- "I looked up information about aqua spinning classes, but I am not sure if this matches my exercise level." (Female 51, group 2)

What should be continued but fine-tuned?

- "The training was scheduled around dinnertime. I would prefer to come in the morning or around noon." (Female 58, group 1)

- "I think it would be even better to exercise two times a week." (Female 60, group 1)

- "I experienced pain reduction that lasted a little while after the training, but I did it only once a week. I think you need to exercise more often to be able to evaluate its effectiveness." (Male 57, group 2)

- "A display with more information about training parameters during aquatic cycling like tempo, pedalling frequency would be useful for feedback and to guide progression." (Male 54, group 2)

What should be dropped?

No suggestions were made.

\section{Quantitative evaluation; self-reported pre- and post-exercise knee pain}

The self-reported pain scores were significantly lower after the training compared with the scores before the training, $z=-2.524, p<0.05, r=-0.21$. Participants had a mean pre-exercise pain score of 4.09 (SD 1.45; 95\% Cl 3.05-5.12). After the training sessions participants had a mean pain value of 3.18 (SD 1.33; 95\% Cl 2.23-4.13).

\section{DISCUSSION}

This study investigated the feasibility of group-based aquatic circuit training for patients with knee OA. The training consisted of gait training, shallow-water toning exercises, flexibility exercises for the lower limbs, and aquatic cycling. Due to the set-up of the training only one aquatic bike was needed.

Seventy per cent of the participants attended all eight sessions. The short time-period for the research project, summer holidays and limited access hours to the therapy pool made it difficult to reschedule sessions for participants who were not able to attend sessions due to holidays and work time. Participants perceived the training as a total 
body workout, focusing on flexibility. They were positive about the immediate pain reduction and the fact that movements felt smoother. In addition, self-reported pain showed a one-point reduction immediately after the training. Evidence suggests that the decompressing effect, the warm temperature and the massage effect due to the hydrostatic pressure in combination with the exercises may explain pain relief., ${ }^{2,10}$

The intensity of aquatic cycling was rated as light to moderate, although participants experienced underwater pedalling as more tiring than on a normal bike or hometrainer. Only three patients, based on the physiotherapists' judgement, progressed to an out-of -the-saddle cycling position and perceived this as moderate to hard due to the fact that cycling in an out-of-saddle-position is less controlled and less stable. It might be that more training is needed before out-of-saddle movements are possible. A good technique is crucial to hold a stable posture with the knees in line with feet and hips. For instance, Moser developed an aquatic cycling programme for patients with rheumatic diseases and was able to introduce cycling in out-of-saddle positions, but not before week seven of a ten-week programme. ${ }^{5}$ These findings suggest that ten minutes of aquatic cycling is probably too short a time to achieve progression, and that cycling in a seated position is preferable during early aquatic circuit training. Moreover, the perception of patients, that aquatic cycling was effortless in the seated position, might be explained by the fact that participants in the present study cycled at a selfselected pace. Previous research on underwater treadmill walking in patients with knee OA showed that walking at a self-selected and comfortable pace resulted in lower energy expenditure than land-based walking. ${ }^{11}$ This might be explained by the fact that during slow underwater walking buoyancy dominates and the water resistance is not sufficient to raise the heart rate. Thus, participants should first progress their pedalling pace before cycling in a standing position. Cycling in a seated position is a controlled movement and few instructions are needed, which creates more time for tailored feedback for patients at other workstations. However, if the period of aquatic cycling is extended variation is needed to prevent monotony, which may require more supervision.

In conclusion, aquatic circuit training including aquatic cycling is feasible for patients with OA. Aquatic cycling in a seated position is a safe and controlled movement that enables the physiotherapist to spend more time on supervision of other patients. Therefore, aquatic cycling is easy to incorporate in circuit training and enables institutions to provide small group trainings even with one aquatic bike. Further research is needed to investigate patient acceptance of a higher exercise frequency of two or three sessions weekly and its impact on symptoms of knee OA. The feasibility and effects on knee OA of exercise programmes incorporating more time spent aquatic cycling have not yet been investigated. 


\section{Acknowledgements}

The AquaCruiser II $^{\mathrm{TM}}$ was provided by AquaKinetiqs ${ }^{\circledR}$. The authors thank Wiel Wijnen at the Department of Orthopaedic Surgery for patient recruitment. George Roox kindly allowed the use of the pool facilities at Maastricht University Medical Centre. 


\section{REFERENCES}

1. Tilden HM, Reicherter EA, Reicherter F. Use of an aquatics program for older adults with osteoarthritis. From clinic to the community. Topics in Geriatric Rehabilitation. 2010;26:128-39.

2. Batterham SI, Heywood S, Keating JL. Systematic review and meta-analysis comparing land and aquatic exercise for people with hip or knee arthritis on function, mobility and other health outcomes. BMC Musculoskeletal Disorders. 2011;12:123-36.

3. Ulatkowski M. Unterwasserfahrrad versus herkömmliche Rehabilitation - Eine retrospektive Studie mit und ohne Unterwasserfahrrad an implantierten Kniegelenksprothesen [Dissertation]. Heidelberg: Heidelberg University; 2009.

4. von Kathen M. Prospektiv-randomisierte Vergleichsstudie zur Rehabilitation vorderer Kreunzbandplastiken zwischen koventioneller Therapie und Unterwasserfahrrad [Dissertation]. Bochum: RuhrUniversität; 1999.

5. Moser S. Entwicklung und Überprüfung eines Aqua-Cycling-Programms für Rheumapatienten [Master Thesis]. Karlsruhe: Universität Karlsruhe; 2009.

6. Bellamy N, Kirwan J, Boers M, Brooks P, Strand V, Tugwell P, et al. Recommendations for a core set of outcome measures for future phase III clinical trials in knee, hip, and hand osteoarthritis. Consensus development at OMERACT III. Journal of Rheumatology. 1997;24:799-802.

7. Barbosa TM, Marinho DA, Reis VM, Silva AJ, Bragada J. Physiological assessment of head-out aquatic exercises in healthy subjects: a qualitative review. Journal of Sports Science \& Medicine. 2009;8:179-89.

8. van der Leeden M, Staal JB, Beekman E, Hendriks H, Mesters I, de Rooij M, et al. Development of a framework to describe goals and content of exercise interventions in physical therapy: a mixed method approach including a systematic review. Physical Therapy Reviews. 2014;19:1-14.

9. Ritchie J, Lewis J. Qualitative Research Practice: A Guide for Social Science Students and Researchers. London: SAGE Publications Ltd; 2003.

10. Hall J, Swinkels A, Briddon J, McCabe CS. Does aquatic exercise relieve pain in adults with neurologic or musculoskeletal disease? A systematic review and meta-analysis of randomized controlled trials. Archives of Physical Medicine and Rehabilitation. 2008;89:873-83.

11. Denning WM, Bressel E, DG D. Underwater Treadmill Exercises as a Potential Treatment for Adults With Osteoarthritis. International Journal of Aquatic Research and Education. 2010;4:70-80. 



\section{CHAPTER 3}

Effect of aquatic cycling on pain and physical

functioning compared with usual care in patients with knee osteoarthritis: study protocol of a randomised controlled trial

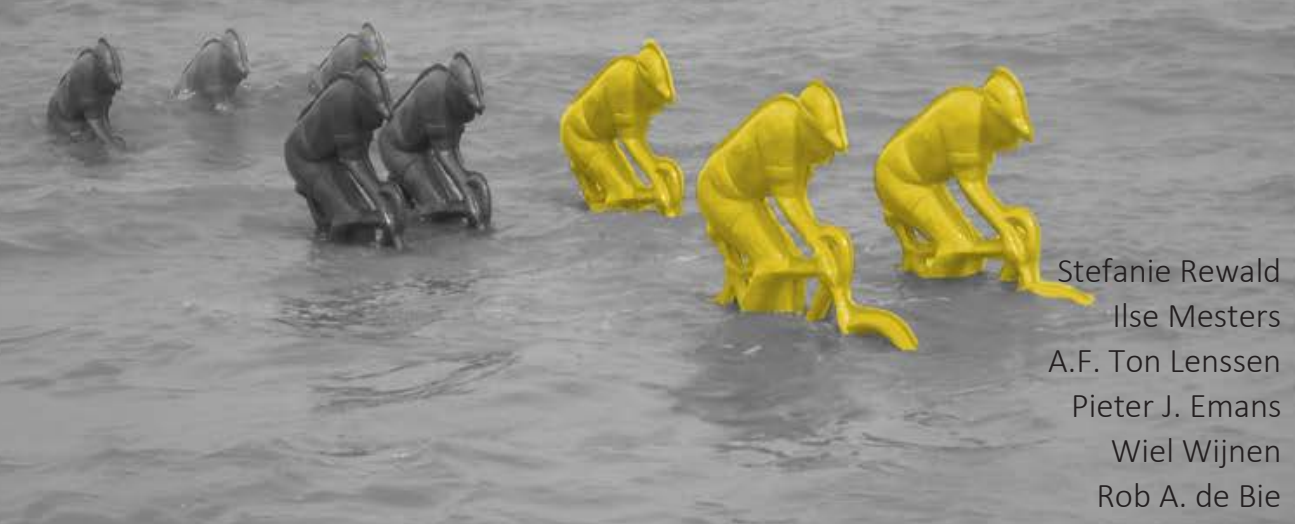




\section{ABSTRACT}

\section{Background}

Over the last decade aquatic exercise has become more and more popular. One of the latest trends is aquatic cycling, where participants sit on a water-resistant stationary bike and, while immersed chest deep in the water, combine continuous cycling with upper body exercises that utilise water resistance. Since stationary cycling and aquatic exercises are frequently recommended to patients with knee osteoarthritis, combining both would seem an obvious step, and an aquatic cycling exercise programme for patients with knee osteoarthritis has indeed been developed. This study protocol gives a detailed description of the exercise programme and the methodology of a study to compare this programme with treatment involving usual care only.

\section{Methods}

The study is a single-blind, parallel-group, randomised controlled trial of Maastricht University Medical Centre+, the Netherlands. Inclusion criteria: knee pain of four to seven on a 10-point pain rating scale; a Kellgren/Lawrence score between one to three; ability to cycle; good mental health; sufficient language skills; indication for physical therapy in conjunction with impairments due to OA. Exclusion criteria: any contra-indication for aquatic exercise; planned total knee replacement; corticosteroid injection $<3$ months and/or hyaluronic acid injection $<6$ months; severe joint complaints (other than knee joint); symptomatic and radiological apparent hip OA; inflammatory joint diseases; inability to safely enter and exit the pool; fear of water. Participants will receive two 45-min moderate intense aquatic cycling sessions weekly over a period of 12 weeks in addition to usual care or usual care only. Usual care consists of an individual intervention plan comprising lifestyle recommendations, medication routine and referral to a physical therapist. Participants will be assessed at baseline, and at 12 and 24 weeks after baseline. The primary outcome is self-reported knee pain and physical functioning. Secondary outcomes are lower limb muscle strength, functional capacity, self-reported disease severity, physical activity level, quality of life, self-efficacy and fear of movement. Daily diaries will collect information on knee pain, physical functioning, level of physical activity, pain medication routine and physical therapy (control group only) or exercise participation over two 30-day periods (during the intervention period).

\section{Discussion}

To our knowledge the present study is the first randomised controlled trial evaluating the effects of aquatic cycling in the pre-surgical stage of knee osteoarthritis. This trial will demonstrate if the newly designed aquatic cycling intervention, in supplement to usual care, can help to improve impairments due to knee osteoarthritis. 


\section{INTRODUCTION}

Aquatic cycling, which is cycling on a water-resistant stationary bike, might be a supplement to the available exercise possibilities for patients with knee osteoarthritis (OA). Knee OA, a common chronic health condition, affects the daily lives of millions of people worldwide by causing knee pain and difficulty performing day-to-day activities. ${ }^{1}$ All dimensions of physical function, as described by the International Classification of Functioning, Disability, and Health (IFC) framework, are affected by knee OA. ${ }^{2}$ For example, as a reaction to load dependent joint pain that commonly occurs during daily functional activities like walking or stair climbing, people tend to underuse the knee and become physically inactive., ${ }^{3,4}$ Avoidance of these activities gives rise to problems with body functions and structures such as cardiovascular deconditioning, muscle weakness and reduced knee range of motion, but also to more general health problems such as a higher risk of comorbidity and premature mortality., ${ }^{5,6}$ Exercise therapy is crucial for maintaining good general health and alleviating the symptom progression of knee $O A .{ }^{4,6}$ In addition to exercise, patient education about treatment options, weight management and strategies to prevent capacity overload of the damaged knee, as well as pharmacological treatment with analgesics or non-steroidal anti-inflammatory drugs (NSAIDs), are recommended for optimal conservative management of OA. ${ }^{6}$ However, only a small part of the population treats their complaints by participating in physical therapy or exercise therapy. ${ }^{7,8}$ The patients' reasons for exercising (or not) depend on their (perception of their) physical ability for exercise; beliefs about exercise; motivational factors such as enjoyment, social support, taking control of the disability; pain and limitations of the lower limb. ${ }^{9}$ Aquatic exercise enjoys a good reputation among patients because exercising in water feels easier and less painful than on land. ${ }^{10,11}$ The buoyancy of the water results in decompression of joints and causes the individual to feel weightless and to move more smoothly than on land. ${ }^{11,12}$ In addition, a warm water temperature promotes muscle relaxation, possibly resulting in pain reduction and the perception of less joint stiffness. ${ }^{12,13}$ Recent systematic reviews of aquatic exercise studies of individuals with $\mathrm{OA}$ and other chronic musculoskeletal disorders showed a small to moderate effect on joint pain, selfreported functioning, and performance tests of physical functioning. ${ }^{14,15}$ These achievements are comparable to the results of land-based training. ${ }^{16}$ Growing recognition of the benefits of aquatic exercise and increasing public interest have resulted in many forms of aquatic exercise. Older patients with OA value individualised, expert-supervised shallow-water exercises, aqua jogging and hydrotherapy. ${ }^{17}$ The exercise possibilities in water range from simple vertical water exercise and water running to more holistic programmes such as Watsu ${ }^{\circledR}$ and the adaptation of land-based fitness trends like Zumba ${ }^{\circledR}$ to the aquatic environment. ${ }^{18}$ With the continual development and refinement of waterproof equipment, even spinning is now possible in a swimming pool. Aquatic cycling, where participants are immersed chest deep in 
water and pedal against water resistance, has recently become a popular water-based fitness activity. It combines the advantages of the aquatic environment with those of stationary land-based cycling, a combination that seems ideal for patients with knee $\mathrm{OA}$. Stationary cycling is often used in the treatment of lower-limb injuries and chronic conditions like OA because of the reduced joint load, the repetitive circular pedalling movement that can be used to improve range of motion (ROM) in a functional manner, and the involvement of the largest muscle groups of the lower limb. ${ }^{10}$ Evidence shows that stationary cycling can reduce knee pain and improve aerobic capacity, selfreported physical functioning and gait. ${ }^{19,20}$ So far, only a small number of studies have documented the therapeutic effects of aquatic cycling. Ulatkowski and von Kathen evaluated the additional effect of aquatic cycling during recovery from total knee surgery and anterior cruciate ligament reconstruction. ${ }^{21,22}$ In both cases, patients who did aquatic cycling showed greater improvements in knee-ROM and a reduction in knee joint swelling compared with patients receiving usual care only. Furthermore, a small one-group pre-test and post-test study on the effects of a 10-week aquatic cycling programme involving patients with rheumatic diseases showed a positive influence on strength, well-being and joint mobility. ${ }^{23}$ Another small study on the feasibility of aquatic cycling, as a part of an aquatic circuit training for patients with knee $\mathrm{OA}$, evaluated aquatic cycling as a safe and controlled exercise regimen and reported that participants were very satisfied with the training. ${ }^{24}$

A 12-week group-based aquatic cycling training for mild to moderate knee OA patients was developed, because currently only a few therapeutic aquatic cycling interventions are available. The results of this study might provide guidance on the clinical use of aquatic cycling and greater insight into the effectiveness of aquatic cycling may help to broaden aquatic treatment possibilities. Furthermore, the study may support instructors of community aquatic cycling classes in dealing with participants with knee OA. For these reasons, it is important to examine whether a 12-week aquatic cycling programme, in supplement to usual care, will result in better outcomes of selfreported knee pain and physical functioning when compared with the relatively less intricate regimen usual care only.

This article provides a full description of the study' s rationale, design and method in accordance with the SPIRIT guidelines for reporting protocols of intervention trials and the CONSORT guidelines. ${ }^{25,26}$

\section{METHODS}

\section{Study design}

The current study is a single-blind, parallel-group, randomised controlled trial (RCT) of Maastricht University Medical Centre+ (MUMC+). Due to the structure of the trial, 
participant blinding is not possible. To design the trial as cost-effectively as possible, the programme coordinator is involved in many project activities such as recruitment, data collection planning and execution of the intervention, precluding blinding. Data collection and entry is performed by blinded and independent physical therapists and research assistants. The data will be analysed by blinded analysts.

The randomisation procedure is performed by an independent research assistant of the Department of Epidemiology of Maastricht University using free, internetbased software to generate the random allocation schedule (http://www.randomizer.org). A block randomisation with a constant block size of eight patients and an allocation ratio of 1:1 is used to keep sample sizes equal across the intervention and control group.

\section{Setting and participants}

Participants were recruited in a hospital (MUMC+) in the Dutch province of Limburg. Patients were recruited from March 2013 until October 2015. The source population were patients diagnosed with mild to moderate knee OA. They were diagnosed by an orthopaedic surgeon or nurse practitioner, and the diagnosis was based on clinical symptoms and $\mathrm{x}$-rays. Patients with an indication for conservative management of knee OA were offered the opportunity to participate in the present study. The orthopaedic specialist briefly explained the project and asked the patient for their agreement to share contact information (name and telephone number) with the programme coordinator. Research on participation in selfmanagement programmes shows that the recommendation of a health professional influences the decision on whether to take part in a programme. ${ }^{27}$

Non-participation had no consequences for further treatment.

\section{Inclusion criteria}

Eligible patients 1) rated knee pain between four and seven on a 10-point numeric pain rating scale, 2) had a Kellgren/Lawrence score between one and three, 3) were able to cycle on a stationary exercise bike, 4) were in good mental health (score $<8$ for anxiety and depression on the Hospital Anxiety and Depression Scale, HADS), 5) had sufficient language skills and 6) had an indication for physical therapy in conjunction with impairments due to OA.

\section{Exclusion criteria}

Potential participants with any contra-indication for aquatic exercise therapy such as 1) severe, unstable cardiorespiratory co-morbidities and 2) open wounds, or patients on a 3) waiting list for total knee surgery were excluded from participation in this study. Furthermore, all potential participants who met one of the following criteria were excluded given that these conditions could limit safe and full participation in the study 
or impede the perception of symptoms of knee OA: 4) corticosteroid injection $<3$ months and/or hyaluronic acid injection <6 months, 5) severe joint complaints (other than knee joint) that interfere the ability to participate in an exercise programme, 6) symptomatic and radiological apparent hip OA, 7) inflammatory joint diseases, 8) inability to safely enter and exit the pool and 9) fear of water.

Eligible patients first received verbal information by telephone. Interested patients were contacted by the programme coordinator after their consultation visit at the MUMC+. If their interest in participation continued after the telephone call, the programme coordinator sent additional information by mail. Each potential participant could consider participation for one week and was instructed to hold off any physical therapy until the randomisation results were known. If a candidate decided to participate, they had to sign an informed consent form in which they declared their voluntary participation. The programme coordinator checked incoming applications, including two short questionnaires, to screen for any contra-indications for physical activity using the physical activity readiness questionnaire (PAR-Q) and to screen for anxiety and depression using the HADS. ${ }^{28,29}$ In case of any doubts about patients' mental and/or physical health, the patient concerned was advised to contact a medical specialist for examination or advice.

After providing their informed consent, participants were randomly assigned to either the usual care control group or a 12-week aquatic cycling programme at MUMC+. Having completed the baseline assessment, participants in the intervention group started the aquatic cycling programme (24 sessions) and the control group could start with physical therapy and continue other usual care routines. The post-programme and follow-up measurements were scheduled after 12 and 24 weeks. After the last assessment, the control group was offered 12 sessions of aquatic cycling in a public swimming pool. The intervention group could also join this group after the 12-week intervention phase, but had to pay the regular rate for aquatic fitness charged by the community pool.

An overview of the participant timeline is given below in Figure 3.1. 


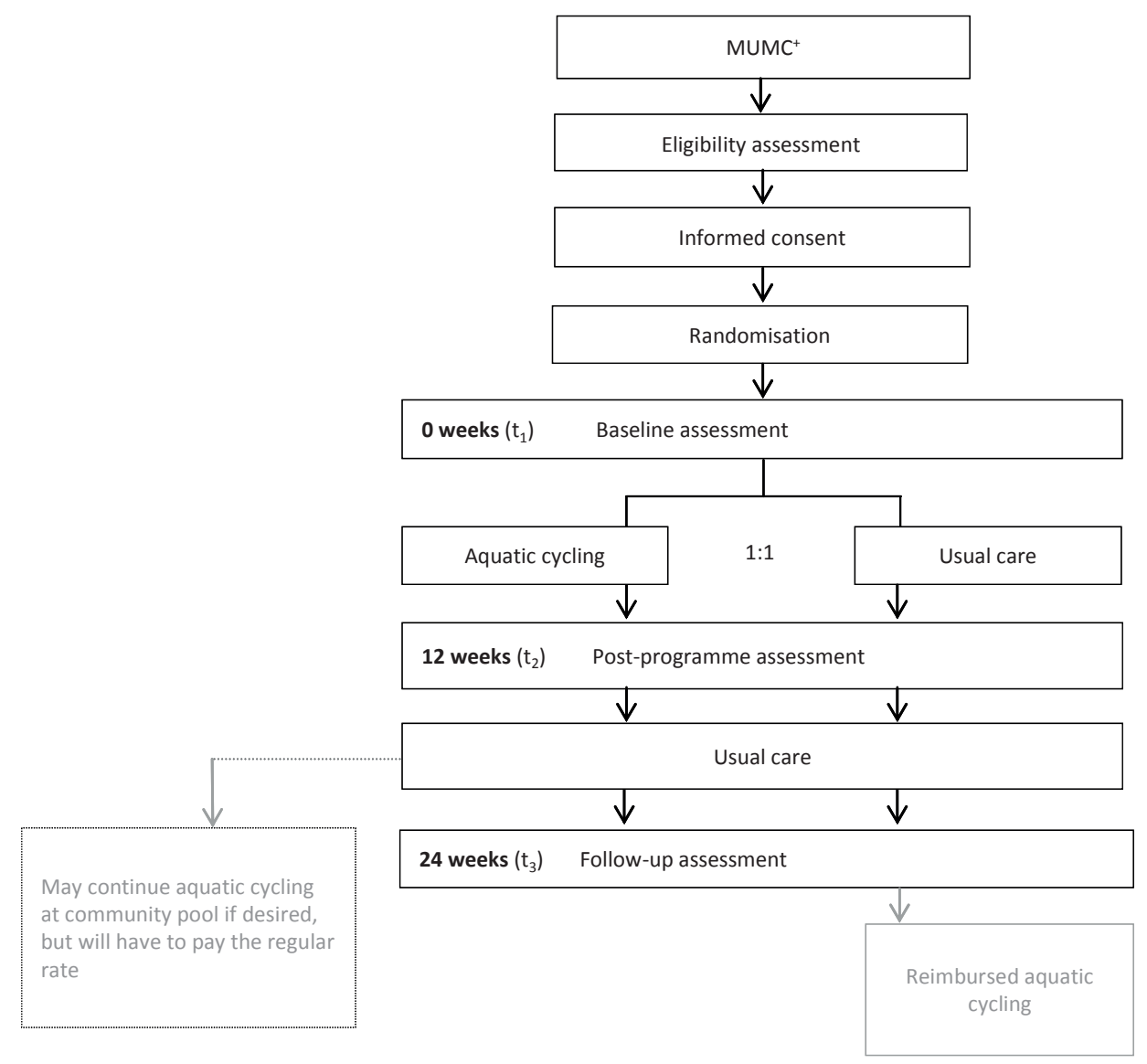

Figure 3.1 Participant timeline

\section{Intervention}

\section{Both groups}

Participants were referred by their general practitioner for a consultation visit to the orthopaedic specialist at MUMC+. Essentially, there were three different types of consultation visits. Participants from the area of Maastricht who have not yet been diagnosed with OA were referred to MUMC+ for further diagnostics of their knee complaints. Based on predictive values for severity of complaints, the MUMC+ scheduled patients for consultation at the Early OA Outpatient Clinic or the department of orthopaedic surgery. The Early OA Outpatient Clinic is responsible for the diagnosis and secondary prevention in patients with pre-surgical knee OA. The diagnosis is based 
on recent x-rays and clinical symptoms. Subsequently, the nurse practitioner provided patients with personalised information on OA, an information booklet on OA and an individual intervention plan consisting of lifestyle recommendations, medication routine and referral to a physical therapist. After six weeks, patients had their second consultation visit to evaluate the treatment. Patients already diagnosed with knee OA and who came back for a follow-up visit at the department of orthopaedic surgery could also participate in the study in case of an indication for physical therapy. These were usually patients who had limited success with pharmacological treatments such as injections and oral pain medication. In the case of injections, patients could still participate in the present trial after a wash-out period of three (in the case of a corticosteroid injection) to six months (in the case of a hyaluronic acid injection). If participants received an injection during the trial, the programme coordinator recorded the date and type. Occasionally, patients were referred to the orthopaedic surgeon for diagnosis and in that event the orthopaedic surgeon provided a diagnosis, lifestyle recommendations and a treatment plan.

All participants were instructed to maintain their usual care routine. The programme coordinator kept track of changes in participants' treatment plans by monitoring patients with diaries that recorded OA-related functional problems, knee pain, physical activity, physical therapy and medication use in the first and third month after baseline assessment. Furthermore, a short interview by phone (control group) or in person (intervention group) was scheduled after six weeks. Prior to the last assessment, the programme coordinator called participants and inquired about any changes in treatment.

\section{Control group}

The control group was instructed to continue usual care, including working on prescribed lifestyle recommendations, medication routine and consultations with their orthopaedic surgeon during the 24-week trial. Furthermore, participants could start with physical therapy, but this was not necessary to participate in the present study. Use of and compliance with non-pharmacological interventions, such as physical therapy and exercise, is low in patients with knee OA. ${ }^{7}$ Motivation to start with and maintain such interventions is influenced by previous treatment experience and perceived effectiveness, attitudes towards exercise, perceived severity of knee symptoms and comorbidity. ${ }^{30,31}$ In addition, due to differences in health care coverage, some participants were unable to afford physical therapy. Funding constraints made it impossible to cover the costs for these participants. To minimise dropout, participants were offered 12 weekly sessions of aquatic cycling after the end of a patient's participation in this study. These sessions were held in a community pool because of size restrictions of the hospital pool. 


\section{Intervention group}

Participants in the intervention group also continued with usual care, though they were instructed not to start additional physical therapy during the 12-week intervention period. Supervised by a physical therapist, participants performed aquatic cycling exercises for 45 minutes twice a week over a period of 12 weeks. The training took place in a heated therapy pool $\left(32^{\circ}\right.$ Celsius) at the MUMC+ department of physical therapy. Depending on the body length of the participants, the water depth varied between 1.20 and 1.30 metres and participants were immersed between the navel and a maximum height of the xiphoid process (Photograph 3.1). The aquatic bike used was the AquaCruiser II ${ }^{\mathrm{TM}}$ from AquaKinetiqs (Photograph 3.2).

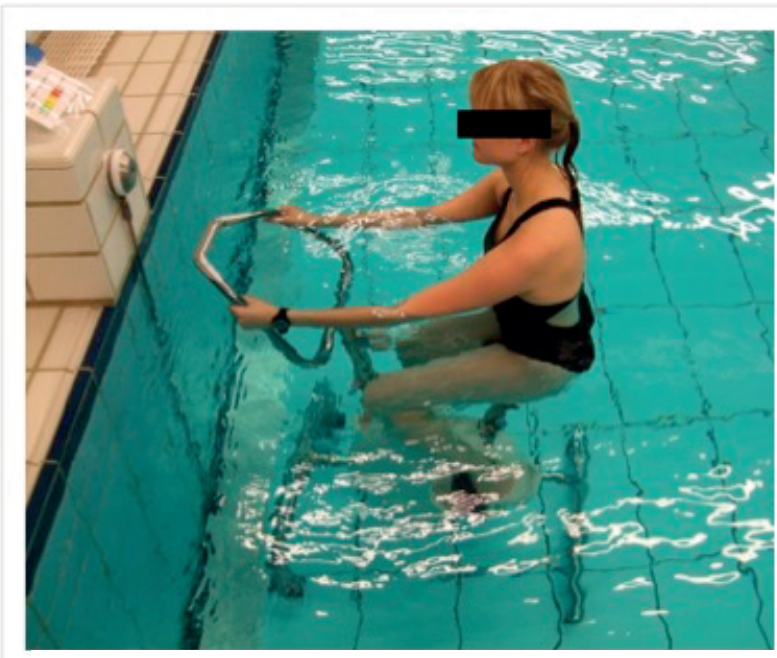

3.1

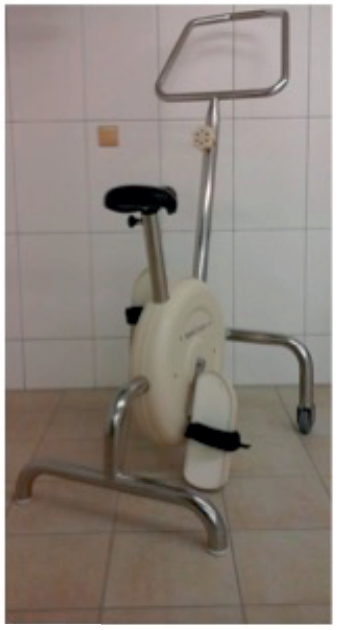

3.2

Photograph 3.1 Basic position on the aquatic bike.

Photograph 3.2 AquaCruiser $1 I^{\mathrm{TM}}$

This bike differs from other aqua bikes used for recreational sporting activities by healthy people (e.g. www.hydrorider.com). Differences consists of cycling barefooted instead of using water shoes, the AquaCruiser II $^{\text {TM }}$ saddle is more comfortable, and the resistance can be adjusted during pedalling via a knob located below the handlebar instead of being set on land prior to the session. The resistance can be adjusted by six reproducible and equal increments by means of a magnetic braking system. Participants cycled on the aquatic bike throughout the whole session. Every session consisted of a warm-up, a conditioning phase and a cool-down. A detailed overview of the programme, reported according to the framework of van der Leeden et al., ${ }^{32}$ is provided in Table 3.1. 
Table $3.1 \quad$ Aquatic cycling programme

Interventions goals (ICF):

- b710: mobility of joint functions

- b715: stability of joint functions

- b740: muscle endurance functions

- b760: control of voluntary movement functions

- b620: proprioceptive function

\section{Exercises}

1. Cycling at self-chosen rpm

2. Mobilisation of upper body

3. 60-rpm cycling = participants focus on pedalling at a minimum of $60 \mathrm{rpm}$

4. Lower leg exercises (1-2 exercises per session)
4.1 one-leg pedalling
4.2 emphasis on upward or downward pedalling movement
4.3 out-of-the-saddle position: standing climb
4.4 out-of-the-saddle position: standing flat

5. Arm exercises (1 exercise per session)

5.1 shoulder abduction/adduction = arm lifts

5.2 shoulder transverse abduction/adduction = fly backs

5.3 shoulder flexion/extension = walking arms/ arm pendulum (one-sided)

5.4 elbow flexion/extension $=$ curl

5.5 shoulder flexion and extension = arm pendulum

arm exercises will be combined with different hand positions (from less intense to more intense): sweeping on water surface, hand slicing sideways through the water ('cutting'), 'fisting', cupped hands ('scoop'), open hand ('fan')

6. Backward pedalling

7. ROM knee = sitting on the aqua bike, feet out of the pedals, flexion and extension of unloaded knees

8. Calf and hamstring stretching

\section{General information:}

- Main focus is on correct aquatic cycling technique, i.e. cycling with a cadence of $60 \mathrm{rpm}$, a good alignment of the lower legs and an upright posture

- Set-up:

- Warm-up: exercise 1, 2

- Conditioning: exercise 3, 4, 5

- Cooling-down: exercise 1, 6, 7, 8

- Total programme duration: 12 weeks (2 sessions per week)

- Frequency (exercise time/repetitions) and resting time:

- Warm-up: 5-10 minutes

- Conditioning: exercise 3: 5-8.20 minutes

exercise $4: 4$ sets of 30-45 seconds, 1 minute resting time

exercise $5: 4$ sets of 1 minute ( $20-40$ repetitions) , 1 minute resting time

- Cooling-down: 5-10 minutes

- Intensity (conditioning): 11-13 Borg Scale/70\% of maximum heart rate ((220-age) x 0.7))

- Progression:

- exercise 3: weekly increase of 15-20 seconds in cycling time

- exercise 4: pedalling resistance (after session 6, depending on performance of the exercise plus no signs of overload in on-going and previous sessions)

- exercise 5: hand position > length of lever arm > speed/small to big amplitude > increased surface area using aqua gloves or discs (depending on performance of the exercise plus no signs of overload in ongoing and previous sessions) 
Table 3.1 (continued)

- Training devices:

- Timer

- Borg Scale

- Aquatic bike 'AquaCruiser II ${ }^{T M}$ '

- Aqua discs

- Aqua gloves

- Aqua dumbbells

ICF = International Classification of Functioning, Disability, and Health; rpm = revolutions per minute

In the conditioning phase, participants cycled for 25 to 30 minutes at a moderate intensity level and combined continuous cycling with exercises for the upper body. In addition, patients cycled in out-of-the-saddle positions, did one-leg pedalling or emphasised one part of the pedal movement (e.g. by actively pulling the pedals upwards). Therefore, the conditioning phase essentially consisted of three segments: continuous cycling at a minimum cadence of 60 revolutions per minute (rpm), upper body exercises and lower body exercises. The continuous cycling segment consisted of at least five minutes of cycling at a minimum pedalling cadence of $60 \mathrm{rpm}$. Exercise duration was increased by 15 to 20 seconds each week. Based on a conditioning phase of 25 minutes, this is an increase of 1\% per week, which is lower than the recommended weekly increase of $2.5 \%$ as advocated by the American Geriatric Society. ${ }^{33}$ This is deliberate, however, as the assumption is that aquatic cycling is more demanding than stationary cycling on land. ${ }^{24,33}$ Increased pedalling resistance was offered with caution and only if a participant was able to cycle continuously at $60 \mathrm{rpm}$ without adverse reactions such as increased knee pain after the session, because increased workload results in increased knee load. This is in turn reported to be associated with worsening of knee pain. ${ }^{34}$

The upper body exercises were used as an active break for the lower limbs as the pedalling tempo decreases with the focus shifted from the legs to the upper body. In addition, the upper body exercises enabled a varied exercise programme and prevented monotony, which might have occurred with 45 minutes of purely cycling. The exercises were typical exercises used in aquatic fitness to strengthen arms (biceps, triceps), shoulders (rotators, flexors, extensors) and upper back (e.g. rhomboids, latissimus). A single repetition maximum as guidance for exercise intensity cannot be transposed to the aquatic environment. Characteristically, aquatic strength exercises are repeated 20 times and more. ${ }^{35}$ Previous research has shown that this is an effective training method to increase muscular strength in chronic pain and OA patients. ${ }^{36-39}$ Additionally, the high number of repetitions allows time to rehearse the exercise to promote execution using strong, powerful movements with good technique and full ROM. $^{40}$ Floating devices and drag equipment were used to increase resistance and to provide a varied exercise programme. The equipment used has not been sponsored by the manufacturers. 
The more exhausting upper-body exercise routine was followed by exercises focusing on the lower limbs. Patients cycled in a half-seated or standing position, emphasised the upwards and downwards pedalling movement and/or cycled with one leg. There is currently no evidence regarding the influence of different body positions in aquatic cycling on knee joint load. Consequently, the results of biomechanical studies of stationary cycling on land have guided the development of this exercise segment. ${ }^{41,42}$ Research on the difference between seated and standing uphill cycling shows an increased activation of monoarticular hip and knee extensors. However, to keep knee load as low as possible, standing positions should be limited during each session. During a land-based spinning class, out-of-saddle positions account for approximately $16 \%$ ( 8 $\mathrm{min}$ ) of the session' $\mathrm{s}$ total time $(50 \mathrm{~min}){ }^{43}$ In comparison, the time spent cycling in standing positions in the aquatic cycling programme was 5 to $8 \%$ (2 to 4 min) of the total cycling time ( $\sim 5 \mathrm{~min}$ ). The cool-down consisted of slowly cycling forward and backward, knee-ROM exercises and static stretching of the lower limbs to decrease the heart rate, prepare participants for the change of body position (e.g. from sitting on the exercise bike to standing position) and environment (the pool floor slowly comes up during the stretching exercises), and to reduces experienced muscle soreness.

The exercise intensity was moderate and was regulated by the patients themselves based on their perceived exertion using the BORG scale. ${ }^{44,45}$ In addition, heart rate was monitored by a Polar Ft 7, Wearlink ${ }^{\circledR}+$ Hybrid chest strap during each training session, and peak and average heart rates are protocolled. An average heart rate of $70-75 \%$ of the maximum heart rate is desirable and recommended by exercise guidelines for OA. ${ }^{46,47}$ Furthermore, the supervising physical therapist assessed the quality of the performance by judging compensational movements, postural control, safe execution, and level of exertion (assessed by the talk test). In the event of any doubt about a participant's health status, the physical therapist discontinued the training and referred the participant to their general practitioner.

\section{Outcome measures}

The current study investigates the effect of aquatic cycling on impairments due to knee $\mathrm{OA}$, such as knee pain, reduced physical functioning over the previous week and on the assessment day, and knee stiffness. It also seeks to make an overall assessment of disease severity and lower limb muscle strength compared with a control group receiving usual care. Furthermore, the phenomenon of aquatic cycling is explored in a more general health context through evaluating the effect of aquatic cycling on functional capacity, physical activity level and quality of life. Psychological measures on self-efficacy and fear of movement are also assessed. Outcomes are assessed in person, but to keep the number of missing values as small as possible, all 
questionnaires will be sent by mail to any participants unable to come to the MUMC+. An overview of all measures and timing of assessment is given in Table 3.2.

Table 3.2 Overview of measures and timing of assessment

\begin{tabular}{|c|c|c|c|c|c|}
\hline Timing of assessment (in weeks) & $\begin{array}{c}-1 \\
\text { Randomisation }\end{array}$ & $\begin{array}{c}0 \\
\text { Baseline }\end{array}$ & $\begin{array}{c}1-12 \\
\text { aquatic cycling / } \\
\text { usual care only }\end{array}$ & $\begin{array}{c}12 \\
\text { Post- } \\
\text { intervention }\end{array}$ & $\begin{array}{c}24 \\
\text { Follow-up }\end{array}$ \\
\hline \multicolumn{6}{|l|}{ Measures } \\
\hline \multicolumn{6}{|l|}{ Screening } \\
\hline - Kellgren/Lawrence score & $x$ & & & & \\
\hline $\begin{array}{l}\text { - Physical Activity Readiness } \\
\text { Questionnaire }\end{array}$ & $\mathrm{x}$ & & & & \\
\hline $\begin{array}{l}\text { - Hospital Anxiety and Depression } \\
\text { Scale }\end{array}$ & $x$ & & & & \\
\hline - Cumulative IIIness Rating Scale & $x$ & & & & \\
\hline \multicolumn{6}{|l|}{ Primary outcome } \\
\hline $\begin{array}{l}\text { - Knee Injury and Osteoarthritis } \\
\text { Outcome Score }\end{array}$ & & $x$ & & $x$ & $x$ \\
\hline \multicolumn{6}{|l|}{ Secondary outcomes } \\
\hline - Lower Extremity Function Scale & & $x$ & & $x$ & $x$ \\
\hline - Numeric pain rating scales & & $x$ & & $x$ & $x$ \\
\hline - Patient Global Assessment & & $x$ & & $x$ & $x$ \\
\hline $\begin{array}{l}\text { - Isometric and isokinetic muscle } \\
\text { strength (hamstring, quadriceps) }\end{array}$ & & $x$ & & $x$ & $x$ \\
\hline - Timed up and Go & & $x$ & & $x$ & $x$ \\
\hline - 6-Minute-Walking-Test & & $x$ & & $x$ & $\mathrm{x}$ \\
\hline $\begin{array}{l}\text { - Short Questionnaire to Assess } \\
\text { Health-enhancing Physical Activity }\end{array}$ & & $x$ & & $x$ & $x$ \\
\hline - Rand-36 Health Survey & & $x$ & & $x$ & $x$ \\
\hline - Tampa Scale for Kinesiophobia & & $x$ & & $x$ & $x$ \\
\hline - Arthritis Self-Efficacy Scale & & $x$ & & $x$ & $x$ \\
\hline \multicolumn{6}{|l|}{ Process measures } \\
\hline $\begin{array}{l}\text { Diaries on OA-related functional } \\
\text { problems, knee pain, physical } \\
\text { activity, physical therapy and } \\
\text { medication use }\end{array}$ & & & $x$ & & \\
\hline - Attendance at aquatic cycling & & & $x$ & & \\
\hline $\begin{array}{l}\text { - Adverse events during aquatic } \\
\text { cycling }\end{array}$ & & & $x$ & & \\
\hline $\begin{array}{l}\text { - Participants' experience with the } \\
\text { training }\end{array}$ & & & $x$ & & \\
\hline $\begin{array}{l}\text { - Average and peak heart rate during } \\
\text { aquatic cycling }\end{array}$ & & & $\mathrm{x}$ & & \\
\hline
\end{tabular}

\section{Primary outcome}

The self-reported score on knee pain and physical functioning assessed with the Knee Injury and Osteoarthritis Outcome Score (KOOS, http://www.koos.nu) is the primary outcome measure. The KOOS questionnaire is an extended version of the Western 
Ontario and McMaster Universities Arthritis Index (WOMAC), which is a wellrecognised, valid and responsible outcome measure in knee OA research. ${ }^{48}$ In addition to the WOMAC subscales for pain, stiffness and physical function (in its complete and original format), the KOOS also takes into account difficulties with sport activities and knee-related quality of life. The five subscales are scored on a five-point Likert scale and final scores are modified to a 0 to 100 scale. A lower score is associated with higher impairments. The Dutch KOOS shows good, internal validity (Cronbach's $\alpha$ : 0.71), construct validity (Spearman correlation between KOOS subscales and SF-36 pain and physical function: $0.63,0.75$ ) and is a reliable (ICC: $0.45-0.89)$ measurement for patients with mild to moderate knee OA. ${ }^{49}$ The KOOS is self-administered and patients need approximately 10 min to answer all questions. ${ }^{50}$

\section{Secondary outcomes}

The Lower Extremity Function Scale (LEFS) is a patient-reported measure on physical functioning on the test day. ${ }^{51}$ The questionnaire consists of 20 questions and patients can complete it within a few minutes. The Dutch version of the LEFS has favourable psychometric properties: good internal consistency $(0.96)$, reliability $(I C C=0.86)$ and a good construct and discriminant validity. ${ }^{52}$ It is a disease-specific questionnaire and each item is scored on a five-point Likert scale. The total score ranges from 0 to 80 points. A higher score is associated with better physical functioning.

Numeric pain rating scales (NPRS) are frequently used to assess pain intensity in OA and the NPRS has been recommended as a core outcome measure for chronic pain trials. ${ }^{53,54}$ Previous research showed that the NPRS is a valid and responsive tool for pain measurements in OA patients and also a reliable tool (ICC: 0.64 to 0.86 ) in patients with orthopaedic problems and musculoskeletal pain. ${ }^{55,56}$ The NPRS is a selfadministered scale, completed in less than 1 min and a lower score indicates less pain. Osteoarthritis research societies have defined a core set of outcome measures for clinical OA trials: pain, function and Patient Global Assessment (PGA). ${ }^{57}$ Participants will be asked to consider all the ways in which illness and health conditions are affecting them at the time of the assessment and to mark one of 21 numbered circles on a visual analogue scale (VAS). ${ }^{58} \mathrm{~A}$ higher scores means that the participant feels more affected by their illness and health conditions. The PGA has a good test-retest reliability (ICC: 0.702 ) in patients with rheumatic arthritis and is completed by patients within a few seconds. ${ }^{58}$

Data on isometric and isokinetic muscle strength of hamstring and quadriceps of the affected leg are collected with the dynamometer Biodex ${ }^{\circledR}$ System 3 Pro. The isometric quadriceps and hamstring muscle strength are tested in $30^{\circ}$ and $60^{\circ}$ fixation with three repetitions each. Isokinetic quadriceps and hamstring muscle strength are measured at $60^{\circ}$ per second (five repetitions) and $180^{\circ}$ degrees per second (five repetitions). The 
reliability of isometric and isokinetic strength testing is moderate $(r=0.8-0.9)$ to high $(r>0.9)$ in patients with mild knee OA. ${ }^{59}$

The Timed up and Go (TUG) performance test measures the time needed by a patient to get out of a chair, walk three metres, return and get back into the chair. The guideline for physical therapy in patients with hip and knee OA of the Royal Dutch Society for Physical

Therapy recommends the use of the TUG in combination with questionnaires (e.g. KOOS) to evaluate treatment goals for physical functioning. ${ }^{60,61}$ The inter-rater reliability between three physical therapists assessing patients with rheumatoid arthritis was high (ICC: 0.97). ${ }^{62}$ Intra-session reliability was also satisfactory: ICC of 0.75 with a time interval of more than 25 weeks and an ICC of 0.87 with a time interval of less than 1 week. ${ }^{63,64}$ In frail elderly patients and elderly patients undergoing orthopaedic rehabilitation, the TUG correlates well with gait speed $(r=-0.61,0.745)$ and performance of day-to-day activities $(r=-0.78)$ and correlates highly with the Berg Balance Scale $(r=-0.81){ }^{65,66}$

The 6-Min-Walking-Test (6MWT) is a simple test, recommended by the Dutch physical therapy guideline for OA, to assess functional capacity. ${ }^{61,67}$ Over a period of $6 \mathrm{~min}$, participants walk at a self-chosen speed with the aim of covering as much ground as possible. Participants have to walk in a square with a total length of 44 metres. This setup deviates from the standard as recommended by the American Thoracic Society which includes a 30-metre corridor or walkway with cones placed at the beginning and end of the 30-metre boundary to indicate turns. ${ }^{68}$ In patients with fibromyalgia and those recovering from total hip and knee surgery, the 6MWT is a reliable test with an ICC for test-retest reliability of 0.94 and $0.98 .^{63,69}$ In terms of validity, the oxygen uptake during the 6MWT shows a high correlation with peak oxygen uptake values $(r=0.86)$ obtained during maximum exercise testing in patients with heart failure. ${ }^{70}$

The Short QUestionnaire to ASsess Health-enhancing physical activity (SQUASH) is a survey to assess habitual physical activity and consists of eleven questions on physical activity in four different contexts: commuting, leisure time, during work and household activities. It is a short and simple questionnaire with proper reliability and validity. ${ }^{71}$ The SQUASH is used to evaluate adherence to the Dutch physical activity guideline, recommending $30 \mathrm{~min}$ or more of at least moderate intense physical activity for a minimum of 5 days per week. ${ }^{72}$ With regard to OA, only one study evaluated the SQUASH. Wagenmakers et al. found a good correlation with an accelerometer $(r=0.56)$ in patients with hip OA after surgery. ${ }^{73}$

The Rand 36-item Health Survey (Rand-36) is a generic tool to measure health-related quality of life (HRQoL). ${ }^{74}$ It consists of 36 items that cover eight HRQoL domains: physical functioning, role limitations because of physical health problems, bodily pain, general health perception, vitality, social functioning, role limitations because of emotional problems, and mental health. The total score ranges from $0-100$, with a higher score indicating better health status. The Rand-36 is almost identical to the 
Medical Outcome Study (MOS) Short-Form-36 (SF-36), and both have a proven sound responsiveness in patients with knee OA (SRM=0.528), and internal consistency (Cronbach' s $\alpha:>0.70$ ) and test-retest reliability (ICC: 0.40-0.82) in a Dutch general population. ${ }^{75-79}$

The Tampa Scale for Kinesiophobia (TSK) is used to assess fear of injury/re-injury due to movement. ${ }^{80}$ It is a 17-item scale that is scored on a four-point scale from 'strongly disagree' to 'strongly agree'. The present study uses the Dutch version, which shows good psychometric properties in patients with acute low back pain: good internal consistency (Cronbach's alpha $=0.70$ ) and satisfactory test-retest reliability (ICC: $0.76)^{81}$

The Arthritis Self-Efficacy Scale (ASES) is a valid and responsible measure providing information on patients' self-efficacy to perform a task (e.g. 'How certain are you that you can walk 100 feet on flat ground in 20 seconds?') or to achieve a specific behaviour (e.g. 'How certain are you that you can decrease your pain quite a bit?'). ${ }^{82,83}$ In total, the scale consists of 20 items that are divided into three subscales: self-efficacy pain scale, self-efficacy function scale and self-efficacy other symptoms scale (e.g. fatigues, enjoyment). The items are scored on a ten-point Likert scale resulting in a total score ranging from 0 to 100 . Higher scores indicate a better self-efficacy. The ASES has been translated and is available in Dutch. ${ }^{84}$ The present study measures the self-efficacy for function. This subscale has a good test-retest reliability (ICC: 0.85) and internal consistency (Cronbach's alpha $=0.89) .{ }^{85}$

\section{Process measures}

Daily diaries collect information on knee pain, physical functioning, level of physical activity, pain medication routine and physical therapy participation over two 30-day periods (during the intervention period). Participants can fill in the diaries on a computer or in a printed booklet version. Information on physical functioning and physical activity is gathered by questions derived from the LEFS and SQUASH questionnaires. ${ }^{52,72}$ Knee pain is measured by NPRS. ${ }^{55}$ The section on medication use asks if pain medication is used for knee pain or other pain, the name of the pain medication and the dosage and time-point(s) of taking the medication. Participation in, duration and intensity of exercise routines or physical therapy will be documented as well. Furthermore, four questions, derived from the RAND- 36 questionnaire, will ask about the restrictions in physical role functioning. Previous research only shed light on the level of hindrance and/or avoidance of activities, but not on the type of hindrance. ${ }^{86}$ The daily repeated measures would provide more insight into the course of pain, physical functioning, physical activity and medication use. The diary data from the intervention group will yield important information on the development of impairments, level of physical activity and medication use in response to the aquatic cycling programme. The diaries of the control group will provide a picture of the level 
of physical activity, participation in exercise therapy and the development of impairments over time. Previous research using booklet diaries and comparable diary periods showed good compliance and a low dropout rate, indicating that this method is acceptable for chronic pain patients. ${ }^{87}$

Participants' experience with aquatic cycling will be assessed after the final training session by means of planned focus-group sessions. Small-group interviews will be planned, and participants will be asked broad, open-ended questions about their expectations, fulfilment of expectations, positive and negative aspects of the training and suggestions for further development of the training. Thirty per cent of the participants ( 20 participants) in the intervention group will be invited to attend smallgroup interviews to provide feedback.

Attendance, adverse events and exercise progression of the intervention group were registered by the physical therapist. For every patient a training logbook exists where the physical therapist documented date and number of the training sessions attended. In total every patient could attend 24 sessions. Pedalling tempo and resistance, heart rate and BORG scores were noted for every exercise during the conditioning phase. Furthermore, the physical therapist documented the occurrence and type of problems with the performance of certain exercises in an indicated open text box in the training logbook. Thus, the physical therapist described the type of problem, whether the participants were able to continue the exercise and in case of performance restrictions the alternative exercise was described. Also, adverse effects during or following the sessions were documented in the training logbook. Non-serious adverse effects were defined as increased joint pain, stiffness, muscle soreness and/or fatigue occurring during or immediately after the last training session. ${ }^{88,89}$ If these adverse events were experienced longer than 24-h or interfered with physical activities and social participation they were classified as severe adverse events serious adverse event was defined as an occurrence that resulted in permanent or severe disability, hospitalization, or death. ${ }^{90}$

\section{Data collection and management}

The data from all measurements will be recorded on paper by the blinded outcome assessors. Patients are instructed not to inform the assessor about group allocation.

The outcome assessors are physical therapists of the MUMC+. The performance measures and strength assessments are part of their routine tasks and no special training prior to the study was needed. The purpose and scoring method of all questionnaires used was explained by the programme coordinator prior to the start of the study. Furthermore, the outcome assessors practised data collection several times in order to get an idea of the time needed. The data are recorded on paper, with numbers used to represent the rank order within the recruitment process in order to guarantee that the data is analysed separately from personal data. The data in these 
paper case reports are digitised by research assistants and the programme coordinator will enforce data integrity through range checks and cross-validation between the same variables assessed on repeated occasions. In addition, visual record verification will be done by comparing the first ten records of a data set with the corresponding paper case reports. ${ }^{91}$ If no inconsistency is found, the programme coordinator will check every tenth record until an incorrect record is found. After correction of the incorrect record, all following records will be checked until successive records free of inconsistencies are found. ${ }^{92}$

All data on paper will be stored in a locked archive for a maximum of 15 years. Only the programme coordinator has access to personal data. After the analysis, other researchers of the team (RAB, IM, AFL, and PJE) will also have access to anonymous data.

\section{Sample size}

The present study is the first to evaluate the effects of aquatic cycling in patients with mild to moderate knee OA. There are no previous data on which to base the sample size calculation. The estimation of the sample size is based on two factors: 1) the minimum clinically important difference (MCID) of WOMAC, and 2) studies with a similar design (aquatic therapy versus usual care) or intervention (one group pretest/post-test feasibility study of aquatic cycling for rheumatic patients). Although the present study uses the KOOS questionnaire, the WOMAC questionnaire has been used to estimate the sample size. The WOMAC is well recognized in OA research and the questionnaire and minimum clinically important differences (MCID) of the WOMAC subscales are known. The MCID changes from baseline to post-interventions on the WOMAC pain and function scale range from $15 \%$ to $18 \%$ for pain and $12 \%$ to $17 \%$ for physical function. ${ }^{75,93}$ The results of previous studies are in line with or exceed the MCIDs referred to. Hinman et al. showed a $21 \%$ and $29 \%$ improvement in WOMAC pain and function scores for the hydrotherapy group. ${ }^{36}$ The usual care group did not improve. A feasibility study of an aquatic cycling programme for rheumatic patients showed an improvement of $14 \%$ in the post-intervention score of self-reported physical functioning. ${ }^{23}$ Based on the above-mentioned data, the aquatic cycling training in the present study is expected to achieve at least similar results as the interventions of Moser and Hinman, or even exceed those results because of a higher exercise frequency and intensity and longer duration of the intervention. ${ }^{23,36}$ Thus, a difference of $25 \%$ between the aquatic cycling group and usual care group in terms of reduction of knee pain and improvement in physical functioning is hypothesised as clinically meaningful. The statistical level of significance was set to an alpha $(\alpha)$ of 0.05 and statistical power to 0.80 . The standard deviation is $20 \%$ of the maximum score of the WOMAC subscale for pain and physical function. ${ }^{94}$ With an expected dropout rate of $20 \%$, the final number of participants needed is 168 . 


\section{Data analysis}

Data analysis will be performed using IBM SPSS Statistics 23. The effect of group membership (aquatic cycling versus usual care) on primary and secondary outcomes will be estimated and tested for significance with a significance level set at 0.05. Furthermore, any significant changes that occur over time will be examined. Demographic variables and clinical background variables (i.e. BMI, co-morbidities) will be used as grouping variables for subgroup analysis or as covariates.

Multilevel analysis will be applied with repeated measures (level 1) that are clustered within persons (level 2), and with patients (level 1) clustered within groups (level 2). Using multilevel analysis allows the use of all data available, including dropout, loss to follow-up, missed appointments and participant incapacity. Diary data will be examined for the time course of level of physical activity, physical functioning, knee pain and pain medication use in the intervention and control group, and for between-group differences in change. In addition, the relationship between the aquatic cycling training and the factors just referred to will be evaluated. Multilevel analysis will be used to estimate and test between-person differences and the within-person processes.

\section{Data monitoring}

The content of the aquatic cycling intervention is comparable to existing physical activity programmes on land. Research has shown that these programmes involve no additional harm or risk to the patient. ${ }^{47,95}$ Aquatic cycling in rheumatic patients was evaluated in a study as safe and feasible. ${ }^{23}$ In addition, there is adequate evidence that aquatic training and stationary cycling are beneficial and safe activities for patients with knee OA. ${ }^{14,19,20}$

Because the risk of any adverse events from participation in the intervention group is small and comparable to the very low risk of adverse events from participation in landbased OA exercise programmes, ${ }^{47}$ no data monitoring committee (DMC) is needed. In case of a serious adverse event, the programme coordinator will inform all professionals involved in the study and report the event via a web portal to the accredited Medical Ethics Board within 24 hours.

\section{Ethics}

Ethical approval has been obtained from the Medical Ethics Board of MUMC+ (reference number 12-2-075) on 06-03-2013. The trial was registered on 21-12-2012 in the Netherlands Trial Register (NTR3766). Any modifications to the protocol that influence the execution of the trial or participant safety, i.e. changes of study design or procedures will be described in a formal amendment. All substantial amendments will require approval from the Medical Ethics Board of MUMC+. Participants in the study are covered by an insurance policy that includes cover against research subject injury 
or death as a result of the study. The research project is covered by liability insurance, which is in accordance with Section 7, subsection 6 of the Medical Research (Human Subjects) Act (WMO). A copy of the insurance certificate of MUMC+ is in the possession of the board of the Medical Ethics Committee.

\section{DISCUSSION}

This trial will demonstrate if the newly designed aquatic cycling intervention, in supplement to usual care, can help to improve impairments due to knee OA. As far as we know, the present study is the first randomised controlled trial evaluating the effects of aquatic cycling in the pre-surgical stage of OA. If this training proves to be effective, the results can provide guidance on the use of aquatic cycling in clinical and community exercise settings. Aquatic cycling could be used to increase the range of motion of the knee, lower limb muscle strength and aerobic capacity in all populations, whereas land-based training is too painful. It might also an option for patients who feel uncomfortable with traditional aquatic exercise because of poor swimming skills or hydrophobia. Previous studies have shown that aquatic cycling is well accepted by patients who have hydrophobia. ${ }^{22,24}$ As aquatic cycling has become a recent fitness trend in Europe and the US, many public swimming pools offer aquatic spinning to a healthy population. Exercise instructors in community exercise settings who are qualified to supervise classes with musculoskeletal disorders could use the training programme described (if proven effective) to adapt aqua-spinning classes to the needs of people with knee OA. The opportunity to participate in a modern and popular exercise class might especially be appealing to knee OA patients who want to be active and/or are young. ${ }^{20}$

The strength of this study is the close monitoring conducted during the intervention phase with diaries, since self-reported measures might be sensitive to day-to-day variations not capturing the development of $\mathrm{OA}$ impairments throughout the intervention. ${ }^{19}$ Another strong aspect of the study is the follow-up assessment three months after the end of the programme, something that is rarely done in aquatic exercise research. ${ }^{14}$ Especially interesting in the follow-up assessment is the evaluation of whether participants in the intervention group continued to aqua-cycle in the community swimming pool or stayed active in another way. This will indicate if people are willing to continue aquatic cycling at their own cost or if it has helped them to become more active. The control group will be invited to attend twelve free aquatic cycling sessions in the community pool. Due to limited access to the hospital pool and the limited number of aqua bikes $(n=4)$, it is not possible to train both groups in the hospital. Funding restraints make it impossible to bear the costs of 24 sessions twice a week for the control group in the community pool. As the programme coordinator will 
give the training, there will be no difference in terms of the training content and structure. However, this waiting-list control design can influence the results of the study in two ways. On the one hand, participants in the control group might be more motivated to follow usual care instructions with regard to physical activity because they do not want to be less active than the intervention group. In addition, this group will be monitored by means of diaries too, which might also motivate them to be more active. On the other hand, it is possible that the control group participants will follow usual care recommendations less strictly as they will be waiting for their turn to try out aquatic cycling. Furthermore, the fact the control group participants did not receive any immediate and free intervention might influence motivation for further participation. Therefore, we will inform participants about group allocation before the baseline assessment. The assessments of the present study are not part of the clinical routine and participants have to come back for the assessments after giving consent and being randomised. By informing participants about group allocation prior to the baseline, we wish to prevent frustration about group allocation and possible dropout.

Nevertheless, this strategy increases the risk of dropout before baseline assessment. In conclusion, this trial will increase the knowledge of aquatic cycling and might be a useful addition to aquatic exercise training. As with aquatic treadmill training, it is possible to adequately monitor and modify exercise intensity since pedalling rate and resistance can be adjusted. ${ }^{96}$ In addition, the exercise programme is based on exercise guidelines and the exercise intensity will be measured by pedalling frequency and resistance, average heart rate, peak heart rate and perceived exertion during the different parts of the conditioning phase. Recent reviews strongly recommend using and reporting exercise intensity, as will be done in this study, in order to obtain a better understanding of the dose-response relationship in aquatic exercise. ${ }^{14,15}$

\section{Dissemination policy}

The scientific integrity of this research project requires that all results of this study be disclosed unreservedly. The results will be submitted for publication to peer-reviewed scientific journals. Furthermore, the results will be presented at national and international congresses. Through to November 2016, four articles have to be submitted with the programme coordinator as first author. These articles will provide the basis for the programme coordinator's PhD thesis. All authors must contribute significantly to the conception of an article and/or the analysis or interpretation of data. Each author needs to revise the concepts of an article critically and has to give final approval of the manuscript that will be published. It is not the intention to collaborate with professional writers. The outcomes of the study will be released to the referring orthopaedic nurse practitioner and orthopaedic surgeons, the participating physical therapists, the local community swimming pool and the general medical 
community. In addition to the study results, every participant will receive an individual summary of her/his study results as soon as possible after participation.

\section{Acknowledgement}

We are grateful to the Netherlands Organisation for Scientific Research (NWO), P.O. box 93138, 2509 AC The Hague, for funding a 4-year PhD position for the programme coordinator. The funding covered the salary of the programme coordinator and all organisational costs of the trial. The NWO grant number is 022.003 .036 . The aquatic bikes used to train the intervention group were funded by the Transmural Care of MUMC+. These funding sources played no role in the design of this study or during any stage of the trial, i.e. execution, analyses and reporting.

We would gratefully acknowledge the department of physical therapy of the MUMC+ for providing the therapy pool and testing facilities. We thank Maastricht Sport and Geusseltbad for confidence in our study and for providing the training facilities. 


\section{REFERENCES}

1. Litwic A, Edwards MH, Dennison EM, Cooper C. Epidemiology and burden of osteoarthritis. British Medical Bulletin. 2013;105:185-99

2. Dreinhofer K, Stucki G, Ewert T, Huber E, Ebenbichler G, Gutenbrunner C, et al. ICF Core Sets for osteoarthritis. Journal of Rehabilitation Medicine. 2004;10.1080/16501960410015498:75-80.

3. Pisters MF, Veenhof C, van Dijk GM, Dekker J. Avoidance of activity and limitations in activities in patients with osteoarthritis of the hip or knee: a 5 year follow-up study on the mediating role of reduced muscle strength. Osteoarthritis and Cartilage. 2014;22:171-7.

4. Holla JF, van der Leeden M, Knol DL, Roorda LD, Hilberdink WK, Lems WF, et al. Predictors and outcome of pain-related avoidance of activities in persons with early symptomatic knee osteoarthritis: a five-year followup study. Arthritis Care \& Research. 2015;67:48-57.

5. Blair SN, Sallis RE, Hutber A, Archer E. Exercise therapy - the public health message. Scandinavian Journal of Medicine and Science in Sports. 2012;22:e24-8.

6. Zhang W, Moskowitz RW, Nuki G, Abramson S, Altman RD, Arden N, et al. OARSI recommendations for the management of hip and knee osteoarthritis, Part II: OARSI evidence-based, expert consensus guidelines. Osteoarthritis and Cartilage. 2008;16:137-62.

7. Hinman RS, Nicolson PJ, Dobson FL, Bennell KL. Use of nondrug, nonoperative interventions by community-dwelling people with hip and knee osteoarthritis. Arthritis Care \& Research. 2015;67:305-9.

8. Smink AJ, van den Ende CH, Vliet Vlieland TP, Swierstra BA, Kortland JH, Bijlsma JW, et al. Beating osteoARThritis: Development of a stepped care strategy to optimize utilization and timing of nonsurgical treatment modalities for patients with hip or knee osteoarthritis. Clinical Rheumatology. 2011;30:1623-9.

9. Thorstensson CA, Roos EM, Petersson IF, Arvidsson B. How do middle-aged patients conceive exercise as a form of treatment for knee osteoarthritis? Disability and Rehabilitation. 2006;28:51-9.

10. Westby MD. A health professional's guide to exercise prescription for people with arthritis: a review of aerobic fitness activities. Arthritis and Rheumatism. 2001;45:501-11.

11. Tilden HM, Reicherter EA, Reicherter F. Use of an aquatics program for older adults with osteoarthritis. From clinic to the community. Topics in Geriatric Rehabilitation. 2010;26:128-39.

12. Becker BE. Aquatic therapy: scientific foundations and clinical rehabilitation applications. $P M \& R$ : the journal of injury, function, and rehabilitation. 2009;1:859-72.

13. Wilcock IM, Cronin JB, Hing WA. Physiological response to water immersion: a method for sport recovery? Sports Medicine. 2006;36:747-65.

14. Waller B, Ogonowska-Slodownik A, Vitor M, Lambeck J, Daly D, Kujala UM, et al. Effect of therapeutic aquatic exercise on symptoms and function associated with lower limb osteoarthritis: systematic review with meta-analysis. Physical Therapy. 2014;94:1383-95.

15. Lu M, Su Y, Zhang Y, Zhang Z, Wang W, He Z, et al. Effectiveness of aquatic exercise for treatment of knee osteoarthritis : Systematic review and meta-analysis. Zeitschrift für Rheumatologie. 2015;10.1007/s00393-014-1559-9.

16. Barker AL, Talevski J, Morello RT, Brand CA, Rahmann AE, Urquhart DM. Effectiveness of aquatic exercise for musculoskeletal conditions: a meta-analysis. Archives of Physical Medicine and Rehabilitation. 2014;95:1776-86.

17. Fisken A, Waters DL, Hing WA, Steele M, Keogh JW. Perception and responses to different forms of aqua-based exercise among older adults with osteoarthritis. International Journal of Aquatic Research and Education. 2014;8:32-52.

18. Schoedinger P. Watsu In Aquatic Rehabilitation. In: Becker Bruce E, Cole Andrew J, editors. Comprehensive aquatic therapy137-51. 3rd ed: Washingtion State University Publishing; 2010:137-51.

19. Mangione K, McCully K, Gloviak A, Lefebvre I, Hofmann M, Craik R. The effects of high-intensity and low-intensity cycle ergometry in older adults with knee osteoarthritis. Journals of Gerontology Series A: Biological Sciences and Medical Sciences. 1999;54:M:184-90. 
20. Salacinski A, Krohn K, Lewis S, Holland M, Ireland K, Marchetti G. The effects of group cycling on gait and pain-related disability in individuals with mild-to-moderate knee osteoarthritis: a randomized controlled trial. Journal of Orthopaedic and Sports Physical Therapy. 2012;42:985-95.

21. Ulatkowski M. Unterwasserfahrrad versus herkömmliche Rehabilitation - Eine retrospektive Studie mit und ohne Unterwasserfahrrad an implantierten Kniegelenksprothesen [Doctoral Dissertation]. Heidelberg: Heidelberg University; 2009.

22. von Kathen M. Prospektiv-randomisierte Vergleichsstudie zur Rehabilitation vorderer Kreunzbandplastiken zwischen koventioneller Therapie und Unterwasserfahrrad [Doctoral Dissertation]. Bochum: Ruhr-Universität; 1999.

23. Moser S. Entwicklung und Überprüfung eines Aqua-Cycling-Programms für Rheumapatienten [Master Thesis]. Karlsruhe: Universität Karlsruhe; 2009.

24. Rewald S, Mesters I, Emans PJ, Arts JJ, Lenssen AF, de Bie RA. Aquatic circuit training including aquacycling in patients with knee osteoarthritis: A feasibility study. Journal of Rehabilitation Medicine. 2015;10.2340/16501977-1937.

25. Chan AW, Tetzlaff JM, Altman DG, Laupacis A, Gotzsche PC, Krleza-Jeric K, et al. SPIRIT 2013 statement: defining standard protocol items for clinical trials. Annals of Internal Medicine. 2013;158:200-7.

26. Schulz KF, Altman DG, Moher D. CONSORT 2010 statement: updated guidelines for reporting parallel group randomised trials. BMJ. 2010;340:c332.

27. Ackerman IN, Buchbinder R, Osborne RH. Factors limiting participation in arthritis self-management programmes: an exploration of barriers and patient preferences within a randomized controlled trial. Rheumatology. 2013;52:472-9.

28. Cardinal BJ, Esters J, Cardinal MK. Evaluation of the revised physical activity readiness questionnaire in older adults. Medicine and Science in Sports and Exercise. 1996;28:468-72.

29. Axford J, Butt A, Heron C, Hammond J, Morgan J, Alavi A, et al. Prevalence of anxiety and depression in osteoarthritis: use of the Hospital Anxiety and Depression Scale as a screening tool. Clinical Rheumatology. 2010;29:1277-83.

30. Campbell R, Evans M, Tucker M, Quilty B, Dieppe P, Donovan JL. Why don't patients do their exercises? Understanding non-compliance with physiotherapy in patients with osteoarthritis of the knee. Journal of Epidemiology and Community Health. 2001;55:132-8.

31. Marks R. Knee osteoarthritis and exercise adherence: a review. Current aging science. 2012;5:72-83.

32. Van der Leeden M, Staal JB, Beekman E, Hendriks H, Mesters I, de Rooij M, et al. Development of a framework to describe goals and content of exercise interventions in physical therapy: a mixed method approach including a systematic review. Physical Therapy Reviews. 2014;19:1-14.

33. Exercise prescription for older adults with osteoarthritis pain: consensus practice recommendations. A supplement to the AGS Clinical Practice Guidelines on the management of chronic pain in older adults. Journal of the American Geriatrics Society. 2001;49:808-23.

34. Ericson MO BA, Nisell R, Nemeth R, Ekholm J. Load moments about the hip and knee joints during ergometer cycling. Scandinavian Journal of Rehabilitation Medicine. 1986;18:165-72.

35. Silva LE, Valim V, Pessanha APC. Hydrotherapy versus conventional land-based exercise for the management of patients with osteoarthritis of the knee: a randomized clinical trial. Physical Therapy. 2008;88:12-21.

36. Hinman RS, Heywood SE, Day AR. Aquatic physical therapy for hip and knee osteoarthritis: results of a single-blind randomized controlled trial. Physical Therapy. 2007;87:32-43.

37. Foley A, Halbert J, Hewitt T, Crotty M. Does hydrotherapy improve strength and physical function in patients with osteoarthritis--a randomised controlled trial comparing a gym based and a hydrotherapy based strengthening programme. Annals of the Rheumatic Diseases. 2003;62:1162-7.

38. Valtonen A, Poyhonen T, Sipila S, Heinonen A. Effects of aquatic resistance training on mobility limitation and lower-limb impairments after knee replacement. Archives of Physical Medicine and Rehabilitation. 2010;91:833-9.

39. Dalichau S, Scheele K. Status of aquatic functional training in the therapy of chronic back pain. Physikalische Medizin Rehabilitationsmedizin Kurortmedizin. 2003;13:35-41.

40. Association AE. Aquatic fitness professional manual. 6th ed. Leeds: Human Kinetics; 2010. 
41. Johnston TE, Barr AE, Lee SC. Biomechanics of submaximal recumbent cycling in adolescents with and without cerebral palsy. Physical Therapy. 2007;87:572-85.

42. Li L, Caldwell GE. Muscle coordination in cycling: effect of surface incline and posture. Journal of Applied Physiology. 1998;85:927-34.

43. Caria MA, Tangianu F, Concu A, Crisafulli A, Mameli O. Quantification of Spinning bike performance during a standard 50-minute class. Journal of Sports Sciences. 2007;25:421-9.

44. Barbosa TM, Marinho DA, Reis VM, Silva AJ, Bragada J. Physiological assessment of head-out aquatic exercises in healthy subjects: a qualitative review. Journal of Sports Science \& Medicine. 2009;8:179-89.

45. Barker KL, Dawes H, Hansford P, Shamley D. Perceived and measured levels of exertion of patients with chronic back pain exercising in a hydrotherapy pool. Archives of Physical Medicine and Rehabilitation. 2003;84:1319-23.

46. Köke AJA, van den Ende CHM, Jansen MJ, Steultjens MPM, C V. Clinical practice guideline for a physical activity interventions for patients with osteoarthritis [KNGF-standaard Beweeginterventie artrose]. Amersfoort: Koninklijk Nederlands Genootschap voor Fysiotherapie (KNGF); 2008.

47. Bennell KL, Hinman RS. A review of the clinical evidence for exercise in osteoarthritis of the hip and knee. Journal of Science and Medicine in Sport. 2011;14:4-9.

48. Bellamy N, Buchanan WW, Goldsmith CH, Campbell J, Stitt LW. Validation study of WOMAC: a health status instrument for measuring clinically important patient relevant outcomes to antirheumatic drug therapy in patients with osteoarthritis of the hip or knee. The Journal of Rheumatology. 1988;15:183340.

49. de Groot I, Favejee M, Reijman M, Verhaar J, Terwee C. The Dutch version of the Knee Injury and Osteoarthritis Outcome Score: a validation study. Health and Quality of Life Outcomes. 2008;6:16.

50. Roos EM, Lohmander LS. The Knee injury and Osteoarthritis Outcome Score (KOOS): from joint injury to osteoarthritis. Health and Quality of Life Outcomes. 2003;1:64.

51. Binkley JM, Stratford PW, Lott SA, Riddle DL. The Lower Extremity Functional Scale (LEFS): scale development, measurement properties, and clinical application. North American Orthopaedic Rehabilitation Research Network. Physical Therapy. 1999;79:371-83.

52. Hoogeboom TJ, de Bie RA, den Broeder AA, van den Ende CH. The Dutch Lower Extremity Functional Scale was highly reliable, valid and responsive in individuals with hip/knee osteoarthritis: a validation study. BMC Musculoskeletal Disorders. 2012;13:117.

53. Bellamy N, Kirwan J, Boers M, Brooks P, Strand V, Tugwell P, et al. Recommendations for a core set of outcome measures for future phase III clinical trials in knee, hip, and hand osteoarthritis. Consensus development at OMERACT III. Journal of Rheumatology. 1997;24:799-802.

54. Perrot S, Rozenberg S, Moyse D, Legout V, Marty M. Comparison of daily, weekly or monthly pain assessments in hip and knee osteoarthritis. A 29-day prospective study. Joint, Bone, Spine: Revue du Rhumatisme. 2011;78:510-5.

55. Price D, Bush F, Long S, Harkins S. A comparison of pain measurement characteristics of mechanical visual analogue and simple numerical rating scales. Pain. 1994;56:217-26.

56. Gallasch $\mathrm{CH}$, Alexandre NM. The measurement of musculoskeletal pain intensity: a comparison of four methods. Revista Gaúcha de Enfermagem. 2007;28:260-5.

57. Pham T, Van Der Heijde D, Lassere M, Altman RD, Anderson JJ, Bellamy N, et al. Outcome variables for osteoarthritis clinical trials: The OMERACT-OARSI set of responder criteria. Journal of Rheumatology. 2003;30:1648-54.

58. Pincus T, Bergman M, Sokka T, Roth J, Swearingen C, Yazici Y. Visual analog scales in formats other than a 10 centimeter horizontal line to assess pain and other clinical data. Journal of Rheumatology. 2008;35:1550-8.

59. Carpenter MR, Carpenter RL, Peel J, Zukley LM, Angelopoulou KM, Fischer I, et al. The reliability of isokinetic and isometric leg strength measures among individuals with symptoms of mild osteoarthritis. Journal of Sports Medicine and Physical Fitness. 2006;46:585-9.

60. Stratford PW, Kennedy DM. Performance measures were necessary to obtain a complete picture of osteoarthritic patients. Journal of Clinical Epidemiology. 2006;59:160-7. 
61. Peter WF, Jansen MJ, Hurkmans EJ, Bloo H, Dekker J, Dilling RG, et al. Physiotherapy in hip and knee osteoarthritis: development of a practice guideline concerning initial assessment, treatment and evaluation. Acta reumatológica portuguesa Sociedade Portuguesa de Reumatologia. 2011;36:268-81.

62. Noren AM, Bogren U, Bolin J, Stenstrom C. Balance assessment in patients with peripheral arthritis: applicability and reliability of some clinical assessments. Physiotherapy Research International. 2001;6:193-204.

63. Kennedy DM, Stratford PW, Wessel J, Gollish JD, Penney D. Assessing stability and change of four performance measures: a longitudinal study evaluating outcome following total hip and knee arthroplasty. BMC Musculoskeletal Disorders. 2005;6:3.

64. Wright AA, Cook CE, Baxter GD, Dockerty JD, Abbott JH. A comparison of 3 methodological approaches to defining major clinically important improvement of 4 performance measures in patients with hip osteoarthritis. Journal of Orthopaedic and Sports Physical Therapy. 2011;41:319-27.

65. Podsiadlo D, Richardson S. The timed "Up \& Go": a test of basic functional mobility for frail elderly persons. Journal of the American Geriatrics Society. 1991;39:142-8.

66. Freter SH, Fruchter N. Relationship between timed 'up and go' and gait time in an elderly orthopaedic rehabilitation population. Clinical Rehabilitation. 2000;14:96-101.

67. Butland RJ, Pang J, Gross ER, Woodcock AA, Geddes DM. Two-, six-, and 12-minute walking tests in respiratory disease. British Medical Journal (Clinical Research Ed). 1982;284:1607-8.

68. ATS Statement: Guidelines for the Six-Minute Walk Test. American Journal of Respiratory and Critical Care Medicine. 2002;166:111-7.

69. Pankoff BA, Overend TJ, Lucy SD, White KP. Reliability of the six-minute walk test in people with fibromyalgia. Arthritis Care and Research. 2000;13:291-5.

70. Faggiano P, D'Aloia A, Gualeni A, Lavatelli A, Giordano A. Assessment of oxygen uptake during the 6minute walking test in patients with heart failure: preliminary experience with a portable device. American Heart Journal. 1997;134:203-6.

71. Wendel-Vos GC, Schuit AJ, Saris WH, Kromhout D. Reproducibility and relative validity of the short questionnaire to assess health-enhancing physical activity. Journal of Clinical Epidemiology. 2003;56:1163-9.

72. de Hollander EL, Zwart L, de Vries SI, Wendel-Vos W. The SQUASH was a more valid tool than the OBiN for categorizing adults according to the Dutch physical activity and the combined guideline. Journal of Clinical Epidemiology. 2012;65:73-81.

73. Wagenmakers R, van den Akker-Scheek I, Groothoff JW, Zijlstra W, Bulstra SK, Kootstra JW, et al. Reliability and validity of the short questionnaire to assess health-enhancing physical activity (SQUASH) in patients after total hip arthroplasty. BMC Musculoskeletal Disorders. 2008;9:141.

74. Ware JE, Jr., Sherbourne CD. The MOS 36-item short-form health survey (SF-36). I. Conceptual framework and item selection. Medical Care. 1992;30:473-83.

75. Angst F, Aeschlimann A, Steiner W, Stucki G. Responsiveness of the WOMAC osteoarthritis index as compared with the SF-36 in patients with osteoarthritis of the legs undergoing a comprehensive rehabilitation intervention. Annals of the Rheumatic Diseases. 2001;60:834-40.

76. Kosinski M, Keller SD, Ware JE, Jr., Hatoum HT, Kong SX. The SF-36 Health Survey as a generic outcome measure in clinical trials of patients with osteoarthritis and rheumatoid arthritis: relative validity of scales in relation to clinical measures of arthritis severity. Medical Care. 1999;37:MS23-39.

77. Veenhof C, Bijlsma JW, van den Ende CH, van Dijk GM, Pisters MF, Dekker J. Psychometric evaluation of osteoarthritis questionnaires: a systematic review of the literature. Arthritis and Rheumatism. 2006;55:480-92.

78. Aaronson NK, Muller M, Cohen PD, Essink-Bot ML, Fekkes M, Sanderman R, et al. Translation, validation, and norming of the Dutch language version of the SF-36 Health Survey in community and chronic disease populations. Journal of Clinical Epidemiology. 1998;51:1055-68.

79. Zee van der KI, Sanderman R. Het meten van de algemene gezondheidstoestand met de RAND-36, een handleiding. Groningen: Rijksuniversiteit Groningen, Noordelijk Centrum voor Gezondheidsvraagstukken; 1992.

80. Kori S, Miller R, Todd C. Kinesiophobia: a new view of chronic pain behavior. Pain Manag. 1990. 
81. Swinkels-Meewisse EJ, Swinkels RA, Verbeek AL, Vlaeyen JW, Oostendorp RA. Psychometric properties of the Tampa Scale for kinesiophobia and the fear-avoidance beliefs questionnaire in acute low back pain. Manual Therapy. 2003;8:29-36.

82. Mielenz TJ, Edwards MC, Callahan LF. Item Response Theory Analysis of Two Questionnaire Measures of Arthritis-Related Self-Efficacy Beliefs from Community-Based US Samples. Arthritis. 2010;2010: 416796.

83. Lorig K, Chastain RL, Ung E, Shoor S, Holman HR. Development and evaluation of a scale to measure perceived self-efficacy in people with arthritis. Arthritis and Rheumatism. 1989;32:37-44.

84. Taal E, Riemsma RP, Brus HL, Seydel ER, Rasker JJ, Wiegman O. Group education for patients with rheumatoid arthritis. Patient Education and Counseling. 1993;20:177-87.

85. Brady TJ. Measures of self-efficacy: Arthritis Self-Efficacy Scale (ASES), Arthritis Self-Efficacy Scale-8 Item (ASES-8), Children's Arthritis Self-Efficacy Scale (CASE), Chronic Disease Self-Efficacy Scale (CDSES), Parent's Arthritis Self-Efficacy Scale (PASE), and Rheumatoid Arthritis Self-Efficacy Scale (RASE). Arthritis Care \& Research. 2011;63 Suppl 11:S473-85.

86. Dekker J, van Dijk GM, Veenhof C. Risk factors for functional decline in osteoarthritis of the hip or knee. Current Opinion in Rheumatology. 2009;21:520-4.

87. Allen KD, Golightly YM, Olsen MK. Pilot study of pain and coping among patients with osteoarthritis: a daily diary analysis. Journal of Clinical Rheumatology : Practical Reports on Rheumatic \& Musculoskeletal Diseases. 2006;12:118-23.

88. Fransen M, McConnell S, Harmer AR, Van der Esch M, Simic M, Bennell KL. Exercise for osteoarthritis of the knee: a Cochrane systematic review. British Journal of Sports Medicine. 2015;49:1554-7.

89. Maiers M, Evans R, Hartvigsen J, Schulz C, Bronfort G. Adverse events among seniors receiving spinal manipulation and exercise in a randomized clinical trial. Manual Therapy. 2015;20:335-41.

90. ICH harmonized tripartite guideline: Guideline for Good Clinical Practice. Journal of Postgraduate Medicine. 2001;47:45-50.

91. King DW, Lashley R. A quantifiable alternative to double data entry. Controlled Clinical Trials. 2000;21:94-102.

92. Dodge HF. Sampling plans for continuous production. Industrial Quality Control. 1947;14:5-9.

93. Tubach F, Ravaud P, Baron G, Falissard B, Logeart I, Bellamy N, et al. Evaluation of clinically relevant changes in patient reported outcomes in knee and hip osteoarthritis: the minimal clinically important improvement. Annals of the Rheumatic Diseases. 2005;64:29-33.

94. Angst F, Aeschlimann A, Stucki G. Smallest detectable and minimal clinically important differences of rehabilitation intervention with their implications for required sample sizes using WOMAC and SF-36 quality of life measurement instruments in patients with osteoarthritis of the lower extremities. Arthritis and Rheumatism. 2001;45:384-91.

95. Ettinger WH, Jr., Burns R, Messier SP, Applegate W, Rejeski WJ, Morgan T, et al. A randomized trial comparing aerobic exercise and resistance exercise with a health education program in older adults with knee osteoarthritis. The Fitness Arthritis and Seniors Trial (FAST). JAMA : the journal of the American Medical Association. 1997;277:25-31.

96. Bressel E, Wing JE, Miller Al, Dolny DG. High-intensity interval training on an aquatic treadmill in adults with osteoarthritis: effect on pain, balance, function, and mobility. Journal of Strength and Conditioning Research. 2014;28:2088-96. 



\section{CHAPTER 4}

Aquatic cycling - what do we know?

A scoping review on head-out aquatic cycling

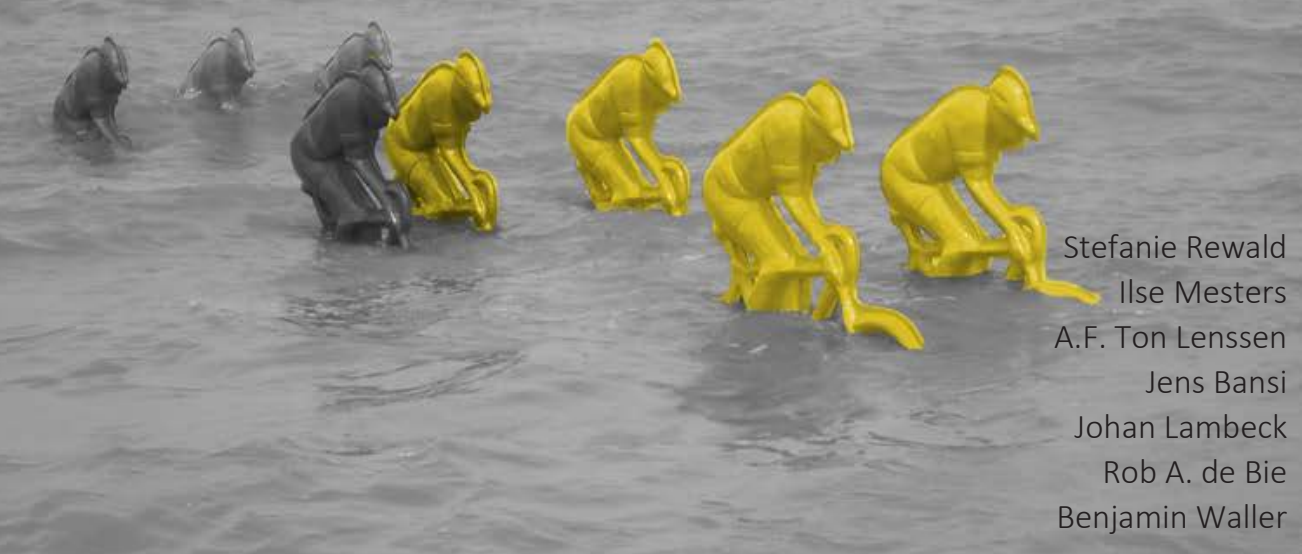

PLoS One. 2017;12(5):e0177704 


\section{ABSTRACT}

Over the past few years, aquatic cycling has become a trending fitness activity. However, the literature has not been reviewed exhaustively. Therefore, using scoping review methodology, the aim of this review was to explore the current state of the literature concerning aquatic cycling. This study specifically focused on study designs, populations and outcomes. A comprehensive search of seven databases (PubMed, MEDLINE, Cinahl, Embase, PEDro,Web of Science, WorldCat) was conducted up to $30^{\text {th }}$ September 2016. GoogleScholar, World Cat, ResearchGate, specific aquatic therapy websites and aquatic therapy journals were searched to identify additional literature. Full-text publications in English, German or Dutch were included. Studies were included when the intervention involved head-out cycling carried out in $10^{\circ}$ to $35^{\circ}$ Celsius water. Exclusion criteria were the use of wet suits or confounding interventions that would affect participants' homeostasis. 63 articles were included and the study parameters of these studies were summarised. Using three grouping themes, included studies were categorised as 1) single session tests comparing aquatic versus land cycling, or 2) aquatic cycling only sessions investigating different exercise conditions and 3) aquatic cycling intervention programmes. Although the experimental conditions differed noticeably across the studies, shared characteristics were identified. Cardiovascular parameters were investigated by many of the studies with the results suggesting that the cardiac demand of aquatic cycling seems similar to land-based cycling. Only six studies evaluated the effect of aquatic cycling interventions. Therefore, future research should investigate the effects of aquatic cycling interventions, preferably in individuals that are expected to gain health benefits from aquatic cycling. Moreover, this comprehensive outline of available literature could serve as a starting point for systematic reviews or clinical studies on the effects of aquatic cycling on the cardiovascular responses. 


\section{INTRODUCTION}

Water-based fitness equipment has gained popularity within aquatic fitness leading to a development of dryland training machines, such as stationary exercise bikes and treadmills, into water-proof exercise gear. Although aquatic cycling has become a trending fitness activity, the modification of standard ergometer bicycles for aquatic programs is nothing new and stems from the late sixties. Researchers used water immersion as an effective simulation of prolonged weightlessness, moreover, the utilization of the aquatic environment has been recognized as useful in rehabilitation. ${ }^{1,2}$ Similar to land-based cycling, the repetitive circular movement of pedalling against the water resistance ensures a use of a large range of motion (ROM) of the lower limbs to improve cardiovascular fitness and muscle strength. The fact that individuals are sitting on the aquatic bike can be beneficial for those who have problems with balance and independent gait. However, in contrast, while the sitting position and hydrostatic pressure assist with postural control, the loss of free movement i.e. reduced challenges to balance, and the few variation of the exercises may limit its effect on functional capacity. A shared characteristic with other types of aquatic exercise is the decrease of joint loading due to the buoyancy of the water. During aquatic cycling participants are immersed in water up to the chest and the buoyancy of the water unloads the joints of the lower extremities and the lower spine, a condition appealing for patients experiencing pain or problems with physical functioning during exercising on land.,4 Despite the potential benefits of aquatic cycling and its long history, the application of aquatic cycling in an exercise and clinical context still appears to be low. Limitations that might prevent clinicians using aquatic cycling for therapeutic purposes could include the investment costs, storage space requirements, and the elaborate set-up of the aquatic bikes. In particular, getting the bikes in and out of the pool, without an adjustable floor, is demanding.

The scientific evidence on the potential benefits of aquatic cycling seems to be scarce as well. Obvious search terms like aqua(tic) cycling, aqua(tic) bike or water cycling yield very few relevant results from scientific search engines. Moreover, the small number of references about aquatic cycling, used in previously published reviews on aquatic exercise, further emphasizes the impression of a scarcity of literature. ${ }^{5-7}$ These reviews summarize the effects on head-out aquatic exercise, including aquatic cycling, or compared physiological responses of different types of aquatic exercise and swimming with each other. ${ }^{5-7}$ Further, the aquatic cycling interventions were not described in detail in these prior reviews with these reviews only including cross-over studies.

Thus, the questions remain how has aquatic cycling been investigated in previous research, and whether a search effort solely on "aquatic cycling" would reveal additional publications and research investigating the effects of aquatic cycling intervention programmes. A systematic review with a meta-analysis would not suit this aim and therefore a scoping review study design was chosen. Systematic reviews are 
guided by specific research questions leading to strict in- and exclusion criteria. The primary aim for performing a scoping review is to map the available literature that meet a comprehensive research question combined without restricting inclusion criteria. ${ }^{8}$ Where systematic reviews evolve out of an initial understanding of the research field, scoping reviews are employed to identify research and explore their features such as target populations, interventions, study designs and outcomes. ${ }^{8,9}$ As a result scoping reviews help to develop an understanding of the extent and possible gaps and uncertainties in the existing literature. Furthermore, a scoping review might identify a sufficient amount of studies that would facilitate a systematic review. ${ }^{9}$

Therefore, the main objective of this study was to identify the scope of available research with regard to aquatic cycling as an exercise activity. Specifically, this scoping review aimed to explore the aquatic cycling exercises, study designs, comparison of training effects (if applicable), populations and outcomes utilised in research investigating aquatic cycling. To enable a comprehensive coverage of available literature the following research question was formulated: What is the available research on head-out aquatic cycling exercise?

\section{METHODS}

\section{Framework of a scoping review}

The procedure of performing a scoping review follows similar steps as those used in systematic review approaches without limiting for study design of included studies and without a quantitative synthesis. The framework of Arksey and O'Malley for scoping reviews was implemented in this study. ${ }^{9}$ The framework consists of five essential stages and one additional stage; 1 ) identifying the research question, 2) identifying relevant studies, 3) study selection, 4) charting the data, 5) collating, summarizing and reporting the results, and additionally 6) consultation of experts (optional). All stages can be performed in an iterative manner allowing refining of search parameters.

\section{Identifying relevant studies}

A comprehensive literature search was conducted in August 2015 and updated to $30^{\text {th }}$ September 2016 in seven electronic academic databases (PubMed, MEDLINE, Cinahl, Embase, PEDro, Web of Science, WorldCat). The search strategy was documented by title of the database searched, date of the search, the complete search string that was used and the number of articles found (Table 4.1). The development of each search string was an iterative process and familiarisation with the literature revealed additional search terms for aquatic cycling such as "immersed cycling" or "underwater pedalling". These terms were combined with more general terms for aquatic therapy 
(e.g. hydrotherapy) the search included the following key terms: ergometer, immersion, hydrotherapy, aqua(tic), cycling, underwater (bi)cycle ergometer, immersed ergocycle.

Table 4.1 Search strategy and results

\begin{tabular}{|c|c|c|c|}
\hline Database & Date & Search string & Results \\
\hline PubMed & $30-09-16$ & $\begin{array}{l}\text { ((ergometer[All Fields] AND (("immersion"[MeSH Terms] OR } \\
\text { "immersion"[All Fields] OR "underwater"[All Fields] OR "aquatic"[All } \\
\text { Fields]) OR ("hydrotherapy"[MeSH Terms] OR "hydrotherapy"[All } \\
\text { Fields]))) OR ((aqua[All Fields] AND cycling[All Fields]) OR "underwater } \\
\text { bicycle ergometer"[All Fields] OR "underwater cycle ergometer"[All } \\
\text { Fields] OR "immersed ergocycle"[All Fields] OR "aquatic bike"[All } \\
\text { Fields] OR "water bike"[All Fields])) AND "humans"[MeSH Terms] }\end{array}$ & 120 \\
\hline MEDLINE & $30-09-16$ & $\begin{array}{l}\text { 1. ((cycling and (hydrotherapy or aquatic exercise or aquatic therapy or } \\
\text { water exercise or immersion)) or (aqua cycling or underwater bike or } \\
\text { aquatic bike or immersed ergocycle or underwater bicycle ergometer } \\
\text { or underwater cycle ergometer or underwater pedalling or } \\
\text { underwater cycling or water bike)).af. }\end{array}$ & 157 \\
\hline Cinahl & $30-09-16$ & $\begin{array}{l}\text { (TX ergometer AND ( (aquatic therapy or hydrotherapy or aquatic } \\
\text { exercise or water exercise) OR immersion) ) OR underwater cycle } \\
\text { ergometer OR immersed ergocycle OR aqua cycling OR underwater } \\
\text { pedalling OR underwater bike OR aquatic bike OR water bike OR aqua } \\
\text { bike) }\end{array}$ & 30 \\
\hline Embase & $30-09-16$ & $\begin{array}{l}\text { 1. ((cycling and (hydrotherapy or aquatic exercise or aquatic therapy or } \\
\text { water exercise or immersion)) or (aqua cycling or underwater bike or } \\
\text { aquatic bike or immersed ergocycle or underwater bicycle ergometer } \\
\text { or underwater cycle ergometer or underwater pedalling or } \\
\text { underwater cycling or water bike)).af. }\end{array}$ & 194 \\
\hline PEDro & $30-09-16$ & $\begin{array}{l}\text { (ergometer AND immersion) } \\
\text { (ergometer AND water exercise) } \\
\text { (ergometer AND hydrotherapy) } \\
\text { (aquatic bike) OR (aqua bike) OR (water bike) OR (underwater bike) }\end{array}$ & 14 \\
\hline $\begin{array}{l}\text { Web of } \\
\text { Science }\end{array}$ & $30-09-16$ & $\begin{array}{l}\text { TS=(((ergometer AND (immersion OR hydrotherapy)) OR ((aqua AND } \\
\text { cycling) OR underwater bicycle ergometer OR underwater cycle } \\
\text { ergometer OR immersed ergocycle or aquatic bike or underwater } \\
\text { pedaling or aqua bike or water bike))) } \\
\text { Refined by: web of science categories: (sport sciences or clinical } \\
\text { neurology or rehabilitation or physiology or multidisciplinary sciences } \\
\text { or medicine research experimental or endocrinology metabolism or } \\
\text { neurosciences or surgery or respiratory system or public } \\
\text { environmental occupational health or medicine general internal or } \\
\text { rheumatology or oncology or orthopedics) }\end{array}$ & 145 \\
\hline WorldCat & $30-09-16$ & $\begin{array}{l}\text { ti:aqua cycling OR ((kw:immersion AND su:aqua-cycling) OR } \\
\text { (ergometer AND hydrotherapy) OR (aqua bike) OR (aquatic bike) OR } \\
\text { (water bike) OR (underwater bike)) }\end{array}$ & 5 \\
\hline \multicolumn{3}{|c|}{ Total number of records } & 674 \\
\hline
\end{tabular}

af, all fields; TX, text; TS, topic ; ti, title; kw, key word ; su, subject

Additionally, ResearchGate, GoogleScholar and relevant aquatic therapy websites (http://www.wcpt.org/apti, http://www.atri.org, https://www.aeawave.com) were 
examined. Moreover, the table of contents of the accessible key journals 'International Journal of Aquatic Research and Education' and 'Journal of Aquatic Physical Therapy' of the American Physical Therapy Association were checked for additional literature. Finally, reference lists of all included articles were hand-searched for new articles and the authors of this paper, all experts in the field of aquatic therapy and aquatic fitness, checked their own libraries for additional literature. The table of contents and reference lists were screened for the key words related to cycling and (immersion) exercise (testing) on land and in water. Throughout the search process it was noticed that no consistent terminology exists with regard to aquatic cycling. To ensure that the search terms used were correct and complete, the terminology used in included articles was re-evaluated. This post-hoc analysis (Appendix 4.1) addressing the terminology used to describe aquatic cycling confirmed our choice of search terms.

\section{Study selection}

The inclusion and exclusion criteria were developed in two stages. In phase one, the authors agreed to include all formats of full-text reports that focused on the effects of head-out aquatic cycling exercise on the human body (Table 4.2, stage one). After familiarisation with the literature the selection criteria were further specified (Table 4.2, stage two). In each step of the selection procedure two or more reviewers were involved and inclusion discrepancies were solved by discussion. Screening of titles and abstracts was performed by two reviewers (BW and SR) with the online programme "Covidence" (Covidence systematic review software, Veritas Health Innovation, Melbourne, Australia, available at: www.covidence.org). Next, all authors were involved with the full-text screening and all results were independently imported into a Microsoft Excel file and compared after completion of the review process. Information on the two-stage development of the inclusion criteria is available in a supporting file (Appendix 4.2).

\section{Charting the data}

Descriptive data were extracted into Microsoft Excel tables including name of the first author, year of publication, primary research question, sample size, age, gender, health status of participants, exercise parameters, main results reported in the abstract, water temperatures, aquatic bike used and level of body immersion. Information on effects of resting immersion was not discussed for this review, but might have been part of the experimental set-up of the included studies. The tables were organised by the body position on the aquatic bike (upright and semi-recumbent), because physiological responses might vary with immersion level related to the body position on the ergometer. ${ }^{2}$ All tables include information on interventions with healthy participants and patients. If patients were involved, information on the disease characteristics is 
reported in the tables. Articles that originated from the same data set, but focusing on different outcomes, were summarised and represented as one study in the tables, but references from all studies are included to aid identification of the separate articles.

Table 4.2 Two stage expert consensus on inclusion and exclusion criteria

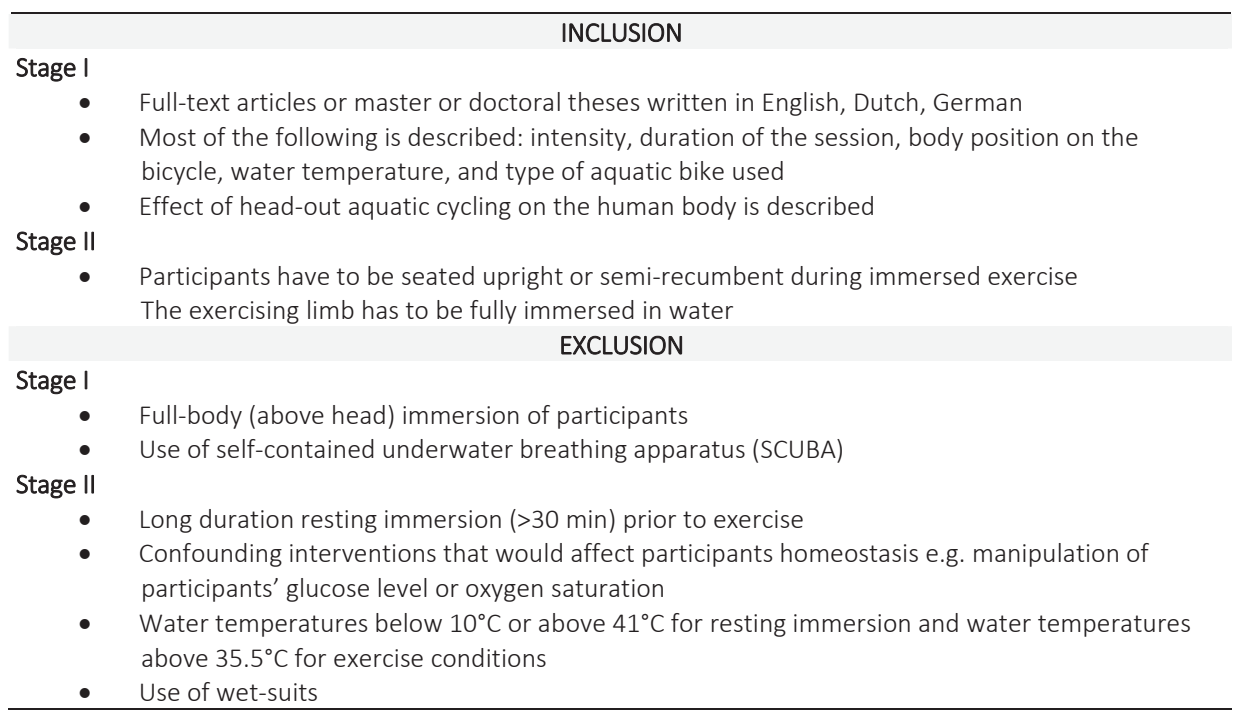

\section{RESULTS}

The search revealed 465 potential studies. After screening of the titles and abstracts, 350 studies were excluded and the full-text versions of 115 publications were read (Figure 4.1). Finally, 63 articles met the inclusion criteria. The reasons for exclusion during the full-text screening and the references of these excluded articles are presented in a supporting file (Appendix 4.3). Nevertheless, some of these publications might contain useful information and were therefore used as supportive literature. All included articles were published in peer-reviewed journals. Three of the included articles were published in German with an English abstract. ${ }^{10-12}$

The included articles were categorised in three groups according to the intervention characteristics. The first group consisted of comparisons using the aquatic bike as a tool for evaluating land versus aquatic cycling. The second group consisted of studies on the physiological responses to single sessions of aquatic cycling under different exercise conditions (e.g. different water temperatures). Research on the effects of multiple aquatic cycling sessions was clustered in a third group. According to these 
three grouping themes the extracted data was organised in three tables (Table 4.2, Table 4.3 and Table 4.4).

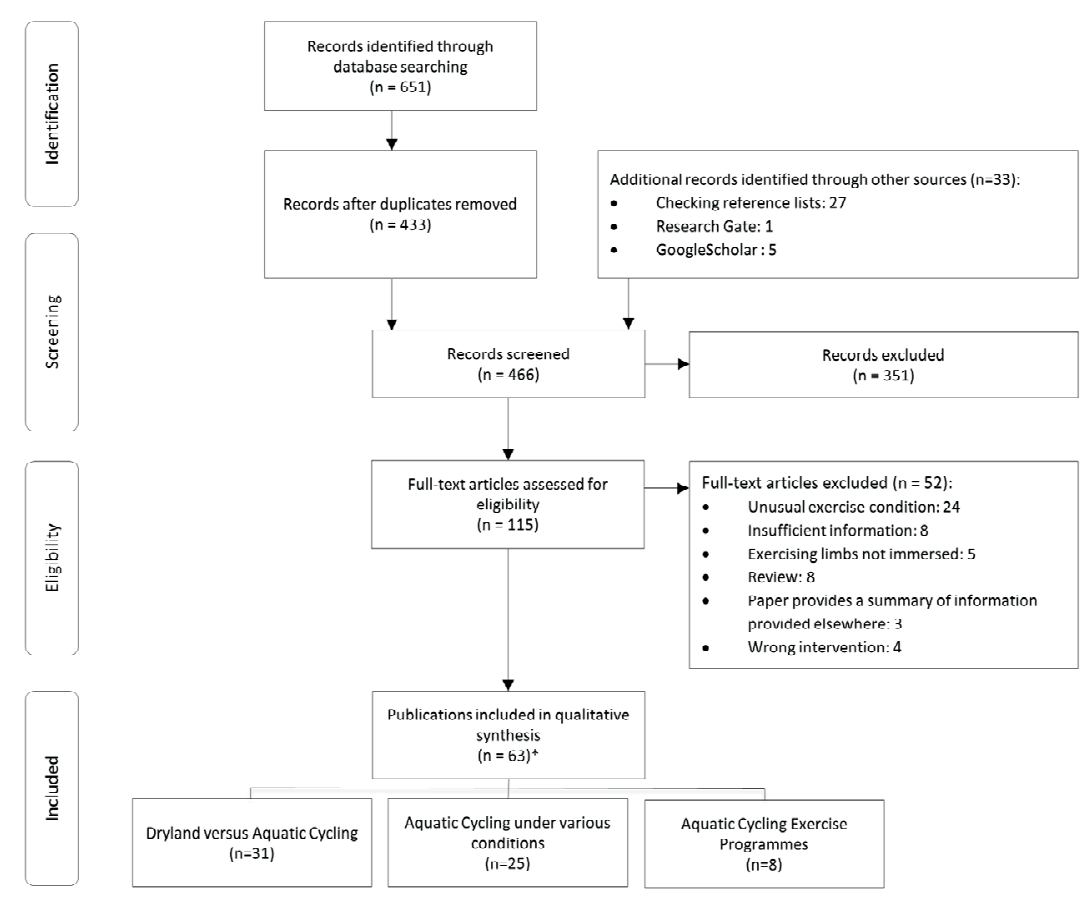

Figure 4.1 Flow diagram of identified publications

* One publication was allocated in two categories

\section{Land-based cycling compared to aquatic cycling}

Thirty-one studies compared aquatic cycling with land cycling (Table 4.3). Half of the studies ( $n=15$ ) used a maximal incremental exercise test to investigate the physiological responses during immersion versus on land exercise testing. ${ }^{11,13-26}$ Submaximal incremental exercise tests were conducted in six studies. ${ }^{27-32}$ Increments were mostly achieved by an increase in pedalling frequency. Seven studies of the aforementioned studies controlled exercise intensity by electronically regulated pedalling resistance. ${ }^{10,21,24-27,31}$ An additional six studies compared submaximal continuous aquatic cycling with land cycling. ${ }^{33-38}$ Three other studies evaluated aquatic cycling as a mean for active recovery after an extensive exercise bout on land. ${ }^{39-41}$ Furthermore, one study compared the effect of moderate intense dryland cycling with high-intensity interval training (HIIT) on land and in water. ${ }^{42}$ Two-third of the aquatic cycling sessions $(n=22)$ were conducted in an upright body position. Nine studies ${ }^{11,24-26,30,31,34-36}$ 
compared semi-recumbent cycling on land and in water. Four semi-recumbent bikes also had arm pedals. ${ }^{11,24,30,36}$ The level of body immersion of the participants varied from chest level to chin level. The water temperature during the exercise sessions ranged from $18^{\circ} \mathrm{C}$ to $35^{\circ} \mathrm{C}$.

All but three studies used a cross-over design to compare both environments. Additional study designs were a randomised controlled trial ${ }^{41,42}$ and a quasiexperimental study. ${ }^{27}$ In 19 out of 31 studies participants were young, healthy males. Five studies included healthy participants of both sexes ${ }^{13-16,26,36}$ and three studies included pregnant women. ${ }^{27,37,38}$ In four other studies participants were middle-aged men, ${ }^{29}$ males with cardiovascular diseases ${ }^{28,32}$ and men and women with hypertension. ${ }^{42}$

Studies $(n=21)$ investigating the difference in cardiovascular responses between aquatic versus land cycling compared oxygen consumption $\left(\mathrm{VO}_{2}\right)$, heart rate (HR), stroke volume, cardiac output and blood pressure. ${ }^{15-23,26-33,37,38,42}$ In total eight studies investigated the maximum $\mathrm{VO}_{2}$ response during land and aquatic cycling, with all but one study ${ }^{15}$ reporting equivalent $\mathrm{VO}_{\text {max }}$ values achieved by the participants on land and in water. ${ }^{17-23,26}$ Maximal HR was found to be lower during aquatic cycling at intensities higher than approximately $80 \%$ of the $V_{2 \max }$ in seven from ten studies. $^{20-23,26,29,30}$ The remaining three studies reported similar maximal HR for the land and water conditions. ${ }^{16-18}$ In men, following recovery from a myocardial infarction, no difference in submaximal HR on land and in water was found. ${ }^{28}$ McMurray et al. reported a trend toward a lower HR at submaximal intensities in water in men with coronary heart disease. ${ }^{32}$ In pregnant women moderate aquatic cycling resulted in lower maternal and foetal HR compared to land-based cycling. ${ }^{38}$ Four studies reported higher stroke volume and cardiac output in the aquatic cycling group consiting of healthy participants. ${ }^{15,21,29,30}$ Systolic blood pressure was similar in healthy males during an incremental exercise test when using aquatic versus land-based cycling. ${ }^{18,21}$ In pregnant women and in men with coronary artery disease the systolic blood pressure was reported to be lower during submaximal aquatic cycling. ${ }^{27,32,37,38}$ Sosner et al. reported a similar post-exercise reduction in blood pressure in patients with hypertension after a high-intensity cycling session on land and in water. ${ }^{42}$

Other key outcomes were ventilation parameters, ${ }^{23,31,33}$ lipid mobilisation and oxidation, ${ }^{18,34}$ sympathoadrenal response, ${ }^{18,20,34}$ lactate accumulation and removal $^{17,18,20,39,40}$ and thermoregulatory responses. ${ }^{35-37}$ Further outcomes were the development of prediction equations to estimate oxygen consumption from pedalling rate during aquatic cycling ${ }^{13,14}$ and to calculate external power output of aquatic cycling. ${ }^{13}$ Fenzl et al. compared the gas exchange measurements with the heart rate variability to estimate the ventilator threshold on an arm-leg aquatic bike. ${ }^{11}$ 


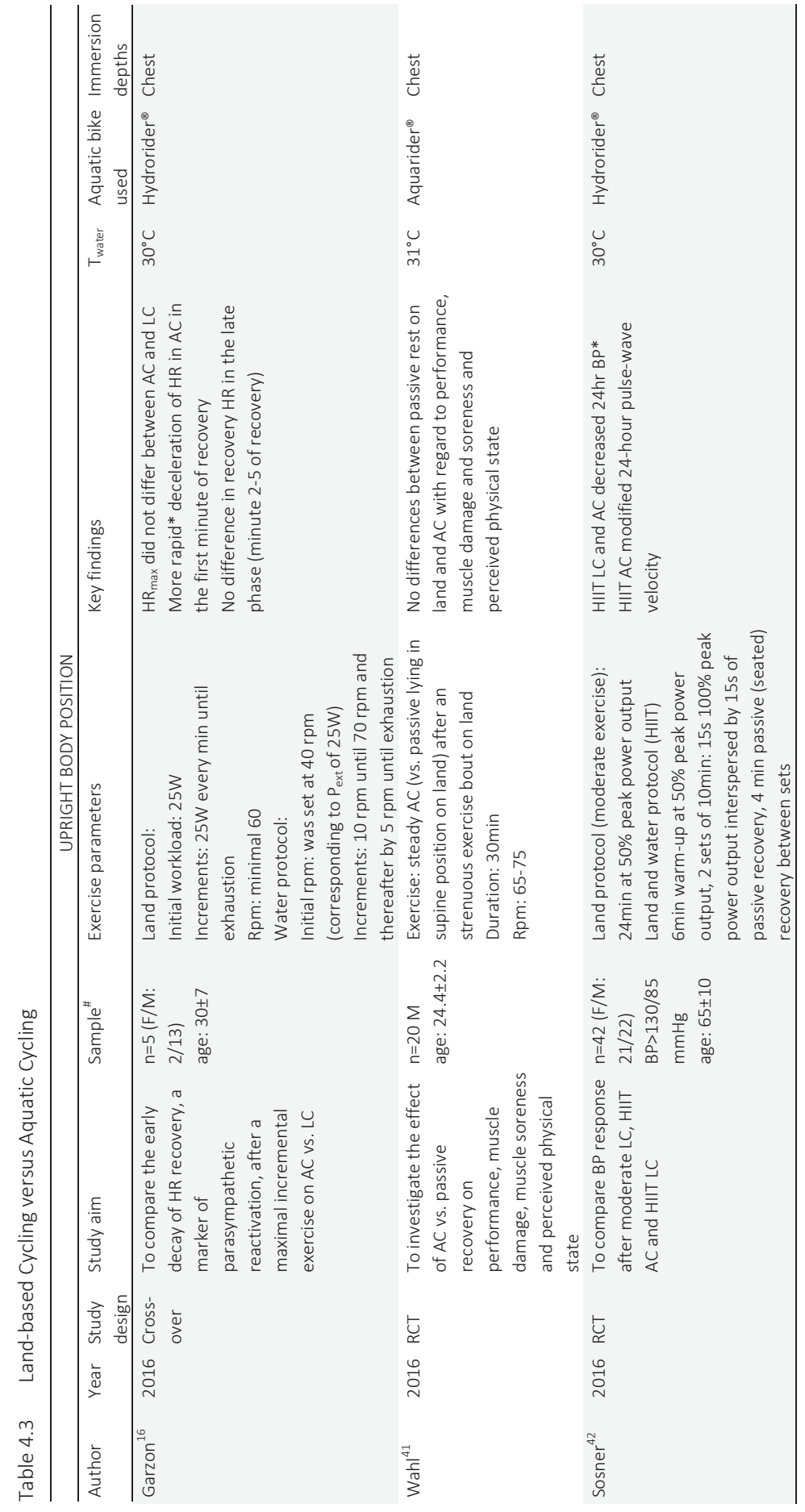




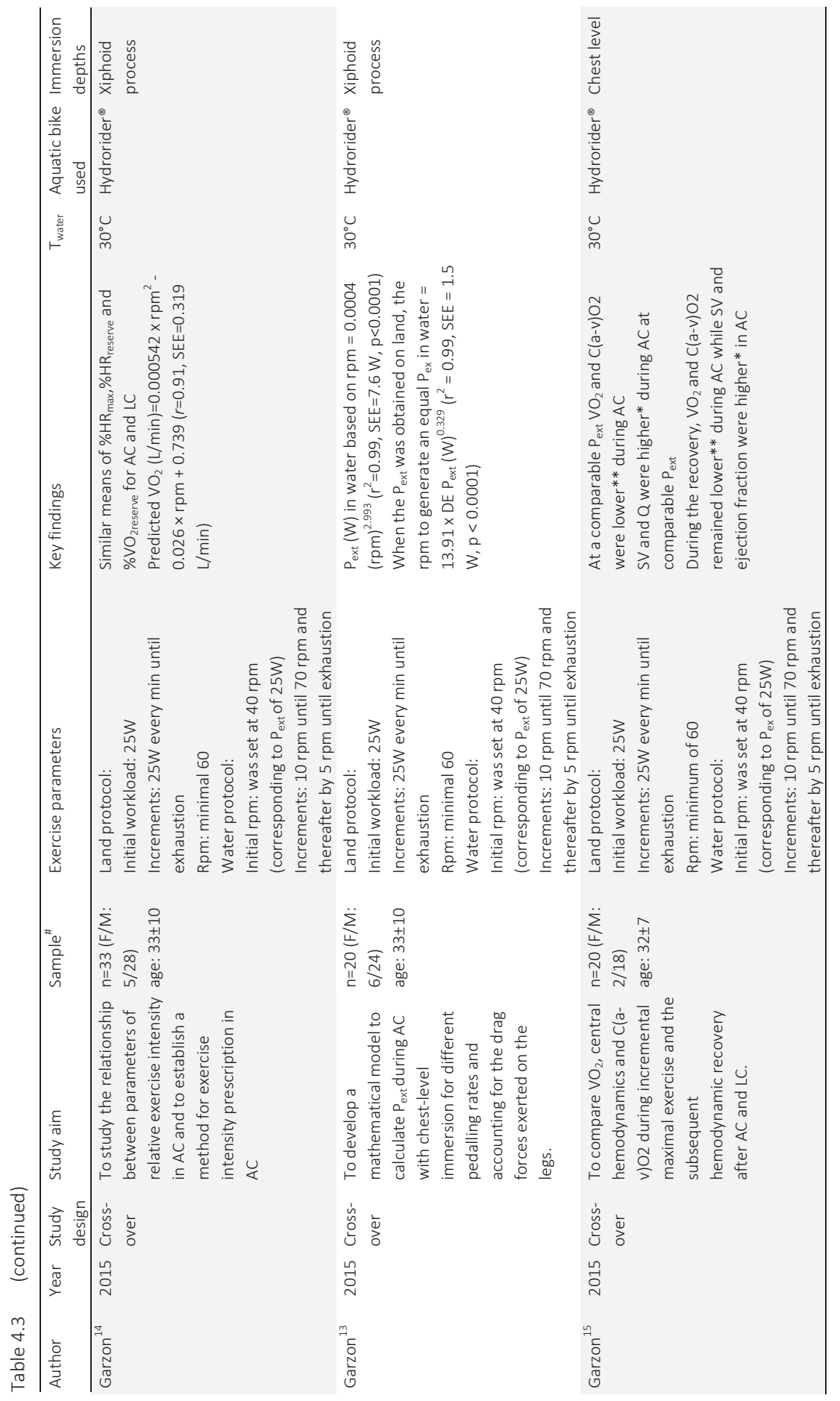




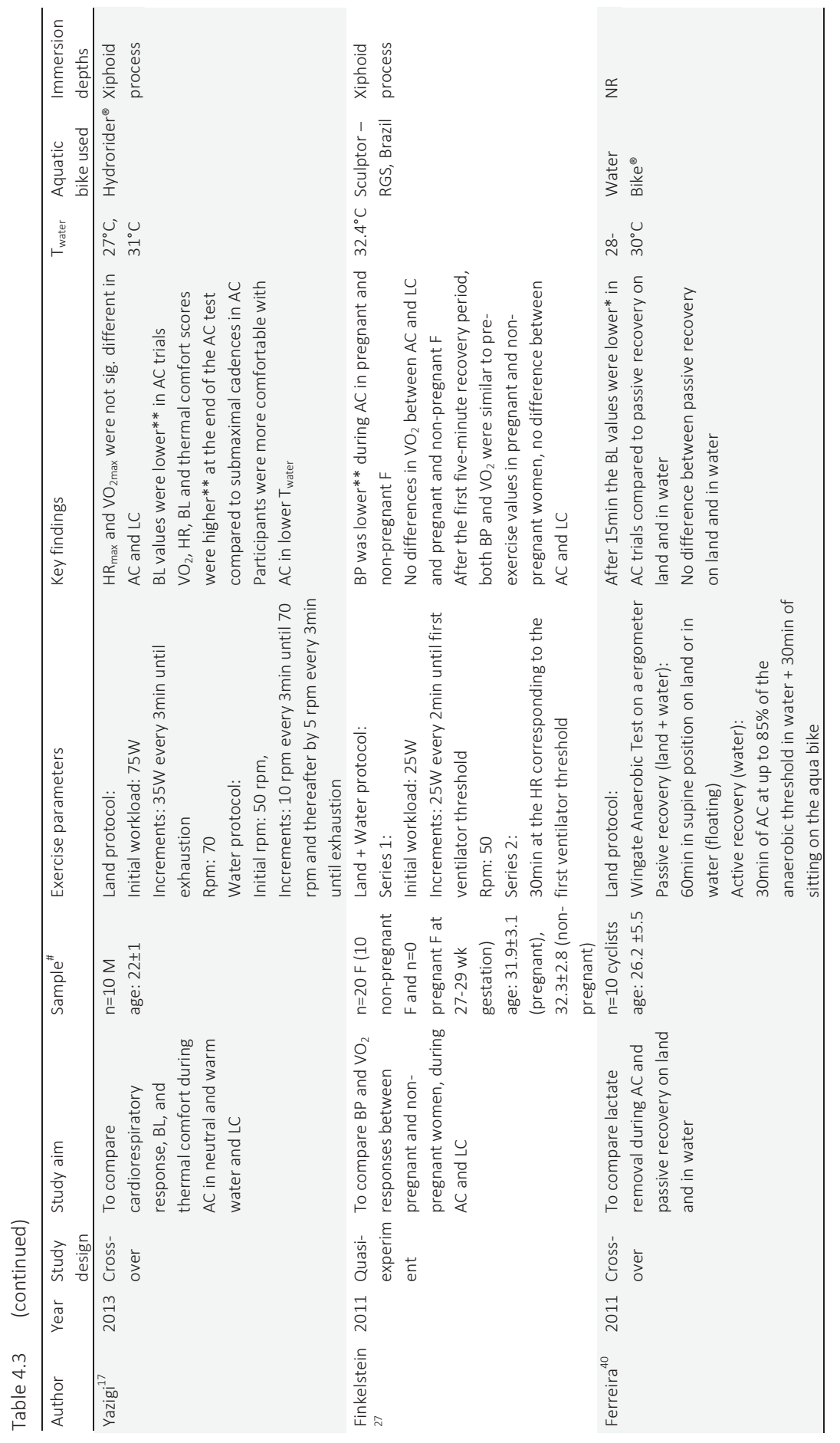




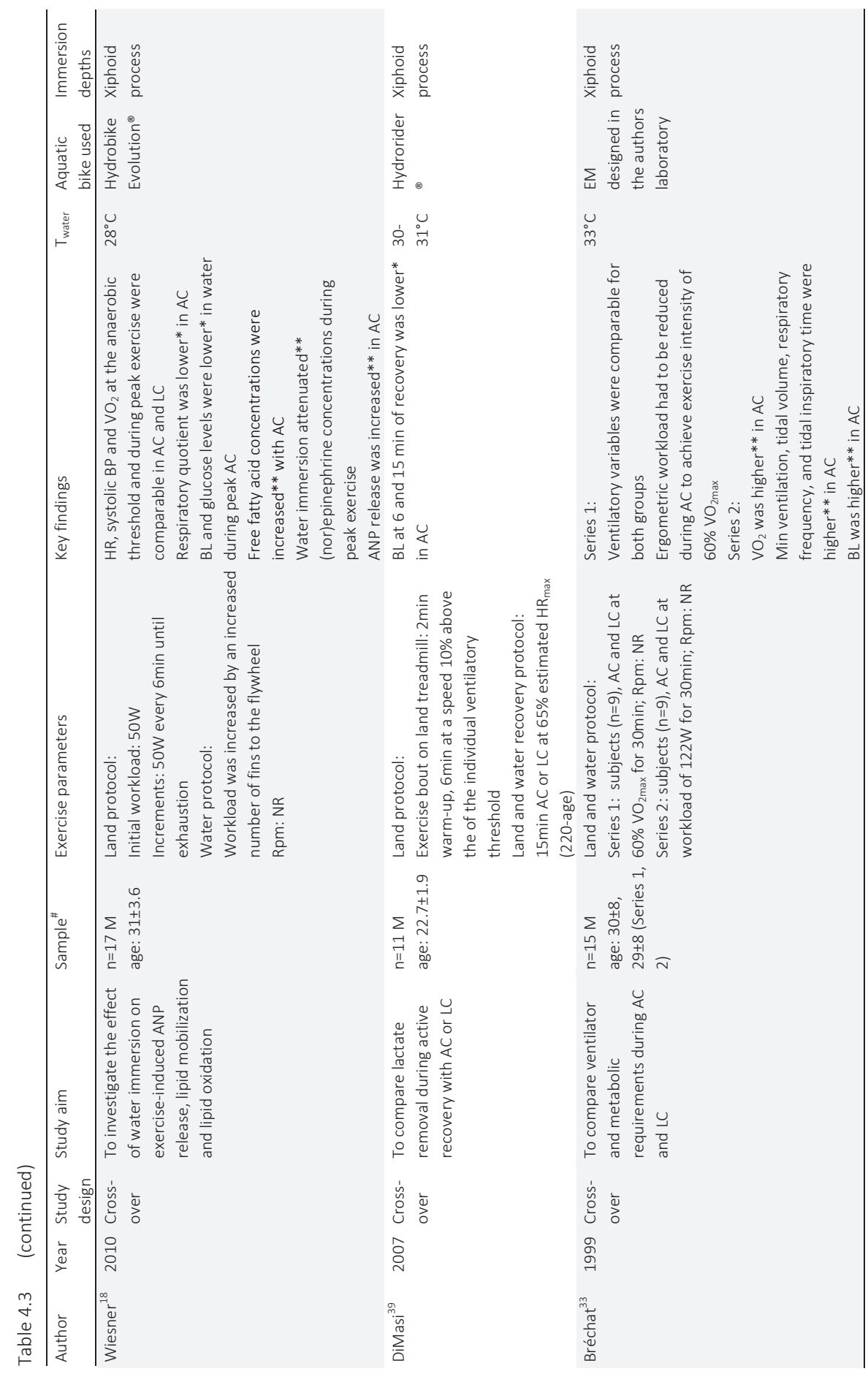




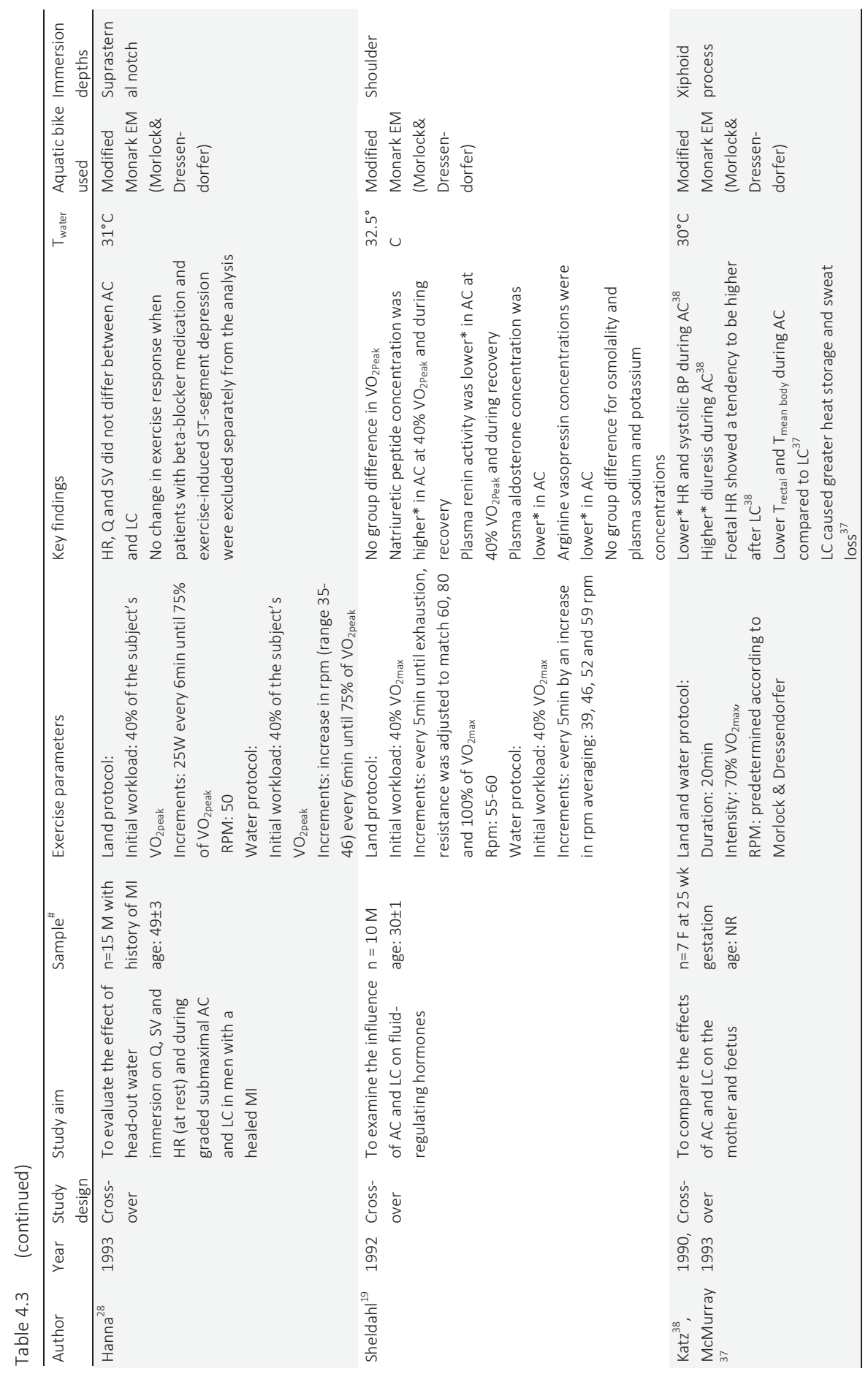




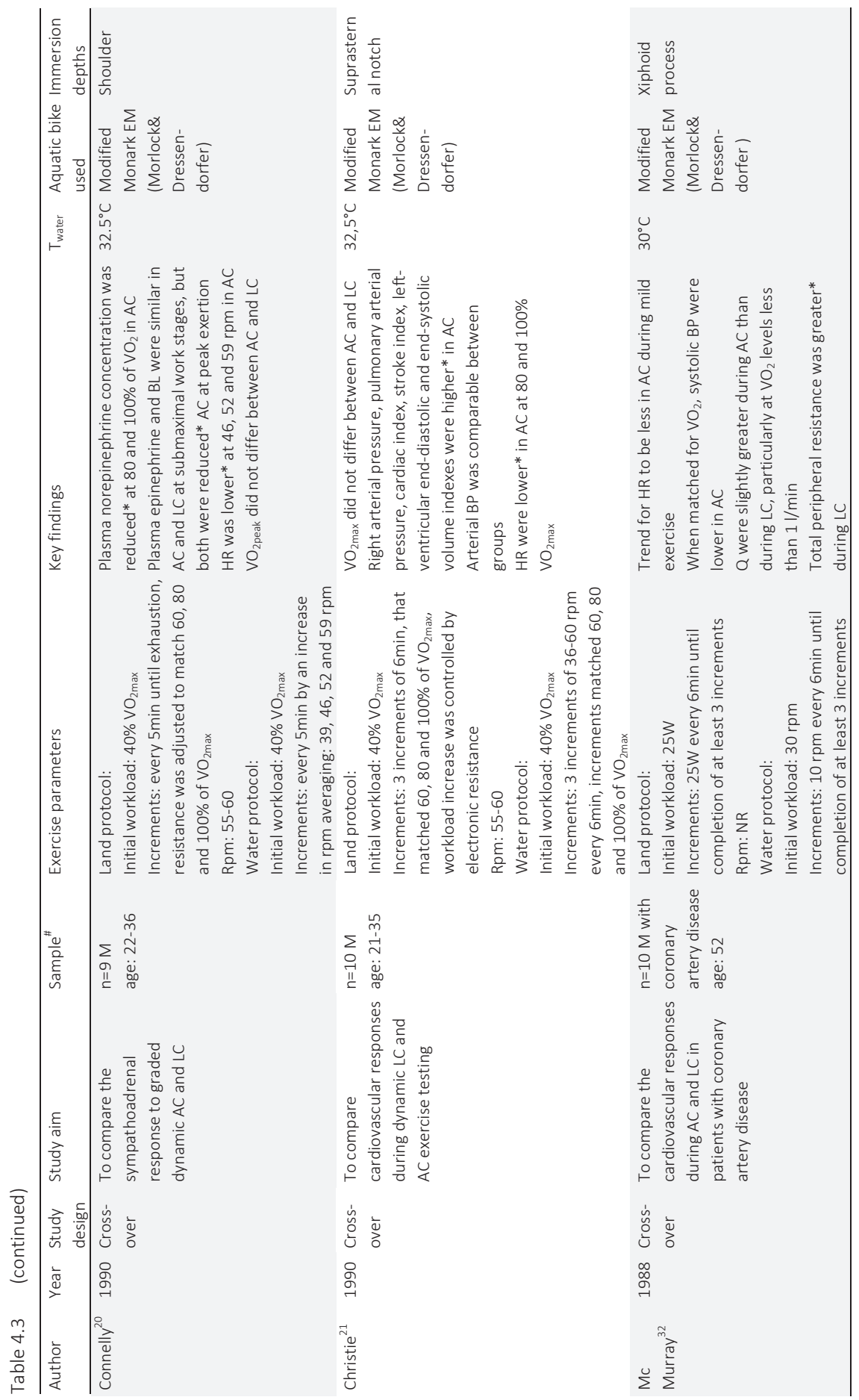




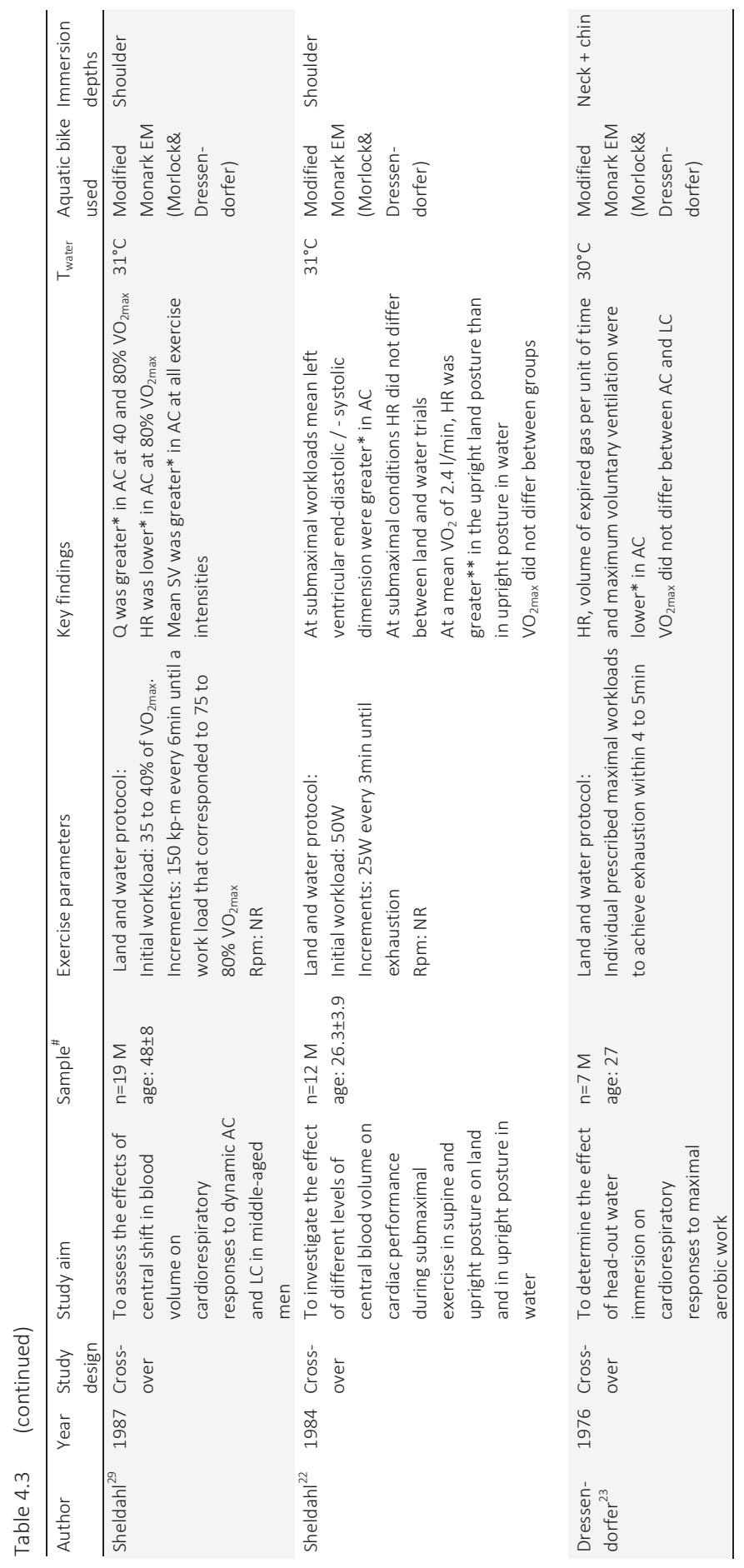




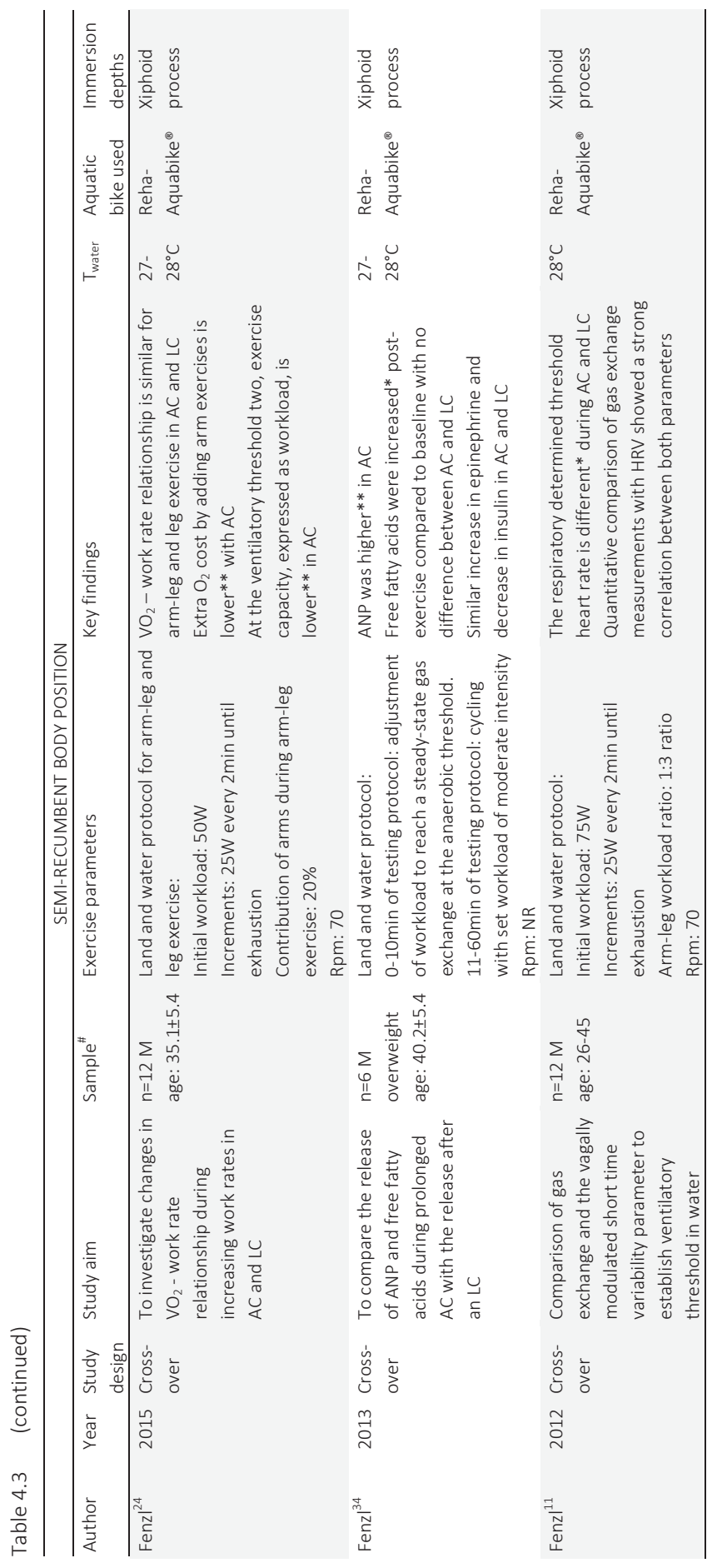




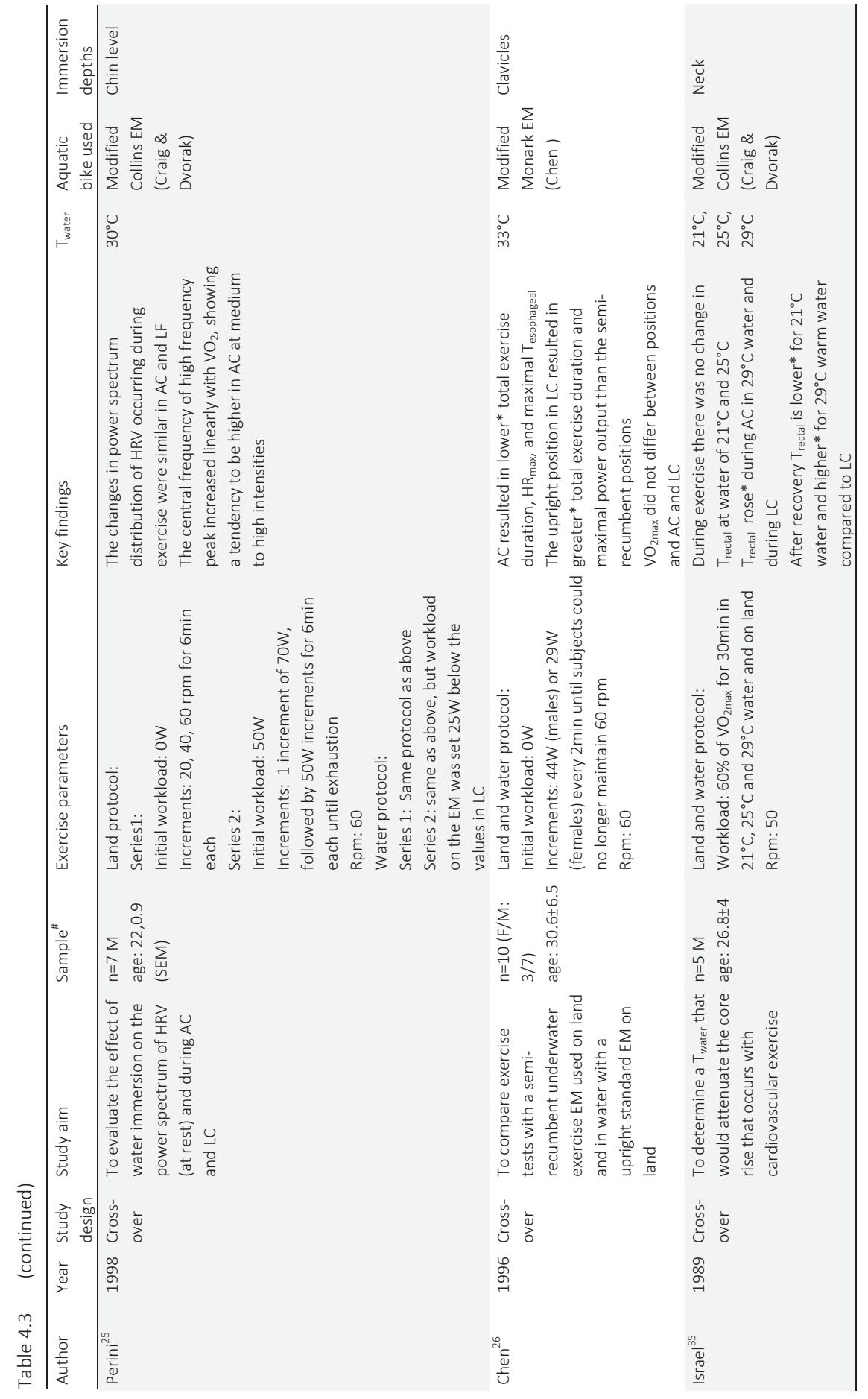




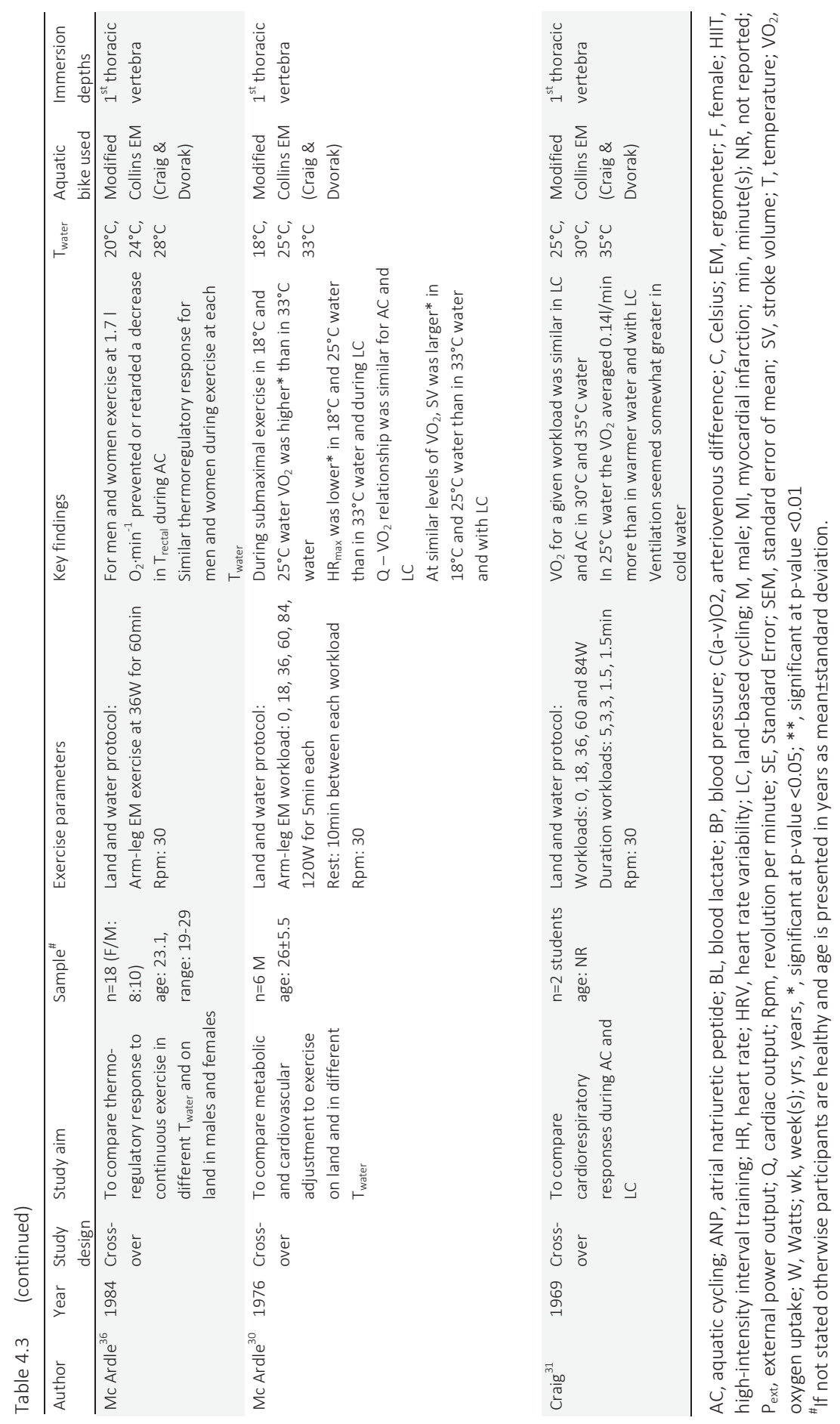




\section{Aquatic cycling under different exercise conditions}

Twenty-five studies investigated the effect of several different exercise conditions during aquatic cycling (Table 4.4). The comparisons are based on cross-over studies with healthy young males with the exception that healthy (non-pregnant) females were included in three studies ${ }^{43-45}$ and one study used a quasi-experimental design to compare age-matched healthy controls with heart disease patients. ${ }^{46}$ Common core outcomes were cardiovascular, ${ }^{12,23,44,45,47-50}$ metabolic $^{36,51-55}$ and thermal response ${ }^{43,49,50,52,56-61}$ to different exercise conditions. Furthermore, approaches to estimate and regulate exercise intensity during aquatic cycling were evaluated. ${ }^{62-64}$

Different exercise conditions were created mostly by changes in water

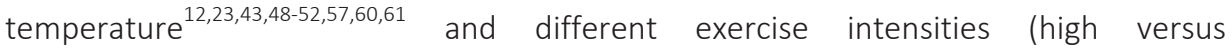
low $)^{23,43,44,50,58-61,63-65}$ With regard to the exercise parameters intensity and duration, studies ( $n=11$ ) utilised continuous, submaximal exercise ( 40 and $60 \%$ of $\mathrm{VO}_{2 \max }$ ) with a duration of 30 to 60 minutes. ${ }^{12,23,43,49,51,52,57,60,61}$ Exercise intensities were either based on graded exercise testing on land ${ }^{12,23,44,45,47,50,51,53-56,58}$ or in water. ${ }^{23,43,46,48,52,57,62-64}$ The water temperatures that were compared ranged from cold $\left(18-20^{\circ} \mathrm{C}\right)$ and $\operatorname{cool}\left(25^{\circ} \mathrm{C}\right)$ to thermoneutral $\left(30-35^{\circ} \mathrm{C}\right)$. Other studies compared different levels of body immersion [46], different types of exercise (interval versus continuous cycling, arm versus arm-leg versus leg exercise $)^{45,49,61}$ and different aquatic bikes with each other. ${ }^{44}$ Furthermore, the maternal and foetal response to submaximal $\left(60 \%\right.$ of $\left.\mathrm{VO}_{2 \max }\right)$ aquatic cycling during different stages of pregnancy was studied. ${ }^{47,53-56}$

Fifteen studies used upright aquatic bikes. ${ }^{23,44-47,51-57,62-64}$ In all these studies pedalling frequency regulated exercise intensity while two studies focused on the influence of pedalling resistance provided by additional fins to the flywheel. ${ }^{44,64}$ Sogabe et al. used the additional fins to increase pedalling resistance in semi-recumbent cycling. ${ }^{65}$ In all other semi-recumbent bikes intensity was set with electronically controlled pedalling resistance mechanisms. ${ }^{43,48-50,58-61}$ 


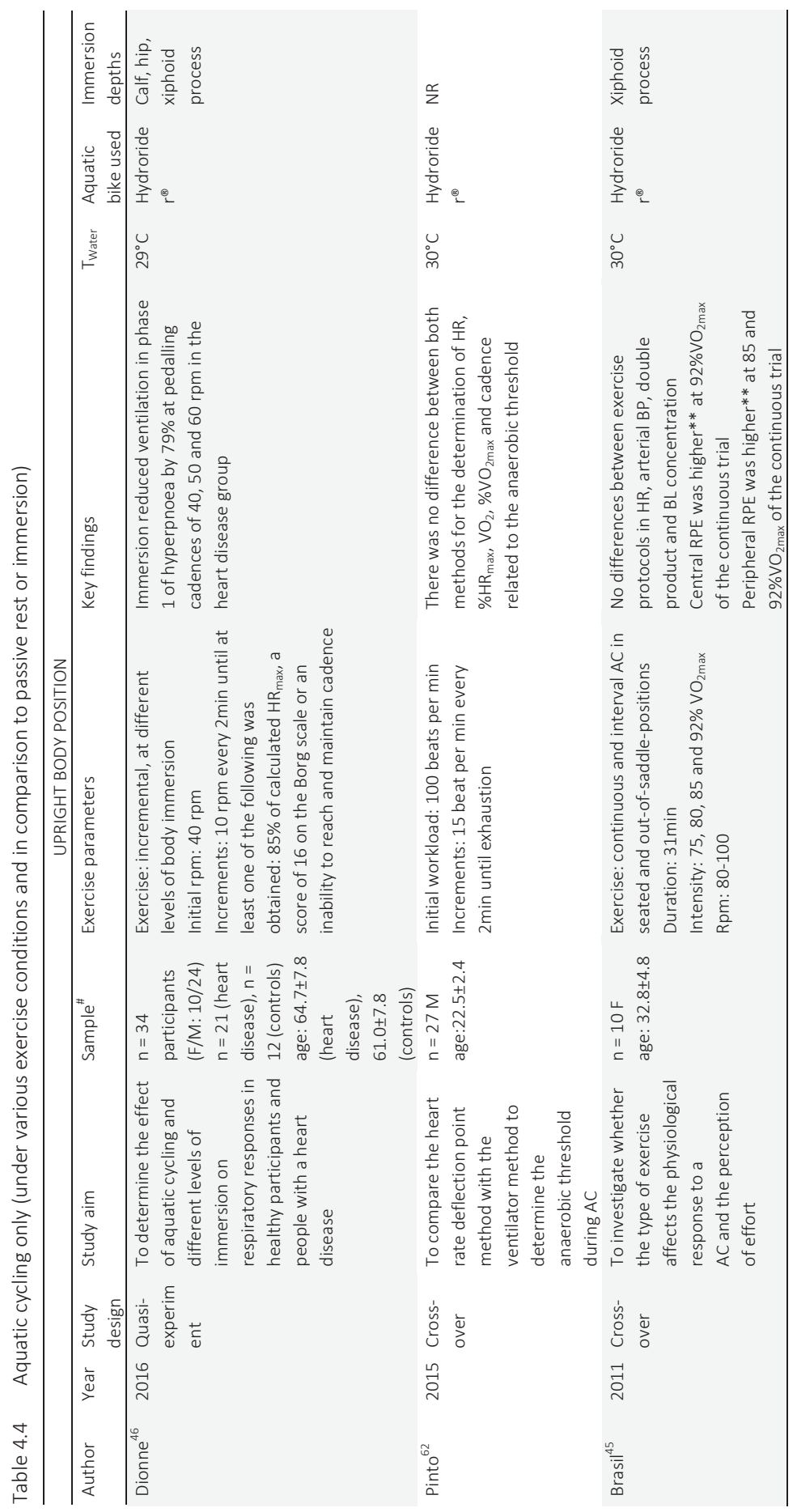




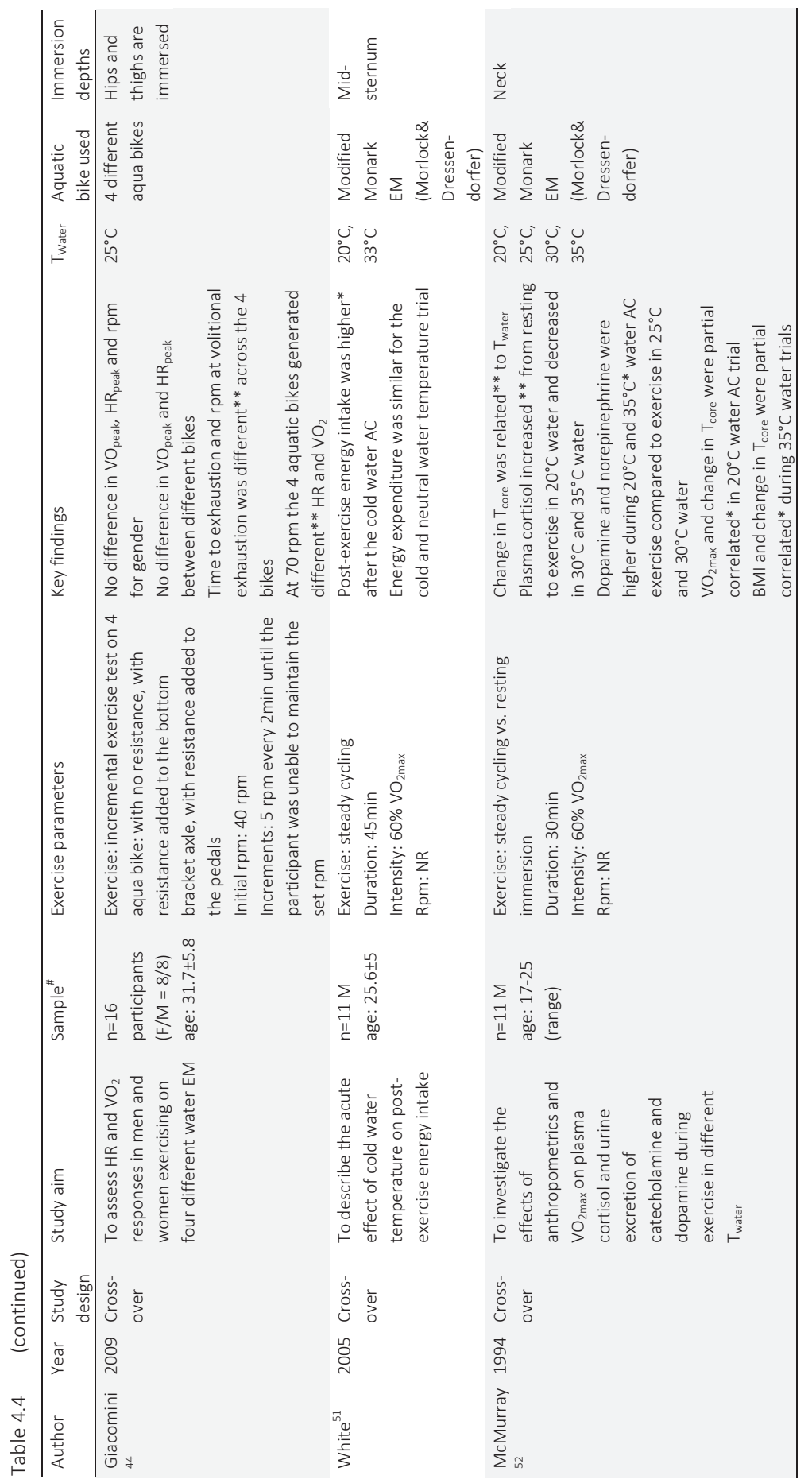




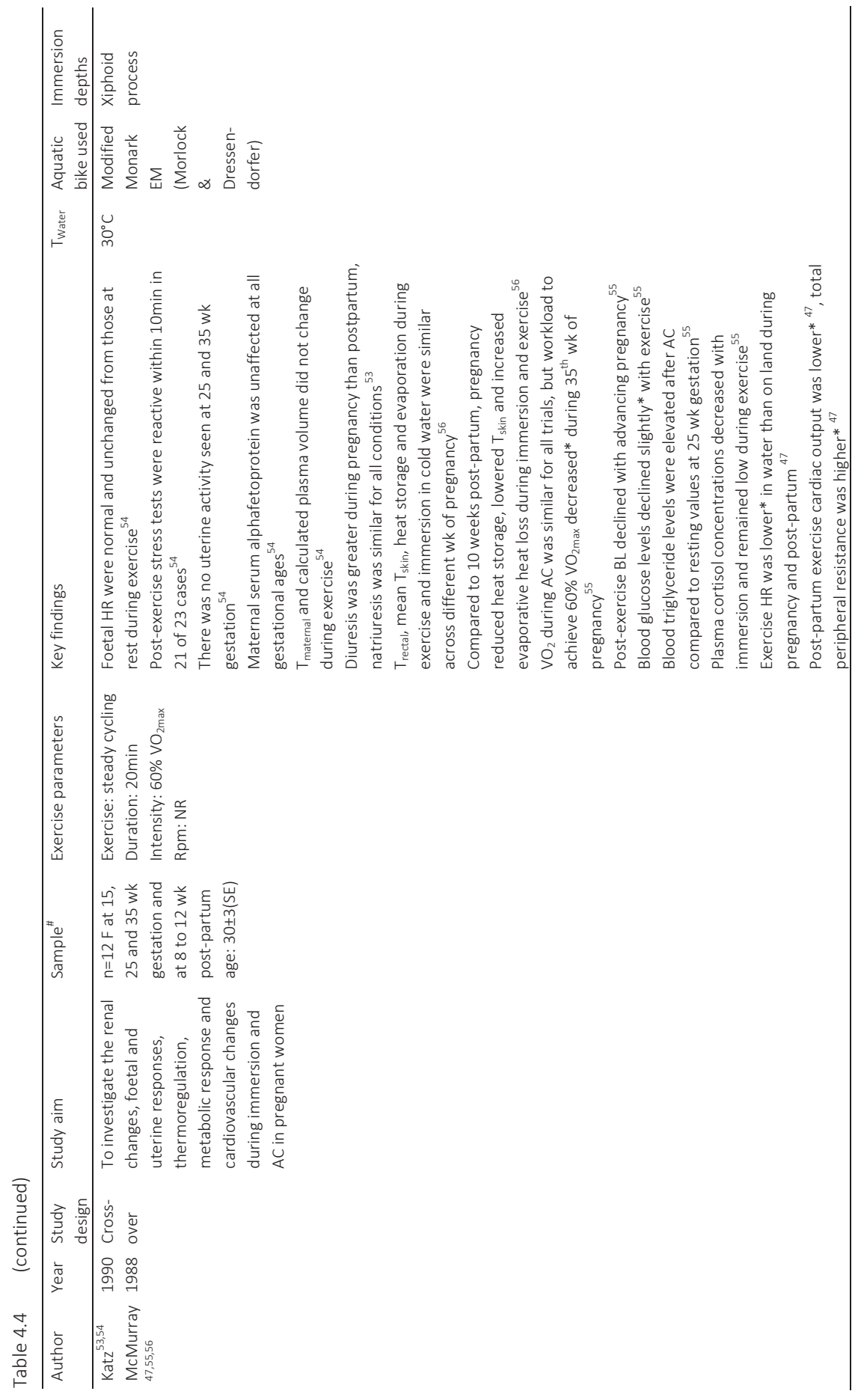




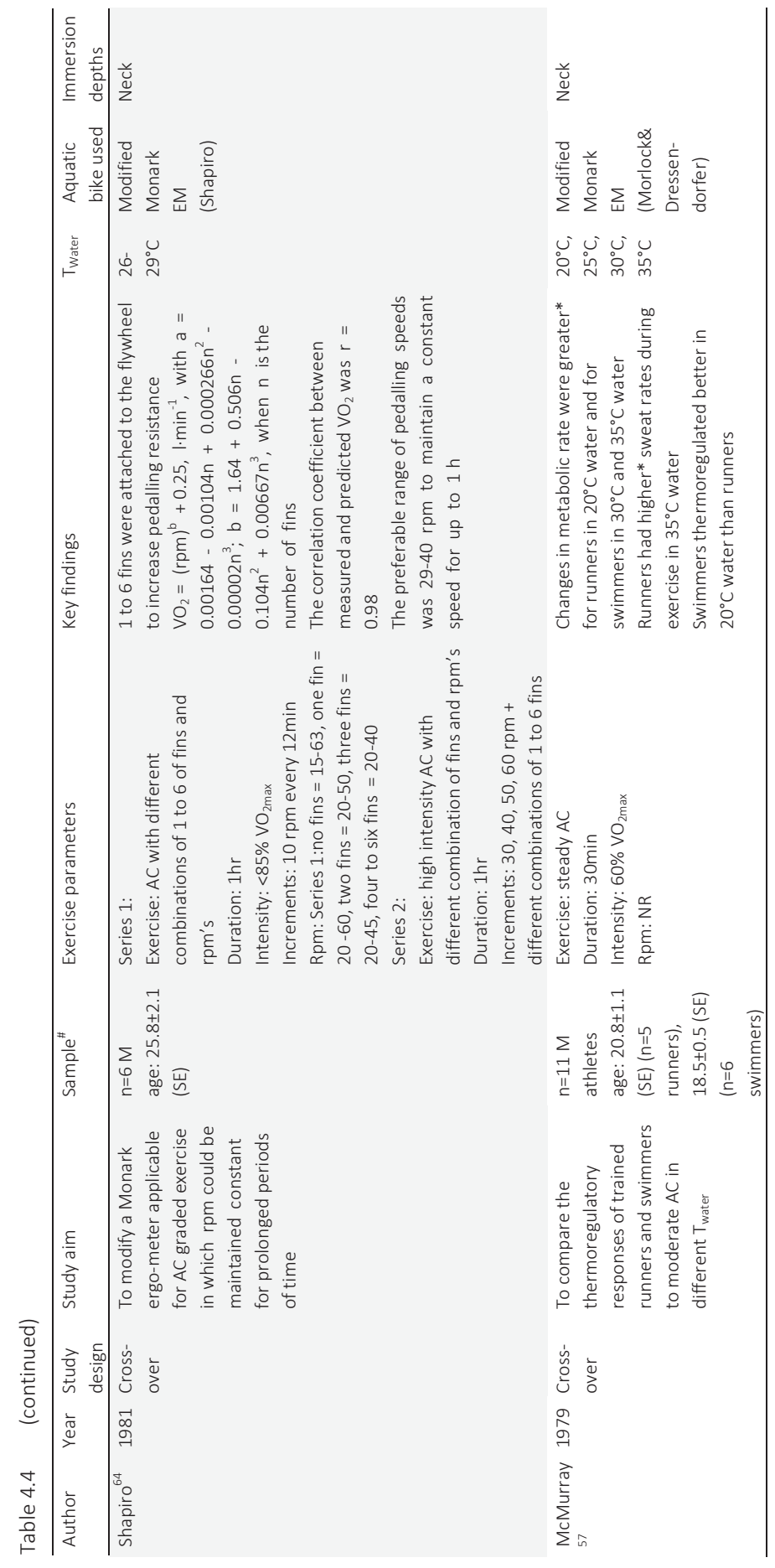




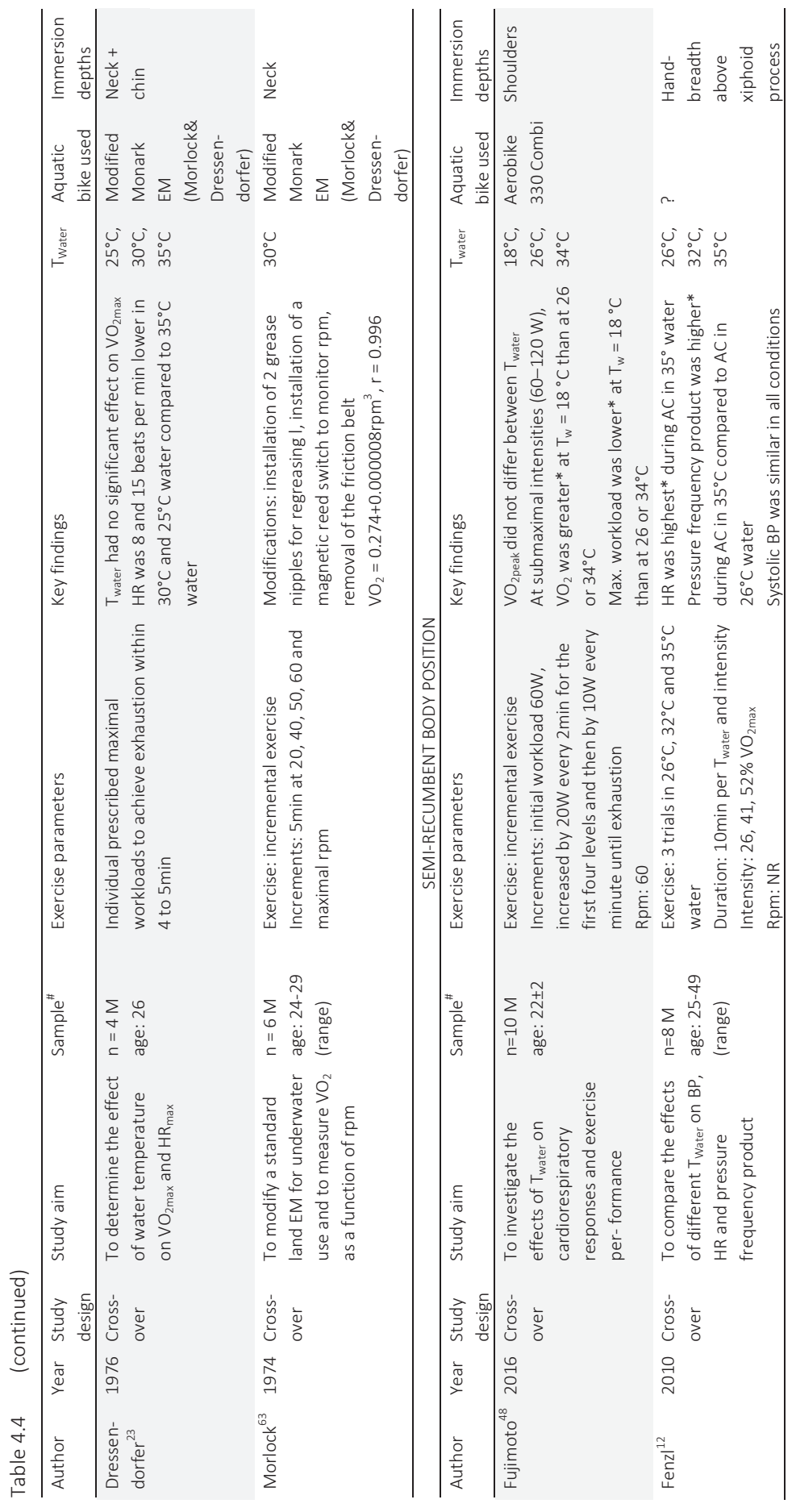




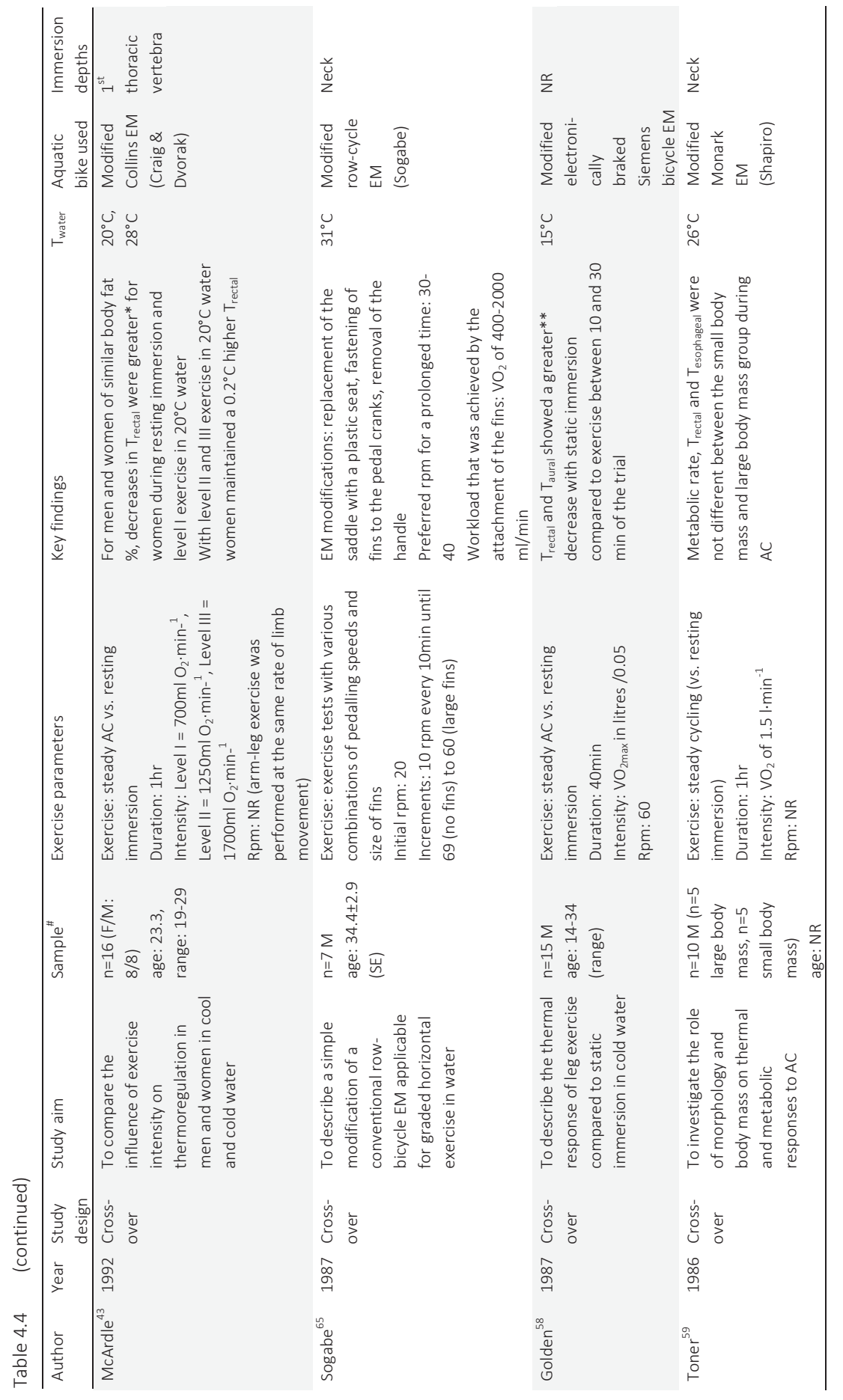




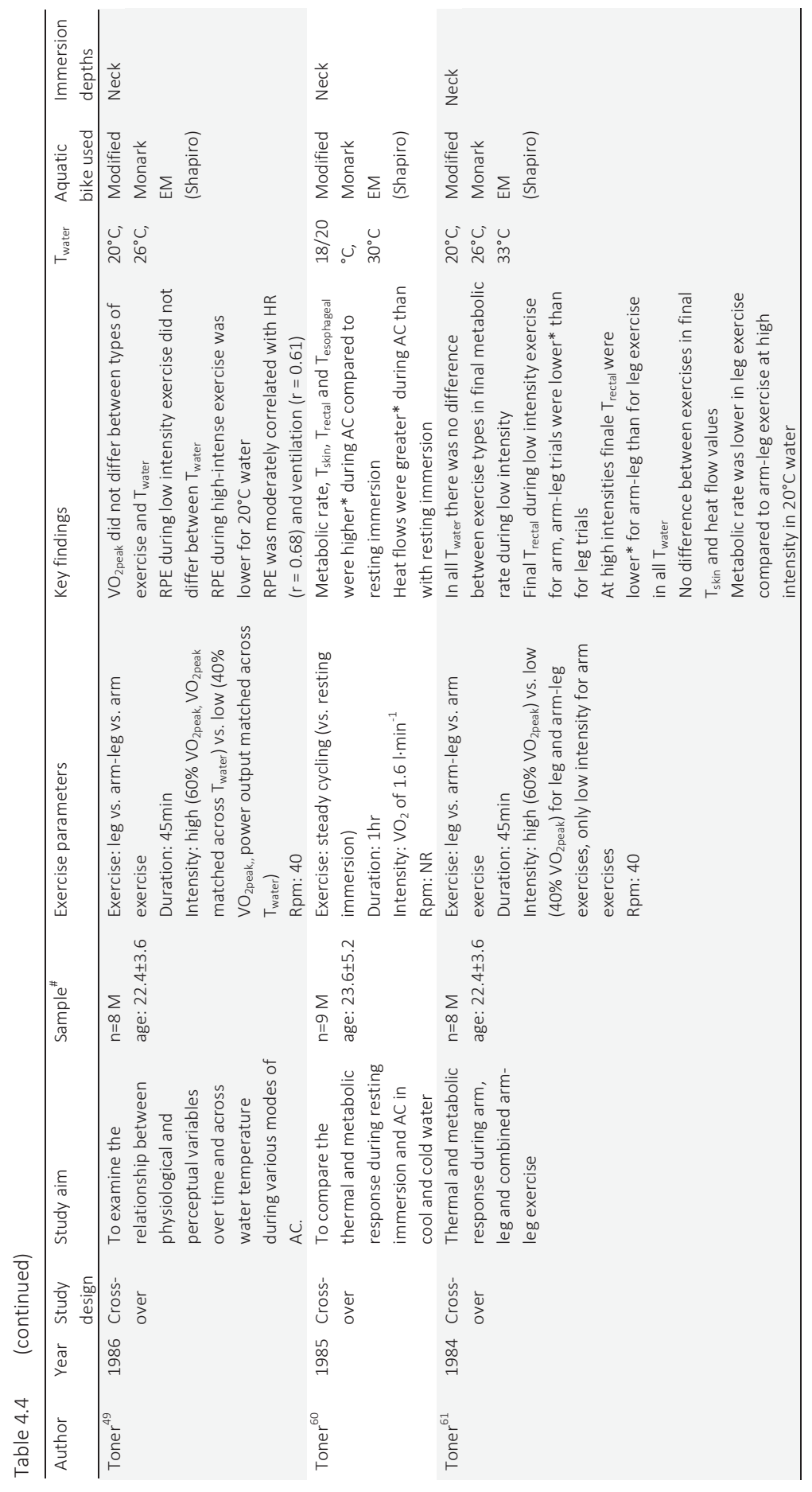




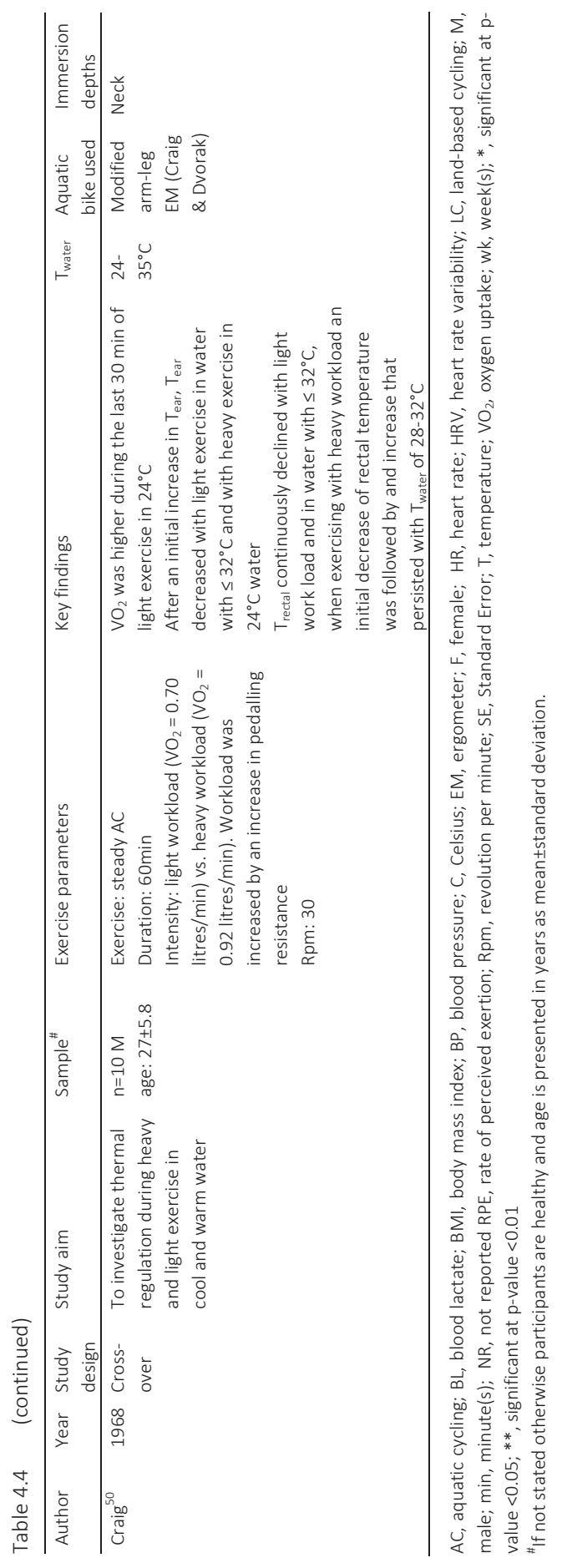




\section{Aquatic cycling intervention programmes}

In total eight intervention studies, investigating the effects of a multiple sessions aquatic cycling exercise programme, were found. ${ }^{66-73}$ The exercise programmes (Table 4.5) lasted between three and 36 weeks with an exercise frequency between two and five times per week. The duration of one session varied between 30 and 90 minutes. Exercise intensities were based on land-based maximal graded exercise-tests and the training intensities were set between 60 and $80 \%$ of the $\mathrm{VO}_{2 \max }$ in all but one study. ${ }^{66}$ In a one-group test-retest study, Sheldahl et al. assessed weight loss in obese women after a low intense ( 30 to $40 \%$ of $\mathrm{VO}_{2 \max }$ ) aquatic cycling programme. ${ }^{66}$ Boidin et al. also evaluated the effects of aquatic cycling on cardiometabolic parameters in obese people. ${ }^{71}$ In this retrospective study the participants underwent an extensive lifestyle programme including high-intensity aquatic cycling or land cycling. Furthermore, two randomised studies evaluated the cardiovascular effect of aquatic cycling compared to land cycling in young healthy males ${ }^{68}$ and patients with multiple sclerosis. ${ }^{72,73}$ Two quasi-experimental studies investigated the influence of water temperature on heat tolerance and aerobic capacity. ${ }^{67,69,70}$

Four studies reported a significant improvement of cardiorespiratory parameters compared to baseline in healthy (obese) people and multiple sclerosis patients. ${ }^{68,71-73}$ Aquatic and land cycling evoked similar improvements in cardiorespiratory parameters. Further, moderate land and aquatic cycling achieved similar improvements in healthrelated quality of life and self-reported physical fatigue in patients with multiple sclerosis. ${ }^{72,73}$ Boidin et al. reported comparable results in weight loss and reduction in fasting glycaemia and triglyceride levels in obese people. ${ }^{71}$ In obese women, an eight week aquatic cycling programme in cold water did not lead to weight loss. ${ }^{66}$

In young, healthy males, there was no superior effect of cold or warm water on the improvements in cardiovascular parameters, ${ }^{67,69,70}$ lactate accumulation lactate accumulation, ${ }^{69}$ dryland heat tolerance ${ }^{67}$ and muscle glycogen utilization. ${ }^{69}$ 


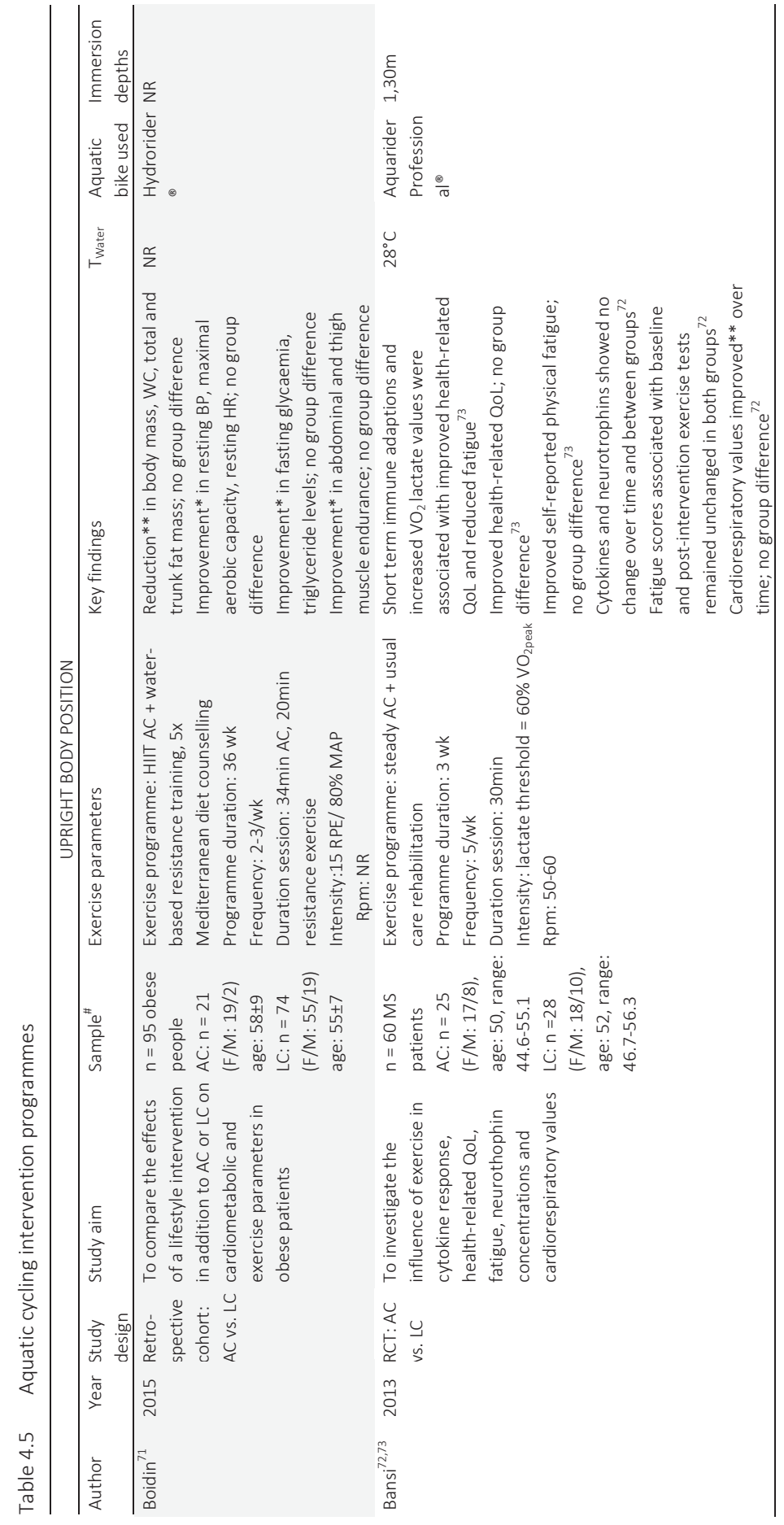




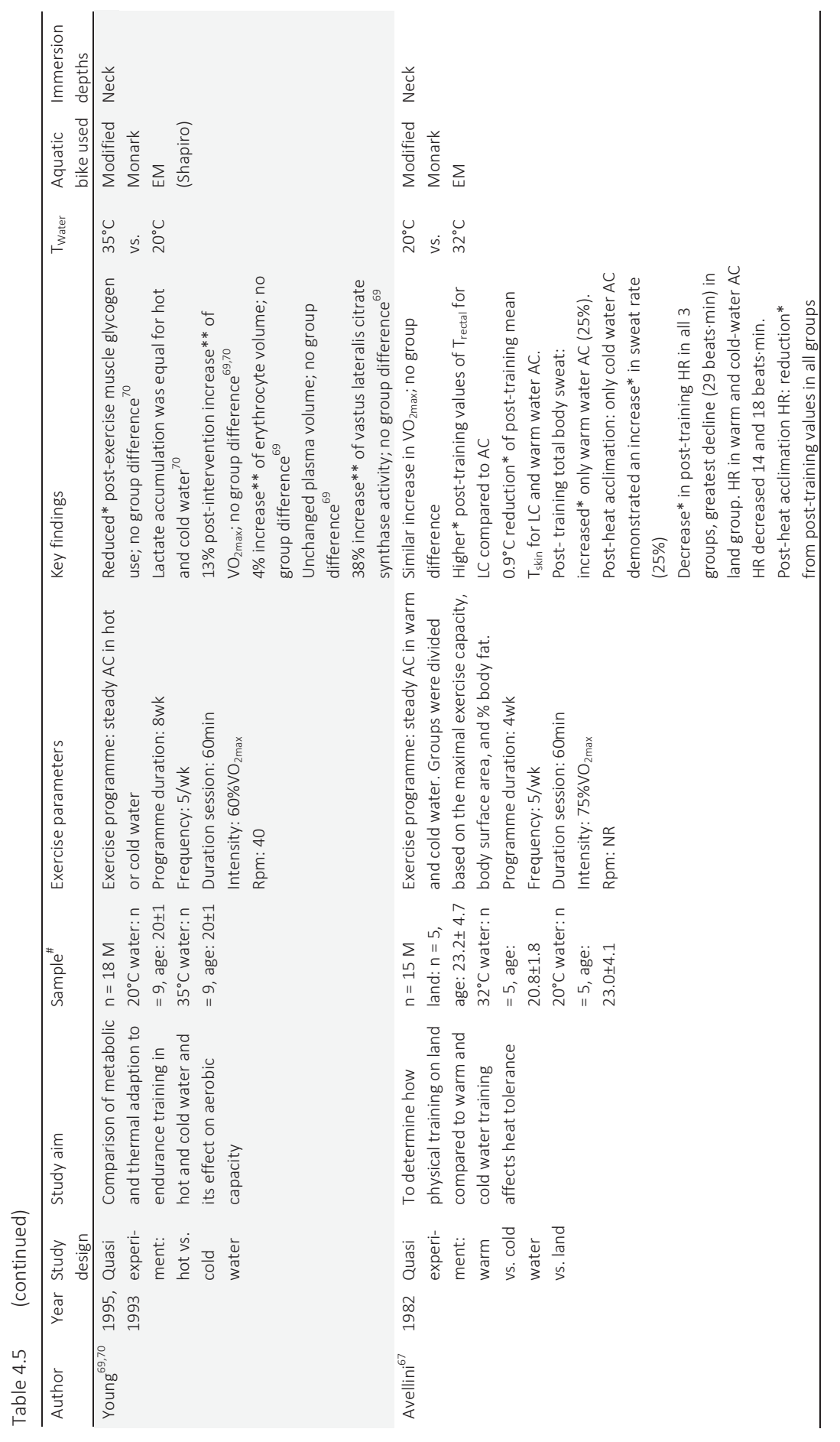




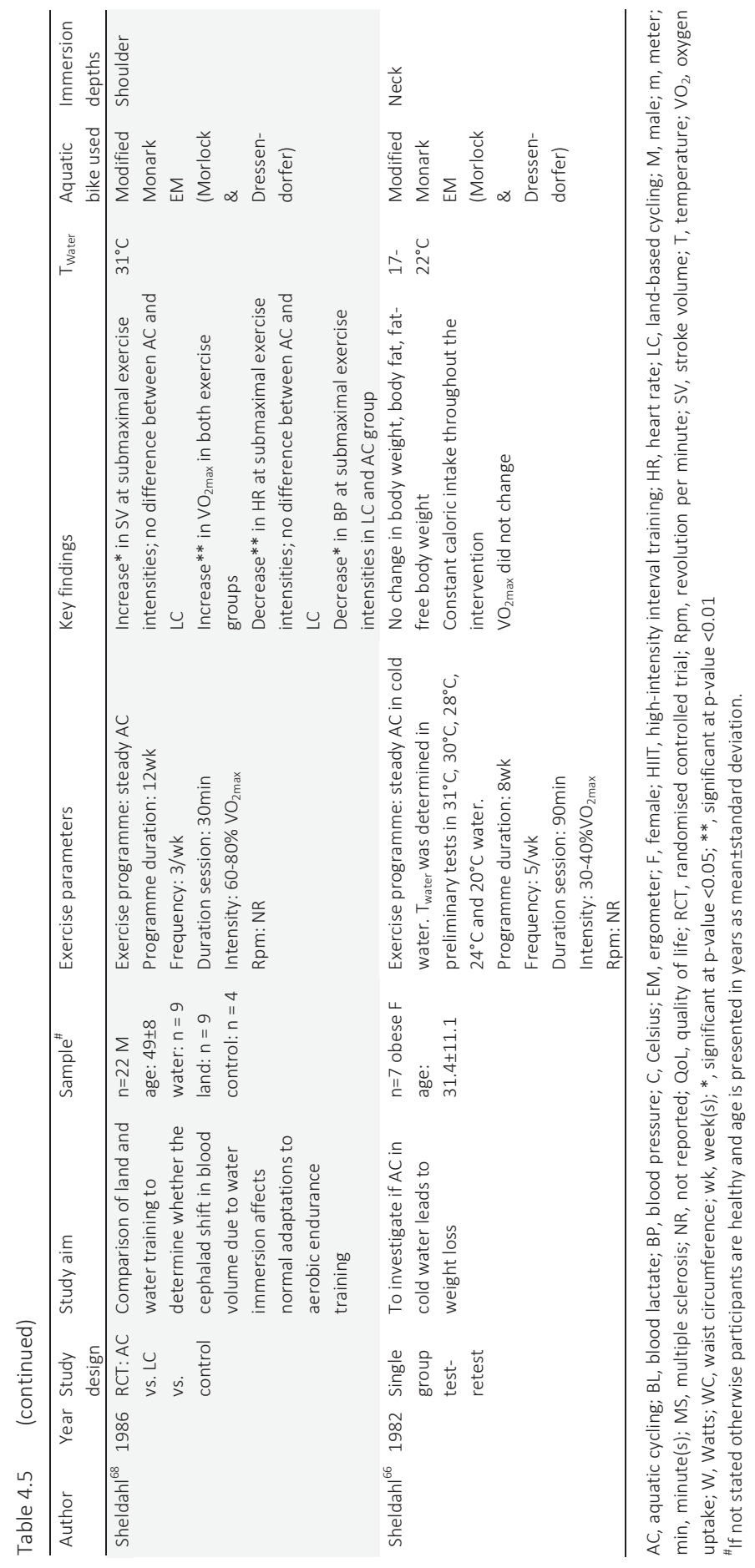




\section{DISCUSSION}

This is the first review to scope the available literature on head-out aquatic cycling exercise. The aim of this review was to describe the study parameters of available research utilising aquatic cycling as an exercise modality. Sixty-three publications were identified and the review provides a full summary of the set-up of aquatic interventions and possible comparisons, core outcomes, involved participants and the study designs utilised in current literature. The exploration of the intervention parameters revealed great variety on the use and execution of aquatic cycling.

\section{Land-based cycling versus aquatic cycling}

The main body of the current research on aquatic cycling focuses on cardiovascular outcomes and the core findings for the comparison between land-based and waterbased cycling showed similar trends. These latter studies ${ }^{17-23,26}$ reported comparable $\mathrm{VO}_{2 \max }$ values of aquatic and land-based cycling and therefore, the cardiac demand of aquatic cycling seems similar to land-based cycling. The results for HR were less consistent with a tendency for a lower HR during aquatic cycling compared to landbased cycling. ${ }^{20-23,26,29,30}$ Further, cardiac output and stroke volume was reported to be higher during aquatic cycling. ${ }^{15,21,29,30}$ These results are in line with the general understanding concerning the effects of water immersion on the human body. Hydrostatic pressure exerts external pressure on the immersed body, which increases with increased depth. ${ }^{2,74}$. Due to the hydrostatic pressure exerted there is a shift of blood from the extremities to the chest cavity, increasing arterial filling, and thus cardiac output and stroke volume are increased. ${ }^{2,74}$ Because cardiovascular parameters are modified by immersion, this could explain why the literature is inconclusive on the optimal recommendations for exercise prescription during aquatic cycling. Another explanation may be as most aquatic bikes are not equipped with an electronically controlled pedalling resistance mechanism and approaches to estimate $\mathrm{VO}_{2}$ from aquatic cycling are often based on pedalling frequency, with or without additional resistance. However, these equations cannot be used for all aquatic bikes, as the design and drag resistance created by pedals and resistance fins vary considerably across the aquatic bikes.

\section{Aquatic cycling under different conditions}

Due to the heterogeneous nature of aquatic cycling, many variables are involved when studying its impact on individuals, for example device-specific factors ${ }^{44,63-65}$ or environmental parameters as water temperature. . $2,23,43,48,49,51,52,56-61$ Thus explaining why the cardiovascular response to different exercise conditions was frequently investigated. For example, it seems that $\mathrm{VO}_{2 \max }$ is comparable across different water 
temperatures and that participants perceived exercising in warm water as more exhaustive. ${ }^{23,48,49}$ Further, included studies concluded that exercise intensities up to maximal limits are achieved by an increase in pedalling frequency and that $\mathrm{VO}_{2 \text { peak }}$ does not differ between the different types of aquatic bikes. ${ }^{44,64}$ However, high-pedal frequencies are difficult to maintain during longer exercise sessions with a continuous character. ${ }^{44,64}$ To avoid discomfort with maintaining high pedal frequencies, exercise intensity can be modified by an increase in pedalling resistance or by utilising an interval training. ${ }^{45}$ The latter was perceived less exhaustive than a continuous protocol. $^{45}$

\section{Aquatic cycling as an intervention}

Only six studies investigated the effect of multiple aquatic cycling sessions. ${ }^{66-73}$ In four studies aquatic cycling was used in a clinical context for patients with multiple sclerosis and as exercise training for older adults and obese individuals. Research showed that aquatic cycling was equally effective than land-based cycling for improving cardiovascular fitness. ${ }^{66,68,71-73}$ Furthermore, none of the included studies reported adverse events related to the training, suggesting that aquatic cycling is a safe exercise modality.

Most of the exercise protocols of the aquatic cycling intervention programmes consisted of steady cycling in a seated position with moderate intensity. Only Boidin et al. used an interval protocol for the training of obese individuals. ${ }^{71}$ It seems that the full potential of aquatic cycling including out-of-saddle positions and arm and trunk exercises is not published yet in peer-reviewed journals. ${ }^{7}$ Addition of these elements might prevent monotony especially in multiple session programmes ${ }^{75}$ and results from supportive literature suggest that a full spectrum aquatic cycling programme is effective in patients with musculoskeletal disorders. ${ }^{76}$

This scoping review has identified a number of areas for further research. Most of the included studies have a cross-over design with few cycling sessions and investigated the exercise response in young healthy males, because gender, body mass and morphology are known to affect the response to aquatic cycling. ${ }^{59,77,78}$ Further, only six studies investigated the effect of an aquatic cycling intervention programme. To improve the use of aquatic cycling in healthcare, future studies, preferably RCTs, should investigate the effects of aquatic cycling interventions in different populations and on outcomes such as (joint) pain, muscle strength or physical functioning, which are yet to be investigated. Of specific interest may also be the biomechanics of aquatic cycling and differences of seated and out-of saddle cycling. Furthermore, the identified literature seems suitable for more systematic reviews. For example it seems worthy to synthesize the available evidence on cardiovascular responses to aquatic cycling. 
To further improve the understanding of acute and long-term physiological adaptions to aquatic cycling training and facilitate between study comparisons, consistent reporting of the following parameters is recommended. Studies should describe the type of aquatic bike, body position, level of immersion, water temperature, methods used to control and assess exercise intensity i.e. training frequency, duration, rpm and pedalling resistance. Furthermore, it should be stated whether or not adverse events occurred. In addition to an accurate description of the aquatic cycling intervention, an agreement of experts on uniform keywords to describe the exercise activity is also strongly advised since this would improve the search in scientific databases. In this review the terms "aquatic cycling" and "aquatic bike" were used, as these expressions nowadays are commonly associated with this type of exercise.

This review has strengths and weaknesses. The extensive search procedure in this review resulted in more than sixty publications on aquatic cycling only, which were summarised and displayed. However, the presented studies should be interpreted with caution, because no quality assessment of the internal validity of the included studies was made in order to cover a broad spectrum of literature. Furthermore, this review provides a very general overview of the research on aquatic cycling without focusing on certain details of the included studies. For example, only the main outcomes reported in the abstract of the included studies were reported in this review. Yet, this comprehensive outline of available literature in this scoping review could serve as a starting point for systematic reviews or clinical studies on the effects of aquatic cycling on the cardiovascular responses.

\section{CONCLUSION}

This is the first scoping review to summarise the literature on head-out aquatic cycling. There are numerous variables related to aquatic cycling e.g., the type of aquatic bike or environmental factors e.g., water temperature or immersion level. As a result, the objectives of the identified studies in this review are heterogeneous. Most of the included studies compared aquatic cycling with land-based cycling or examined how to quantify and modify exercise intensity. Very few studies evaluated the effect of aquatic cycling interventions. Cardiovascular parameters were investigated by many of the studies and the results suggest that the cardiac demand of aquatic cycling seems similar to land-based cycling. Therefore, further research should synthesize the effects of aquatic cycling on cardiovascular parameters in a systematic review. Future studies should evaluate the effects of aquatic cycling interventions in a clinical and rehabilitative context. 


\section{REFERENCES}

1. Duddy $\mathrm{JH}$. The simulation of weightlessness using water immersion techniques: an annotated bibliography. Human Factors. 1969;11:507-40.

2. Becker BE, Cole AJ. Comprehensive Aquatic Therapy. 3rd ed. Pullmann, WA: Washington State University Publishing; 2010.

3. Barker AL, Talevski J, Morello RT, Brand CA, Rahmann AE, Urquhart DM. Effectiveness of aquatic exercise for musculoskeletal conditions: a meta-analysis. Archives of Physical Medicine and Rehabilitation. 2014;95:1776-86.

4. Bartels EM, Juhl CB, Christensen R, Hagen KB, Danneskiold-Samsoe B, Dagfinrud H, et al. Aquatic exercise for the treatment of knee and hip osteoarthritis. Cochrane Database Syst Rev. 2016;3:CD005523.

5. Fenzl M, Schnizer W, Hartmann B, Villiger B., Knüsel O. Unterschiede in der maximalen Sauerstoffaufnahme bei körperlichen Belastungen im Wasser oder an Land. Schweizerische Zeitschrift für Medizin und Traumatologie. 2005;53:172-8.

6. Meyer K, Leblanc MC. Aquatic therapies in patients with compromised left ventricular function and heart failure. Clinical and Investigative Medicine Medecine Clinique et Experimentale. 2008;31:E90-7.

7. Barbosa TM, Marinho DA, Reis VM, Silva AJ, Bragada J. Physiological assessment of head-out aquatic exercises in healthy subjects: a qualitative review. Journal of Sports Science \& Medicine. 2009;8:179-89.

8. Armstrong R, Hall BJ, Doyle J, Waters E. Cochrane Update. 'Scoping the scope' of a cochrane review. Journal of Public Health. 2011;33:147-50.

9. Arksey H, O'Malley L. Scoping studies: towards a methodological framework. International Journal of Social Research Methodology. 2005;8:19-32.

10. Fenzl M, Krebs J, Villiger B, Zaugg T, Gredig J, Walter B, et al. Leistungsmessungen im Wasser mit einem neuen Kraftmess-Kurbelsystem. Physikalische Medizin Rehabilitationsmedizin Kurortmedizin. 2012;22:183-8.

11. Fenzl M, Schlegel C., Villiger B., Aebli N., Gredig J., J. K. Eignung des hochfrequenten Spektralbandes der Herzratenvariabilität für die Leistungsdiagnostik im Wasser. Physikalische Medizin Rehabilitationsmedizin Kurortmedizin. 2013;23:225-30.

12. Fenzl M, Schnizer W, Knüsel O, Hartmann B. Herz-Kreislauf-Belastung bei körperlicher Arbeit am Wasserfahrrad bei verschiedenen Wassertemperaturen gemessen am Druck-Frequenz-Produkt. Physikalische Medizin Rehabilitationsmedizin Kurortmedizin. 2010;20:27-31.

13. Garzon M, Gayda M, Garzon L, Juneau M, Nigam A, Leone M, et al. Biomechanical analysis to determine the external power output on an immersible ergocycle. European Journal of Sport Science. 2015; $15: 271-8$

14. Garzon M, Gayda M, Nigam A, Comtois A-S, Juneau M. Immersible ergocycle prescription as a function of relative exercise intensity. Journal of Sport and Health Science. 2015; http://dx.doi.org/10.1016/ j.jshs.2015.12.004.

15. Garzon M, Juneau M, Dupuy O, Nigam A, Bosquet L, Comtois A, et al. Cardiovascular and hemodynamic responses on dryland vs. immersed cycling. Journal of Science and Medicine in Sport. 2015;18:619-23.

16. Garzon M, Dupuy O, Bosquet L, Nigam A, Comtois AS, Juneau M, et al. Thermoneutral immersion exercise accelerates heart rate recovery: A potential novel training modality. European Journal of Sport Science. 2017; 17:310-6.

17. Yazigi F, Pinto S, Colado J, Escalante Y, Armada-da-Silva PA, Brasil R, et al. The cadence and water temperature effect on physiological responses during water cycling. European Journal of Sport Science. 2013;13:659-65.

18. Wiesner S, Birkenfeld AL, Engeli S, Haufe S, Brechtel L, Wein J, et al. Neurohumoral and metabolic response to exercise in water. Hormone and Metabolic Research. 2010;42:334-9.

19. Sheldahl LM, Tristani FE, Connelly TP, Levandoski SG, Skelton MM, Cowley AW, Jr. Fluid-regulating hormones during exercise when central blood volume is increased by water immersion. American Journal of Physiology. 1992;262:R779-85. 
20. Connelly TP, Sheldahl LM, Tristani FE, Levandoski SG, Kalkhoff RK, Hoffman MD, et al. Effect of increased central blood volume with water immersion on plasma catecholamines during exercise. J Appl Physiol (1985). 1990;69:651-6.

21. Christie JL, Sheldahl LM, Tristani FE, Wann LS, Sagar KB, Levandoski SG, et al. Cardiovascular regulation during head-out water immersion exercise. Journal of Applied Physiology. 1990;69:657-64.

22. Sheldahl LM, Wann LS, Clifford PS, Tristani FE, Wolf LG, Kalbfleisch JH. Effect of central hypervolemia on cardiac performance during exercise. Journal of Applied Physiology. 1984;57:1662-7.

23. Dressendorfer RH, Morlock JF, Baker DG, Hong SK. Effects of head-out water immersion on cardiorespiratory responses to maximal cycling exercise. Undersea Biomedical Research. 1976;3:17787.

24. Fenzl M, Karner-Rezek K, Schlegel C, Gredig J, Villiger B. VO2 kinetics during different forms of cycling exercise on land and in water. Sports and Exercise Medicine - Open Journal. 2015;1:64-70.

25. Perini R, Milesi S, Biancardi L, Pendergast DR, Veicsteinas A. Heart rate variability in exercising humans: effect of water immersion. European Journal of Applied Physiology and Occupational Physiology. 1998;77:326-32.

26. Chen AA, Kenny GP, Johnston CE, Giesbrecht GG. Design and evaluation of a modified underwater cycle ergometer. Canadian Journal of Applied Physiology. 1996;21:134-48.

27. Finkelstein I, de Figueiredo PA, Alberton CL, Bgeginski R, Stein R, Kruel LF. Cardiorespiratory responses during and after water exercise in pregnant and non-pregnant women. Revista Brasileira de Ginecologia e Obstetrícia: Revista da Federação Brasileira das Sociedades de Ginecologia e Obstetrícia. 2011;33:388-94.

28. Hanna RD, Sheldahl LM, Tristani FE. Effect of enhanced preload with head-out water immersion on exercise response in men with healed myocardial infarction. The American journal of cardiology. 1993;71:1041-4.

29. Sheldahl LM, Tristani FE, Clifford PS, Hughes CV, Sobocinski KA, Morris RD. Effect of head-out water immersion on cardiorespiratory response to dynamic exercise. Journal of the American College of Cardiology. 1987;10:1254-8.

30. McArdle WD, Magel JR, Lesmes GR, Pechar GS. Metabolic and cardiovascular adjustment to work in air and water at 18, 25, and 33 degrees C. Journal of Applied Physiology. 1976;40:85-90.

31. Craig ABJ, Dvorak M. Comparison of exercise in air and in water of different temperatures. Medicine and Science in Sports and Exercise. 1969;1:124-30.

32. McMurray RG, Fieselman CC, Avery KE, Sheps DS. Exercise hemodynamics in water and on land in patients with coronary artery disease. Journal of Cardiopulmonary Rehabilitation. 1988;8:69-75.

33. Brechat PH, Wolf JP, Simon-Rigaud ML, Brechat N, Kantelip JP, Berthelay S, et al. Influence of immersion on respiratory requirements during 30-min cycling exercise. European Respiratory Journal. 1999;13:860-6.

34. Fenzl M, Schnizer W, Aebli N, Schlegel C, Villiger B, Disch A, et al. Release of ANP and fat oxidation in overweight persons during aerobic exercise in water. International Journal of Sports Medicine. 2013;34:795-9.

35. Israel DJ, Heydon KM, Edlich RF, Pozos RS, Wittmers LE, Jr. Core temperature response to immersed bicycle ergometer exercise at water temperatures of 21 degrees, 25 degrees, and 29 degrees $C$. Journal of Burn Care and Rehabilitation. 1989;10:336-45.

36. McArdle WD, Magel JR, Spina RJ, Gergley TJ, Toner MM. Thermal adjustment to cold-water exposure in exercising men and women. Journal of Applied Physiology. 1984;56:1572-7.

37. McMurray RG, Katz VL, Meyer-Goodwin WE, Cefalo RC. Thermoregulation of pregnant women during aerobic exercise on land and in the water. American Journal of Perinatology. 1993;10:178-82.

38. Katz VL, McMurray R, Goodwin WE, Cefalo RC. Nonweightbearing exercise during pregnancy on land and during immersion: a comparative study. American Journal of Perinatology. 1990;7:281-4.

39. Di Masi F, De Souza Vale RG, Dantas EHM, Lopes Barreto AC, da Silva Novaes J, Reis VM. Is blood lactate removal during water immersed cycling faster than during cycling on land? Journal of Sports Science \& Medicine. 2007;6:188-92. 
40. Ferreira J, Da Silva Carvalho R, Barroso T, Szmuchrowski L, CEledziewski D. Effect of different types of recovery on blood lactate removal after maximum exercise. Polish Journal of Sport and Tourism. 2011;18:105-11.

41. Wahl P, Sanno M, Ellenberg K, Frick H, Bohm E, Haiduck B, et al. Aqua cycling does not affect recovery of performance, damage markers and sensation of pain. Journal of Strength and Conditioning Research. 2016;10.1519/JSC.0000000000001462.

42. Sosner P, Gayda M, Dupuy O, Garzon M, Lemasson C, Gremeaux V, et al. Ambulatory blood pressure reduction following high-intensity interval exercise performed in water or dryland condition. Journal of the American Society of Hypertension. 2016;10:420-8.

43. McArdle WD, Toner MM, Magel JR, Spina RJ, Pandolf KB. Thermal responses of men and women during cold-water immersion: influence of exercise intensity. European Journal of Applied Physiology and Occupational Physiology. 1992;65:265-70.

44. Giacomini F, Ditroilo M, Lucertini F, De Vito G, Gatta G, Benelli P. The cardiovascular response to underwater pedaling at different intensities: a comparison of 4 different water stationary bikes. Journal of Sports Medicine and Physical Fitness. 2009;49:432-9.

45. Brasil RM, Barreto AC, Nogueira L, Santos E, Novaes JS, Reis VM. Comparison of physiological and perceptual responses between continuous and intermittent cycling. Journal of human kinetics. 2011;29A:59-68.

46. Dionne A, Leone M, Andrich DE, Perusse L, Comtois AS. Acute breathing patterns in healthy and heart disease participants during cycling at different levels of immersion. Respiratory Physiology \& Neurobiology. 2017;235:1-7.

47. McMurray RG, Katz VL, Berry MJ, Cefalo RC. Cardiovascular responses of pregnant women during aerobic exercise in water: a longitudinal study. International Journal of Sports Medicine. 1988;9:443-7.

48. Fujimoto T, Sasaki Y, Wakabayashi H, Sengoku Y, Tsubakimoto S, Nishiyasu T. Maximal workload but not peak oxygen uptake is decreased during immersed incremental exercise at cooler temperatures. European Journal of Applied Physiology. 2016;116:1819-27.

49. Toner MM, Drolet LL, Pandolf KB. Perceptual and physiological responses during exercise in cool and cold water. Perceptual and Motor Skills. 1986;62:211-20.

50. Craig AB, Jr., Dvorak M. Thermal regulation of man exercising during water immersion. Journal of Applied Physiology. 1968;25:28-35.

51. White L, Dressendorfer RH, Holland E, McCoy SC, Ferguson MA. Increased caloric intake soon after exercise in cold water. International Journal of Sport Nutrition and Exercise Metabolism. 2005;15:3847.

52. McMurray RG, Kocher PL, Horvath SM. Aerobic power and body size affects the exercise-induced stress hormone responses to varying water temperatures. Aviation Space and Environmental Medicine. 1994;65:809-14.

53. Katz VL, McMurray R, Berry MJ, Cefalo RC, Bowman C. Renal responses to immersion and exercise in pregnancy. American Journal of Perinatology. 1990;7:118-21.

54. Katz VL, McMurray R, Berry MJ, Cefalo RC. Fetal and uterine responses to immersion and exercise. Obstetrics and Gynecology. 1988;72:225-30.

55. McMurray RG, Katz VL, Berry MJ, Cefalo RC. The effect of pregnancy on metabolic responses during rest, immersion, and aerobic exercise in the water. American Journal of Obstetrics and Gynecology. 1988;158:481-6.

56. McMurray RG, Berry MJ, Katz VL, Graetzer DG, Cefalo RC. The thermoregulation of pregnant women during aerobic exercise in the water: a longitudinal approach. European Journal of Applied Physiology and Occupational Physiology. 1990;61:119-23.

57. McMurray RG, Horvath SM. Thermoregulation in swimmers and runners. Journal of Applied Physiology. 1979;46:1086-92.

58. Golden FS, Tipton MJ. Human thermal responses during leg-only exercise in cold water. Journal of Physiology. 1987;391:399-405.

59. Toner MM, Sawka MN, Foley ME, Pandolf KB. Effects of body mass and morphology on thermal responses in water. J Appl Physiol (1985). 1986;60:521-5. 
60. Toner MM, Sawka MN, Holden WL, Pandolf KB. Comparison of thermal responses between rest and leg exercise in water. J Appl Physiol (1985). 1985;59:248-53.

61. Toner MM, Sawka MN, Pandolf KB. Thermal responses during arm and leg and combined arm-leg exercise in water. Journal of Applied Physiology. 1984;56:1355-60.

62. Pinto SS, Brasil RM, Alberton CL, Ferreira HK, Bagatini NC, Calatayud J, et al. Non-Invasive Determination of the Anaerobic Threshold Based on the Heart Rate Deflection Point in Water Cycling. Journal of Strength and Conditioning Research. 2015;10.1519/JSC.0000000000001099.

63. Morlock JF, Dressendorfer RH. Modification of a standard bicycle ergometer for underwater use. Undersea Biomedical Research. 1974;1:335-42.

64. Shapiro Y, Avellini BA, Toner MM, Pandolf KB. Modification of the Monark bicycle ergometer for underwater exercise. Journal of Applied Physiology. 1981;50:679-83.

65. Sogabe Y, Monji K, Nakashima K, Tajima F, Iwamoto J. Modification of a conventional bicycle ergometer for underwater use. Journal of UOEH. 1987;9:279-85.

66. Sheldahl LM, Buskirk ER, Loomis JL, Hodgson JL, Mendez J. Effects of exercise in cool water on body weight loss. International Journal of Obesity. 1982;6:29-42.

67. Avellini BA, Shapiro Y, Fortney SM, Wenger CB, Pandolf KB. Effects on heat tolerance of physical training in water and on land. Journal of Applied Physiology. 1982;53:1291-8.

68. Sheldahl LM, Tristani FE, Clifford PS, Kalbfleisch JH, Smits G, Hughes CV. Effect of head-out water immersion on response to exercise training. Journal of Applied Physiology. 1986;60:1878-81.

69. Young AJ, Sawka MN, Quigley MD, Cadarette BS, Neufer PD, Dennis RC, et al. Role of thermal factors on aerobic capacity improvements with endurance training. J Appl Physiol (1985). 1993;75:49-54.

70. Young AJ, Sawka MN, Levine L, Burgoon PW, Latzka WA, Gonzalez RR, et al. Metabolic and thermal adaptations from endurance training in hot or cold water. J Appl Physiol (1985). 1995;78:793-801.

71. Boidin M, Lapierre G, Paquette Tanir L, Nigam A, Juneau M, Guilbeault V, et al. Effect of aquatic interval training with Mediterranean diet counseling in obese patients: results of a preliminary study. Annals of Physical and Rehabilitation Medicine. 2015;58:269-75.

72. Bansi J, Bloch W, Gamper U, Kesselring J. Training in MS: influence of two different endurance training protocols (aquatic versus overland) on cytokine and neurotrophin concentrations during three week randomized controlled trial. Multiple Sclerosis. 2012;19:613-21.

73. Bansi J, Bloch W, Gamper U, Riedel S, Kesselring J. Endurance training in MS: short-term immune responses and their relation to cardiorespiratory fitness, health-related quality of life, and fatigue. Journal of Neurology. 2013;260:2993-3001.

74. Becker BE. Aquatic therapy: scientific foundations and clinical rehabilitation applications. $P M \& R$ : the journal of injury, function, and rehabilitation. 2009;1:859-72.

75. Rewald S, Mesters I, Emans PJ, Arts JJ, Lenssen AF, de Bie RA. Aquatic circuit training including aquacycling in patients with knee osteoarthritis: A feasibility study. Journal of Rehabilitation Medicine. 2015;10.2340/16501977-1937.

76. Moser S. Entwicklung und Überprüfung eines Aqua-Cycling-Programms für Rheumapatienten [Master]. Karlsruhe: Universität Karlsruhe; 2009.

77. Stachenfeld NS, Taylor HS. Challenges and methodology for testing young healthy women in physiological studies. American Journal of Physiology: Endocrinology and Metabolism. 2014;306:E84953.

78. Costello JT, Bieuzen F, Bleakley CM. Where are all the female participants in Sports and Exercise Medicine research? European Journal of Sport Science. 2014;14:847-51. 


\section{APPENDIX 4.1}

\section{Post-hoc analysis of search terms}

Across all included articles it was explored how the exercise activity and the water exercise device (ergometer) were described. The majority (84\%) of the studies described the type of exercise in a specific manner rather than using general expressions such as "water exercise" or "immersed leg exercise". Also the word "exercise" (37\%) or "cycling" (32\%) was combined with a term for the exercise device and the exercise environment. Examples of these descriptions are "exercise on a bicycle ergometer (during immersion) in water", "cycling in water immersion" or "water cycling exercise". Nine expressions (15\%) were found that extended description by specifying the exercising limb (e.g. performing leg cycle exercise in water) or the body position on the exercise device resulting in descriptions such as "upright cycling exercises in water".

Likewise to the exercise activity descriptions, most authors (82\%) clearly indicate that the device is used in water. In addition, the term "ergometer" is frequently used (68\%) and combined with the word "(bi)cycle". This results in descriptions such as "(bi)cycle ergometer immersed/used in water", "(under)water (bi)cycle ergometer" or "immersible/submersible ergometer". In recent publications of Garzon et al. the short description "immersible ergocycle" was introduced. Other descriptions like "whole body ergometer" or "arm / leg ergometer for use in water" focus on the exercising $\operatorname{limb}(\mathrm{s})$ or emphasize that the ergometer can be used on land and in water by naming the device an "air-water ergometer". From 2007 onwards the terms "aqua(tic) bike", "water (stationary) bike" or "aqua cycle" are occasionally used and account for $13 \%$ of all identified descriptions. 


\section{APPENDIX 4.2}

\section{Development of the inclusion and exclusion criteria}

The inclusion and exclusion criteria were developed in two stages. Prior to screening any articles, the authors agreed to include all formats of full-text research reports that focused on the effects of head-out immersed cycling on the human body (Table 4.2, stage one). Studies that investigated the effect of full-body immersed underwater cycling, possibly in combination with a self-contained underwater breathing apparatus (SCUBA), were excluded. Two researchers (BW, SR) screened all titles and abstracts to select articles for full-text review. The independent screening and selection of articles was done with the online programme 'Covidence' (Covidence systematic review software, Veritas Health Innovation, Melbourne, Australia, available at www.covidence.org). Next, to become familiar with the literature and to check whether the in- and exclusion criteria needed more specification a pilot full-text review of articles identified from scientific databases $(n=68)$ was carried out. To save time and to stimulate discussion the pilot full-text screening was split between different reviewers. The six reviewers have different backgrounds in physical therapy (AFL, RB, $B W, S R)$, epidemiology (RB, IM), exercise physiology (JB) and aquatic therapy (BW, SR). Thirteen to 14 full-text versions were screened per reviewer and one reviewer (SR) screened all articles. Disagreement between the reviewers concerned whether or not to include studies that do not focus on aqua cycling as an exercise activity, but to study physiological responses as body temperature to immersion. Consequently, the reviewers agreed that these studies might contain useful information as long as the experiments were carried out under usual exercise conditions. Furthermore, the reviewers decided not to exclude a certain type of ergometer. However, the limbs had to be immersed during exercise and the subjects should be seated in upright or semi recumbent position during the exercise. All inclusion and exclusion criteria are summarised in Table 4.2. Finally, two reviewers (SR, AFL) used the extended list of inclusion on all identified full-text articles. 


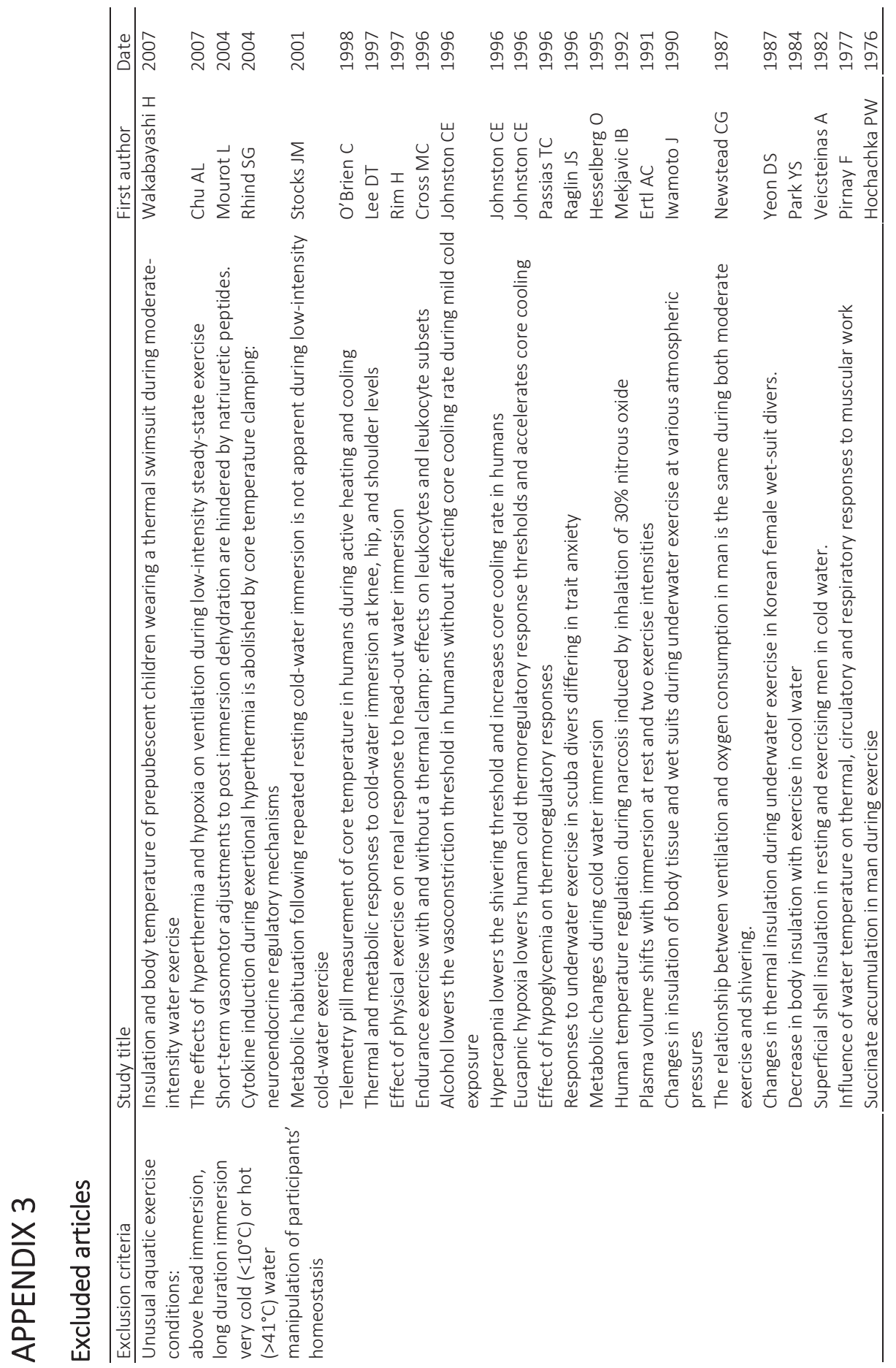




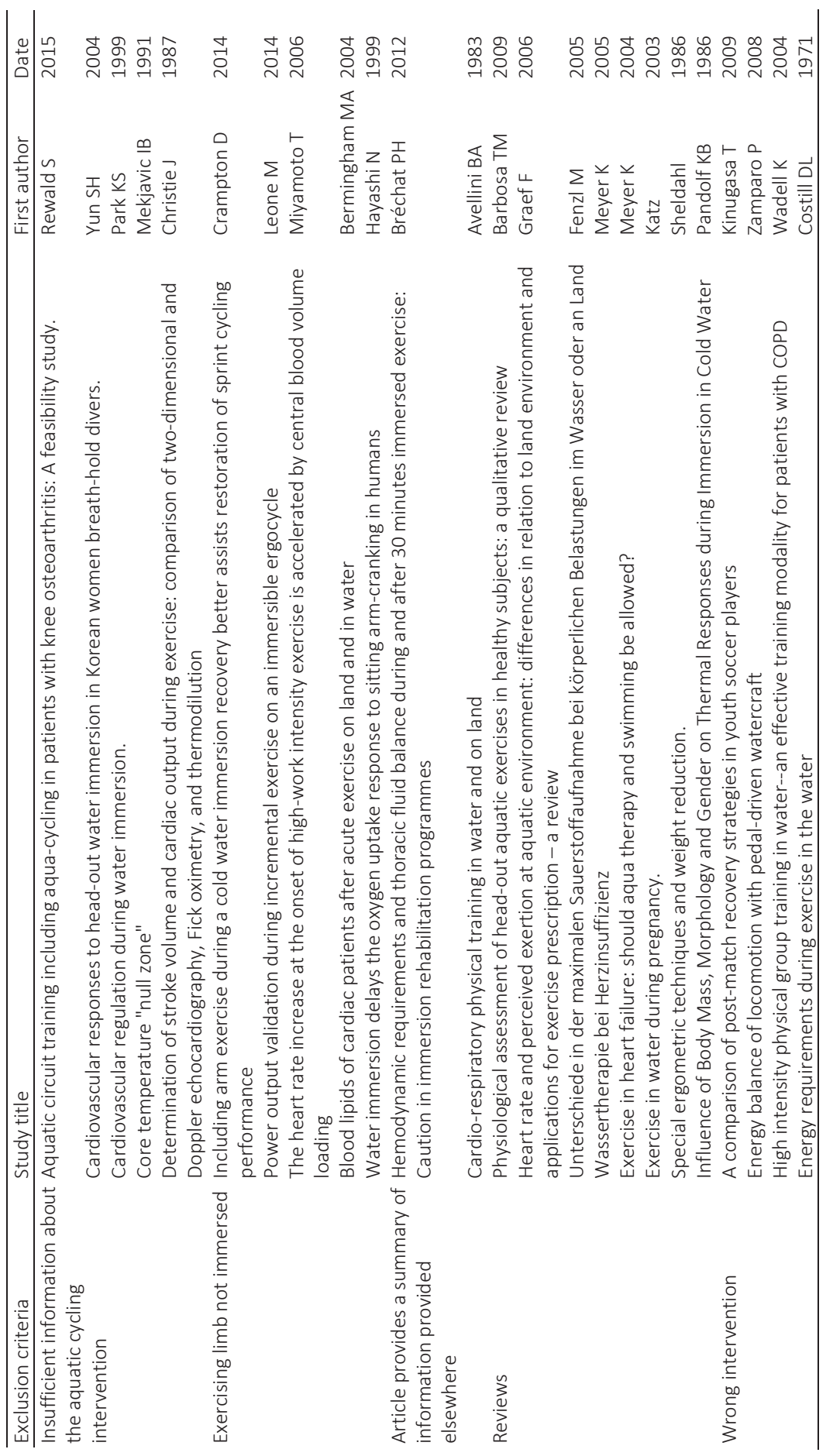





\section{ABSTRACT}

\section{Objective}

To evaluate the effects of aquatic cycling on knee pain and physical functioning in patients with knee osteoarthritis (OA).

\section{Methods}

A randomised controlled trial compared a twelve-week aquatic cycling exercise programme (24 sessions) with usual care for patients with mild to moderate knee OA. After the end of the trial period, the usual care group was invited to twelve aquatic cycling sessions. Primary outcomes were the Knee Injury and Osteoarthritis Outcome Score (KOOS) on knee pain and physical function. Secondary outcomes were KOOS scores on symptoms, sport, and diseasespecific quality of life (QoL), disease severity, physical activity, self-efficacy, kinesiophobia, Rand36 QoL, timed-up-and-go test (TUG), six-minute walking test (6-MWT), and leg strength. Outcomes were assessed at baseline, post-intervention and 24-weeks follow-up. Multilevel (mixed regression) analysis examined the effects.

\section{Results}

One hundred eleven patients were randomised, 9 patients withdrew before baseline, 19 patients were lost to follow-up. Average attendance rate for the aquatic cycling sessions was $80 \%$. Statistically significant differences at post-intervention and follow-up were found for knee pain (KOOS: $B=8.16, p=0.014$ ), physical functioning (KOOS: $B=7.16, p=0.027$; TUG: $B=-0.91, p=0.001$; 6-MWT: $B=46.75, p=0.002)$ and kinesiophobia $(B=-3.84, p=0.002)$ in favour of the aquatic group. Likewise a short-term improvement in disease-specific $Q \circ L(B=13.03, p=0.001)$ was detected in the aquatic group.

\section{Conclusion}

This is the first trial investigating a group-based aquatic cycling programme for patients with mild to moderate knee OA. Compared to usual care aquatic cycling seems effective in improving physical functioning and knee pain. 


\section{INTRODUCTION}

Knee osteoarthritis (OA) is a degenerative disease of synovial joints and the most prominent symptoms are pain and loss of physical function. In the array of non-surgical treatment options, exercise therapy has been shown to reduce pain and improve physical functioning in knee OA. ${ }^{1}$ A group-based aquatic cycling programme might be a useful extension of exercise options for this population. Many OA patients prefer to exercise in water, especially when exercising on land is too painful. ${ }^{2}$ For example, stationary land-based cycling is often recommended ${ }^{3,4}$ for patients with knee OA, but is restricted to seated cycling positions to prevent weight-bearing on the knee joints. Aquatic cycling provides a variety of exercises, because out-of-saddle positions are possible due to the buoyancy of the water and upper body exercise can be combined with seated cycling. Our feasibility study showed that knee OA patients feel secure on the bike and evaluate aquatic cycling as a pleasurable activity. ${ }^{5}$ However, in this study aquatic cycling was part of an aquatic circuit training; there is no high-quality evidence available on the sole effect of aquatic cycling training on the impairments of knee OA., Therefore, we developed a full aquatic cycling training programme. ${ }^{7}$ The aim of the present randomised controlled trial (RCT) is to evaluate the efficacy of a 12-week group-based aquatic cycling programme compared to usual care of an early OA outpatient clinic on knee pain and physical functioning in patients with knee mild to moderate knee OA.

\section{PATIENTS AND METHODS}

\section{Design}

The study was a single-blind, parallel-group RCT in patients with mild to moderate knee OA who consulted Maastricht University Medical Centre+ (MUMC+). The Medical Ethics Committee of the MUMC+ approved the study. The study was registered at the Netherlands Trial Register: NTR3766.

\section{Participants}

Between March 2013 and October 2015 participants were recruited from the Early OA Outpatient Clinic of the MUMC+. Patients with knee OA who rated their knee pain between 4 and 7 on a ten-point numeric rating scale ${ }^{8}$ and a Kellgren/Lawrence score ${ }^{9}$ between 1 and 3 were eligible for the study. Furthermore, eligible patients had a clear indication for conservative treatment of $\mathrm{OA}$, including a primary care physical therapy referral. In addition, patients were able to cycle on a stationary bike, were able to understand and write Dutch and scored 8 points or lower on the Hospital Anxiety and 
Depression Scale (HADS). ${ }^{10}$ Exclusion criteria were any contra-indication for aquatic exercise therapy like open wounds, unstable angina or an acute flare-up of joint inflammation. Further exclusion criteria were a planned total knee surgery, a corticosteroid injection less than three months ago or a hyaluronic acid injection less than six months ago, severe joint complaints elsewhere, symptomatic and radiological proven hip OA, inflammatory joint diseases, and the inability to safely enter and exit the pool or fear of water.

\section{Randomisation and blinding}

After obtaining written informed consent participants were randomised with a constant block size of eight and an allocation ratio of 1:1 by an independent research assistant of the Department of Epidemiology of Maastricht University to guarantee concealment (available at: www.randomizer.org).

Blinded physical therapists collected all data on paper and blinded research assistants entered the paper-based data. Aquatic cycling trainers and patients could not be blinded.

\section{Intervention}

Before baseline assessment, all participants received care as usual from the Early OA Outpatients Clinic of the MUMC+. Usual care included diagnosis of knee OA, followed by information about knee OA (verbal information by the nurse practitioner and a booklet: https://centraal.mumc.nl/sites/central/files/23999-0711_Arthrose.pdf), indication of personal risk factors and a tailored treatment plan including pain medication and a referral for primary care physical therapy.

\section{Usual care group (UC)}

The UC continued with the tailored treatment plan and could decide if they wanted to start with physical therapy. Participation in physical therapy was not obliged. Prior to post-test and 24-weeks follow-up assessment, information on usual care routine was obtained during a short telephone interview. After the last measurement at 24-weeks, people in UC were invited to twelve weekly sessions of aqua cycling in a local community pool in Maastricht.

\section{Aquatic cycling group (AC)}

Participants in the intervention group were instructed not to start additional physical therapy during the intervention period of twelve weeks. Twice a week participants exercised for 45 minutes in small groups of maximally four participants supervised by a physical therapist. Participants cycled in an upright position on the aqua bike "AquaCruiser $\|^{\mathrm{TM}}$ " throughout the whole session. The depth of the therapy pool was 
adjusted to ensure that the legs were immersed during the whole movement. Typically participants were immersed between the xiphoid process and the first rib in warm water $\left(32^{\circ} \mathrm{C}\right)$. The main part of the training consisted of cycling in a sitting position with good postural control. In addition, out-of-the-saddle positions, leg exercises, and upper body exercises were incorporated. Exercise intensity was controlled by the Borg Scale, heart rate (220-minus-age formula), and pedalling tempo. A detailed description of the aquatic cycling programme can be found in our published study protocol. ${ }^{7}$

\section{Measurements}

All outcomes were assessed at baseline, 12-weeks post-intervention and at 24-weeks follow-up. Physical therapists of the MUMC+ collected the data during a one-hour appointment. To minimise the number of missing data, especially on the primary outcomes, the questionnaires were sent by mail to any participant unable to come to the MUMC+.

\section{Primary outcome}

Primary outcomes were the self-reported score on knee pain and physical functioning of the previous week assessed with the Knee Injury and Osteoarthritis Outcome Score questionnaire (KOOS, http://www.koos.nu). The sum scores per subscale were linearly transformed to a scale from zero (severe symptoms) to 100 (no symptoms).

\section{Secondary outcomes}

Secondary outcomes were scores for the KOOS subscales symptoms, sports activity and disease-related quality of life. Furthermore, physical functioning on the test day was assessed with the LEFS; Lower Extremity Function Scale. ${ }^{11}$ Pain intensity was measured with the ten-point Numeric Pain Rating Scale (NRS) after the six-minute walking test. ${ }^{8}$ The Patient Global Assessment (PGA) evaluated patient-rated general health. ${ }^{12}$ The Short QUestionnaire to ASsess Health-enhancing physical activity (SQUASH) collected data on habitual physical activity during the previous month ${ }^{13,14}$ of which total minutes of physical activity were calculated. Moreover, quality of life was measured with the Rand 36-item Health Survey and the mental (Rand-36 MCS) and physical component score (Rand-36 PCS) were calculated. ${ }^{15}$ The Tampa Scale for Kinesiophobia (TSK) measured fear of (re)-injury to movement ${ }^{16}$ and four questions of the Arthritis SelfEfficacy Scale (ASES) assessed self-efficacy for physical functioning. ${ }^{17}$ The total scores of the TSK and ASES were computed. Performance measures of physical functioning were the six-minute walking test $(6-M W T)^{18,19}$ and the timed-up-and-go test (TUG). ${ }^{20,21}$ Isometric and isokinetic muscle strength of the affected leg was measured with the Biodex ${ }^{\circledR}$ System 3 Pro. ${ }^{22}$ 
The psychometric properties of the above mentioned outcomes have been described previously. $^{7}$

\section{Assessment of covariates, session attendance, and adverse events}

Kellgren/Lawrence scores, body mass index (BMI), and comorbidities were obtained from medical records of the MUMC+. In addition, history of comorbidity was completed by a short telephone interview after participants had given informed consent. The researchers used the Chronic Illness Resources Survey (CIRS) to categorize comorbidities. ${ }^{23}$

In the AC the physical therapists monitored the attendance in an exercise logbook. They noted the date, the number of sessions attended, pedalling tempo and resistance, BORG score and heart rate during the main part of the training, and the occurrence of adverse events or problems with the performance of certain exercises.

\section{Sample size}

Sample size calculation was based on the primary endpoint self-reported knee pain. ${ }^{1,24,25}$ A sample size of 168 seemed sufficient to detect a group difference in knee pain with an effect size of $d=0.5$. This pre-calculated sample size was reported in our study protocol and was based on the results of a study with a comparable design (aquatic therapy vs. control) and target group. ${ }^{26}$ Thus, with a two-sided significance level of $5 \%$, a statistical power of $80 \%$ and an expected dropout of $25 \%, 84$ patients per arm (168 in total) would be required.

\section{Statistical analysis}

Data were analysed according to the intention-to-treat principle by including all randomised patients who were measured at least once, using multilevel (mixed) linear regression analysis per outcome. Mixed linear regression models consist of a random part (variances of, and correlations between, the repeated outcome measures) and a fixed part (regression weights, effects of predictors on outcome mean per time point). For the random part of the model, an unstructured covariance matrix was used. The fixed (predictor) model part consisted of time (using dummy coding for post-test and follow-up, with baseline as reference time point), treatment group ( $A C=1, \cup C=0)$, and patient characteristics as predictors. The latter were age (in years), sex (female $=1$, male=0), BMI, quadriceps strength (in Newtonmeter (NM), corrected for body weight), tibiofemoral and patellofemoral Kellgren/Lawrence score and comorbidity count. ${ }^{27}$ Furthermore, the interaction of group with time was added to the model since this interaction represents the group difference in change from baseline to postintervention and follow-up, and is thus the effect of interest in this RCT. Moreover, to explore the effects of physical therapy, resp. the effect of being informed about the 
free aquatic cycling programme after follow-up in the UC arm (14 UC patients did not receive the information about the free post-intervention exercise opportunity before randomisation), the variables 'received $\mathrm{PT}^{\prime}$ resp. 'received info' and their interaction with time were added to the model as well. For each outcome, the mixed model was simplified stepwise and, if the group*time interactions remained stable from post-test to follow-up, the final model was further reduced by including a single term "group*postfollow" to get a more precise estimate of the effect of aquatic cycling for both time points. ${ }^{28}$ Further technical details on the mixed regression analysis, including the steps taken in model reduction, are given in Appendix 5.1.

All outcome analyses were adjusted for all baseline variables by including the latter as covariates. The primary outcomes KOOS knee pain and KOOS physical functioning were analysed separately and the treatment effect (i.e. group by time interaction) was tested using $\alpha=0.05$ two-tailed. In view of multiple testing, the $\alpha$ for all 21 secondary outcomes was $0.05 / 23=0.0022$ (i.e. Bonferroni correction based on a total of 23 outcomes). The effect size (ES) of aquatic cycling was calculated for all outcomes (see Appendix 5.1). All statistical analyses were conducted with the Statistical Package for the Social Sciences (SPSS, version 22.0).

\section{RESULTS}

One hundred eleven participants were randomised to the $A C(n=55)$ and the UC $(n=56)$ arm. Nine participants (all UC) withdrew from the study before baseline assessment and were excluded from further analysis. To check for possible bias in the effect analyses arising from this dropout, we conducted a logistic regression analysis within the UC group, with dropout before baseline (1=yes, $0=$ no) as outcome, and as predictors all measured baseline variables. The potential impact appeared to be ignorable (see Appendix 5.2).

One hundred two participants completed the baseline assessment. Information on baseline characteristics can be found in Table 5.1.

Table 5.1 Baseline characteristics of participants in AC and UC

\begin{tabular}{lcc}
\hline Characteristics & UC & AC \\
& $(n=47)$ & $59(9.5)$ \\
Age, years, mean (SD) & $61(7.4)$ & $39 / 16$ \\
Females/males (n) & $24 / 23$ & $29(5.6)$ \\
BMI, mean (SD) & $29(5.4)$ & $2(0.6)$ \\
K/L TF, mean (SD) & $2(0.5)$ & $0.7(1.1)$ \\
K/L PF, mean (SD) & $0.7(1.0)$ & $2(1.7)$ \\
Count comorbidity, mean (SD) & $1(1.3)$ & \\
\hline
\end{tabular}

AC, aquatic cycling group; BMI, body mass index; BW, body weight; K/L, Kellgren-Lawrence; KOOS, Knee injury and Osteoarthritis Outcome Score; NM, Newtonmeter; PF, patellofemoral; SD, standard deviation; TF, tibiofemoral; UC, usual care group 
Ninety participants completed the post-intervention assessment and 83 patients participated in the follow-up assessment. Figure 5.1 shows the participants' flow, including reasons for withdrawal.

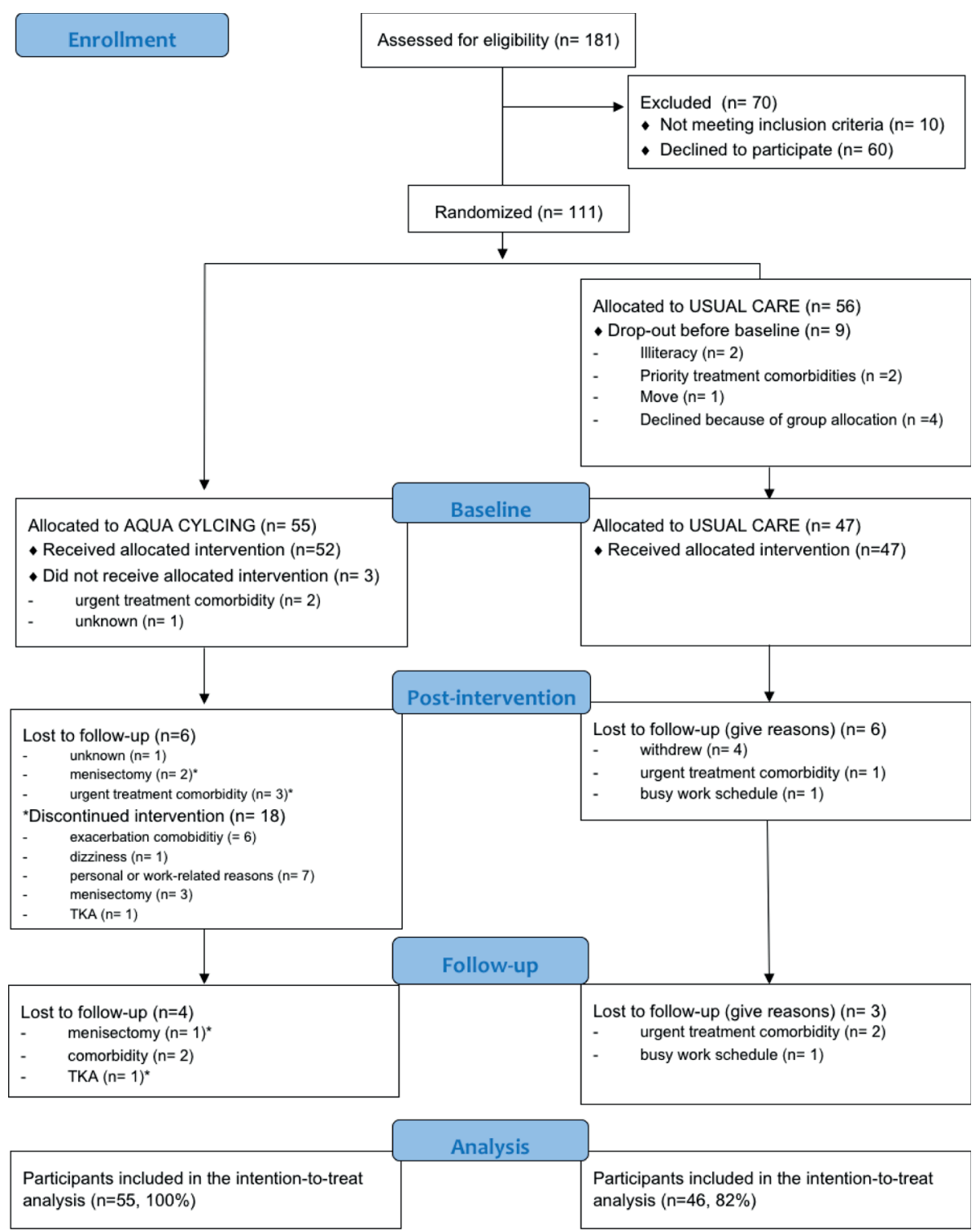

Figure 5.1 Flowchart 


\section{Primary outcome: KOOS knee pain}

The analysis for knee pain included 101 participants (one missing due to a missing baseline KOOS questionnaire and dropout after baseline). Since the group difference appeared to remain stable from post-test to follow-up, the final model was further reduced by replacing the group*posttest and group*follow-up terms with a single term group*postfollow (Appendix 5.2), which comes down to constraining the group difference to be the same at follow-up as at post-test. This constraint was confirmed by likelihood ratio testing and gives a single estimate of the outcome difference between $A C$ and UC, with more precision than estimates per time point (Appendix 5.3). Figure 5.2A shows the observed mean score for knee pain in both groups over time and Figure $5.2 \mathrm{~B}$ shows the predicted mean scores based on the final mixed models presented in Table 5.2. In general, dropout can bias observed means and predicted means correct for that as much as possible. Here, both plots agree quite well with each other. Appendix 5.4 entails an overview of the observed means.

The group by time effect (Table 5.2, Model A) shows that the change in pain score from baseline to 12 and 24-weeks follow-up was significantly higher in the AC arm than in the UC arm ( $p=0.014,95 \% \mathrm{Cl} 1.67$ to 14.64; ES=0.50). Furthermore, a higher BMI was related to more knee pain ( $p=0.046,95 \% \mathrm{Cl}-0.93$ to -0.01 ). There was no significant effect of age $(p=0.088)$, but as said in Appendix 5.1, all covariates with $p<0.10$ were kept in the model. Further, the time effects presented in Table 5.2 are those for the UC control arm (group=0), showing absence of significant change in that arm. Last, the group effect shown in Table 5.2 (Model A) is the group difference at baseline (time=0), showing absence of a baseline group difference in KOOS knee pain.

\section{Primary outcome: KOOS physical functioning}

The analysis of self-reported physical functioning included fewer patients $(n=98)$ than the analysis for knee pain due to missing values on the covariate "strength" (meter out of order, patient refusal), which was in the final model for physical functioning (Table 5.2, Model B) but not in that for knee pain. As for the analysis of knee pain, the group*time interaction terms could be reduced to one single estimate (See Appendix $5.2+5.3$ ). The predicted means (Figure 5.2D) of the final model (see Table 5.2, Model B) agree quite well with the observed means of physical functioning per group and per time point (Figure 5.2C and Appendix 5.4). At baseline the $A C$ and $U C$ arm were comparable and time had no significant influence on the UC arm. The group by time effect in Table 5.2 (Model B) shows a statistically significant group difference $(p=0.027$, $E S=0.43$ ) in favour of the AC. Just like for knee pain, a higher BMI was related to more limitations in physical functioning $(p=0.006,95 \% \mathrm{Cl}-1.26$ to -0.21$)$. Furthermore, quadriceps strength had a significant effect on physical functioning $(p=0.001,95 \% \mathrm{Cl}$ 0.01 to 0.20 ); participants with more quadriceps strength reported fewer problems with physical functioning. An intention-to-treat analysis without covariates (so that 
$\mathrm{n}=101$ instead of 98) resulted in a group*time effect similar to the model in Table 5.2 (regression weight=7.855, SD=3.18, $\mathrm{p}=0.015$ ).

A

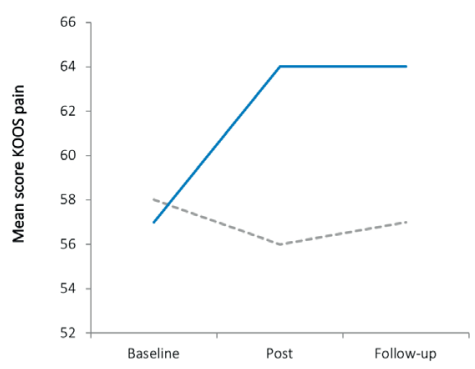

C

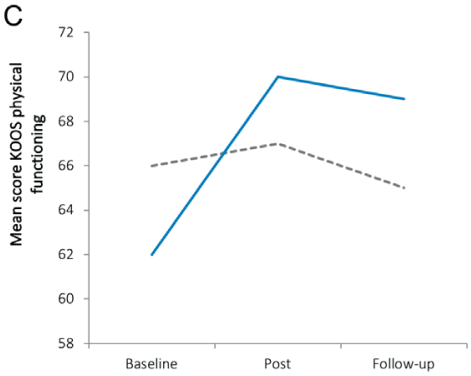

B

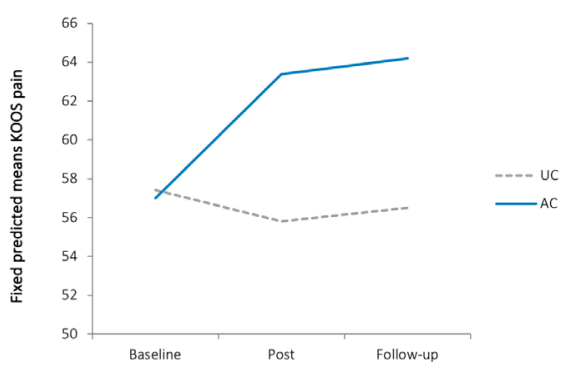

D

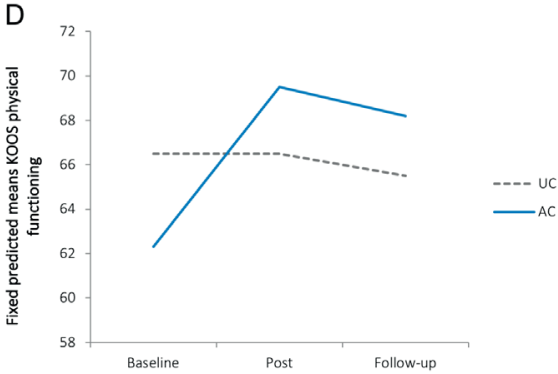

Figure 5.2 KOOS scores on pain (upper half) and physical functioning (lower half) over time (at baseline, post=12-week post-intervention, follow-up: 24 weeks after baseline). The left half shows observed outcome means, right half shows predicted outcome means based on Table 5.2.

Table 5.2 Final mixed models for KOOS pain and physical functioning

\begin{tabular}{|c|c|c|c|c|}
\hline \multicolumn{5}{|c|}{ KOOS PAIN } \\
\hline Fixed effects ( $n=101$ ) & Estimate & SE & p-value & $95 \% \mathrm{Cl}$ \\
\hline Intercept & 56.02 & 12.91 & 0.000 & $30.39,81.64$ \\
\hline Group & -0.46 & 2.89 & 0.874 & $-6.19, \quad 5.27$ \\
\hline Age & 0.25 & 0.15 & 0.088 & $-0.04, \quad 0.55$ \\
\hline $\mathrm{BMI}$ & -0.47 & 0.23 & 0.046 & $-0.93,-0.01$ \\
\hline Post-test & -1.69 & 2.51 & 0.504 & $-6.67, \quad 3.30$ \\
\hline Follow-up & -0.94 & 2.69 & 0.727 & $-6.28, \quad 4.39$ \\
\hline Group * Postfollow & 8.16 & 3.27 & 0.014 & $1.67,14.64$ \\
\hline \multicolumn{5}{|c|}{ KOOS PHYSICAL FUNCTIONING } \\
\hline Fixed effects ( $n=98)$ & Estimate & SE & $\mathrm{p}$-value & $95 \% \mathrm{Cl}$ \\
\hline Intercept & 80.04 & 9.57 & 0.000 & $61.05,99.02$ \\
\hline Group & -3.43 & 3.38 & 0.313 & $-10.13,3.28$ \\
\hline BMI & -0.74 & 0.26 & 0.006 & $-1.26,-0.21$ \\
\hline Strength & 0.11 & 0.05 & 0.029 & $0.01,0.20$ \\
\hline Post-test & -0.05 & 2.45 & 0.984 & $-4.81,4.91$ \\
\hline Follow-up & -1.37 & 2.52 & 0.588 & $-6.38,3.64$ \\
\hline Group * Postfollow & 7.16 & 3.19 & 0.027 & $0.83,13.49$ \\
\hline
\end{tabular}

$\mathrm{BMI}$, body mass index; $\mathrm{Cl}$, Confidence Interval; KOOS, Knee injury and Osteoarthritis Outcome Score; SE, standard error 


\section{Secondary outcomes}

Table 5.3 presents knee specific OA outcomes. ${ }^{12,29}$ Other health outcomes, like level of physical activity or general quality of life, are presented in Appendix 5.5. The group differences for most secondary outcomes remained stable from post-test to follow-up assessment and therefore, the final model was reduced to one group*time interaction (see Appendix 5.2). The observed means for all time-points of all secondary outcomes are presented in Appendix 5.4.

At 12-weeks the AC group achieved significantly higher scores at the KOOS quality of life subscale in comparison to baseline and compared to the UC group (13 points, $\mathrm{Cl}$ : 5.852, 20.215, $p=0.001, E S=0.71)$. Further, the AC group performed the TUG test significantly faster than the UC group at the post- and follow-up assessment (-0.9s, 95\% $\mathrm{Cl}:-1.453,-0.369, \mathrm{p}=0.001, \mathrm{ES}=-0.62)$. And, participants from the $\mathrm{AC}$ intervention group achieved significantly better results at the $6 \mathrm{MWT}$ on a $44 \mathrm{~m}$-squared track than the UC group at both post-intervention and follow-up assessment (46m: 95\% Cl: 17.60, 75.90, $p=0.002, E S=0.49)$. The analysis of the other self-reported outcomes, presented in Appendix 5.5, showed a significant improvement in fear of movement for the AC group compared to the UC group (-3.8 points: $95 \% \mathrm{Cl}$ : $-6.23,-1.45, \mathrm{p}=0.002$, ES=0.14). All other outcomes showed no significant group difference.

Table 5.3 Group difference for the secondary knee-specific outcomes

\begin{tabular}{|c|c|c|c|c|c|}
\hline Outcome & $\mathrm{N}$ & Estimate & SE & p-value & $95 \% \mathrm{Cl}$ \\
\hline KOOS Symptoms & 101 & 5.520 & 2.66 & 0.052 & $-0.039,10.540$ \\
\hline KOOS Sport & 97 & 3.884 & 4.24 & 0.362 & $-4.551,12.318$ \\
\hline KOOS QoL post ${ }^{R}$ & 100 & 13.034 & 3.61 & $0.001^{*}$ & $5.852,20.215$ \\
\hline KOOS QoL follow-up ${ }^{R}$ & 100 & 6.738 & 3.61 & 0.070 & $-0.571,14.046$ \\
\hline LEFS & 99 & 5.960 & 2.05 & 0.005 & $1.890,10.030$ \\
\hline NPRS (post6MWT) & 99 & -1.169 & 0.57 & 0.042 & $-2.295,1.514$ \\
\hline PGA & 99 & -0.618 & 0.535 & 0.252 & $-1.678,0.446$ \\
\hline 6MWT & 98 & 46.750 & 14.640 & $0.002 *$ & $17.600,75.901$ \\
\hline TUG & 98 & -0.911 & 0.272 & $0.001^{*}$ & $-1.453,-0.369$ \\
\hline 4-ceps strength: isokinetic $180^{\circ}$ & 99 & 12.456 & 4.047 & 0.003 & $4.394,20.517$ \\
\hline
\end{tabular}

$\mathrm{Cl}$, Confidence Interval; KOOS, Knee injury and Osteoarthritis Outcome Score; LEFS, Lower Extremity Function Scale; NRS, Numeric Pain Rating Scale; PGA, Patient Global Assessment; QoL, Quality of life; SE, standard error; TSK, Tampa Scale for Kinesiophobia; TUG, Timed-up-and-go test; 4-ceps, quadriceps; 6MWT, SixMinute-Walking-Test. *sig. $p \leq 0.0022$ (the alpha used for all secondary outcomes to adjust for multiple testing), $\mathrm{R}=$ model reduction to one group*time interaction was not valid and therefore, both group*time interactions are presented

\section{Utilisation of usual care in the UC group}

Fifteen participants of the UC group (32\%) consulted a physical therapist about their knee problems. Most patients $(n=9)$ visited the physical therapist between one and six times during the active intervention period; three patients had three to 
12 appointments and one person had more than 12 appointments. Of two patients the follow-up after the first consult is unknown due to dropout of these participants. Physical therapy consisted of education and home exercise $(n=9)$, medical fitness $(n=3)$ and manual therapy $(n=2)$. Three participants received a corticosteroid injection before the post-intervention assessment $(n=2)$ resp. the follow-up assessment $(n=1)$.

\section{Compliance and co-interventions in the AC group}

$62 \%$ of the AC participants completed all 24 sessions and $76 \%$ participated in twothirds ( $\geq 16$ sessions) of the sessions. The average attendance rate for all 24 sessions was $80 \%$ (SD 31\%). Common reasons for non-completing the AC intervention were vacations of three weeks or longer $(n=5)$ and unplanned treatment of comorbidities $(n=8)$. Other reasons were mensicusectonomy $(n=2)$, problems with transportation $(n=1)$, busy work schedule $(n=1)$, and one participant disliked exercising in warm water in retrospect. The following co-interventions were continued during the trial: wearing a brace $(n=3)$ or orthopaedic shoes $(n=2)$, receiving physical therapy for other complaints $(n=4)$ and consulting a dietician for weight loss $(n=1)$. Furthermore, three participants received a corticosteroid injection before post-intervention assessment and three participants started physical therapy for their knee OA after the intervention period.

\section{Exercise intensity of the aquatic cycling programme}

The training was perceived as light to moderate with a mean Borg score of 12 and 50\% of $\mathrm{HR}_{\max }$ according to the 220-age formula. Participants managed the training without the need of major adaptions of the exercises. They cycled with approximately $60 \mathrm{rpm}$ 's and with only water resistance or some extra pedalling resistance, which refers to resistance level one respectively two in the aquatic bike utilised in this study.

\section{Adverse events}

One serious adverse event occurred during the training in the AC group when a participant did not feel well at the end of the training and hyperventilated. Due to the cardiovascular history of the patient the patient was hospitalized for one night and was discharged the following day with the diagnosis of hyperventilation and continued with the training after two weeks of rest.

Furthermore, four patients reported an exacerbation of symptoms after the Biodex strength assessment and refused to do this assessment in the follow-up measurements.

With regard to the training, 10 patients reported increased knee pain the day after the training once $(n=9)$ or twice $(n=1)$. 


\section{DISCUSSION}

The results of this RCT indicate that a 12-week aquatic cycling training programme improves self-reported knee pain and physical functioning in patients with mild to moderate knee OA compared to usual care. Furthermore, our study shows a mediumterm improvement in performance-based physical functioning, a decrease in fear of movement as well as a short-term increase in quality of life in the aquatic cycling group. Except for quality of life, effects were maintained until 12 weeks after the end of the aquatic cycling training. To the authors' best knowledge this is the first study evaluating the short and medium-term effects of a group-based aquatic cycling training programme for patients with knee mild to moderate knee OA. ${ }^{6}$

The magnitude of our treatment effects on self-reported knee pain ( $E S=0.50$ ) and performance-based physical functioning (ES = 6MWT: 0.49, TUG: -0.62 ) were higher than the reported standardised mean differences (pain: 0.26, 0.31; physical functioning: 0.22) of recent systematic reviews comparing aquatic therapy to nontreatment control conditions. ${ }^{2,30}$ Possibly, the comparison of the intervention with a usual care waiting-list control group has inflated our effect estimates. However, several factors suggest that aquatic cycling is effective for patients with mild to moderate knee OA.

The decrease in perceived knee pain in the aquatic cycling group is likely the result of different aspects of the intervention. First, warm water temperature and buoyancy seem to contribute to pain relieve and feelings of well-being. ${ }^{31}$ Second, evidence suggests that aerobic exercise is effective in improving knee pain and physical functioning in patients with knee OA. In comparison with usual care, the aquatic cycling group significantly improved their six-minute walking distance; a surrogate measure of cardiovascular function. This finding suggests that the training intensity was sufficient to achieve improvements in functional aerobic capacity and is in line with findings from aquatic cycling interventions for obese people ${ }^{32}$ and patients with multiple sclerosis. ${ }^{33}$ The improvement of performance-based physical functioning might also be explained by an improvement in muscular coordination of the lower limbs, which for example is required for an efficient gait. ${ }^{34,35}$ Cycling requires co-coordination of the lower $\operatorname{limbs}^{36-38}$ and previous studies on land-based cycling programmes provided evidence that cycling is an effective treatment to improve gait pattern in patients with knee $\mathrm{OA}^{3,4}$

The medium-term follow-up assessment showed that improvements in the aquatic group could be maintained. Interestingly, the maintained treatment effect on the performance-based assessments on physical functioning was small to moderate, whereas the lasting effect for patient-reported physical functioning was small. This discrepancy between what people think they can do and what they, in fact, can do is noticed in other studies. ${ }^{39-41}$ The exercise experience due to participation in our aquatic cycling programme might have reassured participants' perception of their exercise 
capabilities, which is supported by the significant reduction in fear of movement in the aquatic group. ${ }^{42}$ Other features that might have contributed to the maintained effects were the small group size and the set-up of the aquatic bikes close to the edge of the swimming pool. These aspects enabled the supervising physical therapist to provide personalised feedback and to educate participants on the benefits of exercise and physical activity during the training. Studies that provided personalised education on $\mathrm{OA}$ and exercise-related topics ${ }^{43}$ or assured participants exercise abilities with an intensive aquatic resistance training ${ }^{42}$ also found improvements even after cessation of the intervention.

In patients with knee OA quality of life is associated with knee pain and disability and our findings are in line with previous studies suggesting a short-term, small effect of aquatic exercise on quality of life. ${ }^{2,30}$ As stated earlier, the aquatic environment positively influences pain perception and can increase feelings of well-being. ${ }^{31}$ Possibly, the cessation of the aquatic programme and the patients' perception of small improvements in physical functioning explain the vanished effect at the follow-up assessment.

Several aspects should be taken into account when interpreting the results of our study. First, the final number of included participants $(n=102)$ was lower than anticipated $(n=126+25 \%$ dropout $=168)$, and of these 102 only 90 provided post-test data. With this sample size, we had $80 \%$ power to detect an effect size of 0.60 for the primary outcomes (where $\alpha=0.05$ ). Second, the study design might have influenced the behaviour in the UC arm. ${ }^{44}$ Participants were allocated to the groups before the baseline measurement and by doing so; we lost nine participants before the baseline assessment (likely due to an absence of alternative treatment at the time). As a result, these participants could not be included in the effect analysis. Moreover, the final waiting-list control design could have created a wait-and-see attitude in the UC arm, which in turn might have inflated our effects. In our trial, $68 \%$ of the patients in the UC group decided not to visit a physical therapist, probably because most of these participants knew they could try out aquatic cycling after the end of their participation. ${ }^{44}$ However, the outcomes of our control group remained stable from baseline to 24-weeks follow-up, which is in line with a cohort study showing that the impairments of elderly people with hip or knee OA did not change over a five-year period. ${ }^{45}$ Another weakness of our study is that the possibility for the UC group to participate in a free aquatic cycling training in a newly built public swimming pool after study participation became available after the start of the study and so 14 patients did not have this information during the assessments. The outcome analyses did not show any significant outcome difference between the participants in the UC arm who knew $(n=33)$ and the 14 participants who did not know, they could try out AC afterwards. 
Since participants tolerated the training well, future studies should investigate the potential of aquatic cycling for patients with severe knee OA and during post-surgical rehabilitation. Furthermore, an evaluation of the feasibility and cost-effectiveness of a community-based aquatic cycling programme for individuals with knee OA seems indicated, because aquatic therapy is associated with high costs and the adherence to a regular exercise routine is crucial in the conservative management of $\mathrm{OA}$.

In conclusion, aquatic cycling might be a useful extension of the exercise possibilities for participants with mild to moderate knee OA. Compared to usual care, a light to moderate intense aquatic cycling training of 12 -weeks resulted in medium-term improvements of knee pain, self-reported and performance-assessed physical function, and fear of movement. Furthermore, a short-term effect on disease-specific quality of life was detected.

\section{Acknowledgement}

A special thanks goes out to the participants of this study and the therapists who performed the assessments, the student assistants who supported the assessors and trainer or who patiently entered the data, Conny de Zwart who was responsible for the randomisation, and Wiel Wijnen for his great support in patient recruitment. We would gratefully acknowledge the department of physical therapy of the MUMC', Maastricht Sport and the Geusseltbad for providing the training and testing facilities. The study was financially supported by the Netherlands Organisation for Scientific Research (NWO); grant number 022.003.036. None of these organisations played a role during any stage of the trial, i.e. execution, analyses and reporting. 


\section{REFERENCES}

1. Fransen M, McConnell S, Harmer AR, Van der Esch M, Simic M, Bennell KL. Exercise for osteoarthritis of the knee. Cochrane Database of Systematic Reviews. 2015;10.1002/14651858.CD004376.pub3.

2. Waller B, Ogonowska-Slodownik A, Vitor M, Lambeck J, Daly D, Kujala UM, et al. Effect of therapeutic aquatic exercise on symptoms and function associated with lower limb osteoarthritis: systematic review with meta-analysis. Physical Therapy. 2014;94:1383-95.

3. Mangione K, McCully K, Gloviak A, Lefebvre I, Hofmann M, Craik R. The effects of high-intensity and low-intensity cycle ergometry in older adults with knee osteoarthritis. Journals of Gerontology, Series A: Biological Sciences and Medical Sciences. 1999;54:M:184-90.

4. Salacinski A, Krohn K, Lewis S, Holland M, Ireland K, Marchetti G. The effects of group cycling on gait and pain-related disability in individuals with mild-to-moderate knee osteoarthritis: a randomized controlled trial. Journal of Orthopaedic and Sports Physical Therapy. 2012;42:985-95.

5. Rewald S, Mesters I, Emans PJ, Arts JJ, Lenssen AF, de Bie RA. Aquatic circuit training including aquacycling in patients with knee osteoarthritis: A feasibility study. Journal of Rehabilitation Medicine. 2015;10.2340/16501977-1937.

6. Rewald S, Mesters I, Lenssen AF, Bansi J, Lambeck J, de Bie RA, et al. Aquatic cycling-What do we know? A scoping review on head-out aquatic cycling. PloS One. 2017;12:e0177704.

7. Rewald S, Mesters I, Lenssen AF, Emans PJ, Wijnen W, de Bie RA. Effect of aqua-cycling on pain and physical functioning compared with usual care in patients with knee osteoarthritis: study protocol of a randomised controlled trial. BMC Musculoskeletal Disorders. 2016;17:88.

8. Perrot S, Rozenberg S, Moyse D, Legout V, Marty M. Comparison of daily, weekly or monthly pain assessments in hip and knee osteoarthritis. A 29-day prospective study. Joint, Bone, Spine: Revue du Rhumatisme. 2011;78:510-5.

9. Kellgren JH, Lawrence JS. Radiological assessment of osteo-arthrosis. Annals of the Rheumatic Diseases. 1957; 16:494-502.

10. Axford J, Butt A, Heron C, Hammond J, Morgan J, Alavi A, et al. Prevalence of anxiety and depression in osteoarthritis: use of the Hospital Anxiety and Depression Scale as a screening tool. Clinical Rheumatology. 2010;29:1277-83.

11. Hoogeboom TJ, de Bie RA, den Broeder AA, van den Ende CH. The Dutch Lower Extremity Functional Scale was highly reliable, valid and responsive in individuals with hip/knee osteoarthritis: a validation study. BMC Musculoskeletal Disorders. 2012;13:117.

12. Pham T, Van Der Heijde D, Lassere M, Altman RD, Anderson JJ, Bellamy N, et al. Outcome variables for osteoarthritis clinical trials: The OMERACT-OARSI set of responder criteria. Journal of Rheumatology. 2003;30:1648-54.

13. Wagenmakers R, van den Akker-Scheek I, Groothoff JW, Zijlstra W, Bulstra SK, Kootstra JW, et al. Reliability and validity of the short questionnaire to assess health-enhancing physical activity (SQUASH) in patients after total hip arthroplasty. BMC Musculoskeletal Disorders. 2008;9:141.

14. de Hollander EL, Zwart L, de Vries SI, Wendel-Vos W. The SQUASH was a more valid tool than the OBiN for categorizing adults according to the Dutch physical activity and the combined guideline. Journal of Clinical Epidemiology. 2012;65:73-81.

15. Ware JE, New England Medical Center H, Health I. SF-36 physical and mental health summary scales : a user's manual. Boston: Health Institute, New England Medical Center; 1994.

16. Swinkels-Meewisse EJ, Swinkels RA, Verbeek AL, Vlaeyen JW, Oostendorp RA. Psychometric properties of the Tampa Scale for kinesiophobia and the fear-avoidance beliefs questionnaire in acute low back pain. Manual Therapy. 2003;8:29-36.

17. Taal E, Riemsma RP, Brus HL, Seydel ER, Rasker JJ, Wiegman O. Group education for patients with rheumatoid arthritis. Patient Education and Counseling. 1993;20:177-87.

18. Butland RJ, Pang J, Gross ER, Woodcock AA, Geddes DM. Two-, six-, and 12-minute walking tests in respiratory disease. British Medical Journal (Clinical Research Ed). 1982;284:1607-8.

19. Pankoff BA, Overend TJ, Lucy SD, White KP. Reliability of the six-minute walk test in people with fibromyalgia. Arthritis Care and Research. 2000;13:291-5. 
20. Stratford PW, Kennedy DM, Woodhouse LJ. Performance measures provide assessments of pain and function in people with advanced osteoarthritis of the hip or knee. Physical Therapy. 2006;86:1489-96.

21. Freter SH, Fruchter N. Relationship between timed 'up and go' and gait time in an elderly orthopaedic rehabilitation population. Clinical Rehabilitation. 2000;14:96-101.

22. Carpenter MR, Carpenter RL, Peel J, Zukley LM, Angelopoulou KM, Fischer I, et al. The reliability of isokinetic and isometric leg strength measures among individuals with symptoms of mild osteoarthritis. Journal of Sports Medicine and Physical Fitness. 2006;46:585-9.

23. van Dijk GM, Veenhof C, Schellevis F, Hulsmans H, Bakker JP, Arwert H, et al. Comorbidity, limitations in activities and pain in patients with osteoarthritis of the hip or knee. BMC Musculoskeletal Disorders. 2008;9:95.

24. Roos EM, Lohmander LS. The Knee injury and Osteoarthritis Outcome Score (KOOS): from joint injury to osteoarthritis. Health and Quality of Life Outcomes. 2003;1:64.

25. Angst F, Aeschlimann A, Stucki G. Smallest detectable and minimal clinically important differences of rehabilitation intervention with their implications for required sample sizes using WOMAC and SF-36 quality of life measurement instruments in patients with osteoarthritis of the lower extremities. Arthritis and Rheumatism. 2001;45:384-91.

26. Hinman RS, Heywood SE, Day AR. Aquatic physical therapy for hip and knee osteoarthritis: results of a single-blind randomized controlled trial. Physical Therapy. 2007;87:32-43.

27. Bastick AN, Runhaar J, Belo JN, Bierma-Zeinstra SM. Prognostic factors for progression of clinical osteoarthritis of the knee: a systematic review of observational studies. Arthritis Research \& Therapy. 2015; doi: 10.1186/s13075-015-0670-x.

28. Verbeke G, Molenberghs G. Linear Mixed Models for Longitudinal Data: Springer-Verlag New York; 2000.

29. Peter WF, Jansen MJ, Hurkmans EJ, Bloo H, Dekker J, Dilling RG, et al. Physiotherapy in hip and knee osteoarthritis: development of a practice guideline concerning initial assessment, treatment and evaluation. Acta reumatológica portuguesa Sociedade Portuguesa de Reumatologia. 2011;36:268-81.

30. Bartels EM, Juhl CB, Christensen R, Hagen KB, Danneskiold-Samsoe B, Dagfinrud H, et al. Aquatic exercise for the treatment of knee and hip osteoarthritis. Cochrane Database Syst Rev. 2016;3:CD005523.

31. Becker BE. Aquatic therapy: scientific foundations and clinical rehabilitation applications. $P M \& R$ : the journal of injury, function, and rehabilitation. 2009;1:859-72.

32. Boidin M, Lapierre G, Paquette Tanir L, Nigam A, Juneau M, Guilbeault V, et al. Effect of aquatic interval training with Mediterranean diet counseling in obese patients: results of a preliminary study. Annals of Physical and Rehabilitation Medicine. 2015;58:269-75.

33. Bansi J, Bloch W, Gamper U, Riedel S, Kesselring J. Endurance training in MS: short-term immune responses and their relation to cardiorespiratory fitness, health-related quality of life, and fatigue. Journal of Neurology. 2013;260:2993-3001.

34. Bartholdy C, Juhl C, Christensen R, Lund H, Zhang W, Henriksen M. The role of muscle strengthening in exercise therapy for knee osteoarthritis: A systematic review and meta-regression analysis of randomized trials. Seminars in Arthritis and Rheumatism. 2017;10.1016/j.semarthrit.2017.03.007.

35. Mills K, Hunt MA, Leigh R, Ferber R. A systematic review and meta-analysis of lower limb neuromuscular alterations associated with knee osteoarthritis during level walking. Clinical Biomechanics (Bristol, Avon). 2013;28:713-24.

36. Breugem SJ, Haverkamp D, Sierevelt IN, Stibbe AB, Blankevoort L, van Dijk CN. The important predictors of cycling use in three groups of knee patients. Disability and Rehabilitation. 2011;33:1925-9.

37. Johnston TE. Biomechanical considerations for cycling interventions in rehabilitation. Physical Therapy. 2007; 87:1243-52.

38. Liebs TR, Herzberg W, Ruther W, Haasters J, Russlies M, Hassenpflug J. Ergometer cycling after hip or knee replacement surgery: a randomized controlled trial. The Journal of Bone and Joint Surgery American volume. 2010;92:814-22.

39. Zambon S, Siviero P, Denkinger M, Limongi F, Victoria Castell M, van der Pas S, et al. Role of Osteoarthritis, Comorbidity, and Pain in Determining Functional Limitations in Older Populations: European Project on Osteoarthritis. Arthritis Care \& Research. 2016;68:801-10. 
40. Terwee CB, van der Slikke RM, van Lummel RC, Benink RJ, Meijers WG, de Vet HC. Self-reported physical functioning was more influenced by pain than performance-based physical functioning in kneeosteoarthritis patients. Journal of Clinical Epidemiology. 2006;59:724-31.

41. Stratford PW, Kennedy DM. Performance measures were necessary to obtain a complete picture of osteoarthritic patients. Journal of Clinical Epidemiology. 2006;59:160-7.

42. Waller B, Munukka M, Rantalainen T, Lammentausta E, Nieminen MT, Kiviranta I, et al. Effects of high intensity resistance aquatic training on body composition and walking speed in women with mild knee osteoarthritis: a 4-month RCT with 12-month follow-up. Osteoarthritis and Cartilage. 2017;25:1238-46.

43. Fransen M, McConnell S, Harmer AR, Van der Esch M, Simic M, Bennell KL. Exercise for osteoarthritis of the knee: a Cochrane systematic review. British Journal of Sports Medicine. 2015;49:1554-7.

44. Cunningham JA, Kypri K, McCambridge J. Exploratory randomized controlled trial evaluating the impact of a waiting list control design. BMC Medical Research Methodology. 2013;13:150.

45. Pisters MF VC, van Dijk GM, Heymans MW, Twisk JW, Dekker J. The course of limitations in activities over 5 years in patients with knee and hip osteoarthritis with moderate functional limitations: risk factors for future functional decline. Osteoarthritis and Cartilage. 2012;20:503-10. 


\section{APPENDIX 5.1}

\section{Statistical analysis}

Outcomes were analysed with a two-level mixed linear regression model to capture the nesting of repeated measures within patients. Nesting of patients within aquatic cycling groups was not feasible, because we used a dynamic group formation approach for the aquatic cycling training that changed the composition of these groups frequently. Mixed linear regression models consist of a random part (variances of, and correlations between, the repeated outcome measures) and a fixed part (regression weights, effects of predictors on outcome mean per time point).

\section{Specification of the random part}

For the random part, we assumed an unstructured covariance matrix, which is quite flexible and still parsimonious for the present small number of repeated measures (baseline, post-test, follow-up).

\section{Specification of the fixed part}

The fixed (predictor) model part consisted of time (using dummy coding for post-test and follow-up, with baseline as reference time point), treatment group ( $A C=1, U C=0)$, and patient characteristics as predictors. The latter were age (in years), sex (female $=1$, male=0), BMI, quadriceps strength (in Newtonmeter (NM), corrected for body weight), tibiofemoral and patellofemoral Kellgren-Lawrence score and comorbidity count. ${ }^{27}$ Furthermore, to explore the effects of physical therapy, resp. the effect of being informed about the free aquatic cycling programme after trial participation in the UC arm (14 UC patients did not receive the information about the free post-intervention exercise opportunity before randomisation), the variables 'received PT' resp. 'received info' were included as covariates as well. Both covariates were coded such that they were uncorrelated with treatment group. Thus, the group effect in the mixed model still represented the contrast between the total AC arm and the total UC arm, and not

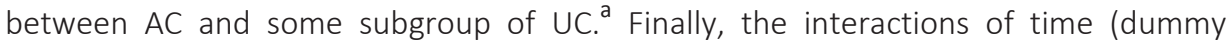
indicators, with baseline as reference category) with treatment group and with the covariates "received PT" and "received info" completed the fixed part of the model. The interaction of group with time represents the group difference in change from baseline to post-intervention and follow-up, and is thus the effect of interest in this RCT. The above-mentioned covariates and interactions were used in all mixed

\footnotetext{
${ }^{a}$ More specifically, both covariates were coded as zero for all patients in the AC arm, and coded as - $p$ for patients in the UC arm not getting PT resp. info, and coded as (1-p) for patients in the UC arm getting PT resp. info. Here, p was the proportion patients in the UC arm getting PT resp. info. In this way, the average covariate value was zero in the UC arm, just like in the AC arm.
} 
regression analyses, except that in the analysis for strength, BMI was not included, because the outcome strength was already corrected for body weight.

\section{Model reduction and likelihood ratio model testing}

For each outcome, the mixed model was simplified stepwise by first dropping covariate ("received PT" resp. "received info") by time interactions if not significant (using $\alpha=0.10$ two-tailed for deleting terms, but not for drawing firm conclusions) and then dropping non-significant covariates likewise (if they were not involved in any interaction). If the treatment group difference (group*time interactions) remained stable from post-test to follow-up, the final model was further reduced by replacing the group*posttest and group*followup terms with a single term group* postfollow (coded 0 for baseline and 1 for each other time point) to get a single and more precise estimate of the effect of aquatic cycling for both time points. Successive models were estimated with the maximum likelihood (ML) method to allow likelihood ratio testing of model reductions, but the final model for each outcome was re-run with the restricted maximum likelihood (REML) method to obtain unbiased standard errors for the regression weights and in particular for the group by time effect of interest. ${ }^{28}$ Each outcome was checked for normality and outliers by residual plots per time point.

\section{Calculation of the effect size}

The effect size (ES) of aquatic cycling was computed from the final model by dividing the regression weight of the group*posttest (resp. group*followup, resp. group*postfollow) interaction by the square root of the estimated outcome variance at post-test (resp. at follow-up, resp. averaged across both time points). 


\section{APPENDIX 5.2}

\section{Results}

\section{Dropout before baseline assessment}

As stated earlier, nine dropouts in the UC arm occurred before baseline assessment. To check possible bias in the effect analyses arising from this dropout, we conducted a logistic regression analysis within the UC group, with dropout before baseline (1=yes, $0=$ no) as outcome, and as predictors all measured baseline variables (sex, age, BMI, Kellgren/Lawrence score the tibiofemoral and patellofemoral joint, count of comorbidities, HADS anxiety and depression score, and having received the information about the free twelve-week aqua cycling programme in a local swimming pool after participation in the study). Stepwise model reduction left only this last variable as a predictor of dropout ( $p=0.003)$. More specifically, the opportunity for the control group to participate in a free twelve-week aqua cycling programme arose after the project had started and so the first 14 participants in the control group did not receive this information. Of these 14 , seven participants declined participation before the baseline assessment, against only two dropouts among the 42 participants who did receive the information. In the absence of a relation of dropout before baseline with any other participant characteristics, and given that our effect analyses adjusted for all measured participant characteristics anyway, the potential impact of this dropout on the effect analysis appears ignorable (note that participants dropping out after baseline were always included into the effect analyses).

\section{Model reduction of the primary outcomes}

A likelihood ratio test confirmed the stability of the group difference from post-test to follow-up (Knee pain: chi-square $=0.031, \mathrm{df}=1, \mathrm{p}=0.86$, Physical Functioning: chisquare $=0.026, d f=1, p=0.87$ ). Appendix 5.3 shows the final models (Model $1 A+1 B$ ) and its reduction (Model $2 \mathrm{~A}+2 \mathrm{~B}$ ) assuming stability of the group difference.

\section{Model reduction of the secondary outcomes}

The reduction of the group by time interaction was not supported for the KOOS subscale quality of life (chi-square=3.99, $d f=1, p=0.0455$ ). That might be a type I error due to multiple testing, but the effect at post-test appeared to be twice as large as at follow-up. Therefore, the effect of aquatic cycling on this outcome is reported per time point (Table 5.3). 


\section{Outliers}

All outcomes were tested for outliers. Although some outcomes showed one or a few outliers, repeating the analysis without the outlier(s) hardly affect the results (significant effects remained significant and non-significant results remained nonsignificant, effect estimates changed very little). 


\section{APPENDIX 5.3}

\section{Model reduction of the primary outcomes}

\begin{tabular}{|c|c|c|c|c|}
\hline \multicolumn{5}{|c|}{ KOOS PAIN } \\
\hline Fixed effects $(n=01)$ & Estimate & SE & $\mathrm{p}$-value & $95 \% \mathrm{Cl}$ \\
\hline \multicolumn{5}{|l|}{ MODEL 1A } \\
\hline Intercept & 56.01 & 12.91 & 0.000 & $30.39,81.64$ \\
\hline Group & -0.43 & 2.89 & 0.882 & $-6.17, \quad 5.31$ \\
\hline Age & 0.25 & 0.15 & 0.089 & $-0.04, \quad 0.55$ \\
\hline BMI & -0.47 & 0.23 & 0.046 & $-0.93,-0.01$ \\
\hline Post-test & -1.82 & 2.62 & 0.489 & $-7.02, \quad 3.38$ \\
\hline Follow-up & -0.71 & 2.99 & 0.812 & $-6.65, \quad 5.22$ \\
\hline Group*Post-test & 8.40 & 3.54 & 0.020 & $1.37,15.43$ \\
\hline Group*Follow-up & 7.74 & 4.05 & 0.059 & $-0.30,15.77$ \\
\hline \multicolumn{5}{|l|}{ MODEL 2A } \\
\hline Intercept & 56.02 & 12.91 & 0.000 & $30.39,81.64$ \\
\hline Group & -0.46 & 2.89 & 0.874 & $-6.19, \quad 5.27$ \\
\hline Age & 0.25 & 0.15 & 0.088 & $-0.04, \quad 0.55$ \\
\hline BMI & -0.47 & 0.23 & 0.046 & $-0.93,-0.01$ \\
\hline Post-test & -1.69 & 2.51 & 0.504 & $-6.67, \quad 3.30$ \\
\hline Follow-up & -0.94 & 2.69 & 0.727 & $-6.28, \quad 4.39$ \\
\hline Group * Postfollow & 8.16 & 3.27 & 0.014 & $1.67,14.64$ \\
\hline \multicolumn{5}{|c|}{ KOOS PHYSICAL FUNCTIONING } \\
\hline Fixed effects $(n=98)$ & Estimate & SE & p-value & $95 \% \mathrm{Cl}$ \\
\hline \multicolumn{5}{|l|}{ MODEL 1B } \\
\hline Intercept & 80.08 & 9.57 & 0.000 & $61.09,99.08$ \\
\hline Group & -3.51 & 3.41 & 0.307 & $-10.28, \quad 3.27$ \\
\hline BMI & -0.74 & 0.26 & 0.006 & $-1.26,-0.21$ \\
\hline Strength & 0.11 & 0.05 & 0.029 & $0.01, \quad 0.20$ \\
\hline Post-test & 0.15 & 2.53 & 0.953 & $-4.88,5.18$ \\
\hline Follow-up & -1.52 & 2.69 & 0.575 & $-6.87,3.84$ \\
\hline Group*Post-test & 6.80 & 3.40 & 0.043 & $0.24,13.71$ \\
\hline Group*Follow-up & 7.44 & 3.63 & 0.043 & $0.23,14.64$ \\
\hline \multicolumn{5}{|l|}{ MODEL 2B } \\
\hline Intercept & 80.04 & 9.57 & 0.000 & $61.05,99.02$ \\
\hline Group & -3.43 & 3.38 & 0.313 & $-10.13,3.28$ \\
\hline BMI & -0.74 & 0.26 & 0.006 & $-1.26,-0.21$ \\
\hline Strength & 0.11 & 0.05 & 0.029 & $0.01,0.20$ \\
\hline Post-test & -0.05 & 2.45 & 0.984 & $-4.81,4.91$ \\
\hline Follow-up & -1.37 & 2.52 & 0.588 & $-6.38,3.64$ \\
\hline Group * Postfollow & 7.16 & 3.19 & 0.027 & $0.83,13.49$ \\
\hline
\end{tabular}

$\mathrm{BMI}$, body mass index; $\mathrm{Cl}$, Confidence Interval; KOOS, Knee injury and Osteoarthritis Outcome Score; SE, standard error 


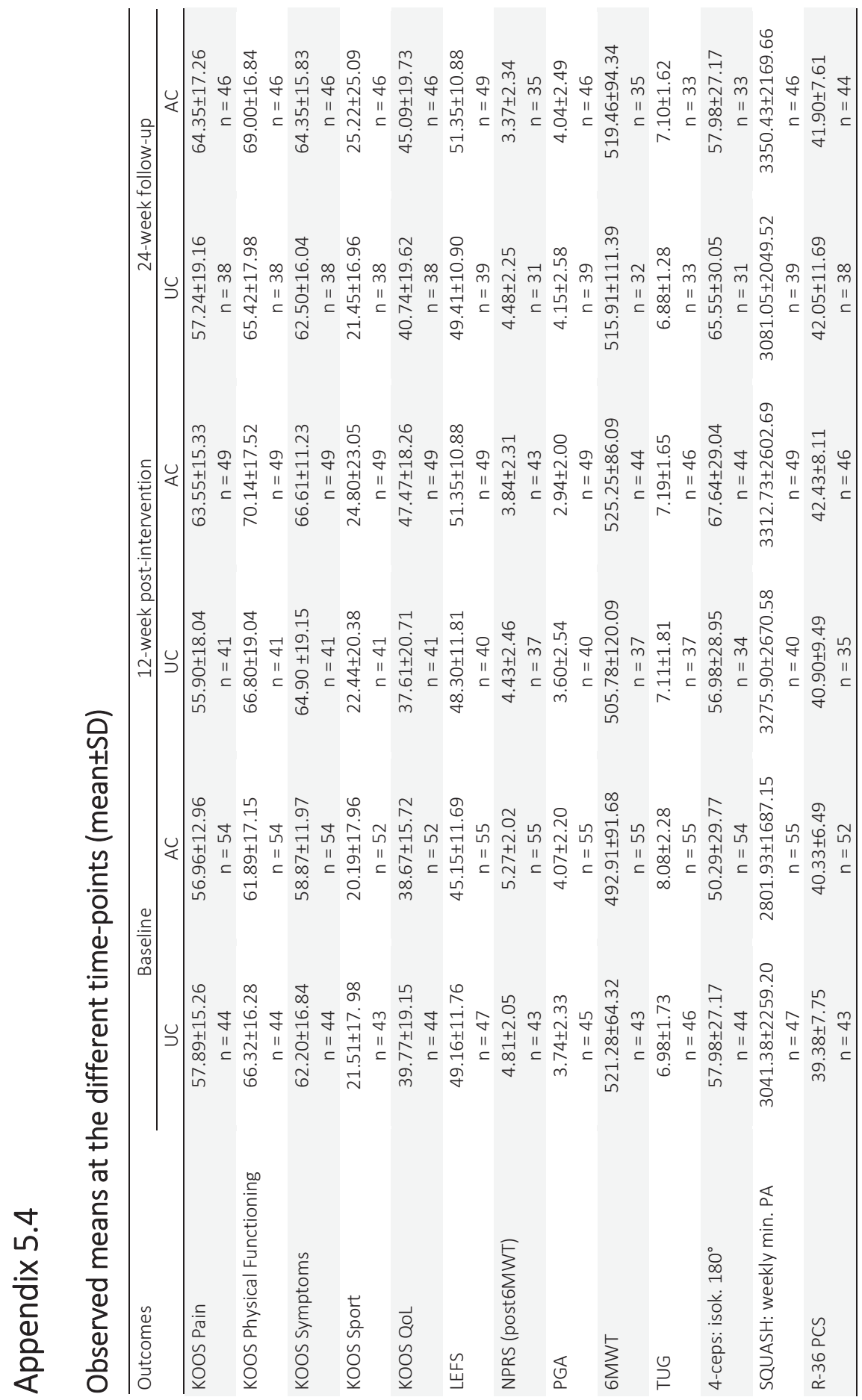




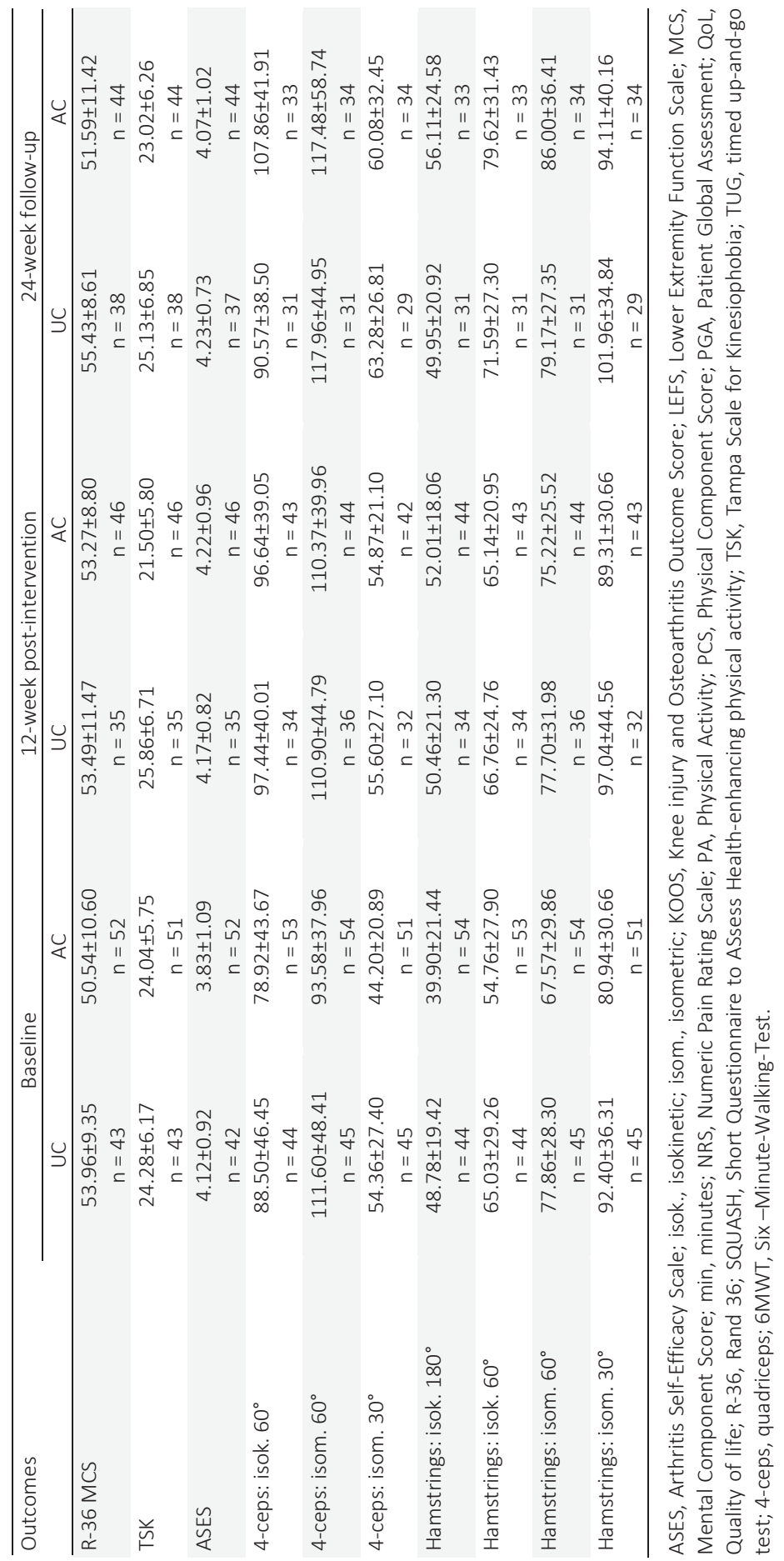




\section{APPENDIX 5.5}

\section{Results of the final mixed model analysis of the other secondary outcomes}

\begin{tabular}{|c|c|c|c|c|c|}
\hline Outcome & $\mathrm{N}$ & Estimate & SE & $p$-value & $95 \% \mathrm{Cl}$ \\
\hline SQUASH: min weekly PA & 99 & 431.422 & 355.00 & 0.228 & $-267.188,1139.032$ \\
\hline R-36 PCS & 97 & 0.721 & 1.40 & 0.609 & -2.070 \\
\hline R-36 MCS & 99 & 1.161 & 1.70 & 0.497 & -2.229 \\
\hline TSK & 100 & -3.835 & 1.20 & $0.002 *$ & $-6.225, \quad-1.446$ \\
\hline ASES & 97 & 0.267 & 0.18 & 0.145 & $-0.093, \quad 0.627$ \\
\hline 4-ceps: isokinetic $60^{\circ}$ & 100 & 10.231 & 6.19 & 0.103 & $-2.119, \quad 22.582$ \\
\hline 4-ceps: isometric $60^{\circ}$ & 99 & 14.938 & 7.04 & 0.037 & $0.913,28.963$ \\
\hline 4-ceps: isometric $30^{\circ}$ & 97 & 10.072 & 4.33 & 0.023 & $1.435,18.710$ \\
\hline Hamstrings: isokinetic $180^{\circ}$ & 99 & 8.573 & 3.30 & 0.011 & $2.000,15.150$ \\
\hline Hamstrings: isokinetic $60^{\circ}$ & 100 & 6.717 & 4.40 & 0.131 & $-2.050,15.483$ \\
\hline Hamstrings: isometric $60^{\circ}$ & 100 & 7.714 & 4.12 & 0.070 & $-0.637,16.065$ \\
\hline Hamstrings: isometric $30^{\circ}$ & 98 & 5.681 & 5.68 & 0.270 & $-4.497,15.858$ \\
\hline
\end{tabular}

ASES, Arthritis Self-Efficacy Scale; CI, Confidence Interval; MCS, Mental Component Score; PCS, Physical Component Score; QoL, Quality of life; R-36, Rand 36; SE, standard error; SQUASH, Short Questionnaire to ASsess Health-enhancing physical activity; TSK, Tampa Scale for Kinesiophobia; 4-ceps, quadriceps. *sig. $p=<0.0022$ (the alpha used for all secondary outcomes to adjust for multiple testing) 


\section{CHAPTER 6}

General discussion 

The aim of this dissertation was to develop and evaluate an aquatic cycling training programme for patients with mild to moderate knee osteoarthritis (OA). This general discussion presents an overview of the research preceding the development of an aquatic cycling training programme in addition to an evaluation of the intervention itself. Furthermore, methodological and practical considerations are discussed followed by a brief outline of implications for the future.

\section{MAIN FINDINGS}

In 2010, at the beginning of this project, research on understanding the effects of aquatic cycling exercises in both the clinical and non-clinical settings was scarce. Furthermore, neither primary nor secondary care institutions in the Maastricht area were familiar with aquatic cycling or possessed aquatic bikes. Nevertheless, a smallscale aquatic bike manufacturer expressed interest in collaborating with Maastricht University. At the start of the collaboration, the manufacturer already had a single aquatic bike prototype designed with the intent to be used in patient populations.

Accordingly, the initial step was to design and conduct a feasibility study using the aquatic bike prototype during aquatic circuit training in patients with knee OA (Chapter 2). The training programme combined aquatic cycling with traditional aquatic exercises (e.g., gait training, shallow-water toning exercises, and flexibility exercises for the lower limb). Evaluation of the programme included use of traditional feasibility criteria such as: patient adherence and acceptance, possibility to progress in exercise level, occurrence of adverse events and operational aspects. ${ }^{1}$

The major findings from our study suggested: First, patients demonstrated an overall high attendance rate indicating acceptance of the programme, with attendance rates being consistent with other feasibility studies of aquatic training programmes for patients with knee OA. ${ }^{2,3}$ Second, focus group interviews suggested patient satisfaction with the variety and intensity of exercises. Participants also reported the pain relieving effects of the programme, which occurred immediately during the training sessions. Third, participants performed well with shallow water exercises and seated aquatic cycling. However, performing aquatic cycling in an out-of-the-saddle position was too demanding for most participants. This suggested that ten minutes of aquatic cycling once a week was probably too short to achieve progression to out-of-saddle movements. Lastly, participants expressed desire to cycle longer than ten minutes, but emphasized, that exercise variation was needed to prevent monotony, particularly during seated cycling.

We used the feedback and results from our feasibility study to develop a full aquatic cycling programme for patients with mild to moderate knee OA (Chapter 3). To prevent monotony, we combined arm exercises, leg exercises and out-of-saddle positions with 
continuous cycling in seated positions. However, we introduced out-of-saddle exercises only after a minimum of two weeks of training, and we kept the total time of cycling in standing positions low to prevent overload of knee joints. Due to a lack of prior research on the effects of full aquatic cycling programmes, we based exercise parameters such as duration, frequency and exercise intensity on exercise guidelines for OA. ${ }^{4-6}$ Furthermore, we relied on evidence taken from knee loading during landbased cycling and spinning to design the composition and set-up of different exercises. ${ }^{7-10}$ Chapter 3 outlines our training programme as well as the design of a single-blinded, two-arm, randomised controlled trial to compare the effects of the 12 -week aquatic cycling programme with usual care. The primary outcomes included self-reported knee pain and physical functioning because these are the most prominent symptoms of knee OA. In accordance with recommendations from the Dutch Physical Therapy Guideline for OA and international research societies, secondary outcomes included performance tests of physical functioning, muscle strength, quality of life and patient global assessment of disease status. ${ }^{5,11-14}$ We also included measurements of self-report physical activity, fear of movement and selfefficacy for physical functioning. Data measurement time-points included baseline, at the end of the 12-week intervention period and a follow-up at 24-weeks post-baseline. Participants in both groups also filled out diaries during the intervention phase in order to provide information on compliance to usual care (e.g. medication use, utilisation and content of physical therapy, level of physical activity) while also capturing the development of OA impairments throughout the intervention. However, the analysis of the diary data is not part of this dissertation.

During the developmental phase of the interventions included in this dissertation (Chapter 2 and 3) we performed systematic searches of online scientific databases to find evidence on the effects aquatic cycling exercise. Chapter 4 includes a scoping review of scientific data on the topic of aquatic cycling. We identified 63 publications with most research focusing on the comparison between aquatic cycling and land cycling, or studies investigated the effects of different exercise conditions (e.g. water temperature) during aquatic cycling. Only six studies evaluated the effects of aquatic cycling exercise interventions. Results from our review confirmed our initial hypothesis that there is a dearth of scientific clinical-based peer-reviewed research that has investigated the effects of aquatic cycling exercises, including out-of-saddle positions and upper body exercises.

Chapter 5 describes the results of our randomised controlled trial, which to the best of our knowledge is the first study to evaluate the effects of a group-based aquatic cycling training programme for patients with mild to moderate knee OA. Our research study is also the first to evaluate the effects of group-based aquatic cycling exercise accompanied by a medium-term follow-up period. According to recent systematic reviews, ${ }^{15-17}$ only three aquatic exercise studies to date have included a follow-up period. ${ }^{18-20}$ Accordingly, the results of our randomised controlled trial suggested that a 
12-week aquatic cycling exercise programme is effective for improving self-reported knee pain and physical functioning compared with usual care. Observations from our study also suggested that our programme resulted in an improvement in performancebased physical functioning, a decrease in fear of movement and an increase in diseaserelated quality of life exclusive to the aquatic cycling group. Interestingly, participants maintained favourable effects of the aquatic cycling programme (except for quality of life) at three months following cessation of the intervention.

\section{METHODOLOGICAL CONSIDERATIONS}

The following section highlights four aspects important to the development and evaluation of the aquatic cycling training programme, including: recruitment and dropout, comparison of aquatic cycling with usual care, usual care compliance and the efficacy of the aquatic cycling exercise programme.

\section{Recruitment and dropout}

When interpreting results from our RCT it is noteworthy that the final number of patients $(n=102$ ) included in this study was lower than the calculated a priori sample size $(n=168)$. It is possible that our recruitment setting and the wait-list control design impeded recruitment and facilitated dropout.

\section{Recruitment}

General practitioners in the Netherlands typically manage patients using a conservative treatment approach for OA, largely because there are only few documented reasons requiring a referral to an orthopaedic surgeon. For example, one instance is if a patient responds unsatisfactory to conservative treatment or if the diagnosis is unclear. ${ }^{21}$ However, a majority of patients are still referred to an orthopaedic specialist resulting in unnecessary hospital visits. ${ }^{21}$

Therefore, to address this problem, the $\mathrm{MUMC}^{+}$set up a two-visit specialist care intervention programme (i.e. initial and evaluation consults), coordinated by an orthopaedic nurse practitioner, in 2011. The Early OA Outpatient Clinic supports patient self-management for knee OA, but also provides guidance on available treatment options following a stepped care model. ${ }^{22,23}$ In the initial step, patients receive education and lifestyle advice. If additional care is needed, patients are then referred to primary care such as physical therapy or weight loss therapy (step 2). Patients may also have the option of receiving an injection with hyaluronic acid or pain medication, receive other minor interventions or they may be referred to an orthopaedic surgeon (step 3). 
Participants were recruited from the Early OA Outpatient Clinic of the MUMC+. Consistent with other aquatic exercise studies, ${ }^{18,24-26}$ our study population involved participants with an indication for conservative treatment (e.g. not listed for total knee surgery) including a referral for physical therapy (step 2), and no contra-indications for aquatic exercise. Advantages of using this recruitment setting and strategy were the availability of comprehensive diagnoses documentation, which included radiographs and patient education delivered by an experienced nurse practitioner.

The evaluation of the number of referred patients to the Early OA Outpatient Clinic showed that only a small fraction of the referred patients was eligible for participation in our trial. Approximately 250 patients contact the clinic per year, ${ }^{27}$ and from this pool of potential participants only $35 \%(n=88)$ demonstrate an indication for primary care physical therapy. ${ }^{27}$ From our feasibility study we knew that $50 \%$ of eligible patients would be willing to participate and this would result in a recruitment rate of 44 patients per year and a study duration of almost four years. These estimates were optimistic as nearly $41 \%$ of all patients receive an injection of hyaluronic acid of corticosteroid, which was an exclusion criterion for participation in our trial (if patients received an injection in the last three to six months). Unfortunately, we did not have access to these numbers when the design phase of this trial began. Therefore, we extended our recruitment duration from 1.5 to 2.5 years, which enabled us to recruit 102 participants. As shown above, this was the maximum number of patients that could have been recruited in this period. Due to funding restrictions, any further extension of the recruitment phase was not possible.

A possible alternative recruitment strategy would have been the involvement of general practitioners, since most patients with mild to moderate knee OA are treated in primary care. ${ }^{28}$ However, the patients that are referred to the Early Outpatient Clinic are likely to be different compared with those not referred. In many cases, patients demonstrating a sudden flare-up or those needing a medical evaluation for exclusion of other diagnoses are referred to the clinic by their general practitioner.

\section{Dropouts}

Although the actual dropout rate of $24 \%(n=27)$ was close to the expected percentage $(25 \%)$ some dropouts may have been preventable. For example, nine participants in the usual care dropped out before the baseline assessment and were lost for the analysis. Because an extra visit to the hospital needed to be scheduled for the baseline assessment, participants requested to be informed about their group allocation before the baseline assessment. Providing this information on the treatment allocation is a recommended strategy to improve recruitment for randomised controlled trials. ${ }^{29}$ Despite this, four participants declined because they were unsatisfied with being allocated to the control group. 
Most of the dropouts ( $n=12$ ) occurred following the baseline assessment. Similar to before, the main reason for dropout in the control group $(n=6)$ was disappointment about group allocation $(n=4)$. Therefore, in an attempt to minimise dropout we offered participants in the usual care group 12 weekly sessions of aquatic cycling after the last follow-up measurement at 24-weeks. However, due to organisational problems (e.g. timing of the opening of the new regional swimming pool) this action plan could not be delivered until four months following the initiation of recruitment. Prior to the updated plan for controls, individuals were offered a one-day walking clinic as compensation for participation. After we could offer the try-out sessions to the usual group only one participant in the usual care group withdrew from the trial because of disappointment with the group allocation.

Consistent with our study, others reporting research study participation satisfaction in cancer patients suggest that offering a shorter post-trial exercise programme is not able to adequately compensate for disappointment about usual care group allocation. ${ }^{30}$ In contrast, de Rooij et al. offered the full programme of 20 weeks tailored exercise therapy (i.e. for patients with knee OA) to usual care group participants following 32 weeks trial participation and this resulted only in a single dropout because of dissatisfaction with group allocation. ${ }^{31}$

\section{Aquatic Cycling compared to Usual Care}

The design of our RCT is consistent with other studies as reported in systematic reviews comparing aquatic therapy with a control group associated with no specific intervention such as usual care, education or social attention. ${ }^{15,16}$

In our study, the aquatic cycling programme was compared with usual care provided by the Early OA Outpatient Clinic. All eligible patients received education and individual lifestyle advice regarding $\mathrm{OA}$ and a referral for physical therapy from an orthopaedic nurse practitioner. Research shows that these specialist care visits are effective for improving self-reported pain, physical functioning and health related quality of life in patients with lower limb OA. ${ }^{22,32}$ These improvements are also accompanied by high patient satisfaction. ${ }^{22,27,32}$

Although we found no improvement in the usual care group, patient symptoms remained stable with no changes over time, despite the fact that only $32 \%$ of our participants in the usual care group consulted with a physical therapist. These results are in line with a longitudinal Dutch cohort study of patients with hip and knee OA receiving usual care (e.g. medication, physical therapy) from a hospital or rehabilitation centre. ${ }^{33}$ Unfortunately, underutilisation of physical therapy and other conservative treatment modalities for knee OA is common. ${ }^{32,34}$ The reasons for the low utilisation of physical therapy in our trial will be discussed in later sections.

The physical therapy provided to participants varied from manual therapy, education and home exercises, to supervised exercise therapy including neuromuscular, aerobic 
and/or strength exercises. The different types of exercise offered to our usual care group align with the general recommendation that exercise is effective for $\mathrm{OA}$, and that there is no evidence supporting the benefits of a certain type of exercise more than others. ${ }^{12,35}$ The individualised education and advice offered by the Early OA Outpatient Clinic in combination with the different physical therapy treatments are also consistent with the understanding that treatments should be tailored to the needs and preferences of the OA patient. ${ }^{35}$ Therefore, the selection of usual care as a comparison group seems adequate. ${ }^{36}$

The results from our study cannot be used to answer the question whether aquatic cycling is superior to land-based exercise, which is commonly applied in primary care physical therapy for knee OA. However, any comparison with land-based exercise is not likely to appropriate due to highly different training mediums. ${ }^{16}$

Nevertheless, our findings add to the body of evidence suggesting that exercise is effective for improving pain and physical functioning in patients with knee OA. 11,12,35,37 However, our study design may have increased the risk of a positive bias towards aquatic cycling because participants were aware they received a free treatment compared with the usual care who did not receive free exercise therapy during the active study period. ${ }^{16}$ But our study design was appropriate with respect to our outlined goals of testing the possible effects of aquatic cycling in patients with mild to moderate knee OA. ${ }^{36}$

\section{Usual care compliance}

Although stepped care models should theoretically reduce the underutilisation numbers of conservative treatment options, ${ }^{38} 68 \%$ of our participants in the control group did not consult a physical therapist. Even if the absolute reasons are unknown, we have several hypotheses that may account for our findings.

First, physical therapy for OA is currently not included in the basic health care package in the Netherlands, and even in upgraded packages physical therapy sessions are often limited. ${ }^{34,39}$ Financial costs are considered a barrier for exercise participation and adherence in patients with knee OA. ${ }^{34}$

Second, the effectiveness of an intervention plays an important role in the treatment choice of patients. Lack of knowledge on the benefits of exercise might detour patients from consulting with a physical therapist about the benefits of exercise. ${ }^{40}$ Despite this, our patients received information on the benefits of physical therapy and exercise during their consultation at the early outpatient clinic. This brief exposure to new information might not be strong enough to outweigh personal beliefs and experiences with exercise, which are strong predictors of exercise participation. ${ }^{41-43}$

Third, the opportunity to try aquatic cycling following study participation might have influenced the decision of participants in the control group on whether to consult a physical therapist or not. In order to participate in our trial, participants in the control 
group were not obliged to start with physical therapy. This aligns with recommendations to minimalize the influence of the study on usual care. ${ }^{44}$ Still, the wait-list aspect of our RCT design may have reduced participant motivation to consult with a physical therapist. ${ }^{45}$

Remarkably, out of all 32 patients who consulted with a physical therapist, only one participated in a group-based exercise programme according to the Dutch Physical Therapy Guideline for exercise programmes in OA. ${ }^{37}$ The other participants who consulted a physical therapist followed short-term (three to six sessions) individual trajectories. ${ }^{5,28,46}$ Previous research on attitudes and beliefs of physical therapists regarding exercise for knee $\mathrm{OA}$ in the United Kingdom demonstrated that four to five sessions were evaluated adequately enough to set-up an exercise programme. ${ }^{47}$ The physical therapists felt that patients needed to continue with the exercise programme on their own and take responsibility for their own health. ${ }^{47}$ In addition, access to more sessions of physical therapy might be limited from a patient perspective, including lack of financial resources ${ }^{39}$ or concerns that physical therapy might be needed again in the future (e.g. for OA or comorbidities). However, recent research suggests that twelve sessions of physical therapy are effective for creating an exercise routine, improve symptoms and reduce costs associated with more complex healthcare linked to worsening of symptoms. ${ }^{39}$ Therefore, the Dutch Ministry of Health and Welfare and Sport made the decision to add twelve physical therapy sessions for patients with hip and knee OA per year to the basic healthcare insurance as of January $1^{\text {st }} 2018 .{ }^{39}$

\section{Exercise programme}

Exercise treatments for knee OA should reduce pain and physical disability. Aquatic cycling may be effective for reducing these impairments. Participants in our studies demonstrated positive attitudes about the type of exercise and valued the immediate pain relief. However, while this instant relief phenomenon is frequently reported across different aquatic exercise studies, ${ }^{25,26,48-50}$ it is more likely that acute pain relief is attributable to the aquatic environment (e.g. joint-specific local physiological responses to buoyancy, hydrostatic pressure and warm water temperature $)^{51,52}$ as opposed to type of aquatic exercise.

Nevertheless, according to a recent Cochrane review, ${ }^{16}$ aquatic exercise contributes to small short-term improvements in pain and physical function, suggesting aquatic exercise adds to the beneficial effects of the aquatic environment.

\section{Effect of aquatic cycling on pain and physical functioning}

We observed a medium effect on pain and small-to-moderate improvements in both self-reported and performance-based physical functioning. The reasons for the reported improvements are likely multifaceted. 
First, the aquatic cycling programme can be categorised as single-exercise aerobic training. Regardless of whether the body position changed or the focus of the exercises shifted (e.g. to the upper body) during training, participants kept cycling for 45 minutes. A systematic review of Juhl et al. ${ }^{53}$ shows that exercise sessions focusing on one aim (e.g. aerobic capacity or muscle strength) are more efficacious than mixed sessions. Our results are in line with studies on the effects of land-based aerobic walking or cycling exercises for $\mathrm{OA}$, which showed a reduction of pain and physical limitations in OA patients. ${ }^{7,8,54-56}$ An advantage of aquatic cycling is that cycling can be combined with exercises of the upper body and different body positions, which ensures the involvement of the whole body during one session. According to Fransen et al., ${ }^{25}$ whole body movements might have a beneficial influence on self-reported physical functioning.

Second, our findings suggest that exercise intensity was appropriate in leading to improvements in functional aerobic capacity and muscle endurance. Following the training period, participants in the aquatic cycling group walked more meters during the six-minute walk test, a surrogate measure for cardiovascular function. ${ }^{57}$ These observations are consistent with research showing that aquatic cycling interventions improved cardiovascular fitness in patients with multiple sclerosis as well as healthy obese participants [58-60]. Furthermore, isokinetic quadriceps strength testing with high velocities, an indicator for muscular endurance, reached a borderline significance in favour of the aquatic cycling group and probably the real effect could not be detected due to insufficient power.

Third, we controlled exercise intensity to ensure a light to moderate intense training. We used the age-predicted equation (220-age=max. heart rate) to estimate maximum heart rate. We made no corrections for possible effects of immersion because previous research showed that heart rate on land and during aquatic cycling are comparable. ${ }^{61} \mathrm{~A}$ disadvantage of this equation is that it does not take into account individual variation and may underestimate maximum heart rate in older adults. ${ }^{62}$ Therefore, we also used the Borg scale and pedal speed. The Borg scale is commonly used to determine exercise intensity of aquatic exercises ${ }^{63,64}$ with evidence suggesting the BORG scale is also useful for the regulation of exercise intensity during aquatic treadmill exercise ${ }^{65}$ and aquatic cycling training. ${ }^{66,67}$ Since buoyancy might assist upward movements in water (e.g. during cycling when the pedal is pulled upwards during a cycle) control of exercise intensity is crucial to ensure that water resistance offsets buoyancy. ${ }^{48}$ Therefore, we aimed to keep participants at a pedal speed of $60 \mathrm{rpm}$ during seated cycling, which was guided and controlled by counting the frequencies and simulating pedal pace with rhythmic commands. This frequency was commensurate with a "somewhat hard" intensity $(13,6$ to 20 Borg scale) and a heart rate of $50 \%$ of maximum, which is consistent with the recommendations for exercise intensity in knee OA. ${ }^{4,37}$ 
Fourth, improvements in physical functioning in our study might be explained by the fact that (out-of saddle) cycling requires a muscular activation and coordination similar to land-based walking and sit-to-stand activities. ${ }^{7,8,68-70}$ Moreover, the aquatic environment might have led to improvements in neuromuscular function of the knee joint, which has been observed to lead to less symptoms of knee OA. ${ }^{71,72}$ Throughout training sessions participants were repeatedly reminded to keep the knees aligned. However, water turbulence and pressure presented an extra challenge in the ability to keep the alignement, and therefore this might have enhanced the training effect.

\section{Effect of aquatic cycling on quality of life and fear of movement}

In addition to improvements in pain and physical functioning, participants in the aquatic cycling group also reported an increase in quality of life and less fear of movement. We found a short-term medium effect size $(E S=0.71)$ for quality of life. A Cochrane Review on aquatic exercise in hip and knee OA ${ }^{16}$ found an effect size of 0.25 for quality of life. However, the Cochrane Review took general and disease-specific quality of life questionnaires into account, while we only found an effect for diseasespecific quality of life. Disease-specific tools are more responsive and can detect subtle effects on quality of life. ${ }^{73}$

The pain relieving effect of the aquatic environment might explain the reduction in fear of movement. Patients are suggested to experience less pain with exercise in water, and this may have influenced participant perception of physical capabilities. ${ }^{74,75}$ Research on the effects of aquatic treadmill exercise also showed that the aquatic environment might serve as a supporting factor in the ability to exercise at a certain level of intensity without an increase in pain. ${ }^{49}$ This is in line with the experience of our participants, who perceived aquatic cycling more demanding than on land, but while at the same time exercise in water appeared less painful than on land.

\section{Medium-term effects of aquatic cycling}

The effects on pain, physical functioning and fear of movement were maintained until the follow-up measurement period. While interpreting our results, the study setting and supervision should be taken into account since both may have influenced adherence and the lasting effects observed. ${ }^{76}$

According to Dobson et al., ${ }^{76}$ the environmental context influences participation and adherence. The intervention programme was free of cost, conducted in a small hospital therapy pool with individual shower and changing facilities and the location was easily reachable either by bus or car. The impact of these factors became clear since only one participant in the intervention group continued regularly with aquatic cycling in the public swimming pool. Other participants from the intervention group did not continue with the sessions in the public swimming pool or stopped after a few sessions. Reported reasons for discontinuing with aquatic cycling were costs ( $7 €$ per sessions), 
location (e.g. difficult to reach by bus), colder water temperature and the larger group size of approximately 10-15 participants. Another explanation for not continuing with aquatic cycling may have been that experienced benefits did not outweigh the increased time and monetary investment related with the sessions in the public swimming pool. On the other hand the maintained improved functioning may have been sufficient to do daily activities so the additional training effort might not be considered as needed at that time point.

With regard to study supervision, physical therapists educated patients on the benefits of exercise and encouraged patients during exercise. Guidelines emphasize that education is an important element in the persistent management of OA with both landbased and aquatic exercise studies demonstrating favourable effects of including patient education. ${ }^{19,31,56}$ Moreover, the training set-up (e.g. participants were sitting stable on bikes close to the edge of the pool, which facilitated easy communication) enabled the supervising physical therapist to educate participants during training. This education might have altered participants perception of their physical ability and, in combination with improvements in functional capacity (e.g. progression in six minute walk test), participants may have perceived less restrictions during activities of daily living. Finally, this might have resulted in an increased physical activity during activities of daily living even after cessation of our programme, which we can only hypothesize at this time, could have contributed to the maintained effects observed at the follow-up period.

\section{PRACTICAL CONSIDERATIONS}

There are practical considerations that accompany the question of whether investment in aquatic bikes in health care settings or public swimming pools is worthwhile.

\section{Aquatic cycling - a trendy sports activity?}

Several indicators suggest that aquatic cycling is a lasting trendy niche within the field of aquatic fitness. First, closely following the beginning of the $21^{\text {th }}$ century there has been the development of many new sport- and fitness concepts and activities. Sport has developed into a lifestyle and is present in pop cultures as (social) media, music, fashion and marketing. ${ }^{77}$ Often times these 'new' sports are a mix of already existing sports. For example, "taebo" combines dancing, boxing and aerobics. ${ }^{77}$ Aquatic cycling is also a 'sampling' sport and exclusive aquatic cycling centres in New York, France and the Netherlands offer aquatic cycling training in a trendy environment to meet the aesthetic dimension that is nowadays often related to sports. ${ }^{77}$ To meet the current plurality of lifestyles the aquatic cycling sessions offered in these centres are further specialised by combining aquatic cycling with yoga or provide special classes for men. 
Second, due to the increasing use of wearables and technology in sports, people want to exercise smarter and quantify their achievements. According to Etkin, ${ }^{78}$ "Over onein-five U.S. adults use some form of personal health tracking device....and an estimated 485 million wearable computing devices will be in the market by 2018.". The new generation of aquatic bikes comes with displays that enables participants to choose an exercise programme, receive information on duration, speed and calorie expenditure and provides the opportunity to watch television or listen to music during training.

Third, aquatic cycling has now been available to consumers on the open market for several years. According to Lambrecht and Stamm, ${ }^{79}$ it is likely that after five years a respective trend in sport loses its character of being a new activity and then becomes an established 'normal sport. Thus, it is likely that aquatic cycling has lasting power in the fitness market.

\section{Aquatic cycling - advantages and disadvantages}

Aquatic cycling provides several advantages over traditional (aquatic) exercise for knee OA. First, the movement is very controlled and easy to learn. Cheating is not possible because participants must overcome water resistance with every move and this requires self-powered cycling. With traditional water exercise moving the target limb with less tension or speed can easily decrease the intensity of an exercise. Second, individuals with knee OA often experience discomfort at other body sites. Therefore, land-based cycling may be uncomfortable (e.g. due to lower back pain or wrist pain)., 80 As such, with aquatic cycling, the lower extremities and lower back are immersed in warm water resulting in a relief of joint loading. Therefore, aquatic cycling is a promising exercise alternative for people with knee OA. Third, aquatic cycling can be extended to a whole body workout by involving the arms and upper body. Fourth, due to the stationary character of training, the supervising trainer can easily communicate with participants and readily assess the performance of each individual. Moreover, participants sit stable on the bike and are immersed in water to chest level, which could be a psychological advantage for individuals with poor swimming skills and/or embarrassment related to high body weight. Obese individuals are often times too buoyant in traditional aquatic exercise classes, whereas sitting on the aquatic bike prevents this problem. Use of apparel such as bike shorts and t-shirts in order to lessen exposure of body regions is acceptable during aquatic cycling.

In contrast, the stable and stationary character of aquatic cycling that prevents participants from floating also limits variation in exercise. Furthermore, aquatic bikes are also costly, take up storage space and the transfer from the deck to the water takes extra time if patients are not able to place bikes in the pool themselves. Therefore, with respect to operational aspects, our experience suggested that a swimming pool with an adjustable floor might be preferable not only for setting up bikes, but also for adjusting water depth according to participant body height. ${ }^{2}$ With traditional shallow- 
water aquatic exercise equipment is not necessarily needed to achieve the intended training goals and exercise intensities. ${ }^{81,82}$

\section{Aquatic cycling for patients with knee OA - between therapy and lifestyle intervention}

The results of our trial suggest that aquatic cycling can be used for primary care physical therapy. Since health guidelines recommend an individualised treatment strategies that meet the needs of a heterogeneous population of OA patients, ${ }^{12,35,37}$ aquatic cycling is a feasible option for those needing to improve cardiovascular fitness, muscular endurance and/or neuromuscular coordination.

Nevertheless, the availability of a pool and aquatic bikes in a primary care physical therapy setting is not currently an option that is readily offered. Thus, aquatic cycling in the current format is more likely to be effective as a community-based intervention than a treatment option in primary care settings. Consequently, the question remains as to whether our programme can be translated to a community-based aquatic cycling programme.

Research suggests that community-based aquatic exercise programmes increase quality of life ${ }^{83-87}$ and physical function. ${ }^{84,87}$ These programmes are commonly open to a broader target population (e.g. hip and knee OA) and supervised by sport and lifestyle professionals. The latter provides a pragmatic alternative to the delivery of interventions by health professionals, such as physical therapists. However, to ensure safe and beneficial exercise participation it is important that fitness professionals are educated with regard to musculoskeletal pathology. ${ }^{76}$ This dissertation provides insight into different training set-ups for patient populations (chapter 2-4), and based on these findings a well-educated aquatic fitness professional should be able to adjust training sessions to meet the needs of a participant with knee OA. By contrast, patients need to be able to participate in community-based exercise classes. For example, patients with restrictions in joint functioning and daily activities should consult a physical therapist first. $^{37}$ For patients that do not exercise regularly, but who are willing to and able to start an exercise programme, physical therapists can provide guidance on how to design an exercise routine while also providing advice to participants in making the transition to community-based exercise programmes. ${ }^{37}$

\section{IMPLICATIONS FOR FUTURE RESEARCH}

This final section outlines ideas for future research with regard to aquatic cycling. Further research should support three important goals of (aquatic) exercise research in $\mathrm{OA}$ : 1) optimising the use of aquatic exercise therapy, 2) assessing the (long-term) effectiveness of (aquatic) exercise on symptoms and structural changes of $\mathrm{OA}$, and 
3) improving post-intervention maintenance of an exercise routine or lifestyle physical activity. ${ }^{15,16,88}$

The use and potential benefits of aquatic cycling in a therapeutic context need further research. Our findings suggest that aquatic cycling may be used as therapeutic exercise for patients with mild to moderate knee OA. Based on high patient acceptance, it is likely that aquatic cycling might also be an exercise possibility for patients with more severe knee OA. Furthermore, aquatic cycling might be a valuable option for postsurgical treatment. Previous research indicates that aquatic cycling might be useful during rehabilitation following total knee surgery ${ }^{89}$ or anterior cruciate ligament reconstruction. ${ }^{90}$ Another patient group that might benefit from aquatic cycling are patients with hip OA since land-based cycling has been deemed a suitable type of exercise. ${ }^{91}$ To the best of our knowledge, there is no evidence available on the effects of aquatic cycling in patients with hip OA.

With regard to the long-term effectiveness of aquatic cycling, future studies should incorporate longer follow-up periods of six months and 12-months post-baseline. In addition, the knowledge regarding the effects of aquatic cycling should be extended. For example, it would be interesting to find out whether aquatic cycling could be used to improve neuromuscular control in patients with knee OA. The turbulence of water provides a stimulating environment for neuromuscular training, and therefore proper alignment of the lower limbs can be trained in a functional manner. Additionally, research on the effect of exercise on cartilage health and serum biomarkers is still in its infancy. ${ }^{92}$ Research in humans and rats suggests that tibiofemoral cartilage might be responsive to aquatic training, ${ }^{81,93}$ but further research is required to better understand the exercise-induced responses of cartilage and its clinical relevance.

Likewise, muscle strength is an important contributor to the improvement of knee pain and physical function, ${ }^{94,95}$ but whether aerobic cycling interventions can achieve increases in muscle strength remains unclear. ${ }^{7,8,55,96}$ Therefore, it would be interesting to investigate the effects on muscle strength of an aquatic cycling programme that is complimented with resistance training. Another valuable extension of the aquatic cycling programme might be the addition of dietary therapy ${ }^{21}$ since obesity might influence progression of $\mathrm{OA} .^{97}$

To improve our understanding of patient responsiveness to aquatic exercise, future studies need to better describe the study population (e.g. age, sex, BMI, disease status and duration, diagnostic criteria) and intervention (e.g. goal, intensity, duration and frequency). ${ }^{16}$ For aquatic cycling studies, the latter should include information on type of aquatic bike, immersion depth, water temperature, rpm, pedal resistance and external power output. External power output is a possibility to control exercise intensity by the work that is generated, which is usually expressed in watt with landbased cycling. Due to the many factors influencing the power output in the aquatic environment we were not able to quantify and control the power output. Recently, a 
simple equation was developed to estimate the external power output in aquatic cycling. ${ }^{98}$

In order to increase accessibility and support long-term adherence to exercise, research on the implementation of aquatic cycling as a community-based intervention for patients with OA seems indicated. Future research should establish criteria that ensure a safe transition to community-based aquatic cycling interventions. For example, patients and aquatic cycling instructors should be properly educated to prevent overload of the symptomatic joints during community-based group classes.

Another area of concern should be the cost-effectiveness of community-based aquatic cycling classes. Aquatic therapy, particularly when delivered one-to-one via a physical therapist, is associated with higher costs than land-based exercise therapy. ${ }^{100}$ However, community-based programmes might be cost-effective in terms of health care and societal costs. ${ }^{20,101}$

Finally, lack of reliable care data and/or subsequent overly optimistic recruitment projections delayed recruitment of participants in many trials including our own. ${ }^{99}$ To ensure that future studies have sufficient power we recommend evaluating the recruitment strategy during the design phase of a future study. 


\section{REFERENCES}

1. Bowen DJ, Kreuter M, Spring B, Cofta-Woerpel L, Linnan L, Weiner D, et al. How we design feasibility studies. American Journal of Preventive Medicine. 2009;36:452-7.

2. Segal NA, Wallace R. Tolerance of an aquatic power training program by older adults with symptomatic knee osteoarthritis. Arthritis. 2012;2012:895495.

3. Lau MC, Lam JK, Siu E, Fung CS, Li KT, Lam MW. Physiotherapist-designed aquatic exercise programme for community-dwelling elders with osteoarthritis of the knee: a Hong Kong pilot study. Hong Kong Medical Journal Xianggang Yi Xue Za Zhi. 2014;20:16-23.

4. Exercise prescription for older adults with osteoarthritis pain: consensus practice recommendations. A supplement to the AGS Clinical Practice Guidelines on the management of chronic pain in older adults. Journal of the American Geriatrics Society. 2001;49:808-23.

5. Peter WF, Jansen MJ, Hurkmans EJ, Bloo H, Dekker J, Dilling RG, et al. Physiotherapy in hip and knee osteoarthritis: development of a practice guideline concerning initial assessment, treatment and evaluation. Acta reumatológica portuguesa Sociedade Portuguesa de Reumatologia. 2011;36:268-81.

6. Barker KL, Dawes H, Hansford P, Shamley D. Perceived and measured levels of exertion of patients with chronic back pain exercising in a hydrotherapy pool. Archives of Physical Medicine and Rehabilitation. 2003;84:1319-23.

7. Mangione K, McCully K, Gloviak A, Lefebvre I, Hofmann M, Craik R. The effects of high-intensity and low-intensity cycle ergometry in older adults with knee osteoarthritis. Journals of Gerontology Series A: Biological Sciences and Medical Sciences. 1999;54:M:184-90.

8. Salacinski A, Krohn K, Lewis S, Holland M, Ireland K, Marchetti G. The effects of group cycling on gait and pain-related disability in individuals with mild-to-moderate knee osteoarthritis: a randomized controlled trial. Journal of Orthopaedic and Sports Physical Therapy. 2012;42:985-95.

9. Ericson MO BA, Nisell R, Nemeth R, Ekholm J. Load moments about the hip and knee joints during ergometer cycling. Scandinavian Journal of Rehabilitation Medicine. 1986;18:165-72.

10. Caria MA, Tangianu F, Concu A, Crisafulli A, Mameli O. Quantification of Spinning bike performance during a standard 50-minute class. Journal of Sports Sciences. 2007;25:421-9.

11. Fransen M, McConnell S, Harmer AR, Van der Esch M, Simic M, Bennell KL. Exercise for osteoarthritis of the knee: a Cochrane systematic review. British Journal of Sports Medicine. 2015;49:1554-7.

12. Zhang W NG, Moskowitz RW, Abramson S, Altman RD, Arden NK, Bierma-Zeinstra S, Brandt KD, Croft P, Doherty M, Dougados M, Hochberg M, Hunter DJ, Kwoh K, Lohmander LS, Tugwell P. OARSI recommendations for the management of hip and knee osteoarthritis: part III: Changes in evidence following systematic cumulative update of research published through January 2009. Osteoarthritis and Cartilage. 2010;18:476-99.

13. Bellamy N, Kirwan J, Boers M, Brooks P, Strand V, Tugwell P, et al. Recommendations for a core set of outcome measures for future phase III clinical trials in knee, hip, and hand osteoarthritis. Consensus development at OMERACT III. Journal of Rheumatology. 1997;24:799-802.

14. Dobson F, Hinman RS, Roos EM, Abbott JH, Stratford P, Davis AM, et al. OARSI recommended performance-based tests to assess physical function in people diagnosed with hip or knee osteoarthritis. Osteoarthritis and Cartilage. 2013;21:1042-52.

15. Waller B, Ogonowska-Slodownik A, Vitor M, Lambeck J, Daly D, Kujala UM, et al. Effect of therapeutic aquatic exercise on symptoms and function associated with lower limb osteoarthritis: systematic review with meta-analysis. Physical Therapy. 2014;94:1383-95.

16. Bartels EM, Juhl CB, Christensen R, Hagen KB, Danneskiold-Samsoe B, Dagfinrud $H$, et al. Aquatic exercise for the treatment of knee and hip osteoarthritis. Cochrane Database Syst Rev. 2016;3:CD005523.

17. Lu M, Su Y, Zhang Y, Zhang Z, Wang W, He Z, et al. Effectiveness of aquatic exercise for treatment of knee osteoarthritis : Systematic review and meta-analysis. Zeitschrift für Rheumatologie. 2015;10.1007/s00393-014-1559-9. 
18. Lund $\mathrm{H}$, Weile $\mathrm{U}$, Christensen R, Rostock B, Downey A, Bartels EM, et al. A randomized controlled trial of aquatic and land-based exercise in patients with knee osteoarthritis. Journal of Rehabilitation Medicine. 2008;40:137-44.

19. Stener-Victorin E, Kruse-Smidje C, Jung K. Comparison between electro-acupuncture and hydrotherapy, both in combination with patient education and patient education alone, on the symptomatic treatment of osteoarthritis of the hip. Clinical Journal of Pain. 2004;20:179-85.

20. Cochrane T, Davey RC, Matthes Edwards SM. Randomised controlled trial of the cost-effectiveness of water-based therapy for lower limb osteoarthritis. Health Technology Assessment. 2005;9:iii-iv, ix-xi, 1114.

21. Hofstede SN, Vliet Vlieland TP, van den Ende CH, Nelissen RG, Marang-van de Mheen PJ, van BodegomVos L. Variation in use of non-surgical treatments among osteoarthritis patients in orthopaedic practice in the Netherlands. BMJ Open. 2015;5:e009117.

22. Voorn VM, Vermeulen HM, Nelissen RG, Kloppenburg M, Huizinga TW, Leijerzapf NA, et al. An innovative care model coordinated by a physical therapist and nurse practitioner for osteoarthritis of the hip and knee in specialist care: a prospective study. Rheumatology International. 2013;33:1821-8.

23. Smink AJ, van den Ende CH, Vliet Vlieland TP, Swierstra BA, Kortland JH, Bijlsma JW, et al. Beating osteoARThritis: Development of a stepped care strategy to optimize utilization and timing of nonsurgical treatment modalities for patients with hip or knee osteoarthritis. Clinical Rheumatology. 2011;30:1623-9.

24. Foley A, Halbert J, Hewitt T, Crotty M. Does hydrotherapy improve strength and physical function in patients with osteoarthritis--a randomised controlled trial comparing a gym based and a hydrotherapy based strengthening programme. Annals of the Rheumatic Diseases. 2003;62:1162-7.

25. Fransen M, Nairn L, Winstanley J, Lam P, Edmonds J. Physical activity for osteoarthritis management: a randomized controlled clinical trial evaluating hydrotherapy or Tai Chi classes. Arthritis and Rheumatism. 2007;57:407-14.

26. Hinman RS, Heywood SE, Day AR. Aquatic physical therapy for hip and knee osteoarthritis: results of a single-blind randomized controlled trial. Physical Therapy. 2007;87:32-43.

27. Fiolet H, Huijnen B, Metsemakers J, van Hoef L, Schulpen G, Wesseling G et al. Substitutie in de ketenzorg. Praktijk. 2014:9 [cited 2018 Feb 18]. Available from: http://www.heritage.azm.nl/ afbeeldingen/praktijk/praktijk2014_2.pdf

28. Barten D-JJA, Swinkels ICS, Dorsman SA, Dekker J, Veenhof C, de Bakker DH. Treatment of hip/knee osteoarthritis in Dutch general practice and physical therapy practice: an observational study. BMC Family Practice. 2015;16:75.

29. Treweek S, Pitkethly M, Cook J, Kjeldstrom M, Taskila T, Johansen M, et al. Strategies to improve recruitment to randomised controlled trials. Cochrane Database Syst Rev. 2010;10.1002/14651858.MR000013.pub5:Mr000013.

30. Courneya KS, Forbes CC, Trinh L, Sellar CM, Friedenreich CM, Reiman T. Patient satisfaction with participation in a randomized exercise trial: effects of randomization and a usual care posttrial exercise program. Clinical Trials (London, England). 2013;10:959-66.

31. de Rooij M, van der Leeden M, Cheung J, van der Esch M, Hakkinen A, Haverkamp D, et al. Efficacy of Tailored Exercise Therapy on Physical Functioning in Patients With Knee Osteoarthritis and Comorbidity: A Randomized Controlled Trial. Arthritis Care \& Research. 2017;69:807-16.

32. Brand CA, Amatya B, Gordon B, Tosti T, Gorelik A. Redesigning care for chronic conditions: improving hospital-based ambulatory care for people with osteoarthritis of the hip and knee. Internal Medicine Journal. 2010;40:427-36.

33. Pisters MF VC, van Dijk GM, Heymans MW, Twisk JW, Dekker J. The course of limitations in activities over 5 years in patients with knee and hip osteoarthritis with moderate functional limitations: risk factors for future functional decline. Osteoarthritis and Cartilage. 2012;20:503-10.

34. Selten EM, Vriezekolk JE, Geenen R, van der Laan WH, van der Meulen-Dilling RG, Nijhof MW, et al. Reasons for Treatment Choices in Knee and Hip Osteoarthritis: A Qualitative Study. Arthritis Care \& Research. 2016;68:1260-7. 
35. Fernandes L, Hagen KB, Bijlsma JW, Andreassen O, Christensen P, Conaghan PG, et al. EULAR recommendations for the non-pharmacological core management of hip and knee osteoarthritis. Annals of the Rheumatic Diseases. 2013;72:1125-35.

36. Freedland KE, Mohr DC, Davidson KW, Schwartz JE. Usual and unusual care: existing practice control groups in randomized controlled trials of behavioral interventions. Psychosomatic Medicine. 2011;73:323-35.

37. Köke AJA, van den Ende CHM, Jansen MJ, Steultjens MPM, C V. Clinical practice guideline for a physical activity interventions for patients with osteoarthritis [KNGF-standaard Beweeginterventie artrose]. Amersfoort: Koninklijk Nederlands Genootschap voor Fysiotherapie (KNGF); 2008.

38. Smink AJ, Dekker J, Vliet Vlieland TP, Swierstra BA, Kortland JH, Bijlsma JW, et al. Health care use of patients with osteoarthritis of the hip or knee after implementation of a stepped-care strategy: an observational study. Arthritis Care \& Research. 2014;66:817-27.

39. van Rijn MJ. Kamerbrief over Basispakket Zvw per 2018. Ministerie van Volksgezondheid, Welzijn en Sport.Den Haag.2017.

40. Thorstensson CA, Roos EM, Petersson IF, Arvidsson B. How do middle-aged patients conceive exercise as a form of treatment for knee osteoarthritis? Disability and Rehabilitation. 2006;28:51-9.

41. Smith TO, Purdy R, Lister S, Salter C, Fleetcroft R, Conaghan PG. Attitudes of people with osteoarthritis towards their conservative management: a systematic review and meta-ethnography. Rheumatology International. 2014;34:299-313.

42. Campbell R, Evans M, Tucker M, Quilty B, Dieppe P, Donovan JL. Why don't patients do their exercises? Understanding non-compliance with physiotherapy in patients with osteoarthritis of the knee. Journal of Epidemiology and Community Health. 2001;55:132-8.

43. Hendry M, Williams NH, Markland D, Wilkinson C, Maddison P. Why should we exercise when our knees hurt? A qualitative study of primary care patients with osteoarthritis of the knee. Family Practice. 2006;23:558-67.

44. Smelt AF, van der Weele GM, Blom JW, Gussekloo J, Assendelft WJ. How usual is usual care in pragmatic intervention studies in primary care? An overview of recent trials. British Journal of General Practice. 2010;60:e305-18.

45. Cunningham JA, Kypri K, McCambridge J. Exploratory randomized controlled trial evaluating the impact of a waiting list control design. BMC Medical Research Methodology. 2013;13:150.

46. Holden MA, Nicholls EE, Hay EM, Foster NE. Physical Therapists' Use of Therapeutic Exercise for Patients With Clinical Knee Osteoarthritis in the United Kingdom: In Line With Current Recommendations? Physical Therapy. 2008;88:1109-21.

47. Holden MA, Nicholls EE, Young J, Hay EM, Foster NE. UK-based physical therapists' attitudes and beliefs regarding exercise and knee osteoarthritis: findings from a mixed-methods study. Arthritis and Rheumatism. 2009;61:1511-21.

48. Denning WM, Bressel E, DG D. Underwater Treadmill Exercises as a Potential Treatment for Adults With Osteoarthritis. International Journal of Aquatic Research and Education. 2010;4:70-80.

49. Bressel E, Wing JE, Miller Al, Dolny DG. High-intensity interval training on an aquatic treadmill in adults with osteoarthritis: effect on pain, balance, function, and mobility. Journal of Strength and Conditioning Research. 2014;28:2088-96.

50. Fisken A, Waters DL, Hing WA, Steele M, Keogh JW. Perception and responses to different forms of aqua-based exercise among older adults with osteoarthritis. International Journal of Aquatic Research and Education. 2014;8:32-52.

51. Hall J, Swinkels A, Briddon J, McCabe CS. Does aquatic exercise relieve pain in adults with neurologic or musculoskeletal disease? A systematic review and meta-analysis of randomized controlled trials. Archives of Physical Medicine and Rehabilitation. 2008;89:873-83.

52. Westby MD. A health professional's guide to exercise prescription for people with arthritis: a review of aerobic fitness activities. Arthritis and Rheumatism. 2001;45:501-11.

53. Juhl C, Christensen R, Roos EM, Zhang W, Lund H. Impact of exercise type and dose on pain and disability in knee osteoarthritis: a systematic review and meta-regression analysis of randomized controlled trials. Arthritis \& rheumatology. 2014;66:622-36. 
54. Roddy E, Zhang W, Doherty M. Aerobic walking or strengthening exercise for osteoarthritis of the knee? A systematic review. Annals of the Rheumatic Diseases. 2005;64:544-8.

55. Alkatan M, Baker JR, Machin DR, Park W, Akkari AS, Pasha EP, et al. Improved Function and Reduced Pain after Swimming and Cycling Training in Patients with Osteoarthritis. Journal of Rheumatology. 2016;43:666-72.

56. Brosseau L, Wells GA, Kenny GP, Reid R, Maetzel A, Tugwell P, et al. The implementation of a community-based aerobic walking program for mild to moderate knee osteoarthritis: a knowledge translation randomized controlled trial: part II: clinical outcomes. BMC Public Health. 2012;12:1073.

57. Ross RM, Murthy JN, Wollak ID, Jackson AS. The six minute walk test accurately estimates mean peak oxygen uptake. BMC Pulmonary Medicine. 2010;10:31-.

58. Bansi J, Bloch W, Gamper U, Kesselring J. Training in MS: influence of two different endurance training protocols (aquatic versus overland) on cytokine and neurotrophin concentrations during three week randomized controlled trial. Multiple Sclerosis. 2012;19:613-21.

59. Bansi J, Bloch W, Gamper U, Riedel S, Kesselring J. Endurance training in MS: short-term immune responses and their relation to cardiorespiratory fitness, health-related quality of life, and fatigue. Journal of Neurology. 2013;260:2993-3001.

60. Boidin M, Lapierre G, Paquette Tanir L, Nigam A, Juneau M, Guilbeault V, et al. Effect of aquatic interval training with Mediterranean diet counseling in obese patients: results of a preliminary study. Annals of Physical and Rehabilitation Medicine. 2015;58:269-75.

61. Karnahl B. Vergleichende Untersuchungen von Leistungs- und Stoffwechselparametern im ergometrischen Test an Land und im Wasser [Dissertation]. Potsdam: Universität Potsdam; 2010.

62. Tanaka H, Monahan KD, Seals DR. Age-predicted maximal heart rate revisited. Journal of the American College of Cardiology. 2001;37:153-6.

63. Barbosa TM, Marinho DA, Reis VM, Silva AJ, Bragada J. Physiological assessment of head-out aquatic exercises in healthy subjects: a qualitative review. Journal of Sports Science \& Medicine. 2009;8:179-89.

64. Carvalho VO, Bocchi EA, Guimaraes GV. The Borg scale as an important tool of self-monitoring and selfregulation of exercise prescription in heart failure patients during hydrotherapy. A randomized blinded controlled trial. Circulation Journal. 2009;73:1871-6.

65. Shono T, Fujishima K, Hotta N, Ogaki T, Ueda T, Otoki K, et al. Physiological responses and RPE during underwater treadmill walking in women of middle and advanced age. Journal of Physiological Anthropology and Applied Human Science. 2000;19:195-200.

66. Brasil RM, Pinto S, Borreani S, Bagatini NC, Barreto AC, Senra AC, et al. Correlation between Borg scale (6-20) with a new water cycling scale (Brasil scale). Medicine and Science in Sports and Exercise. 2014;46:942.

67. Finkelstein I, de Figueiredo PA, Alberton CL, Bgeginski R, Stein R, Kruel LF. Cardiorespiratory responses during and after water exercise in pregnant and non-pregnant women. Revista Brasileira de Ginecologia e Obstetrícia: Revista da Federação Brasileira das Sociedades de Ginecologia e Obstetrícia. 2011;33:38894.

68. Breugem SJ, Haverkamp D, Sierevelt IN, Stibbe AB, Blankevoort L, van Dijk CN. The important predictors of cycling use in three groups of knee patients. Disability and Rehabilitation. 2011;33:1925-9.

69. Johnston TE. Biomechanical considerations for cycling interventions in rehabilitation. Physical Therapy. 2007;87:1243-52.

70. Liebs TR, Herzberg W, Ruther W, Haasters J, Russlies M, Hassenpflug J. Ergometer cycling after hip or knee replacement surgery: a randomized controlled trial. The Journal of bone and joint surgery American volume. 2010;92:814-22.

71. Skou ST, Roos EM. Good Life with osteoArthritis in Denmark (GLA:D): evidence-based education and supervised neuromuscular exercise delivered by certified physiotherapists nationwide. BMC Musculoskeletal Disorders. 2017;18:72.

72. Villadsen A, Overgaard S, Holsgaard-Larsen A, Christensen R, Roos EM. Immediate efficacy of neuromuscular exercise in patients with severe osteoarthritis of the hip or knee: a secondary analysis from a randomized controlled trial. Journal of Rheumatology. 2014;41:1385-94.

73. Beaudart C, Biver E, Bruyere O, Cooper C, Al-Daghri N, Reginster JY, et al. Quality of life assessment in musculo-skeletal health. Aging Clinical and Experimental Research. 2017;10.1007/s40520-017-0794-8. 
74. Tilden HM, Reicherter EA, Reicherter F. Use of an aquatics program for older adults with osteoarthritis. From clinic to the community. Topics in Geriatric Rehabilitation. 2010;26:128-39.

75. Waller B, Munukka M, Rantalainen T, Lammentausta E, Nieminen MT, Kiviranta I, et al. Effects of high intensity resistance aquatic training on body composition and walking speed in women with mild knee osteoarthritis: a 4-month RCT with 12-month follow-up. Osteoarthritis and Cartilage. 2017;25:1238-46.

76. Dobson F, Bennell KL, French SD, Nicolson PJ, Klaasman RN, Holden MA, et al. Barriers and facilitators to exercise participation in people with hip and/or knee osteoarthritis: synthesis of the literature using behavior change theory. American Journal of Physical Medicine and Rehabilitation. 2016;95:372-89.

77. Schwier J. Do the right things - Trends im Feld des Sports. dsv-Informationen. 1998;13:7-13.

78. Etkin J. The hidden cost of personal quantification. The Journal of consumer research. 2016;42:967-84.

79. Lamprecht M, Stamm H. Vom Avantgardistischen Lebensstil Zur Massenfreizeit: Eine Analyse Des Entwicklungsmusters Von Trendsportarten. Sportwissenschaft. 1998;28:370-87.

80. Wesseling J, Welsing PM, Bierma-Zeinstra SM, Dekker J, Gorter KJ, Kloppenburg M, et al. Impact of selfreported comorbidity on physical and mental health status in early symptomatic osteoarthritis: the CHECK (Cohort Hip and Cohort Knee) study. Rheumatology (Oxford, England). 2013;52:180-8.

81. Munukka M, Waller B, Rantalainen T, Hakkinen A, Nieminen MT, Lammentausta E, et al. Efficacy of progressive aquatic resistance training for tibiofemoral cartilage in postmenopausal women with mild knee osteoarthritis: a randomised controlled trial. Osteoarthritis and Cartilage. 2016;24:1708-17.

82. Torres-Ronda L, Del Alcazar XS. The Properties of Water and their Applications for Training. Journal of human kinetics. 2014;44:237-48.

83. Cadmus L, Patrick MB, Maciejewski ML, Topolski T, Belza B, Patrick DL. Community-based aquatic exercise and quality of life in persons with osteoarthritis. Medicine and Science in Sports and Exercise. 2010;42:8-15.

84. Suomi R, Collier D. Effects of arthritis exercise programs on functional fitness and perceived activities of daily living measures in older adults with arthritis. Archives of Physical Medicine and Rehabilitation. 2003;84:1589-94.

85. Belza B, Topolski T, Kinne S, Patrick DL, Ramsey SD. Does adherence make a difference? Results from a community-based aquatic exercise program. Nursing Research. 2002;51:285-91.

86. Patrick DL, Ramsey SD, Spencer AC, Kinne S, Belza B, Topolski TD. Economic evaluation of aquatic exercise for persons with osteoarthritis. Medical Care. 2001;39:413-24.

87. Barker AL, Talevski J, Morello RT, Nolan GA, De Silva RD, Briggs AM. Jumping into the deep-end: results from a pilot impact evaluation of a community-based aquatic exercise program. Clinical Rheumatology. 2016;35:1593-601.

88. Fransen M, McConnell S, Harmer AR, Van der Esch M, Simic M, Bennell KL. Exercise for osteoarthritis of the knee. Cochrane Database of Systematic Reviews. 2015;10.1002/14651858.CD004376.pub3.

89. Ulatkowski M. Unterwasserfahrrad versus herkömmliche Rehabilitation - Eine retrospektive Studie mit und ohne Unterwasserfahrrad an implantierten Kniegelenksprothesen [Dissertation]. Heidelberg: Heidelberg University; 2009.

90. von Kathen M. Prospektiv-randomisierte Vergleichsstudie zur Rehabilitation vorderer Kreunzbandplastiken zwischen koventioneller Therapie und Unterwasserfahrrad [Dissertation]. Bochum: Ruhr-Universität; 1999.

91. Damm P, Dymke J, Bender A, Duda G, Bergmann G. In vivo hip joint loads and pedal forces during ergometer cycling. Journal of Biomechanics. 2017;60:197-202.

92. Roberts HM, Moore JP, Griffith-McGeever CL, Fortes MB, Thom JM. The effect of vigorous running and cycling on serum COMP, lubricin, and femoral cartilage thickness: a pilot study. European Journal of Applied Physiology. 2016;116:1467-77.

93. Milares LP, Assis L, Siqueira A, Claudino V, Domingos H, Almeida T, et al. Effectiveness of an aquatic exercise program and low-level laser therapy on articular cartilage in an experimental model of osteoarthritis in rats. Connective Tissue Research. 2016;57:398-407.

94. Nur H, Sertkaya BS, Tuncer T. Determinants of physical functioning in women with knee osteoarthritis. Aging Clinical and Experimental Research. 2017;10.1007/s40520-017-0784-x.

95. van der Esch M, Holla JF, van der Leeden M, Knol DL, Lems WF, Roorda LD, et al. Decrease of muscle strength is associated with increase of activity limitations in early knee osteoarthritis: 3-year results 
from the cohort hip and cohort knee study. Archives of Physical Medicine and Rehabilitation. 2014;95:1962-8.

96. Van Zant RS, Bouillon LE. Strength cycle training: effects on muscular strength and aerobic conditioning. Journal of Strength and Conditioning Research. 2007;21:178-82.

97. Bastick AN, Runhaar J, Belo JN, Bierma-Zeinstra SM. Prognostic factors for progression of clinical osteoarthritis of the knee: a systematic review of observational studies. Arthritis Research \& Therapy. 2015; doi: 10.1186/s13075-015-0670-x.

98. Garzon M, Gayda M, Garzon L, Juneau M, Nigam A, Leone M, et al. Biomechanical analysis to determine the external power output on an immersible ergocycle. European Journal of Sport Science. 2015;15:271-8.

99. Walters SJ, Bonacho dos Anjos Henriques-Cadby I, Bortolami O, Flight L, Hind D, Jacques RM, et al. Recruitment and retention of participants in randomised controlled trials: a review of trials funded and published by the United Kingdom Health Technology Assessment Programme. BMJ Open. 2017;7:e015276.

100. Gibson AJ, Shields N. Effects of Aquatic Therapy and Land-Based Therapy versus Land-Based Therapy Alone on Range of Motion, Edema, and Function after Hip or Knee Replacement: A Systematic Review and Meta-analysis. Physiotherapy Canada. 2015;67:133-41.

101. Gusi N, Tomas-Carus P. Cost-utility of an 8-month aquatic training for women with fibromyalgia: a randomized controlled trial. Arthritis Research \& Therapy. 2008;10:R24-R. 


\section{Summary}

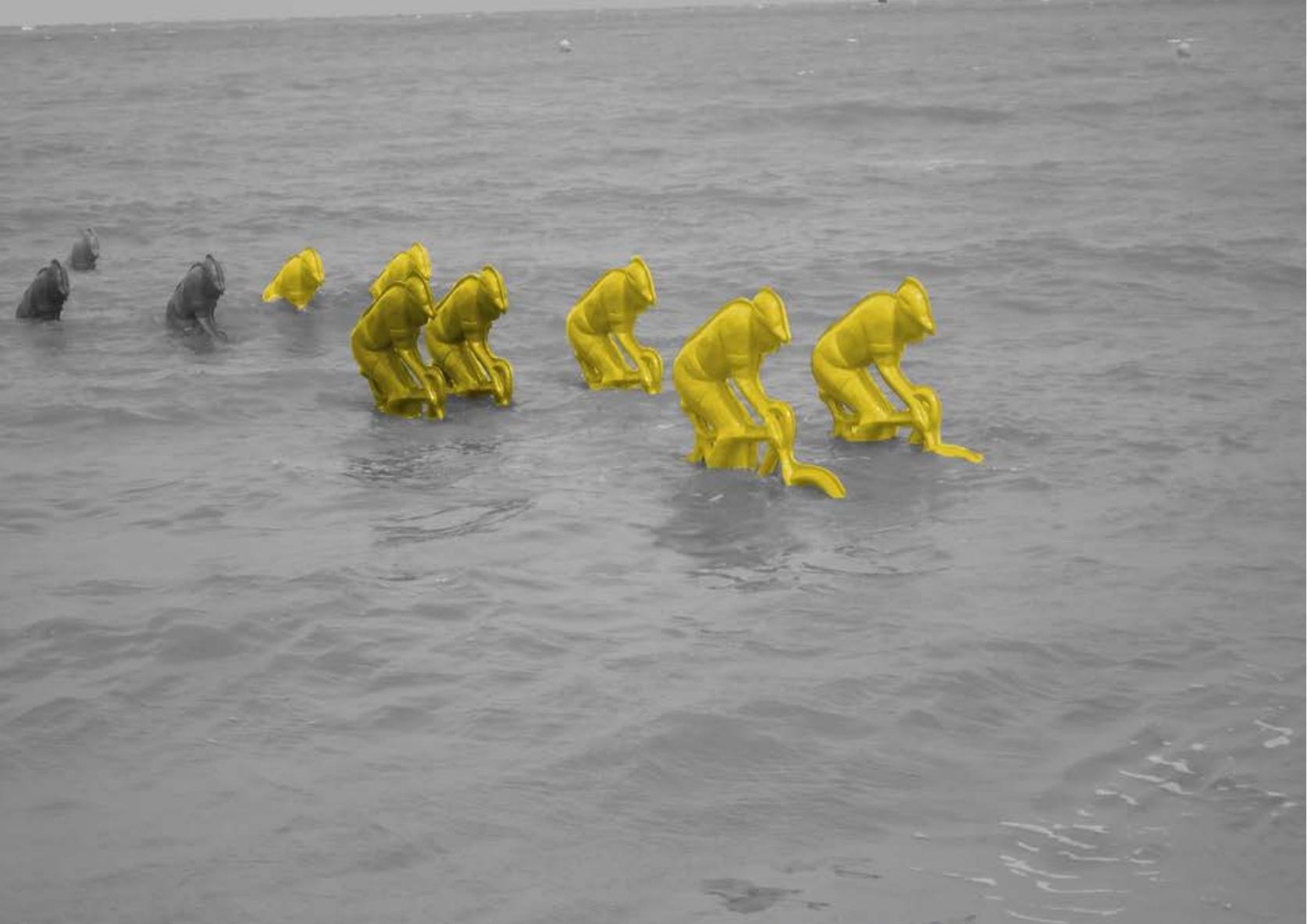



Cycling exercises on a stationary bike in a (heated) pool, called aquatic cycling, may prove to be useful as a therapeutic tool for individuals with knee osteoarthritis to reduce knee pain and improve physical functioning. However, this therapeutic approach for patients with mild to moderate knee osteoarthritis has not been investigated. Therefore, this dissertation aimed to develop and evaluate an aquatic cycling programme that is tailored to the needs of patients with knee osteoarthritis.

\section{Chapter 1}

This section provides an introduction to the central topics of this thesis: knee osteoarthritis and aquatic cycling. Knee osteoarthritis is a chronic joint disease that burdens individuals with knee pain and disability. Both increasing age and obesity are the primary contributors to the rise in the prevalence of osteoarthritis. By 2020 osteoarthritis is expected to rank among the top five of the most disabling diseases worldwide. Many of the risk factors (e.g. obesity, muscle weakness) and symptoms of knee osteoarthritis can be lessened and improved by performing regular physical exercise. For individuals who have limited tolerance for weight-bearing activities, water-based exercise is frequently recommended. Aquatic immersion initiates physiological changes that are beneficial in the management of knee osteoarthritis. For example, the buoyancy of the water offloads joints, hydrostatic pressures result in a massaging effect that reduces pain sensation and warm water temperature supports a feeling of relaxation. More recently, aquatic cycling has emerged as a trendy fitness activity. Aquatic cycling is a head-out aquatic exercise activity performed on a stationary bike in a swimming pool. Participants are immersed in water levels rising to between navel and chest height where they perform cycling in seated as well as out-ofsaddle positions. Additional exercise movements can be combined with typical cycling sessions such as upper body and arm exercises performed against water resistance.

\section{Chapter 2}

The second chapter describes a feasibility study of an aquatic exercise programme for patients with knee osteoarthritis. Ten patients with knee osteoarthritis participated in eight weekly sessions consisting of aquatic exercises and ten minutes of aquatic cycling. The training programme was deemed safe and feasible. In addition to high levels of attendance and positive patient feedback, individuals also stated that their knee pain improved immediately following exercise. Participants also demonstrated the ability to readily execute most exercises while showing progression. However, as opposed to the seated position, aquatic cycling in an out-of-the-saddle position was too demanding for most participants. This finding suggests that more training is needed before out-ofsaddle position exercise is safe and effective. Feedback from focus groups suggested high levels of patient satisfaction with the selection of exercises and that aquatic 
cycling time could be extended beyond ten minutes. Although seated aquatic cycling was perceived as more tiring than land-based cycling, actual movements were perceived as easier and smoother when performed in water than on land. However, participants also stated that seated cycling for an extended period of time may become monotonous. Evaluation of operational aspects of this programme showed that aquatic cycling could be readily incorporated into circuit training. Seated cycling was easy to learn and only a few instructions were needed, which created more time to supervise patients at other workstations.

\section{Chapter 3}

This section presents a detailed description of a 12-week aquatic cycling exercise programme as well as the design of a randomised controlled trial to evaluate the efficacy of this programme in comparison with usual care for patients with knee osteoarthritis. The aquatic cycling programme consisted of twice-weekly 45-minute sessions conducted in a therapy pool and delivered to small groups of up to four patients. Each session combined seated cycling, out-of-saddle position cycling, leg exercises and upper body exercises. Because there is a paucity of aquatic cycle research and no established guidelines specific to this therapeutic approach for patients with knee osteoarthritis exist, general exercise guidelines for osteoarthritis and evidence taken from land-based cycling programmes provided guidance with regard to exercise intensity and training set-up. The training programme was designed for patients with mild to moderate knee osteoarthritis. Inclusion criteria for participation in the training programme and randomised controlled trial were: knee pain between four and seven on a 10-point numeric pain rating scale, a Kellgren/Lawrence score between one to three (maximum score: four) and indication for physical therapy in combination with impairments due to osteoarthritis. Potential participants with any contra-indication for aquatic exercise therapy such as severe and unstable cardiorespiratory co-morbidities, open wounds or patients on a waiting list for total knee surgery were excluded. Moreover, all potential participants with conditions that could limit the safe participation or bias symptoms of knee osteoarthritis (e.g. corticosteroid injection and/or hyaluronic acid injection in the last three resp. six month) were excluded. Primary outcome measurements included knee pain and physical function assessed with the Knee Injury and Osteoarthritis Outcome Score (KOOS). Secondary outcome measurements included KOOS subscales for symptoms, sport and disease-specific quality of life, patient-reports on general disease severity and quality of life, physical activity, self-efficacy, and kinesiophobia. Performance-based outcomes were the timed "up and go" test, the six-minute walk test and lower limb muscle strength. Measurements were performed at baseline, 12-weeks postintervention, and 24-weeks follow-up. 


\section{Chapter 4}

Chapter four provides a scoping review of the current state of the literature on the topic of aquatic cycling. Sixty-three publications were identified with this review providing a summary of programme set-ups of aquatic interventions as well as potential comparisons, core outcomes and involved participants. Detailed review of intervention parameters revealed that there is heterogeneity regarding the use and execution of aquatic cycling. Numerous variables have been tested related to aquatic cycling (e.g. type of aquatic bike, water temperature or immersion level, etc.). Although the experimental conditions differed notably across the studies, several shared characteristics could be identified. Most research focused on the comparison between aquatic and land cycling or investigated the effects of different exercise conditions (e.g. water temperature) during aquatic cycling in healthy (mostly male) participants using a cross-over study design. In many of the studies cardiovascular parameters were investigated with results suggesting that cardiac demand of aquatic cycling is not different compared with land-based cycling. Out of all of the reviewed studies, only six studies evaluated the effect of aquatic cycling interventions. These studies demonstrated that an aquatic cycling training programme is equally effective as landbased cycling to improve cardiovascular fitness in healthy participants as well as in obese participants and patients with multiple sclerosis.

\section{Chapter 5}

Chapter five describes the results of the two-arm single-blind, parallel-group, randomised controlled trial studying the effects of a 12-week aquatic cycling programme on knee pain and physical function in patients with mild to moderate knee osteoarthritis. Effects of the aquatic cycling programme were compared with a patient group receiving the usual care of the Early Osteoarthritis Outpatient Clinic of the Maastricht University Medical Centre+. Following the conclusion of the study trial period, participants randomised to the usual care group were invited to attend twelve weekly aquatic cycling sessions in a local indoor community pool. Enrolled into this study were 111 patients. However, nine patients withdrew their consent prior to completing baseline testing, whereas 19 patients were lost to follow-up. Since most group differences remained stable from post-intervention to 24-weeks follow-up, a single estimate for the group differences at both time points could be used. Significant improvements occurred for self-reported knee pain $(B=8.16, p=0.014)$ and physical function $(B=7.16, p=0.027)$ in the aquatic cycling group. Participants of the aquatic cycling group also performed the timed "up and go" test faster $(B=-0.91, p=0.001)$ and walked more metres during the six-minute walk test $(B=46.75, p=0.002)$ compared with the usual care group. Furthermore, participants of the aquatic cycling group reported decreased fear of movement $(B=-3.84, p=0.002)$ and a short-term increase in diseasespecific quality of life $(B=13.03, p=0.001)$ compared with the usual care group. 


\section{Chapter 6}

Chapter six provides a broad overview of the main findings of this thesis. This section briefly discusses the four essential aspects considered in both the development and evaluation of the aquatic cycling training programme: recruitment and dropouts, comparison of aquatic cycling with usual care, usual care compliance, and the effectiveness of the aquatic cycling exercise programme. Practical considerations on the pros and cons of aquatic cycling and thoughts on the future accessibility of aquatic cycling are described as well. The final comments in this dissertation include ideas regarding the important next steps for this line of research. 


\section{Samenvatting}

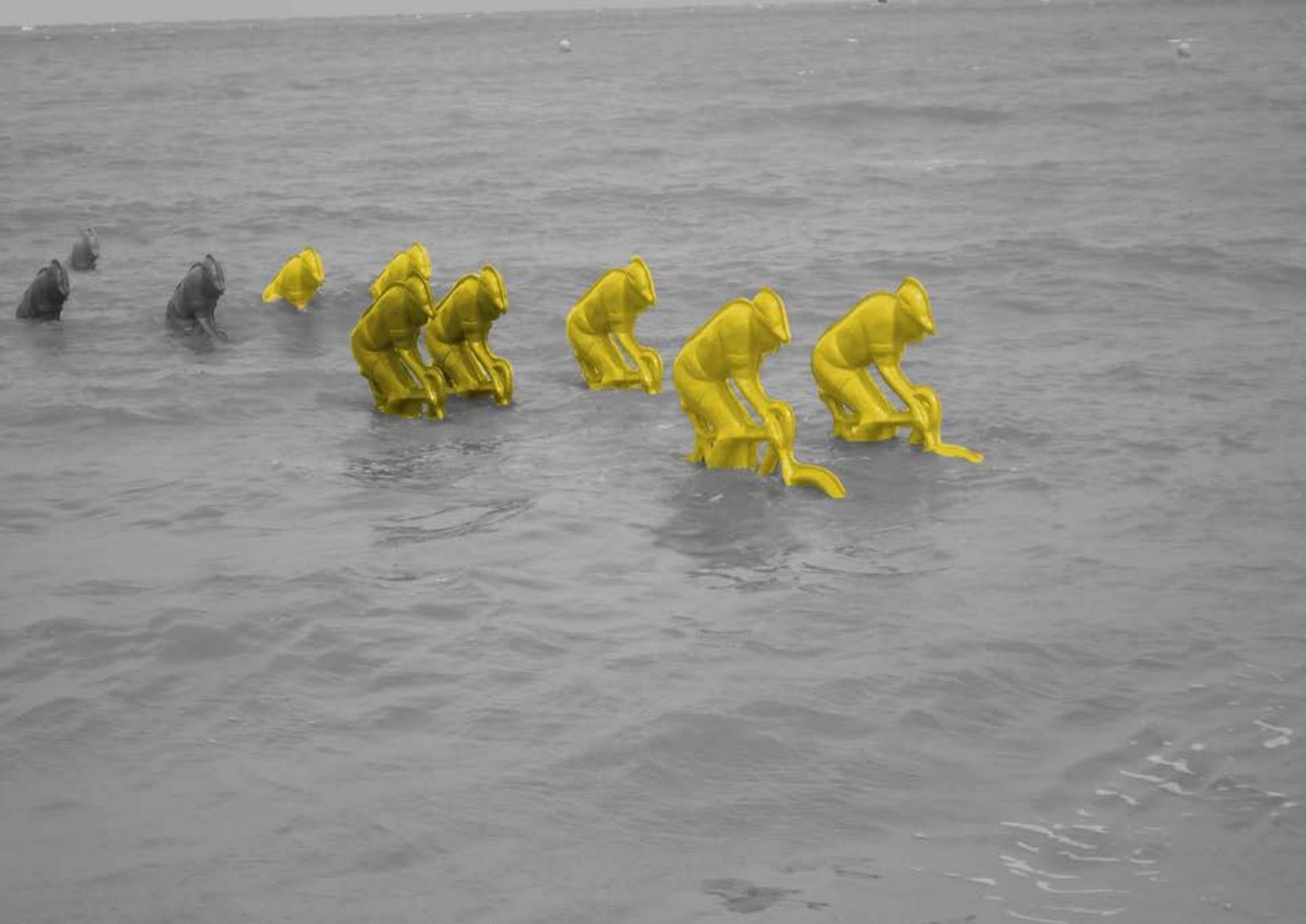



Waterfietsen in een verwarmd zwembad is mogelijk een veelbelovende oefenactiviteit voor mensen met artrose in de knie om pijn te verlichten en het fysiek functioneren te verbeteren. Echter, het effect van fietsen in het water (Engels: aquatic cycling) is nog nooit eerder onderzocht bij patiënten met knieartrose. Het doel van dit proefschrift was het ontwikkelen en evalueren van een waterfietsprogramma voor patiënten met lichte tot matige knieartrose.

\section{Hoofdstuk 1}

Het eerste hoofdstuk introduceert de centrale onderwerpen van dit proefschrift: knieartrose en waterfietsen. Knieartrose is een chronische gewrichtsaandoening die kniepijn en problemen met het fysieke functioneren veroorzaakt. De vergrijzing en de toename van overgewicht in de bevolking zorgen ervoor dat steeds meer mensen last krijgen van (knie)artrose en hierdoor zal de vraag naar gezondheidszorgvoorzieningen toenemen. Verwacht wordt dat artrose in 2020 tot de top vijf van de meest beperkende ziekten wereldwijd zal behoren. Veel risicofactoren (bijvoorbeeld overgewicht of spierzwakte) en symptomen van knieartrose kunnen worden verminderd en verbeterd door regelmatige lichaamsbeweging. Voor patiënten die veel last hebben van oefenen op het droge kan het oefenen in water een alternatief zijn. De fysiologische veranderingen die optreden zodra een mens omgeven is van water hebben een gunstig effect op de symptomen van knieartrose. Het drijfvermogen van het water ontlast de gewrichten, de hydrostatische druk resulteert in een massageeffect dat het pijngevoel vermindert, en warme watertemperaturen ondersteunen een gevoel van ontspanning. In de afgelopen jaren heeft waterfietsen zich ontwikkeld tot een populaire fitnessactiviteit. Waterfietsen is fietsen in water op een ergometer die vaststaat op de grond van een zwembad. Deelnemers zitten tot borsthoogte in het water en fietsen in zittende en staande houdingen. Bovendien wordt het fietsen met oefeningen voor het bovenlichaam tegen de waterweerstand gecombineerd in een typische waterfiets-sessie.

\section{Hoofdstuk 2}

Het tweede hoofdstuk beschrijft een haalbaarheidsstudie van een circuit-training in het water (inclusief waterfietsen) bij patiënten met knieartrose. Tien patiënten namen deel aan acht wekelijkse sessies, bestaande uit klassieke waterfitness-oefeningen en tien minuten waterfietsen. De circuit-training werd als veilig en haalbaar beoordeeld. De opkomst van de meeste patiënten was goed, patiënten tolereerden de oefeningen en rapporteerden een onmiddellijke pijnvermindering in de knie. De deelnemers waren goed in staat om de oefeningen uit te voeren en vertoonden vooruitgang in de moeilijkheidsgraad van de oefeningen. Echter, waterfietsen in een staande houding was te veeleisend voor de meeste deelnemers. Deze bevinding suggereert dat er meer 
trainingssessies nodig zijn voordat staand fietsen mogelijk wordt. Groepsinterviews toonden aan dat de deelnemers zeer tevreden waren over de keuze en afwisseling van de oefeningen. Met betrekking tot het waterfietsen verklaarden patiënten dat zij graag langer dan tien minuten hadden willen fietsen. Hoewel zittend fietsen in het water als vermoeiender werd ervaren dan fietsen op het land, werd de beweging ook als gemakkelijker ervaren en voelde het soepeler aan dan de fietsbeweging op het droge. De deelnemers benadrukten echter dat enkel zittend fietsen voor een langere periode te eentonig kan zijn. De evaluatie van de operationele aspecten toonde aan dat waterfietsen eenvoudig in een circuit-training kan worden opgenomen, omdat er slechts een paar instructies nodig waren en daardoor meer tijd was voor patiënten die met andere oefeningen in het circuit bezig waren.

\section{Hoofdstuk 3}

Dit hoofdstuk geeft een gedetailleerde beschrijving van een 12-weken durende waterfiets-oefenprogramma en beschrijft de opzet van een gerandomiseerde studie om de effecten van het oefenprogramma te vergelijken met de gebruikelijke zorg voor patiënten met knieartrose. Het oefenprogramma werd twee keer per week met sessies van 45 minuten gegeven aan kleinschalige groepen van maximaal vier patiënten in een therapiebad. In elke sessie werd zittend fietsen met staande fietshoudingen, beenoefeningen en oefeningen voor het bovenlichaam gecombineerd. Vanwege een gebrek aan voorafgaand onderzoek naar de effecten van waterfiets-interventies voor patiënten met knieartrose, was de trainingsintensiteit en de opbouw gebaseerd op algemene oefenrichtlijnen voor artrose en de resultaten van fietsinterventies op het droge. Het waterfietsprogramma werd ontwikkeld voor patiënten met milde tot matige knieartrose en de volgende inclusiecriteria voor de gerandomiseerde gecontroleerde studie werden gehandhaafd: kniepijn tussen vier en zeven op een numerieke pijnschaal met tien punten, een Kellgren / Lawrence-score tussen één en drie (vier is de maximum score) en een indicatie voor fysiotherapie in verband met de knieartrose. Potentiële deelnemers met een contra-indicatie voor watertherapie zoals ernstige, onstabiele cardiorespiratoire aandoeningen en open wonden of patiënten op een wachtlijst voor een gewricht-vervangende knieoperatie werden uitgesloten van de deelname. Verder werden patiënten uitgesloten waarbij een veilige deelname aan een oefenprogramma niet gegarandeerd was of waarbij de symptomen van de knieartrose mogelijk vertekend waren (bijvoorbeeld door recente injectie met corticosteroïden en / of hyaluronzuur in de afgelopen drie c.q. zes maanden). De primaire uitkomstmaten waren kniepijn en fysiek functioneren gemeten met de KOOS (Knee Injury and Osteoarthritis Outcome Score) vragenlijst. Secundaire uitkomstmaten waren de KOOSvragenlijsten voor symptomen, sport en ziekte-specifieke kwaliteit van leven, en patiënt-gerapporteerde scores over de algemene ernst van de ziekte en de algemene kwaliteit van leven, fysieke activiteit, eigen effectiviteit en beweegangst. Het fysiek 
functioneren werd bovendien met de getimede "up and go" test en de zes minuten wandeltest geëvalueerd. Verder werd de spierkracht van de onderste ledematen gemeten.

\section{Hoofdstuk 4}

Hoofdstuk vier beschrijft een literatuuroverzicht waarin de huidige stand van zaken met betrekking tot het fietsen in het water werd onderzocht. Drieënzestig publicaties werden geïdentificeerd. Het onderzoek geeft een samenvatting van de kenmerken van de studies zoals de opzet van de interventie, de belangrijkste resultaten, de kenmerken van deelnemers en de studiedesigns. De studies vertoonden veel variatie in termen van externe factoren en de uitvoering van waterfietsen. Zo zijn in de studies bijvoorbeeld verschillende waterfietsen gebruikt en zijn er veel verschillen gevonden met betrekking tot de omgevingsfactoren zoals waterhoogte of watertemperatuur tijdens de interventies. Hoewel de experimentele omstandigheden in de studies duidelijk verschilden, werden er ook gedeelde kenmerken geïdentificeerd. De meeste studies waren gericht op de vergelijking tussen water- en landfietsen of onderzochten de effecten van verschillende omstandigheden (bijvoorbeeld de watertemperatuur) tijdens waterfietsen in gezonde (meestal mannelijke) deelnemers met behulp van een cross-over studiedesign. Bovendien werden cardiovasculaire parameters in veel van de studies onderzocht, waarbij de resultaten suggereerden dat de cardiale belasting van waterfietsen vergelijkbaar is met fietsen op het droge. Slechts zes studies evalueerden het effect van een waterfiets-oefenprogramma. Uit deze interventiestudies bleek dat een waterfietsprogramma net zo effectief is als land-fietsen om het uithoudingsvermogen te verbeteren bij gezonde deelnemers, maar ook bij mensen met overgewicht en patiënten met multiple sclerose.

\section{Hoofdstuk 5}

Hoofdstuk vijf beschrijft de resultaten van een tweearmige gerandomiseerde studie naar de werkzaamheid van een 12-weken durende waterfietsprogramma op kniepijn en lichamelijk functioneren bij patiënten met lichte tot matige knieartrose. Het waterfietsprogramma werd vergeleken met de gebruikelijke zorg van de polikliniek voor vroegartrose van het Maastricht Universitair Medisch Centrum+. Na het einde van de trialperiode werden de mensen in de gebruikelijke zorggroep uitgenodigd voor waterfiets-sessies gedurende 12 weken in een lokaal zwembad. In deze studie werden 111 patiënten gerandomiseerd, waarvan negen patiënten hun toestemming vóór de eerste meetsessie terugtrokken en 19 patiënten tijdens de onderzoeksperiode stopten met deelname aan het onderzoek. Aangezien de meeste groepsverschillen stabiel bleven van de nameting tot aan de 24 weken follow-up, werd één enkele schatting gebruikt voor de groepsverschillen op beide meetmomenten. Significante verschillen 
werden gevonden voor zelf gerapporteerde knie-pijn $(B=8.16, p=0.014)$ en fysiek functioneren $(B=7.16, p=0.027)$ in het voordeel van de waterfietsgroep. Bovendien voerden de deelnemers van de waterfietsgroep de getimede "up and go" test significant sneller uit $(B=-0.91, p=0.001)$ en liepen ze significant meer meters gedurende de zes minuten wandeltest $(B=46.75, p=0.002)$. Verder had de waterfietsgroep een verminderde bewegingsangst $(B=-3.84, p=0.002)$ en werd een kortdurende verbetering van ziekte-specifieke kwaliteit van leven $(B=13.03, p=0.001)$ aangetoond in vergelijking met de gebruikelijke zorggroep.

\section{Hoofdstuk 6}

Dit hoofdstuk geeft een overzicht van de belangrijkste bevindingen van dit proefschrift, gevolgd door een discussie met betrekking tot vier essentiële aspecten in de ontwikkeling en evaluatie van het waterfietsprogramma: rekrutering en uitval van deelnemers, de vergelijking van waterfietsen met gebruikelijke zorg, gebruik van fysiotherapie in de controle groep, en het waterfietsprogramma. Verder worden praktische overwegingen over de voor- en nadelen van waterfietsen en gedachten over de (toekomstige) toegankelijkheid van waterfietsen beschreven. Ten slotte worden implicaties voor toekomstig onderzoek gepresenteerd. 


\section{Zusammenfassung}

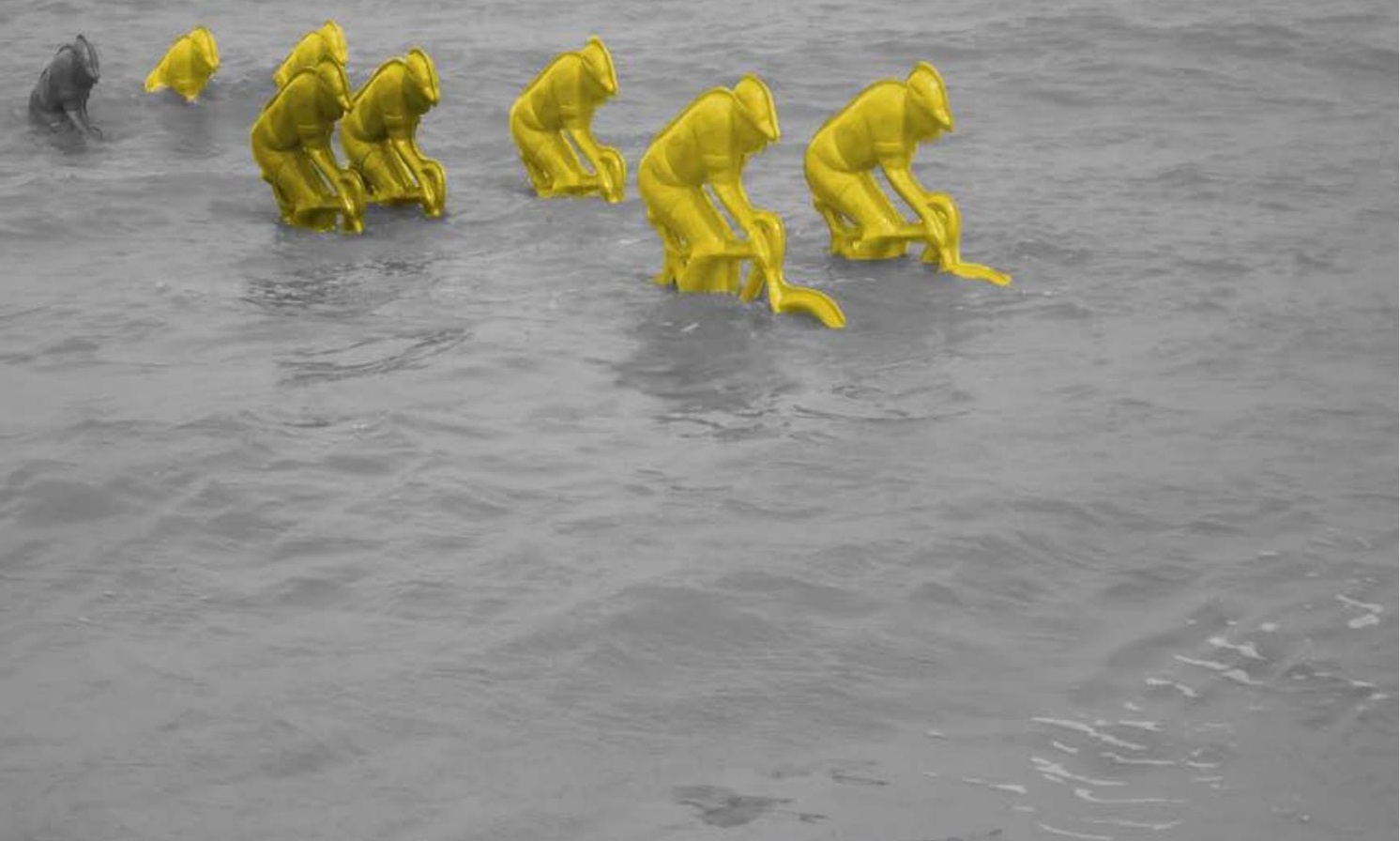



Ein Fahrradtraining im Wasser könnte als therapeutisches Mittel bei Patientinnen und Patienten mit Kniearthrose eingesetzt werden. Dieser therapeutische Ansatz wurde jedoch bisher noch nicht für Patientinnen und Patienten mit leichter bis mittelschwerer Kniearthrose erforscht. Ziel dieser Dissertation war es daher, ein auf die Bedürfnisse von Kniearthrotikern abgestimmtes Übungsprogramm auf einem aqualen Fahrrad zu entwickeln und die Effekte dieses Trainings zu evaluieren.

\section{Kapitel 1}

Dieses Kapitel gibt eine Einführung in die zentralen Themen der vorliegenden Dissertation: Kniearthrose und aquales Fahrradtraining. Kniearthrose ist eine chronische Gelenkerkrankung, die sich bei den meisten Patientinnen und Patienten mit Knieschmerzen und körperlichen Einschränkungen äußert. Prägende Merkmale unserer modernen Gesellschaft, wie eine steigende Lebenserwartung und die Zunahme von Übergewicht, tragen zum Anstieg der Prävalenz von Arthrose bei. Es wird davon ausgegangen, dass Arthrose im Jahr 2020 zu den fünf meist einschränkenden Krankheiten weltweit zählt. Viele der Risikofaktoren (z. B. Fettleibigkeit, Muskelschwäche usw.) und Symptome der Kniearthrose können durch regelmäßiges Training verbessert werden. Für Personen, die eine eingeschränkte Belastbarkeit für Sportaktivitäten vorweisen, wird häufig ein Training im Wasser empfohlen. Das Eintauchen ins Wasser löst physiologische Veränderungen aus, die beim Trainieren mit Kniearthrose von Vorteil sein können. Der Auftrieb des Wassers entlastet die Gelenke. Zusätzlich führt der hydrostatische Druck einen Massageeffekt herbei, der das Schmerzempfinden reduziert. Weiterhin führt eine warme Wassertemperatur zu einem Gefühl der Entspannung. In jüngster Zeit hat sich das aquale Fahrradfahren, oftmals auch mit dem englischen Begriff "aqua cycling" betitelt, zu einem Trend im Fitnessbereich entwickelt. „Aqua cycling" wird auf einem feststehenden Fahrrad, ähnlich eines Ergometers oder Spinningfahrrads, in einem Schwimmbecken durchgeführt. Die Teilnehmerinnen und Teilnehmer sitzen auf dem Fahrrad und sind bis maximal Brusthöhe im Wasser eingetaucht. Die Übungen bestehen aus einer Kombination von Fahrradfahren in sitzender und stehender Position und Oberkörperund Armübungen gegen den Wasserwiderstand.

\section{Kapitel 2}

Das zweite Kapitel umfasst eine Machbarkeitsstudie eines aqualen Zirkelprogramms bei Patientinnen und Patienten mit Kniearthrose. Insgesamt zehn Patientinnen und Patienten nahmen an acht wöchentlichen Trainingseinheiten teil, die aus Wassergymnastikübungen und zehn Minuten „aqua cycling“ bestanden. Die Mehrheit der Patientinnen und Patienten nahm an allen acht Einheiten teil. Nach Beendigung der Studie wurden die Teilnehmenden in Fokusgruppen zum Trainingsprogramm befragt. Das Ergebnis zeigt eine hohe Patientenzufriedenheit mit der Auswahl und 
Zusammenstellung des Übungsprogramms. Weiterhin gaben die Patientinnen und Patienten, dass sich die Knieschmerzen unmittelbar nach dem Training verbesserten. Die Patientinnen und Patienten konnten die meisten Übungen ohne Probleme ausführen und zeigten Fortschritte in Bezug auf den Schwierigkeitsgrad bei fast allen Übungen. Das Radfahren in einer stehenden Position war jedoch für die meisten Patientinnen und Patienten körperlich zu anspruchsvoll. Dieses Ergebnis deutet darauf hin, dass ein differenziertes Training erforderlich ist, bevor die Ausübung stehender Positionen sicher und effektiv ist. Obwohl das aquale Fahrradfahren im Sitzen als ermüdender war als das Fahrradfahren an Land, wurde die Bewegung im Wasser auch als leichter und angenehmer empfunden. Die Patientinnen und Patienten äußerten daher auch den Wunsch, die Übungszeit auf dem aqualen Fahrrad zu verlängern. Gleichzeitig gaben die Patientinnen und Patienten an, dass Radfahren im Sitzen über einen längeren Zeitraum monoton werden könnte. Die Bewertung der operationellen Aspekte des Übungsprogramms zeigte, dass das aquale Fahrradtraining problemlos in ein aquales Zirkeltraining integriert werden kann. Das aquale Fahrradfahren im Sitzen war einfach zu erlernen und der Trainerin stand somit mehr Zeit für die individuelle Betreuung der Teilnehmenden an anderen Stationen des Zirkeltrainings zur Verfügung.

\section{Kapitel 3}

Dieses Kapitel beschreibt die Methodik einer randomisierten kontrollierten Studie zur Evaluation eines 12-wöchigen Übungsprogramms mit einem aqualen Fahrrad im Vergleich zu einer Kontrollgruppe, welche die üblichen Behandlungsempfehlungen einer Früharthrose Sprechstunde erhielt. Das Training mit dem aqualen Fahrrad wurde zweimal wöchentlich für 45 Minuten in Kleingruppen mit bis zu vier Patientinnen und Patienten in einem Therapiebad durchgeführt. In jeder Trainingseinheit wurde das Radfahren im Sitzen mit stehenden Positionen oder Beinübungen ergänzt sowie mit Übungen für die Arme und dem Oberköper kombiniert. Aufgrund der mangelnden Evidenz zum Fahrradtraining im Wasser und der Anwendung dieser Trainingsform bei Kniearthrotikern, dienten Forschungsergebnisse bezüglich des körperlichen Trainings bei Arthrose und dem Ergometertraining an Land als Richtlinie zur Bestimmung der Trainingsintensität und dem Trainingsaufbau. Einschlusskriterien für die Teilnahme am Trainingsprogramm und der randomisierten Studie waren: Knieschmerzen mit einem Wert zwischen vier und sieben auf einer numerischen 10-Punkte Schmerzskala, ein Kellgren / Lawrence-Score zwischen eins und drei (maximaler Wert: vier) und eine Indikation für eine physiotherapeutische Behandlung der Kniearthrose. Patientinnen und Patienten mit einer Kontraindikation für Bewegungstherapie im Wasser (z. B. kardiorespiratorische Nebenerkrankungen oder offene Wunden) und Patientinnen und Patienten mit einer Indikation für ein künstliches Kniegelenk wurden von der Teilnahme ausgeschlossen. Darüber hinaus wurden Patientinnen und Patienten ausgeschlossen, deren körperliche Beeinträchtigungen eine sichere Teilnahme am 
Training verwehrten. Ebenfalls von der Teilnahme ausgeschlossen waren Patientinnen und Patienten mit Erkrankungen (bspw. Rheuma) oder Behandlungen (z. B. Injektion von Kortikosteroiden und / oder Hyaluronsäure in den letzten drei bzw. sechs Monaten), die Symptome der Kniearthrose verschleiern. Die primären Outcomes der Studie waren Knieschmerzen und körperliche Funktionsfähigkeit gemessen mit dem KOOS-Fragenbogen (engl. Knee injury and Osteoarthritis Outcome Score). Sekundäre Outcomes umfassten die KOOS-Subskalen für Beschwerden, Probleme mit sportlicher Aktivität und krankheitsspezifische Lebensqualität, sowie Fragebögen zur allgemeinen Krankheitsbelastung und Lebensqualität, körperlicher Aktivität, Selbstwirksamkeit und Bewegungsangst. Performance-basierte Messungen waren der "Timed-Up-and-Go“Test, der 6-Minuten-Gehtest und die Messung der Muskelkraft der unteren Extremitäten. Alle Messungen wurden zu Beginn der Studie, nach Ablauf der 12-wöchigen Interventionsperiode und 24 Wochen nach Beginn der Studie durchgeführt.

\section{Kapitel 4}

Das vierte Kapitel bietet eine Übersicht der wissenschaftlichen Literatur zum Thema aquales Fahrradtraining. Eine systematische Literaturrecherche identifizierte 63 Publikationen, die anhand der folgenden Merkmale zusammengefasst wurden: Aufbau und Inhalt der Intervention und möglicher Vergleichsinterventionen, Probandenanzahl und -eigenschaften, sowie die Kernergebnisse der Studien. Es zeigte sich, dass das aquale Fahrradtraining in den identifizierten Studien sehr heterogen angewendet wurde. Neben Unterschieden im Aufbau und Inhalt des Trainings erschwerte auch die Ausgestaltung von externen Faktoren (z. B. Design des Fahrrads, Wassertemperatur oder Eintauchtiefe der Probanden) die Vergleichbarkeit der Studien. Allerdings konnten auch gemeinsame Merkmale identifiziert werden. Die meisten Forschungsarbeiten konzentrierten sich auf den Vergleich zwischen Wasser- und Landtraining oder untersuchten die Auswirkungen verschiedener Trainingsbedingungen (z. B. Wassertemperatur) während des Radfahrens im Wasser bei gesunden (meist männlichen) Teilnehmern, unter Verwendung eines Cross-OverStudiendesigns. In vielen Studien wurden zudem kardiovaskuläre Parameter untersucht. Die Ergebnisse deuten darauf hin, dass sich die kardiale Belastung während des aqualen Fahrradfahrens nicht von der Belastung an Land unterscheidet. Nur sechs Studien untersuchten die Wirkung von mehrwöchigen Übungsprogrammen. Diese Studien zeigten, dass ein Trainingsprogramm mit dem aqualen Fahrrad genauso effektiv ist wie das Radfahren an Land, um die kardiovaskuläre Fitness bei gesunden Teilnehmerinnen und Teilnehmern, sowie bei übergewichtigen Menschen und Patientinnen und Patienten mit Multipler Sklerose zu verbessern. 


\section{Kapitel 5}

Kapitel fünf beschreibt die Ergebnisse der randomisierten, zweiarmigen Parallelgruppenstudie, in der die Effekte des 12-wöchigen Trainingsprogramms mit dem aqualen Fahrrad auf Knieschmerzen und körperliche Funktionsfähigkeit bei Patientinnen und Patienten mit leichter bis mittelschwerer Kniearthrose untersucht wurden. Das Übungsprogramm wurde mit der Standardbehandlung der FrüharthroseSprechstunde des Universitätsklinikums Maastricht verglichen. Nach Abschluss der Studienteilnahme wurden die Patientinnen und Patienten der Kontrollgruppe zu zwölf Trainingseinheiten auf dem aqualen Fahrrad in ein lokales Schwimmbad eingeladen.

Insgesamt wurden 111 Patientinnen und Patienten randomisiert. Neun Patientinnen und Patienten zogen ihre Zustimmung vor der Durchführung der Baseline-Tests zurück. Im Verlauf der Studie beendeten 19 weitere Patientinnen und Patienten ihre Teilnahme vorzeitig.

Die Analyse der Daten ergab, dass der Unterschied der aqualen Trainingsgruppe mit der Kontrollgruppe zu beiden Zeitpunkten der Nachmessung, also direkt im Anschluss an die Intervention und 24-Wochen nach dem Start der Studienteilnahme, für die meisten Messwerte vergleichbar war. Somit konnte ein einziger statistischer Schätzwert für beide Zeitpunkte zur Ermittlung der Gruppenunterschiede berechnet werden. Die Analyse zeigte eine signifikante Verbesserungen der aqualen Trainingsgruppe hinsichtlich der Knieschmerzen $(B=8,16 ; p=0,014)$ und der körperlichen Funktionsfähigkeit $(B=7,16 ; p=0,027)$. Die Patientinnen und Patienten der aqualen Trainingsgruppe absolvierten auch den "Timed Up and Go" -Test schneller $(B=-0,91 ; \quad p=0,001)$ und erzielten mehr Meter im 6-Minuten-Gehtest $(B=46,75$; $p=0,002)$ als die Kontrollgruppe. Des Weiteren gaben die Teilnehmenden der aqualen Trainingsgruppe im Vergleich zur Kontrollgruppe eine verringerte Bewegungsangst $(B=-3,84 ; p=0,002)$ an sowie eine kurzzeitige Verbesserung der krankheitsspezifischen Lebensqualität $(B=13,03 ; p=0,001)$.

\section{Kapitel 6}

Kapitel sechs gibt einen umfassenden Überblick über die wichtigsten Ergebnisse dieser Dissertation. Außerdem werden vier Aspekte erörtert, die hinsichtlich der Interpretation der Studienergebnisse unbedingt beachtet werden sollten: Rekrutierung und Ausfälle, der Vergleich des aqualen Übungsprogramms mit der üblichen Behandlung, sowie die Einhaltung der Behandlungsempfehlungen der Kontrollgruppe. Weiterhin werden Vor- und Nachteile des aqualen Fahrradtrainings beschrieben und Hypothesen zur Beständigkeit dieses aktuellen Trendsports aufgestellt. Abschließend werden Ideen zur weiteren Erforschung dieser Bewegungsart als Therapie- und Sportmöglichkeit präsentiert. 


\section{Valorisation addendum}

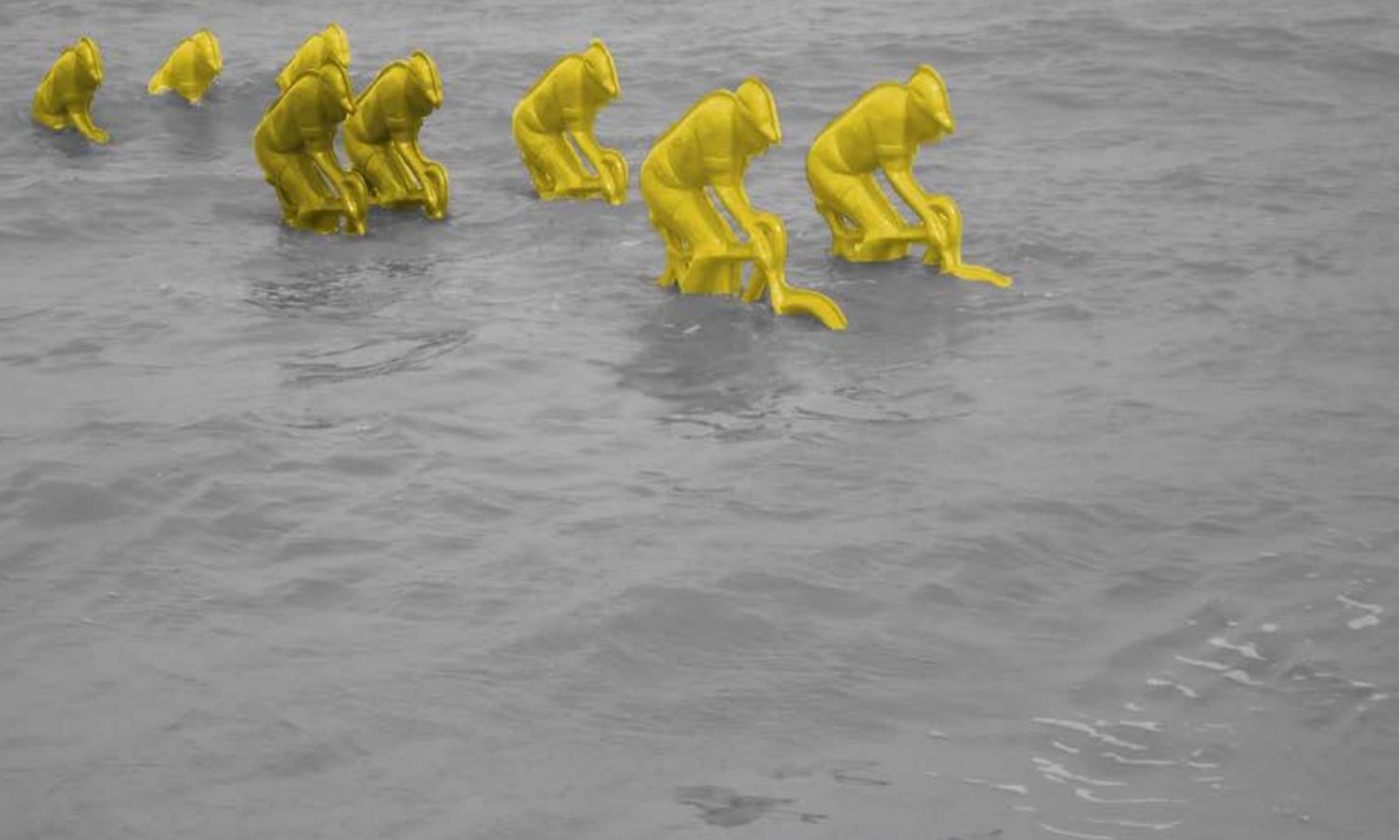



„Knowledge is of no value unless you put it into practice." Anton Chekov

Exercise is a cornerstone in the conservative management of knee osteoarthritis. Physical therapists and scientists are driven to alleviate symptoms and slow down the progression of knee osteoarthritis. In daily practice and in research we aim to "get them up, moving and out the door". ${ }^{1}$ Ideally, recommendations and results from physical therapy and research should be integrated and accessible in the daily life of patients. However, the translation of research outcomes to the real world needs some careful thinking on how the results could add value to our society in the broadest sense. This process is called knowledge valorisation and is defined as the "process of creating value from knowledge, by making knowledge suitable and/or available for social (and/or economic) use and by making knowledge suitable for translation into competitive products, services, processes and new commercial activities". (adapted definition based on the National Valorisation Committee 2011:8).

In this chapter, we outline the potential relevance of our project for society. Furthermore, we describe the actions that were taken to disseminate our knowledge to different target groups.

\section{Relevance}

Osteoarthritis is already the most common joint disease in older adults worldwide. ${ }^{2}$ In addition, obesity and muscle impairments, but also knee injuries accelerate the onset of osteoarthritis at younger ages. ${ }^{3}$ Therefore, an adequate care management of knee osteoarthritis is and will be of great importance. The younger patients ( \pm 45 years of age) will suffer for a longer period of time from this chronic disease, which is likely accompanied by the need for medical treatment. As a result, healthcare utilisation for knee osteoarthritis will increase further. Moreover, indirect costs related to knee osteoarthritis, such as productivity loss or lost wages, will also increase since these younger patients still belong to the workforce. ${ }^{4}$ Because care management for knee osteoarthritis should be personalised and acceptable to patients, ${ }^{5}$ exercise therapy should meet the exercise preferences preferred by this younger generation of osteoarthritis patients. ${ }^{6}$ Aquatic cycling might be an attractive option as it is a trending sports activity offered by local swimming pools and modern sports studios. The latter facilities clearly meet the aesthetic dimension that is nowadays often related to exercise. ${ }^{7}$ Furthermore, aquatic cycling is easy to learn, which might be appealing to people who do not have much experience with exercising. In addition, obese patients might appreciate this type of aquatic activity, since the stable character of the bike prevents them from floating too much. Furthermore, water immersion reduces body exposure.

This dissertation focused on the development and evaluation of a head-out aquatic cycling exercise programme for patients with mild to moderate knee OA. So far, the 
evidence on the effects of aquatic cycling for patients with knee osteoarthritis or other target populations is scarce. We hope that our project increased the awareness among patients, healthcare providers, and aquatic fitness professionals to consider aquatic cycling as a suitable and effective exercise modality for themselves or their patients or clients.

\section{Target groups}

\section{Researchers}

This PhD project contributed to the academic field of aquatic exercise therapy. To our best knowledge, our randomised trial was the first that evaluated an aquatic cycling programme for patients with knee osteoarthritis. Researchers can use our results as a starting point for further research; possibly about the impact of aquatic cycling on various other outcomes relevant for patients with knee osteoarthritis or its effect among other patient groups. Hopefully, the detailed reporting of the intervention characteristics of our own trial and the results from our literature review will stimulate fellow researchers to summarise their interventions comprehensively. This would increase our understanding of the effects of aquatic cycling and increase reproducibility and comparability of interventions and findings. ${ }^{8}$

Furthermore, researchers should actively support the translation from scientific evidence into information that is useful and understandable to aquatic therapists and aquatic fitness instructors. The process of discovering new knowledge and its application in public health and clinical settings can take a long time ${ }^{9}$ and the translation from the scientific knowledge about aquatic cycling into daily practice will need some time as well. In order to be able to transfer our evidence into daily practice, we need to learn more about the effectiveness of aquatic cycling (for example in community settings). Since aquatic cycling is a niche in the field of aquatic exercise and aquatic therapy, the (relatively few) individuals and intermediaries with expertise in aquatic cycling, such as (local) health professionals, researchers, aquatic exercise professionals, educators, and opinion leaders in the field of aquatic fitness and therapy, should collaborate to increase our scientific knowledge about aquatic cycling and to transfer the results into daily practice. ${ }^{10}$

\section{Aquatic exercise professionals}

Aquatic professionals, including aquatic exercise instructors and aquatic therapists, are the most important target group to bring our scientific knowledge into (clinical) practice. The information from this PhD project can provide guidance in the set-up of aquatic cycling classes for patients with knee osteoarthritis. To increase the knowledge transfer, the evidence should be summarised and become available in sources frequently consulted by aquatic professionals. For instance, aquatic fitness and therapy 
associations could publish the information on their websites or incorporate the knowledge in their course manuals. Aquatic fitness professionals have the opportunity to follow a two-day course that educates them to become an aquatic cycling instructor. The available knowledge from our study and fellow researchers regarding aquatic cycling for patients could be implemented in these courses or could serve as a basis for an advanced aquatic cycling instructor course. Offering training courses, which allows potential users to observe and experience aquatic cycling with patients themselves before acquiring this training modality and applying it, will stimulate the transition of knowledge into practice. In order to stimulate this development, this dissertation will be sent to several aquatic fitness associations.

\section{Aquatic fitness industry and providers}

The aquatic fitness industry is another possibility to disseminate research results. Manufacturers of aquatic bikes and organisations that provide aquatic training (e.g. rehabilitation centres, larger physiotherapy centres, and local swimming pools) are a group that may receive financial incentives for establishing aquatic cycling programmes for patients with knee osteoarthritis. For these activities, a dissemination plan, possibly with a more market-oriented approach, to disseminate our findings needs to be developed. ${ }^{11,12}$ However, the development of such a dissemination plan is beyond the scope of this dissertation. And, it should be noted that there is a risk that our findings could be overestimated or generalised for such marketing purposes. Currently, the fitness industry already promotes aquatic cycling with various benefits ranging from reducing cellulitis to improving coordination and supporting rehabilitation and treatment of musculoskeletal disorders. In fact, none of these benefits are completely false since aquatic exercise, in general, has a positive influence on the abovementioned conditions. However, most aquatic cycling classes, as provided in local public swimming pools, very likely do not fit the needs of the average knee osteoarthritis patient. For example, a very fast pedalling tempo or long-lasting out-ofsaddle intervals might reduce patients' ability for proper alignment of the knee, which can increase the risk of knee pain (for example by causing irritation of the collateral ligaments or increased loading of the knee joint).

\section{Patients with knee osteoarthritis}

The strongest motivation of medical research is to improve the health of patients, and our research was driven by the motivation to explore aquatic cycling as an exercise opportunity for patients with knee osteoarthritis. The evaluation of our trial showed a positive impact on the impairments of our intervention group. Furthermore, our feasibility study suggested that most patients accepted and enjoyed this type of exercise. Thus, participation might not only have resulted in improvements of symptoms, but might also have increased the patients' motivation to stay active after 
the end of the trial. We hypothesize that participants gained a positive impression about exercise, which is a facilitator for future exercise adherence and maintenance.

Possibly, patients with mild symptoms or at a higher risk for developing knee osteoarthritis (e.g. overweight persons) might also benefit from aquatic cycling exercises and, depending on their exercise abilities, might be able to join regular aquatic cycling classes provided by sports instructors. However, from anecdotal evidence from our trial participants, we feel that patients need more guidance in the development of an active lifestyle and exercise routine. Our patients reported typical barriers to physical activity and exercise like doubting the effectiveness, not being aware of adequate (low-cost) exercise opportunities, lacking support from health professionals, or limited financial coverage of health services by health insurances. ${ }^{13,14}$ Physical therapists are commonly the primary healthcare practitioners to whom patients with knee osteoarthritis are referred for support in their osteoarthritis management. However, comparable to other conservative treatment options, physical therapy is under-utilised in the management of knee osteoarthritis. ${ }^{15}$ To increase utilisation of physical therapy in the management of knee osteoarthritis, 12 annual physical therapy sessions for osteoarthritis of the knee or the hip have recently been added to the basic healthcare package in The Netherlands. This is an important step towards the needs of osteoarthritis patients ${ }^{16}$ and will hopefully increase exercise participation among this large group of patients.

\section{Activities and products}

This PhD project resulted in various activities to increase awareness and knowledge regarding aquatic cycling exercise in the above-mentioned target groups. Results of our studies are or will be published in (open access) journals for health care and exercise professionals. Furthermore, we presented our results at national and international conferences, national symposia, and informal hospital meetings to physical therapists, aquatic exercise professionals, and orthopaedic surgeons. Next to our scientific output, undergraduate professionals of physical therapy and movement science participated in our project during their internships at the Maastricht University Medical Centre+ or as part of their bachelor and master theses.

Another activity of this project was the collaboration with "Maastricht Sport", an organisation of the municipality of Maastricht that aims to support inhabitants of Maastricht to achieve an active lifestyle. The organisation is based in the building of the newly built public swimming pool, the "Geusseltbad", which opened its doors in 2014; a few months after we had started our trial. Because the "Geusseltbad" offered aquatic cycling classes, the research team of this PhD project approached "Maastricht Sport" for collaboration. This resulted in the set-up of an aquatic cycling group for patients with musculoskeletal problems in the lower extremities and/or a low fitness level. The author of this dissertation provided the training sessions for the first two years (2014 to 
2016), and the training was based on elements of the 12-week programme for the intervention group. Participants of the control group of our trial were invited to this group and could participate in 12 free try-out sessions. In addition, participants from the intervention group and other interested people could join the group as well against payment of the regular admission fee. The group size grew from around five participants from our trial population by word-of-mouth recommendation to approximately twelve participants every week. In total, 24 patients from the control group (out of 39 people who completed all three measurements and received the invitation) and ten people from the intervention group (out of 42 who followed the intervention and participated in all three measurements) participated in these sessions. After the last patient from our trial had finished the free try-out sessions (summer 2016), the "Geusseltbad" continued with offering these classes due to the high demand of the participants. To date (April 2018), the classes are on the regular schedule of the "Geusseltbad".

Thus, the knowledge of our research project could be implemented in the schedule of aquatic fitness activities of the "Geusseltbad" and provides an exercise opportunity to a population beyond our original trial population. Although the evidence of the effectiveness of this community approach is lacking, the positive response of the 'new' participants is promising. However, the implementation of our programme should be investigated systematically to prevent generalisation of our trial data and to serve as an example for other community sports facilities and research projects about the effectiveness of aquatic cycling. As a starting point and inspiration for this future work, the author of this dissertation asked the team leader from "Maastricht Sport" to reflect on the cooperation and to share some ideas for future collaborations. "The collaboration had a positive impact on several aspects. First, we could attract a new target group to our aquatic cycling classes, which we had not thought of before. In addition, our aquatic fitness instructors learned how to adjust the regular lessons to the needs of people with knee osteoarthritis." Furthermore, he explained that the participants benefitted from a positive exercise experience. "Once participants realise that exercise is fun, they get open-minded and interested in other activities. For example, some participants from the aquatic cycling trial started with dry-land exercise like tai chi." Future collaborations with researchers and health professionals from acute care should be installed to evaluate the effectiveness of aquatic cycling and to create a guidance and support network helping patients with knee osteoarthritis to become and to stay physically active. The team leader emphasised that "the collaboration was a starting point to expand a community support system for hospital-based and primary care therapy activities in the Maastricht area." For example, in collaboration with medical specialists, "Maastricht Sport” developed the exercise intervention „beweeg bewust" (Engl. move deliberately; http://www.maastrichtsport.nl/maastrichtsport/maastricht-sport-verbindt/gezondheid/beweegbewust) to help patients moving from acute care management through revalidation into an active lifestyle maintenance. 
We encourage the partners of this project to continue their collaboration and to develop research-practice partnerships ${ }^{17}$ that support the collaboration across sectors and that speed up the translation of evidence-based exercise interventions into practice. We hope that many aquatic interventions will be developed, evaluated and disseminated by this partnership and by other care-to-lifestyle projects because aquatic exercise/therapy suits the needs of many patients. "We feel there is a bright future for the field [of aquatic therapy] as a better scientific understanding of the many physiologic benefits emerges, therapeutic techniques evolve, more therapists are educated in the techniques and public and professional awareness of these broadens utilisation. A wetter world should lead to faster and more efficient health recovery from injury or surgery, [and] health maintenance in an aging population..." (Bruce E. Becker, $\mathrm{MD}$; Andrew J. Cole, MD). ${ }^{18}$ 


\section{REFERENCES}

1. McArthur C, Ziebart C, Papaioannou A, Cheung AM, Laprade J, Lee L, et al. "We get them up, moving, and out the door. How do we get them to do what is recommended?" Using behaviour change theory to put exercise evidence into action for rehabilitation professionals. Archives of Osteoporosis. 2018; 13:7.

2. Litwic A, Edwards MH, Dennison EM, Cooper C. Epidemiology and burden of osteoarthritis. British Medical Bulletin. 2013;105:185-99.

3. Deshpande BR, Katz JN, Solomon DH, Yelin EH, Hunter DJ, Messier SP, et al. The number of persons with symptomatic knee osteoarthritis in the United States: Impact of race/ethnicity, age, sex, and obesity. Arthritis Care \& Research. 2016;68:1743-50.

4. Gupta S HG, Laporte A, Croxford R, Coyte PC. The economic burden of disabling hip and knee osteoarthritis (OA) from the perspective of individuals living with this condition. Rheumatology (Oxford, England). 2005;44:1531-7.

5. Roos EM, Arden NK. Strategies for the prevention of knee osteoarthritis. Nature Reviews: Rheumatology. 2016;12:92-101.

6. Salacinski A, Krohn K, Lewis S, Holland M, Ireland K, Marchetti G. The effects of group cycling on gait and pain-related disability in individuals with mild-to-moderate knee osteoarthritis: a randomized controlled trial. Journal of Orthopaedic and Sports Physical Therapy. 2012;42:985-95.

7. Schwier J. Do the right things - Trends im Feld des Sports. dsv-Informationen. 1998;13:7-13.

8. O'Neil J, McEwen D, Del Bel MJ, Jo D, Thevenot O, MacKiddie OS, et al. Assessment of the content reporting for therapeutic exercise interventions among existing randomized controlled trials on knee osteoarthritis. Clinical Rehabilitation. 2018;10.1177/0269215518763714:269215518763714.

9. Morris ZS, Wooding S, Grant J. The answer is 17 years, what is the question: understanding time lags in translational research. Journal of the Royal Society of Medicine. 2011;104:510-20.

10. Osterling KL, Austin MJ. The dissemination and utilization of research for promoting evidence-based practice. Journal of Evidence-Based Social Work. 2008;5:295-319.

11. Ziebart C, McArthur C, Lee L, Papaioannou A, Laprade J, Cheung AM, et al. "Left to my own devices, I don't know": using theory and patient-reported barriers to move from physical activity recommendations to practice. Osteoporosis International. 2018;10.1007/s00198-018-4390-3.

12. Wilson PM, Petticrew M, Calnan MW, Nazareth I. Disseminating research findings: what should researchers do? A systematic scoping review of conceptual frameworks. Implementation Science : IS. 2010;5:91.

13. Dobson F, Bennell KL, French SD, Nicolson PJ, Klaasman RN, Holden MA, et al. Barriers and facilitators to exercise participation in people with hip and/or knee osteoarthritis: synthesis of the literature using behavior change theory. American Journal of Physical Medicine and Rehabilitation. 2016;95:372-89.

14. Kanavaki AM, Rushton A, Efstathiou N, Alrushud A, Klocke R, Abhishek A, et al. Barriers and facilitators of physical activity in knee and hip osteoarthritis: a systematic review of qualitative evidence. BMJ Open. 2017;7:e017042.

15. Selten EM, Vriezekolk JE, Geenen R, van der Laan WH, van der Meulen-Dilling RG, Nijhof MW, et al. Reasons for Treatment Choices in Knee and Hip Osteoarthritis: A Qualitative Study. Arthritis Care \& Research. 2016;68:1260-7.

16. Hurley M, Dickson K, Hallett R, Grant R, Hauari H, Walsh N, et al. Exercise interventions and patient beliefs for people with hip, knee or hip and knee osteoarthritis: a mixed methods review. Cochrane Database Syst Rev. 2018;4:Cd010842.

17. Harden SM, Johnson SB, Almeida FA, Estabrooks PA. Improving physical activity program adoption using integrated research-practice partnerships: an effectiveness-implementation trial. Translational Behavioral Medicine. 2017;7:28-38.

18. Becker BE, Cole AJ. Comprehensive Aquatic Therapy. 3rd ed. Pullmann, WA: Washington State University Publishing; 2010. p. xiv 


\section{Acknowledgements}

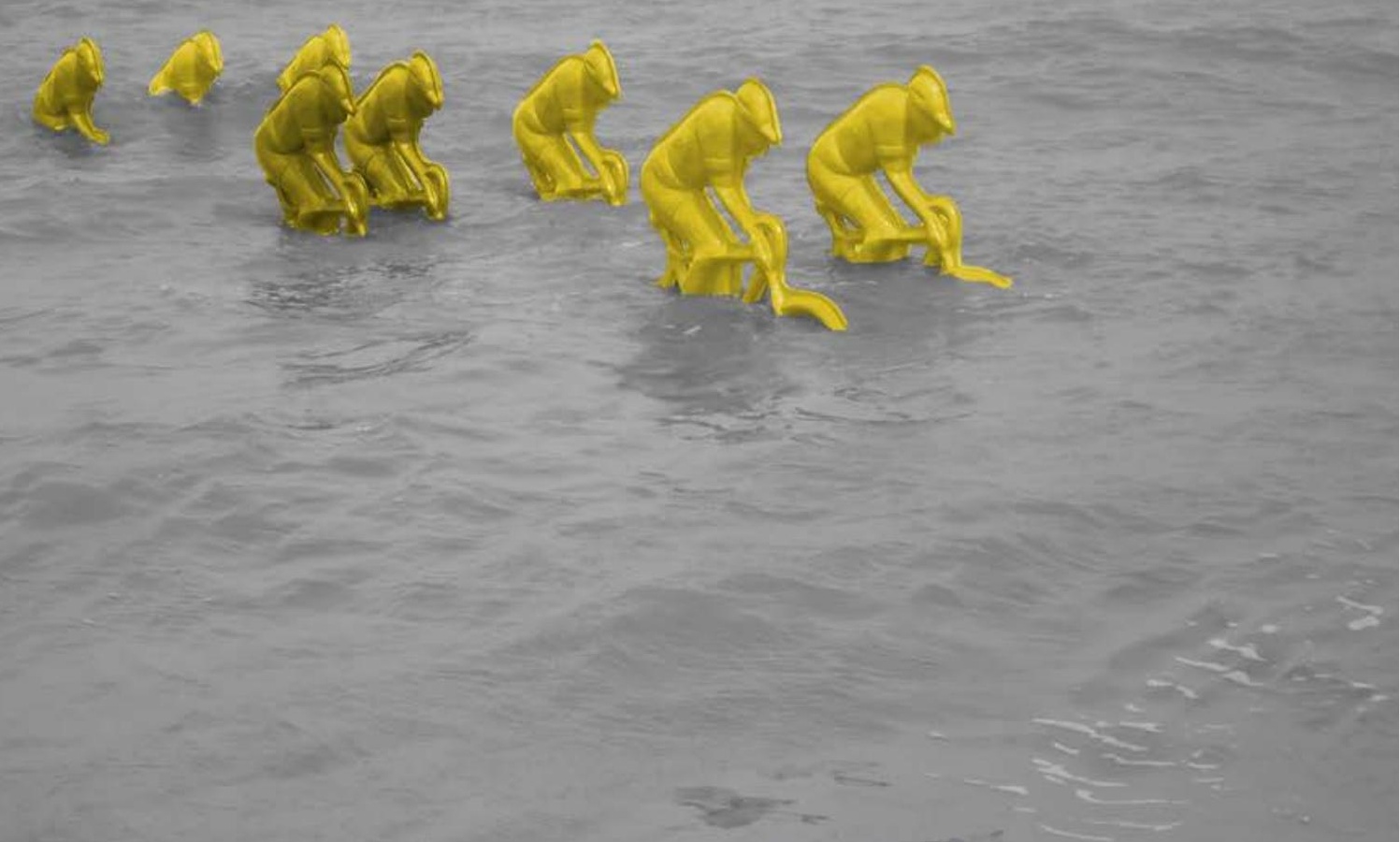



Often, a PhD project is compared to a marathon run - it is long and weary. To finish the race you need to train hard and you need supporters who carry you through when it gets though. I think this is true, particularly because my PhD was more 'Tour de France' style and I am a terrible cyclist. I broke my arm during mountain biking in the Australian rainforest, got a large graze in my face after trying to ride my bike hands-free as a child, and passed out after a spinning session. I guess this is substantial evidence that I could not have reached the finishing line without many great people who supported me along the way. So, grab a coffee or tea and look forward to your hooray!

First, I would like to thank my supervision team. My promoter Prof. Dr. Rob de Bie, my daily supervisor Dr. Ilse Mesters, and my supervisors Prof. Dr. Ton Lenssen, and Dr. Pieter Emans. The combination of your different backgrounds and networks enabled me to set-up the trial and forced me to look at this project from different perspectives. Furthermore, I could swing by for advice at any time, which I appreciated very much. I learned a lot from each of you and I would like to thank you for all the valuable discussions, your constructive feedback and your support and encouragement, especially during the recruitment and intervention period.

Dear Rob, I am very thankful that you heartened my enthusiasm for aquatic exercise. You you brought me into contact with AquaKinetiqs (the aquatic bike manufacturer) and thanks to your network I was able to do my feasibility study in the therapy pool of Maastricht University Medical Centre+. I am thankful for the trust you placed in me and that you believed in the opportunity to continue the aquatic cycling journey as a PhD project. Without you, this special bike tour would have never happened.

Dear IIse, I want to thank you for your constant support and encouragement. You became a very committed support rider ${ }^{a}$, which was a tremendous help, especially in difficult situations. I appreciated that you found the positive in every situation. Your optimism always cheered me up and motivated me to go on. I am also very thankful for your good and helpful advice on my papers and the final chapters of this dissertation. You helped me to sharpen the view for the essentials while reminding me to never lose sight of the bigger picture.

Dear Ton, I am thankful that you were part of the 'aqua cycling' team. I valued your rational perspective on my ideas and your clear comments on my papers. Your ability to put my ideas and challenges into a simple black and white perspective made many aspects less overwhelming (also thanks to your great sense of humour), forced me to

\footnotetext{
a In road bicycle racing a support rider, also called domestique, is a rider who works for the benefit of his team and leader, rather than trying to win the race.
} 
reconsider certain aspects, and motivated me to work harder to convince you of some of my ideas.

Dear Pieter, you complemented the team so well, although this project was a little bit outside of your daily business. Your comments often led to the finishing touch of the papers and this dissertation. Furthermore, you helped a lot with the recruitment of the participants and you never got tired of reminding your colleagues about the aquatic cycling study. Thank you very much for your effort and support.

The term 'aquatic cycling' implies that you need more than a great supervision team. I needed swimming pools and assessment facilities, and of course aquatic bikes. Luckily, I could count on the support of the Department of Orthopaedic Surgery and the Department of Physiotherapy at Maastricht University Medical Centre+, AquaKinetiqs, and Maastricht Sport and the Geusseltbad. Some people I would like to thank in particular.

Wiel Wijnen, you did an amazing job with the recruitment of our participants. Thank you so much for explaining the trial over and over again to potential participants! Furthermore, I valued our discussions on conservative osteoarthritis management and your input during the design phase of our trial.

Georg Roox, I am very grateful for your support. Thanks to your permission we could actually do the research on aquatic cycling. You allowed us to use the therapy pool and assessment facilities of the Department of Physiotherapy. Furthermore, I really appreciated your professional advice and the personal conversations.

I would like to give a special thanks to my A-team (assessment team): Gert Vandebosch, Stephan Kleynen, and Roy de Ridder. You did just great: explaining the questionnaires and assessments hundreds of times and making sure to collect as much data as possible (despite Biodex problems, patients who came late etc.).

Victoire Loffeld and Ilse Luijten-Philippi, thank you for some extra support here and there with regard to the coordination of the assessments and for your interest in my project.

Margot Jansen-Jacob, thank you for supporting me with the execution of the training in the very early beginning.

I would like to thank Rik Alkemade and Cees Scholtmeijer from AquaKinetiqs for the good collaboration and our honest discussions on how to improve the AquaCruiser II $^{\mathrm{TM}}$. 
Hein Poell, thank you to pave the way for the collaboration with Maastricht Sport and the Geusseltbad.

In addition to all the great people mentioned above, I could count on some extra support riders, which I am very grateful for.

Ben Ummels from Adelante Rehabilitation, thank you for sharing your thoughts on the training programme, the try-out sessions in the pool and your enthusiasm for the topic.

Furthermore, I enjoyed collaborating with Bachelor students from Zuyd University of Applied Sciences in Heerlen who supported the data collection and execution of the training as part of their internships and thesis periods: Darcy Ummels, Deborah Thijssen, Wim Rovers, Thomas Wellink, Remco Palmen, Marijke Kuijs, Linda Bloemer and Mick Arets. Many thanks for your great support!

Darcy and Wim thank you for your continuing support as student assistants during your Masters. Together with Willem Bemelmans you did a great job of entering all the data.

Rachelle van den Brand (TU Eindhoven) and Joop Waijers (Maastricht University), your research for your Master theses resulted in some valuable and additional insights on the topic of aquatic cycling. Thank you for your effort and the interesting knowledge exchange.

Last but not least this project would not have been possible without participants. I am very grateful for your participation. Thank you so much for filling in all the questionnaires and diaries, and doing your best during the performance tests. And, of course, thank you for participating in the aquatic cycling training. The supervision of the training was one of the best parts of my whole PhD trajectory.

Next to all the fun in the pool, some data analysis and writing had to be done, too. Thankfully, I had great co-authors, in addition to my supervision team, from whom I learned a lot.

Dr. Chris Arts, thank you so much for your enthusiasm about the topic and your great supervision during the feasibility study.

Dr. Ben Waller, Johan Lambeck and Dr. Jens Bansi, I am very thankful for the collaboration on the review paper; I learned a lot from all of you.

Prof. Dr. Gerard van Breukelen, thank you very much for your clear guidance during the analyses of the trial data. I am still surprised that I was able to do the analyses and, maybe even more surprising, enjoyed it.

Tiny Wouters, thank you for making all the text and tables look 'pretty'. 
I also want to thank the members of the assessment committee for taking the time to read my dissertation: Prof. Dr. Rob Smeets, Prof. Dr. Annelies Boonen, Prof. Dr. Joost Dekker, Dr. Albère Köke, and Dr. Philip van der Wees.

Furthermore, I want to thank my PhD fellows and colleagues for their support. The dinners and social activities with the PhD fellows from 'Young Epid' were always fun and refreshing. Big thanks to the 'Epi-ladies': Judith, Esther, Vivian, Emmylou, Sarah, and Audrey who were always ready to support me. I am very happy that we are still in touch. See you soon in Copenhagen!?

Special thanks to my roomies at Maastricht University, Sarah, Vivian and Emmylou, for never complaining about all the recruitment calls, my wet bathing suit drying in our office and a big hooray for your encouragement, helpful feedback, hugs, and chocolate. Sarah, thanks for all the good talks on our way home, your willingness to come to some training sessions in the evening, and the fun times we had when having dinner together.

Thank you to my PhD fellows from the Department of Health Promotion: Astrid, Karin, Kristina, and Domi. Our lunch breaks, coffee dates, and sports sessions were important moments for recharging my batteries.

Furthermore, I would like to thank the PhD representative team for their support in addition to our 'rep tasks': Gili Yaron and Latifia Abidi.

Hannerieke van den Boom, thank you for all your support, empathy and encouragement. You are a great PhD coordinator.

Moreover, I would like to thank all my colleagues from the 'Epid - musculoskeletal disorders group' for their interest in my research and their helpful advice. In particular, I would like to thank Conny de Zwart for her help with the randomisation and the great the support with all the administration that comes with a trial and the defence preparation.

I also want to thank my colleagues from Zuyd University of Applied Sciences and Region Aachen - Zweckverband for the great teamwork, your support and your understanding (especially in stressful situations).

Finally, I am very grateful for my friends and family who added a little sparkle and lots of joyful and happy moments to this PhD adventure.

Sam, Michael, Armelle, and Finnian. My time in your family was the very early beginning of my PhD research since I wrote my proposal at your kitchen counter. Thank you so much for providing a wonderful Au-Pair experience in Australia that charged my batteries for the new adventures in Maastricht. 
Dear Philipp, you will find some p-values in this book, but you are definitely the best P! Diana, Christian, Elena, Cristina, Philipp - thank you for all the good times together.

Dear Isa and Ines, regardless how many kilometres apart and no matter how busy our lives are - we keep connected. Thank you for your interest and encouragement throughout the years. Our friendship means so much to me.

Dear 'meisjes', Stephie, Anika and Domi, our friendship is one of the best things that happened during my time at Maastricht University. Your understanding, encouragement, honesty, and support made tough times easier and good times even better. Thank you and 'Stammtisch' forever!

Silke and Karin, my paranymphs. I am grateful to be supported by such positive, strong, loving and caring women. Silke, we were such a good thesis team during our Bachelor and you became a precious friend. I have known for years that I would ask you to be my paranymph! Karin, whenever we meet I feel inspired and motivated afterwards. It was an honour to be your paranymph and I am very happy you are mine now. I also want to thank you for all the great support during the preparation of my thesis and the defence.

Dear Belgium family and friends, thank you for the warm welcome and your support, especially during Seattle times. Rudi, Sonja, Jelka, Julia, Laurens, Sien - thank you for making me feel like a part of your family.

Annika, you are such a loving and caring sister and I am very thankful for our strong connection. Thanks a lot for the great cover design! I am looking forward to a lot more quality time with you, Christian, Milan and our parents.

Mama and Papa, you never asked me to win the race; instead, you valued all the sweat I put in during practice and always reminded me what is most important: to enjoy life! Thank you for all your love, support and your encouragement.

Milan, you are the best thing that happened to me during my PhD. You are my special blue mind ${ }^{b}$ - like being in the water, you bring an immeasurable sense of peace to my heart and mind. Mercikes for everything!

\footnotetext{
b The term 'blue mind' describes a state of water-associated peace; it is "a mildly meditative state characterized by calm, peace, unity, and a sense of general happiness and satisfaction with life in the moment." (Wallace J. Nichols)
} 
About the author

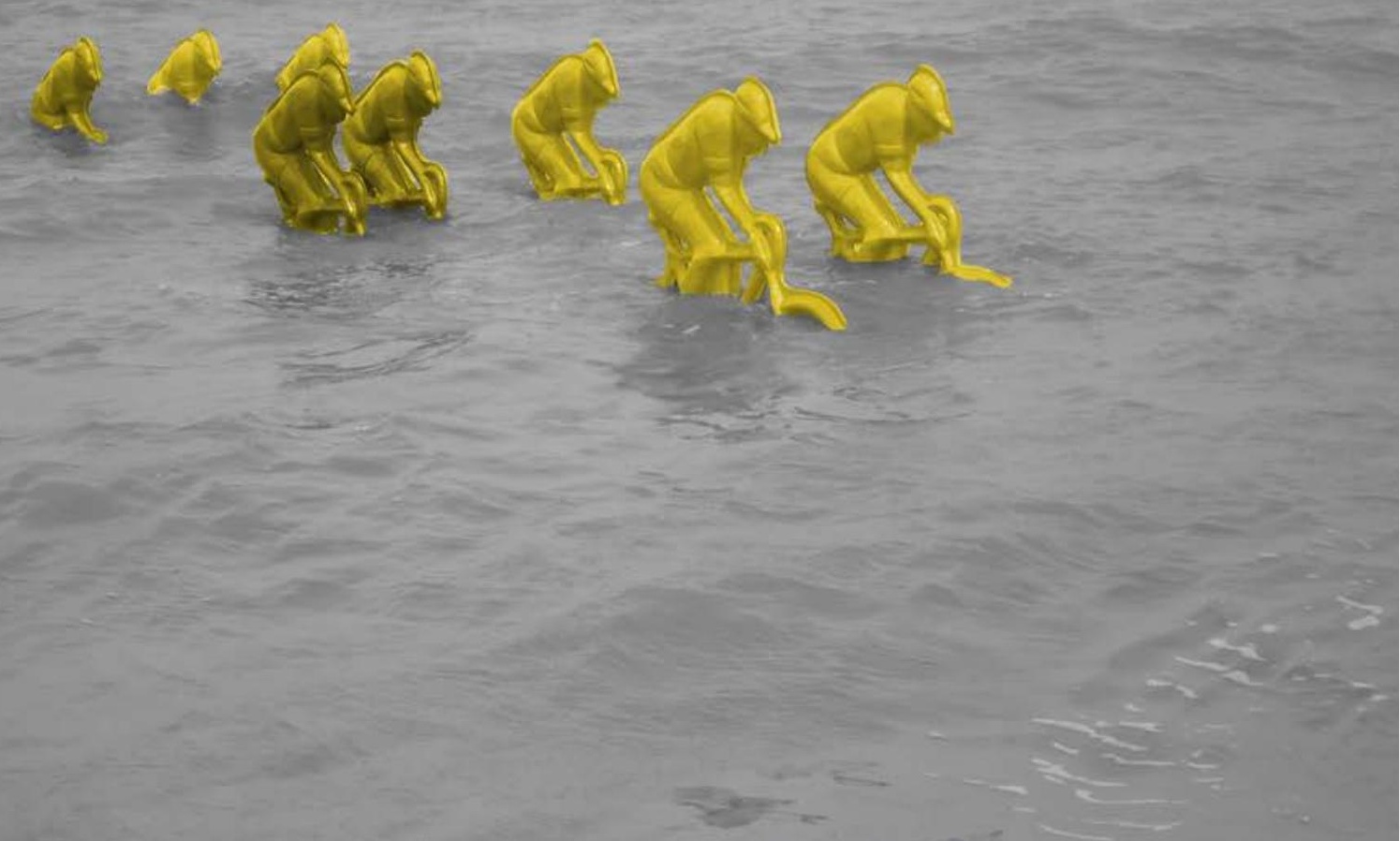



Stefanie Rewald was born on June $3^{\text {rd }}, 1985$ in Kassel, Germany. In 2004, she received her Gymnasium diploma at the 'Städtisches Gymnasium' in Eschweiler, Germany. Subsequently, she studied Physiotherapy at Zuyd University of Applied Sciences in Heerlen, The Netherlands. After obtaining her Bachelor's degree in 2008 (cum laude), she worked as a physiotherapist in a primary care practice, 'Niessen \& Stein', in Eschweiler. Since she enjoyed supervising (aquatic) exercise groups, Stefanie decided to combine her clinical work with the Master Programme 'Sports and Physical Activity Interventions' at Maastricht University, Maastricht, The Netherlands. For her Master thesis, she investigated the feasibility of an aquatic circuit programme for patients with knee osteoarthritis. The Master thesis was awarded with the 'Catharina Pijls Award' (2012). After her graduation in 2011, she travelled to Brisbane, Australia to support a working family of four as an Au-Pair. During her time in Australia, she worked on a research proposal for a randomised controlled trial to further examine the effects of aquatic cycling. In 2012, the proposal was awarded with a NWO Graduate Programme grant that enabled Stefanie to continue her research as a PhD candidate at the Department of Epidemiology within the Care and Public Health Research Institute (CAPHRI) at Maastricht University. In 2015, Stefanie received the 'Young Investigators Award' for her research on aquatic cycling at the international aquatic therapy congress "Aqua Leuven" in Leuven, Belgium.

During her PhD trajectory, Stefanie also worked as a physiotherapist (July 2014 to February 2015) at Maastricht University Medical Centre+ to support her colleagues who conducted the data collection for her trial. Furthermore, Stefanie was an active member of the CAPHRI PhD representative team (December 2014 to September 2016). This included being a low-threshold contact for her fellow PhD candidates, organising various meetings, editing the monthly newsletters, and acting as a sounding board for the PhD management of CAPHRI. In addition to her academic and clinical work, Stefanie also worked as an aquatic cycling instructor at the 'Geusseltbad' in Maastricht (October 2014 to September 2016). Here, she got the opportunity to transfer her scientific knowledge of aquatic cycling into daily practice. Moreover, Stefanie gained experience in teaching undergraduate students. From September 2015 to May 2018, she worked as a junior lecturer at the Physiotherapy Department of the Zuyd University of Applied Sciences in Heerlen. Furthermore, she combined her teaching and research activities with a job as a scientific staff member of the 'Region Aachen - Zweckverband' in Aachen, Germany (February 2017 to March 2018). She was responsible for various events and initiatives focusing on occupational health, the implementation of health innovations in the Aachen area, and the promotion of the local health care sector.

As of June 2018, Stefanie is living with her partner in Copenhagen, Denmark. 
List of publications

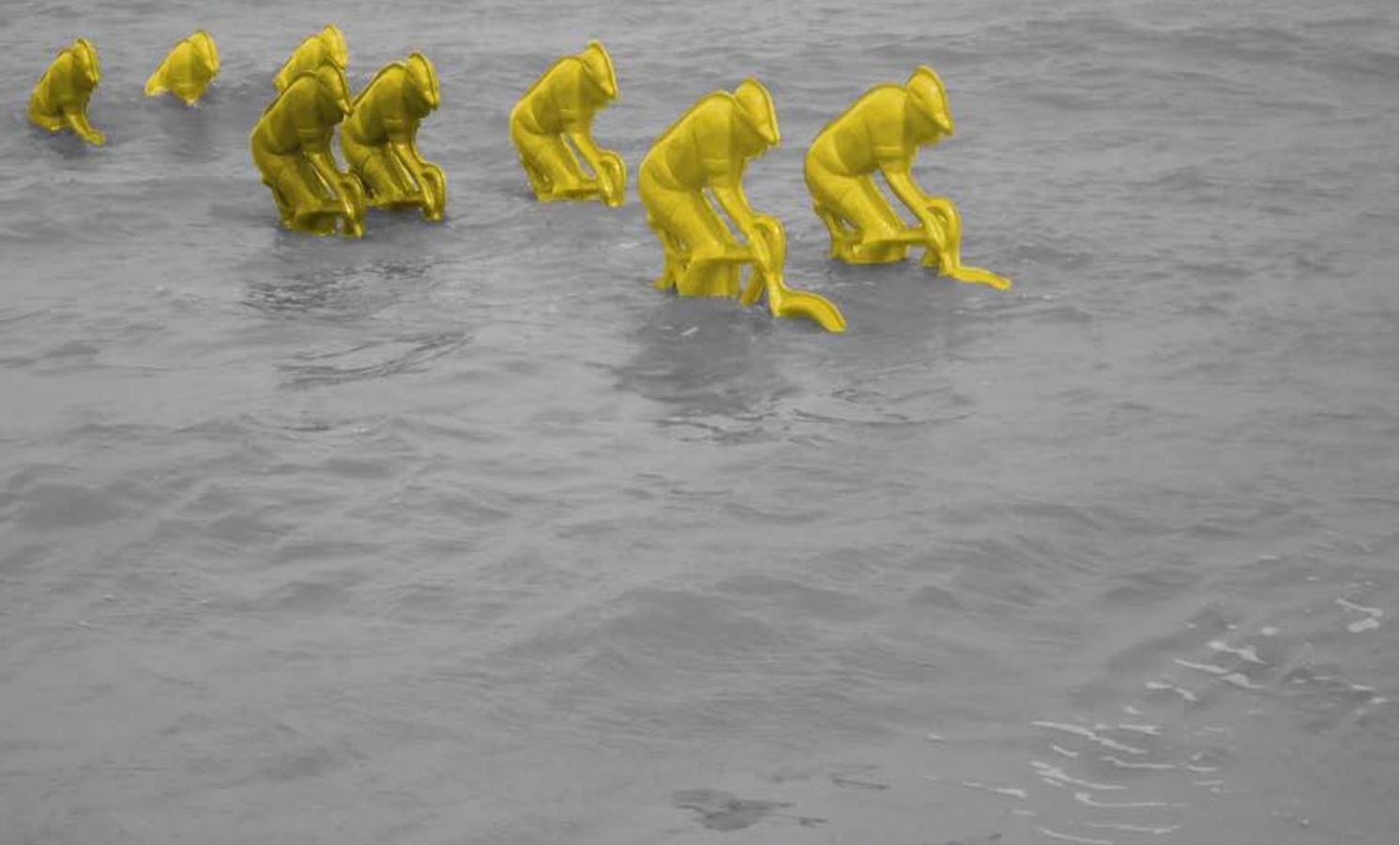





\section{LIST OF PUBLICATIONS}

Rewald S, Mesters I, Lenssen AF, Bansi J, Lambeck J, de Bie RA, Waller B. Aquatic cycling-What do we know? A scoping review on head-out aquatic cycling. Plos One. 2017;12(5):e0177704.

Rewald S, Mesters I, Emans PJ, Lenssen AF, Wijnen W, de Bie RA. Effect of aqua-cycling on pain and physical functioning compared with usual care in patients with knee osteoarthritis: study protocol of a randomised controlled trial. BMC Musculoskelet Disord. 2016;17:88.

Rewald S, Mesters I, Emans PJ, Arts JJ, Lenssen AF, de Bie RA. Aquatic circuit training including aqua-cycling in patients with knee osteoarthritis: A feasibility study. J Rehabil Med. 2015;47(4):376-81.

Rewald S, Mesters I, Emans PJ, Lenssen AF, de Bie RA. Feasibility of aqua cycling in patients with knee osteoarthritis - A pilot study. Ann Rheum Dis. 2014;73:1226.

\section{Submitted for publication:}

Rewald S, Mesters I, Emans PJ, Arts JJ, Lenssen AF, van Breukelen G, de Bie RA. Efficacy of aquatic cycling on knee pain and physical functioning in patients with knee osteoarthritis: a randomised controlled trial.

\section{Conference proceedings}

Effect of aqua-cycling on pain and physical functioning compared with usual care in patients with knee osteoarthritis: short term results from a RCT (oral presentation). $3^{\text {rd }}$ conference of Evidence-Based Aquatic Therapy (Comprehensive Aquatic Therapy put into Practice), Queretaro, Mexico, October 2016.

Knee OA and Aqua Cycling (oral presentation). Dutch symposium about knee osteoarthritis organised by Fy'net and Maastricht University Medical Centre+, Maastricht, The Netherlands, June 2016.

Cycle away from pain? (poster presentation). Annual CAPHRI Research Day, Maastricht, The Netherlands, December 2015.

Aquatic circuit training including aqua cycling in patients with knee osteoarthritis - a feasibility study (oral presentation). $2^{\text {nd }}$ conference on Evidence-based Aquatic Therapy (Aqua Leuven), Leuven, Belgium, April 2015. 
De pijn onder de knie krijgen. Aqua cycling en knie artrose (oral presentation). Dutch symposium 'Kennis in Bedrijf', Hogeschool Zuyd, Heerlen, The Netherlands, November 2013.

Aqua cycling and knee osteoarthritis - cycle away from pain?! From pilot testing to a RCT (poster presentation). VRA annual congress, Noordwijkerhout, The Netherlands, November 2013.

Design ideas for an aquatic cycling trial (oral presentation). Symposium Jagiellonian University, Krakow, Poland, November 2012. 


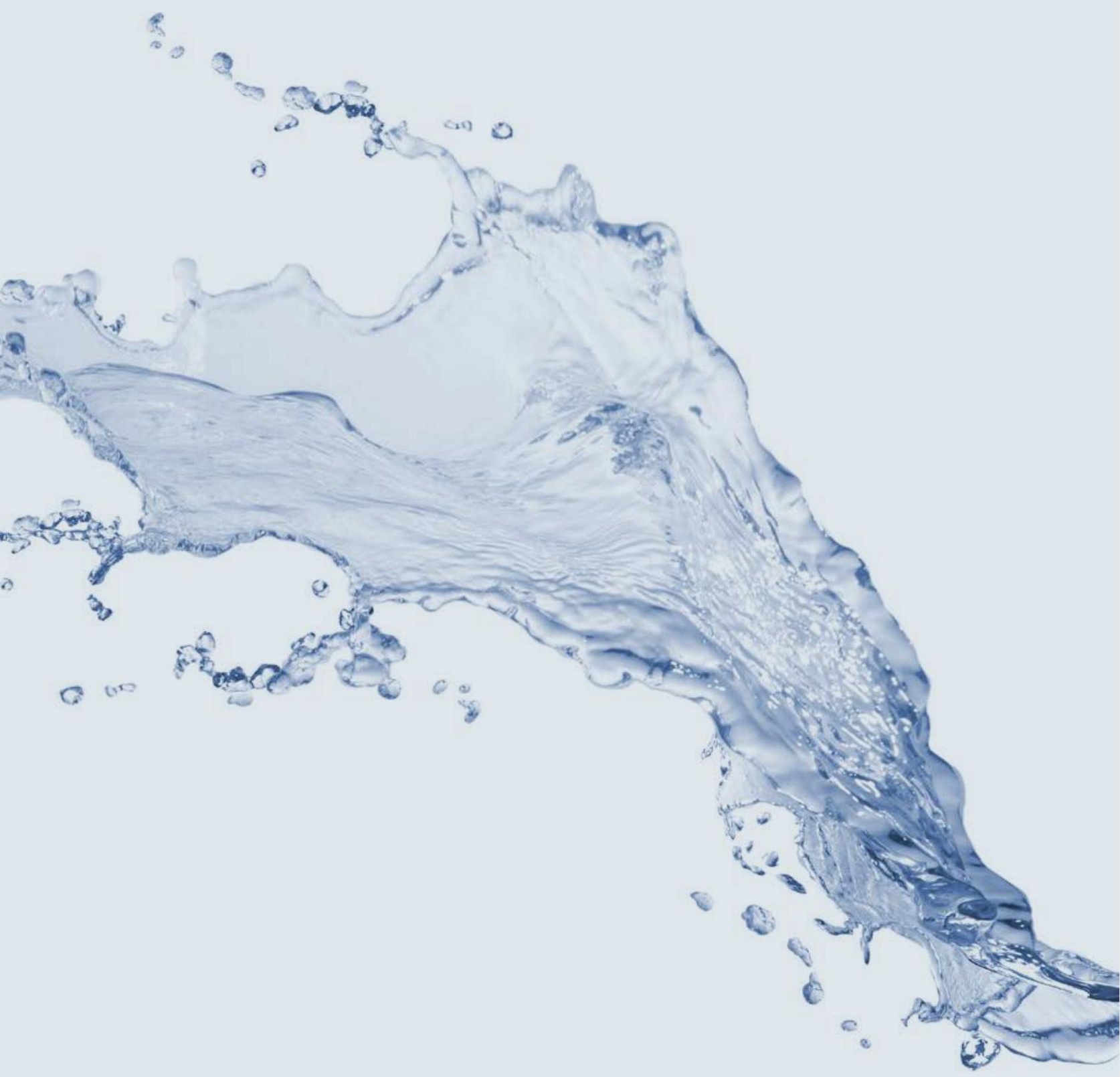

Life is like riding a bicycle. To keep your balance, you must keep moving.

Albert Einstein 